\title{
Bioactive compounds in whole grain wheat
}

Citation for published version (APA):

Mateo Anson, N. (2010). Bioactive compounds in whole grain wheat. [Doctoral Thesis, Maastricht University]. Maastricht University. https://doi.org/10.26481/dis.20100528nm

Document status and date:

Published: 01/01/2010

DOI:

10.26481/dis.20100528nm

Document Version:

Publisher's PDF, also known as Version of record

\section{Please check the document version of this publication:}

- A submitted manuscript is the version of the article upon submission and before peer-review. There can be important differences between the submitted version and the official published version of record.

People interested in the research are advised to contact the author for the final version of the publication, or visit the DOI to the publisher's website.

- The final author version and the galley proof are versions of the publication after peer review.

- The final published version features the final layout of the paper including the volume, issue and page numbers.

Link to publication

\footnotetext{
General rights rights.

- You may freely distribute the URL identifying the publication in the public portal. please follow below link for the End User Agreement:

www.umlib.nl/taverne-license

Take down policy

If you believe that this document breaches copyright please contact us at:

repository@maastrichtuniversity.nl

providing details and we will investigate your claim.
}

Copyright and moral rights for the publications made accessible in the public portal are retained by the authors and/or other copyright owners and it is a condition of accessing publications that users recognise and abide by the legal requirements associated with these

- Users may download and print one copy of any publication from the public portal for the purpose of private study or research.

- You may not further distribute the material or use it for any profit-making activity or commercial gain

If the publication is distributed under the terms of Article $25 \mathrm{fa}$ of the Dutch Copyright Act, indicated by the "Taverne" license above, 
BIOACTIVE COMPOUNDS IN

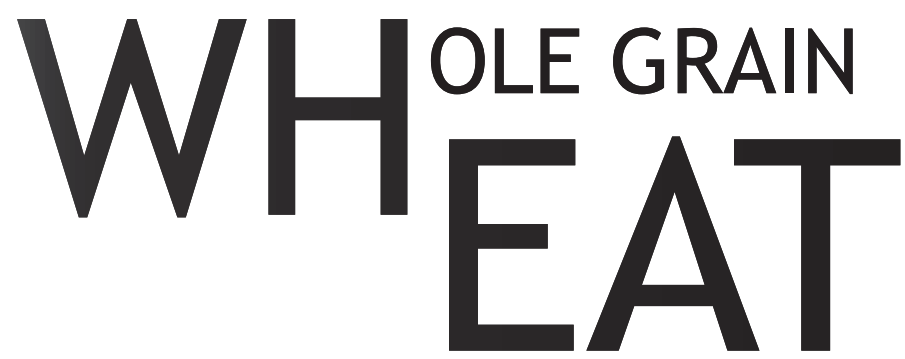


(CNuria Mateo Ansón, Maastricht 2010

ISBN: 978-90-5335-275-5

Cover design: Ingo Douwma

Lay-out design: Nuria Mateo Ansón

Printed by: Riddeprint grafisch bedrijf

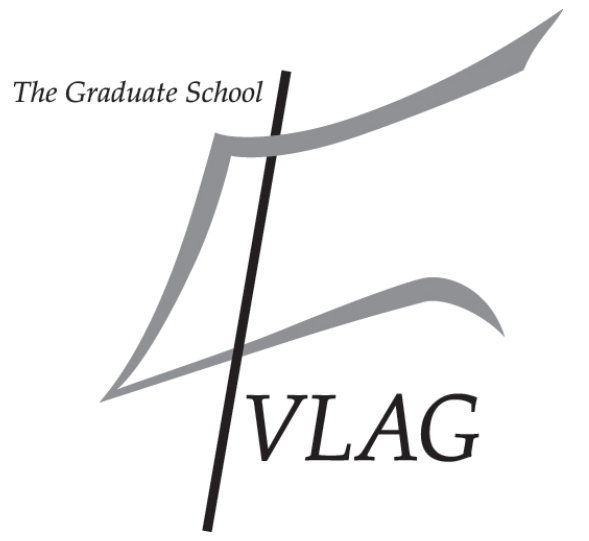

\section{iftútin}
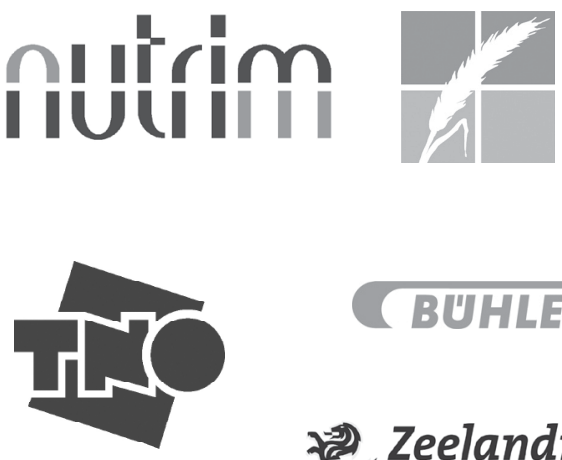

BUHLER

\section{Zeelandia}

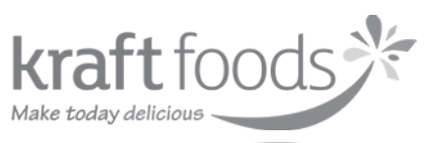

The studies presented in this thesis were performed within the Nutrition and Toxicology Research Institute Maastricht (NUTRIM) which participates in the Graduate School of Food Technology, Agrobiotechnology, Nutrition and Health Sciences (VLAG), accredited by the Royal Netherlands Academy of Arts and Sciences. This research was financially supported by the European Commission in the Communities 6th Framework programme, Project HEALTHGRAIN (FOODCT-2005-514008). It reflects author's views and the Community is not liable for any use that may be made of the information contained in this publication. Financial support for the printing of this thesis was kindly provided by Kraft foods, Bühler and Zeelandia. 


\title{
BIOACTIVE COMPOUNDS IN WHOLE GRAIN WHEAT
}

\author{
DISSERTATION
}

To obtain the degree of Doctor at the Maastricht University, on the authority of the Rector Magnificus, Prof. mr. G.P.M.F. Mols in accordance with the decision of the Board of Deans, to be defended in public on the Friday $28^{\text {th }}$ May 2010, at 14:00 hours

by

Nuria Mateo Ansón

born on the $9^{\text {th }}$ June 1982, Zaragoza (Spain) 


\section{Supervisor}

Prof. dr. A. Bast

\section{Co-supervisors}

Dr. G.R.M.M. Haenen

Dr. R. Havenaar (TNO Zeist)

\section{Assessment Committee}

Prof. dr. ir. A.M.W.J. Schols (chairman)

Dr. F. Brouns

Prof. dr. D. Kromhout (Wageningen University)

Prof. dr. A. Masclee

Prof. dr. K. Poutanen (Technical Research Center VTT, Finland) 
Let food be my medicine

(Hippocrates, adapted) 

CHAPTER 1 General introduction ............................................................ 10

CHAPTER 2 Ferulic acid from aleurone determines the antioxidant potency of wheat grain (Triticum aestivum L.)

CHAPTER 3 Bioavailability of ferulic acid is determined by its bioaccessibility

CHAPTER 4 Antioxidant and anti-inflammatory capacity of bioaccessible compounds from wheat fractions after gastrointestinal digestion.....

CHAPTER 5 Bioprocessing of wheat bran improves in vitro bioaccessibility and colonic metabolism of phenolic compounds.....

CHAPTER 6 Bioprocessed wheat bran in whole-meal breads increases colonic butyrate production 100

CHAPTER 7 Effect of bioprocessing of wheat bran in whole-meal breads on the bioavailability of phenolic compounds and postprandial antioxidant and anti-inflammatory potential

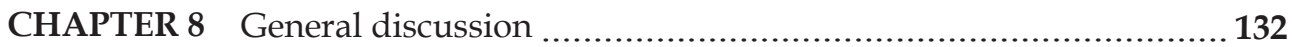

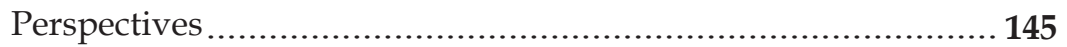

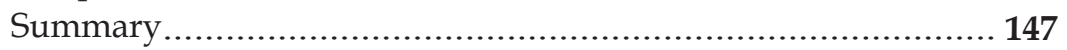

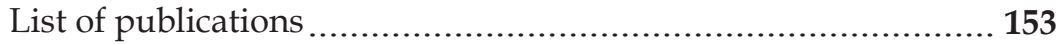

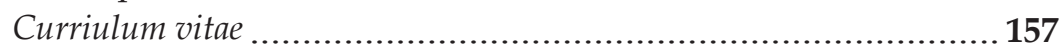

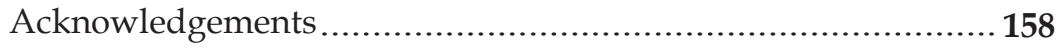




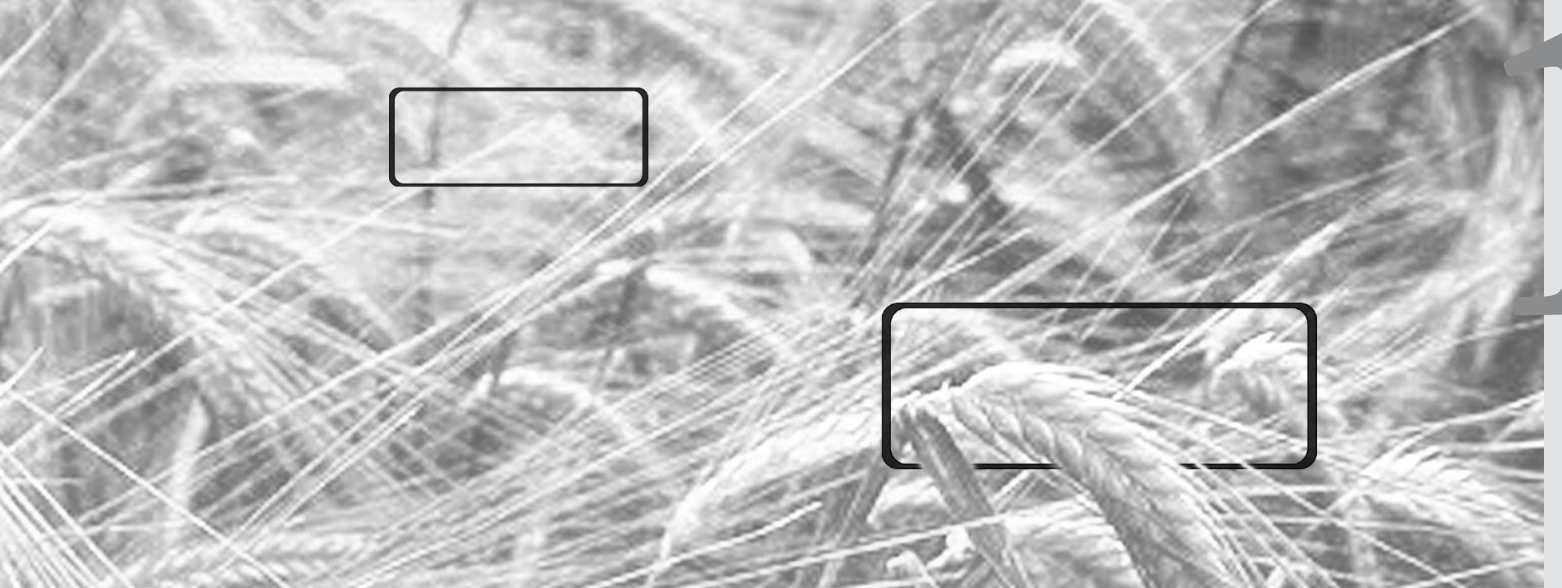

488
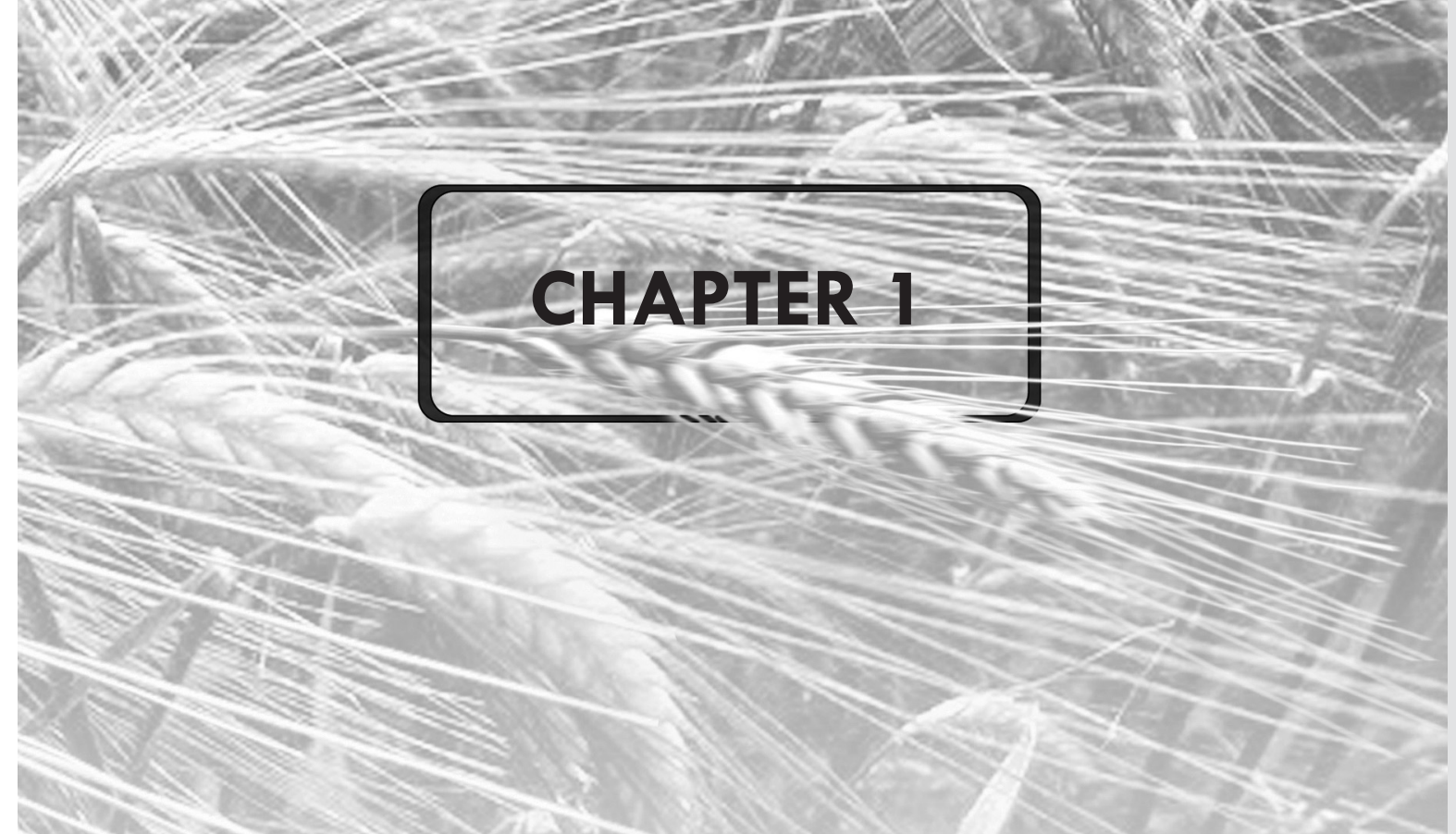

\section{GENERAL INTRODUCTION}




\section{WHEAT IN GLOBAL NUTRITION}

Wheat has an historical background of global dietary staple. Together with other cereals it has solved the hunger of civilization (1). The origin of wheat is thought to date back more than 10,000 years (2). There are different species of wheat, the most extensively cultivated is the common wheat or Triticum aestivum. Today wheat is the most produced food crop globally. Wheat in the form of bread historically and currently has provided more nutrients than any other food source world-wide $(3,4)$.

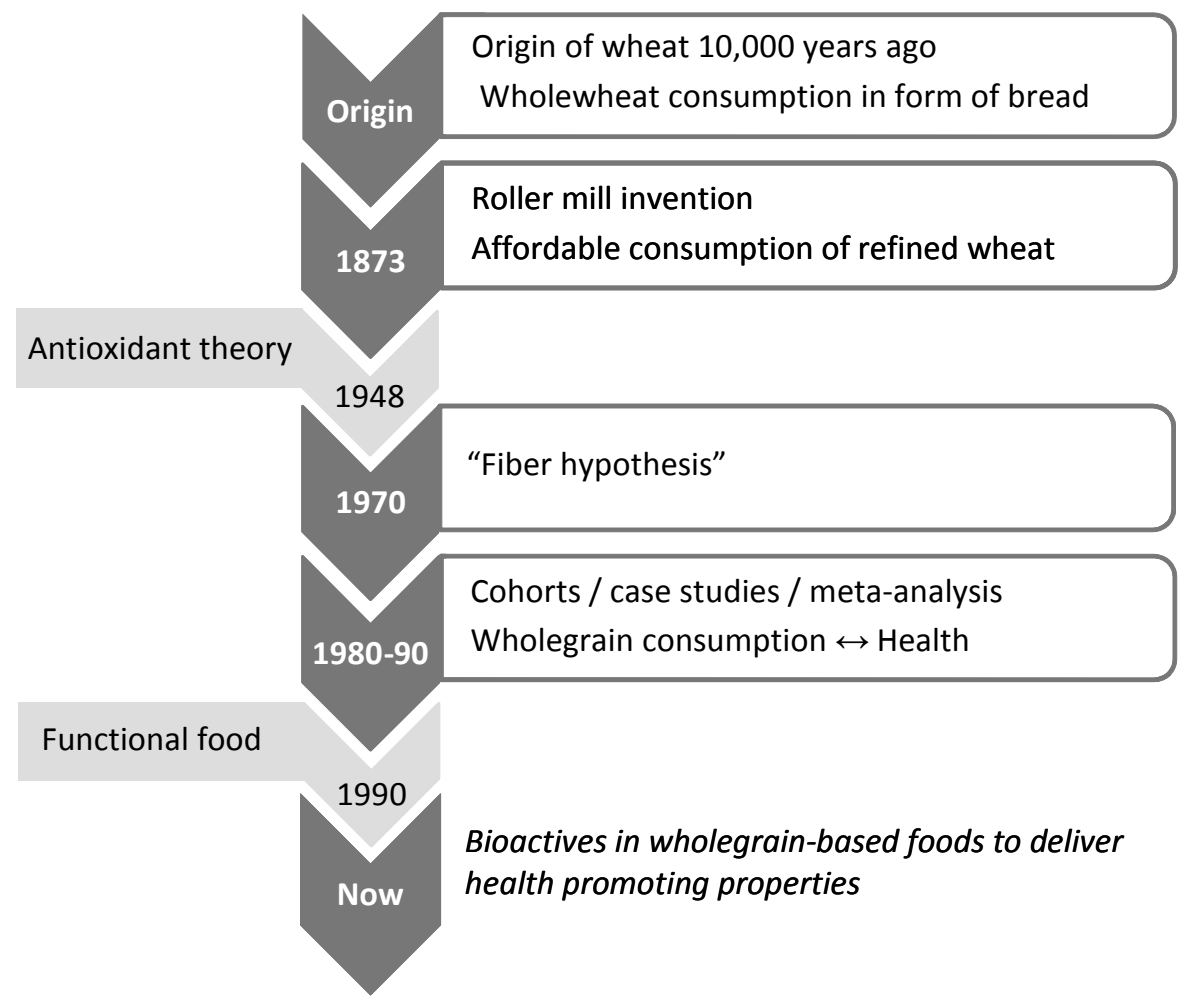

Figure 1. Historical events influencing the consumption of wheat.

Consumption of refined wheat products has been a relatively recent event in the history of wheat consumption (2). Refined wheat was not available to the majority of the human population due to cost-prohibitive inefficient milling technologies. In 1873, the invention of the roller mill provided a milling technology to efficiently separate wheat fractions (1). This made refined wheat products affordable to the majority of the population, which increased the consumption of refined wheat products. 
Mid 19th century, however, it was more and more realized that refined wheat products might be less healthy than whole-grain foods. In the seventies, researchers linked these properties to the fiber in the outermost parts of the grain, i.e. the bran (2). This "fiber hypothesis" originated from observational studies in African populations that consumed mostly diets rich in fiber and did not develop western diseases such as cardiovascular disease (CVD) (5).

Since that time, numerous epidemiological and clinical studies have provided strong evidence that consumption of whole-grain foods significantly reduces the risks for numerous chronic pathologies. Between 1996 and 2001, five extensive cohort studies in the US, Finland and Norway reported that subjects consuming relatively large amounts of whole grains have significantly lower rates of cardiovascular disease (6). Specifically, a meta-analysis of twelve studies showed a $26 \%$ risk reduction for CVD for regular whole-grain intake (7). Also significantly reduced risks for type-2 diabetes, ischemic stroke, obesity, and overall incidence of all-cause mortality have been associated with whole-grain consumption (8-11).

Although the protective effect was initially linked to the dietary fiber in whole grain, this "fiber hypothesis" has turned into a "high-fiber food hypothesis", in which fiber only plays a partial role $(7,12,13)$. Recent epidemiological studies show that the inclusion of the bran fraction seems to be the key part of the wheat kernel in the relationship between whole-grain consumption and health $(12,14)$. The bran fraction contains the highest amount of phenolic compounds within the grain, which are attached to the indigestible cell wall polysaccharides of the fiber $(11,15)$. One hypothesis is that these phenolic compounds, acting as antioxidants, play an important role in the protective effect of whole-grain consumption.

Given the evidence linking whole-grain consumption to a reduced risk of chronic disease, recent research has been aimed at identifying the mechanisms and the bioactive compounds responsible for these health promoting properties, such as the present investigations conducted within the Sixth Framework Programme of the European Commission, the HEALTHGRAIN project.

\section{THE WHEAT GRAIN FROM INSIDE OUT}

The three main milling fractions obtained from a wheat grain are: bran, endosperm and germ (Figure 2). The endosperm accounts for the majority of the wheat kernel or caryopsis (80-85\%). The cells in the endosperm are specialized in the storage of starch $(80 \%)$ and proteins $(13 \%)$ that will function as source of energy for the embryo during germination (16). The germ represents the smallest portion $(2-3 \%)$ of the wheat grain and consists of the embryonic axis and scutellum. It contains lipids, small amounts of protein and minerals and mainly bioactives of lypophilic nature such as vitamin E, phytosterols and some phenols (17). 


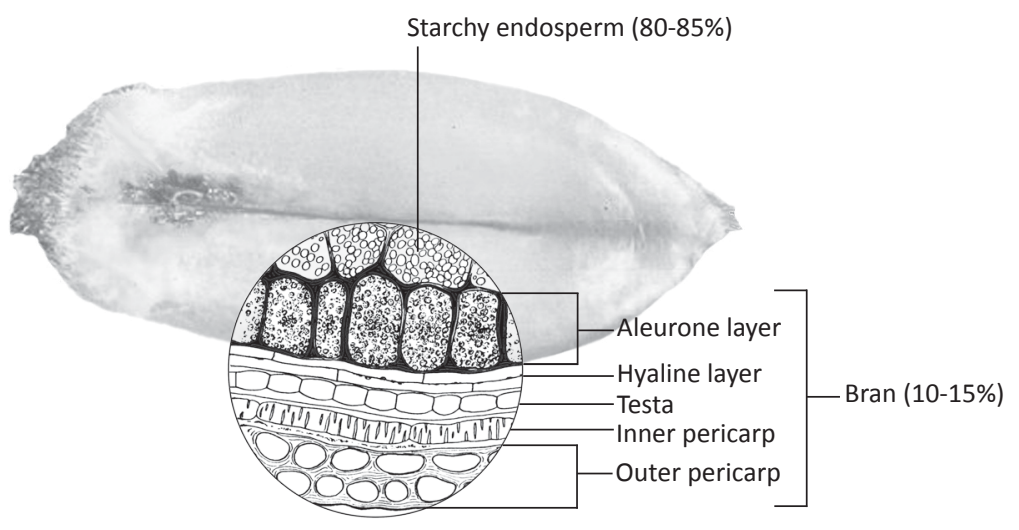

Figure 2: Histological composition of the wheat grain, and proportions of its main constitutive tissues (17).

Wheat bran is the outermost fraction of the wheat kernel comprising around 10$15 \%$ of the kernel weight, and consists of multiple layers. From the inner layer to the exterior of the wheat kernel are: the aleurone layer, the hyaline layer (nucellar epidermis), the testa or seed coat, the inner pericarp (cross and tube cells), and the outer pericarp. All these layers constitute the bran, of which the main physiological function is the protection of the seed. During the conventional milling, the bran is removed as a by-product. The aleurone layer (6-8\%) which is a monolayer of cells overlaying the endosperm, is highly adhered to the pericarp and normally discarded along with the bran (17). The aleurone cells contain high levels of lysine and arginine rich protein, fiber, and low levels of lipids. Among all the bran layers, aleurone has the highest content in vitamins (B and E), minerals ( $\mathrm{P}, \mathrm{K}, \mathrm{Mn}, \mathrm{Mg}, \mathrm{Zn}$ ) and phytochemicals (phenolic acids, alkylresorcinols) (18). Interestingly, the aleurone cells play a crucial role in the plant physiology, since the aleurone cells host hormonal signaling processes that are necessary for the seed germination. Some of these processes involve reactive oxygen species, whose production in the cell is regulated by antioxidant and oxidant enzymes (19).

The high levels of bioactive compounds found in wheat bran fractions have drifted our perception of bran from a by-product to a functional ingredient. 


\section{BIOACTIVES IN WHEAT GRAIN}

In the plant physiology, the production of some phytochemical compounds has been proposed as an evolutionary strategy to cope with the static nature of the plant, as they can provide a chemical defense against changing environmental conditions and to pathogen and herbivore attacks.

Many phytochemicals are bioactive compounds that have been used as drugs for millennia. For instance Hippocrates used willow tree to abate fever. It was 2,000 years later that salicin was identified and extracted from the tree for its antiinflammatory properties. Finally, synthetically produced, it became a staple overthe-counter drug; aspirin (acetylsalicylic acid).

Table 1. Content of bioactive compounds per $100 \mathrm{~g}$ of wheat grain and wheat bran.

\begin{tabular}{|lccc|}
\hline BIOACTIVE & WHEAT & BRAN & REF \\
\hline Phytic acid $(a)$ & $910-1930 \mathrm{mg}$ & $2180-5220 \mathrm{mg}$ & $(15,20)$ \\
\hline Ferulic acid $(b)$ & $10-200 \mathrm{mg}$ & $500-1500 \mathrm{mg}$ & $(15,21-23)$ \\
\hline Alkylresorcinols $(c)$ & $28-140 \mathrm{mg}$ & $220-400 \mathrm{mg}$ & $(15,24,25)$ \\
\hline Vitamin E $(d)$ & $1.4-2.2 \mathrm{mg}$ & $1.4 \mathrm{mg}$ & $(15,26)$ \\
\hline Betaine $(e)$ & $6.9-290 \mathrm{mg}$ & $1000-1300 \mathrm{mg}$ & $(15,27,28)$ \\
\hline Choline $(f)$ & $1.6-14 \mathrm{mg}$ & $47 \mathrm{mg}$ & $(15,27)$ \\
\hline Niacin $(g)$ & $4.0-9.3 \mathrm{mg}$ & $14-18 \mathrm{mg}$ & $(26,29-31)$ \\
\hline Pantothenic acid $(h)$ & $0.7-1.1 \mathrm{mg}$ & $2.2-3.9 \mathrm{mg}$ & $(26,32)$ \\
\hline Riboflavine $(i)$ & $0.19-0.37 \mathrm{mg}$ & $0.39-0.75 \mathrm{mg}$ & $(26,31,33)$ \\
\hline Folate $(j)$ & $20-87 \mu \mathrm{g}$ & $79-200 \mu \mathrm{g}$ & $(15,26,34)$ \\
\hline Glutathione $(k)$ & $82-670 \mu \mathrm{g}$ & & $(35,36)$ \\
\hline Iron & $3.2 \mathrm{mg}$ & $11 \mathrm{mg}$ & $(15,26)$ \\
\hline Manganese & $3.1 \mathrm{mg}$ & $12 \mathrm{mg}$ & $(15,26)$ \\
\hline Zinc & $2.6 \mathrm{mg}$ & $7.3 \mathrm{mg}$ & $(15,26)$ \\
\hline Selenium & $0.5-75 \mu \mathrm{gg}$ & $78 \mu \mathrm{g}$ & $(15,26)$ \\
\hline
\end{tabular}

Assuming that $13 \%$ of the grain is water, the dry weights have been converted to wet matter<smiles>CCCCCCCCCc1cc(O)cc(O)c1</smiles> 


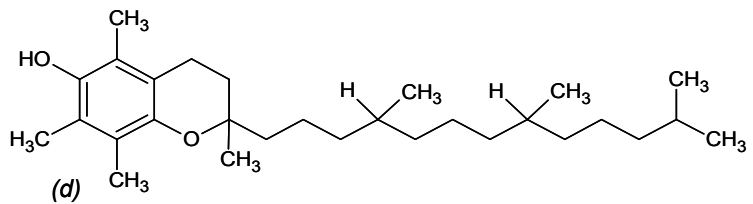<smiles>C[N+](C)(C)CC(=O)O</smiles>

(e)<smiles>C[N+](C)(C)CCO</smiles>

(f)<smiles>O=C(O)c1cccnc1</smiles><smiles>CC(C)(CO)C(O)C(=O)NCCC(=O)O</smiles>

(g)<smiles>Nc1nc(O)c2nc(CNc3ccccc3)cnc2n1</smiles>
(j)

The term bioactivity actually refers to a modulating effect on any particular biological process in a living cell or organism, however, is often used in terms of human health. Bioactivity is not any longer merely restricted to drugs but also used for food components with health benefits. The bioactive compounds present in wheat grain are reviewed below in relation to their antioxidant and antiinflammatory activities. Their contents in wheat grain and wheat bran are given in Table 1. The wide ranges found in the contents of some compounds are the result of different wheat varieties, geographical areas of cultivation or extraction and quantification methods.

\section{Antioxidant mechanisms}

Research on the antioxidant activity of food compounds has received much attention in the last decades since the postulation of the free-radical-theory of aging by Denham Harman in 1956 (37). Free radicals are atoms, molecules or ions with unpaired electrons on an otherwise open shell configuration (38). According to Halliwell, antioxidants are substances that at low concentration can delay or inhibit the oxidation of a substance, e.g. by free radicals or other reactive species (39).

Reactive oxygen species (ROS) and reactive nitrogen species (RNS) are produced in several physiological cellular processes. For instance, ATP production by oxidative phosphorilation in mytochondria is accompanied by ROS formation. Also in the inflammatory process ROS and RNS are produced by neutrophils and 
macrophages in an attempt to kill invading agents. Additionally, redox signaling has been involved in cellular apoptosis, muscle relaxation and other cellular functions. However, an excess and uncontrolled production of free radicals can lead to oxidative damage and further oxidative stress (40). Oxidative stress has been involved in the aggravation of various diet-related disorders such as type- 2 diabetes, cardiovascular disease, obesity, and the all-in-one metabolic syndrome $(41,42)$.

Globally the total antioxidant capacity of whole grain is comparable to that of some fruits and vegetables when expressed on a "per serving" basis (43). From high to low content, wheat grain contains numerous compounds involved in antioxidant mechanisms: phytate, phenolic compounds, methyl donors, B-vitamins and minerals.

Phytates is the generic term for myo-inositol tri- $\left(\mathrm{IP}_{3}\right)$, tetra- $\left(\mathrm{IP}_{4}\right)$, penta- $\left(\mathrm{IP}_{5}\right)$ and hexakis- $\left(\mathrm{IP}_{6}\right)$ phosphate. Phytic acid $\left(\mathrm{IP}_{6}\right)$ constitutes the main storage of phosphate in the seed, it is mainly contained in the bran (Table 1) which function was believed to be protection against oxidative damage during storage. The antioxidant activity of phytic acid is mainly attributed to iron chelating, which interrupts the reactions of the Haber-Weiss cycle:

$$
\begin{aligned}
& \mathrm{Fe}^{3+}+\mathrm{O}_{2}{ }^{--} \rightarrow \mathrm{Fe}^{2+}+\mathrm{O}_{2} \\
& \mathrm{Fe}^{2+}+\mathrm{H}_{2} \mathrm{O}_{2} \rightarrow \mathrm{Fe}^{3+}+\mathrm{OH}^{-}+\cdot \mathrm{OH} \text { (the Fenton reaction) }
\end{aligned}
$$

As a consequence, the formation of hydroxyl radicals $(\cdot \mathrm{OH})$ is prevented which in turn can prevent lipid peroxidation (44). Phytic acid has also been shown to inhibit xanthine oxidase mediated $\mathrm{O}_{2}{ }^{\cdot-}$ generation (45). Dietary phytic acid is hydrolyzed during digestion by phytase, which cleaves the phosphate groups from the inositol ring. This reduces the chelating activity of phytate (46).

The phenolic compounds found in wheat grain are basically phenols containing one aromatic ring: phenolic acids, such as ferulic acid, sinapic acid, and $p$-coumaric acid, alkylresorcinols, and vitamin E (Table 1). The polyphenols found in wheat grain are mainly lignins and lignans.

Phenolic compounds display antioxidant activity by different multi-faceted antioxidant mechanisms. Their free radical scavenging activity is one of the best documented. The hydroxyl group of the phenolic ring donates one electron to the radical molecule, which is followed by a rapid proton transfer. The net result is the equivalent to one hydrogen atom transfer to the free radical. In turn, the phenol is oxidized. However, the phenol radical does not progress the oxidative reaction, since it is relatively stable due to resonance, in which the unpaired electron is delocalized to the ortho or para position of the phenyl ring. Finally, the oxidized antioxidant can be converted back to its reduced form by enzymatic and non enzymatic antioxidants (47). 
Ferulic acid acid is the common name for 3-(4-hydroxy-3-methoxyphenyl) propionic acid. Ferulic acid is mostly located in the bran of wheat grain (Table 1), where it occurs in the trans isomer form and linked by ester binding to cell wall polysaccharides (48). The antioxidant potential of ferulic acid is mainly attributed to the electron donation and hydrogen atom transfer to free radicals (47). Its ability to inhibit lipid peroxidation by superoxide $\left(\mathrm{O}_{2}{ }^{--}\right)$scavenging is of greater magnitude than that of cinnamic acid but less than that of caffeic acid (49). Its ability to inhibit oxidation of low-density lipoprotein (LDL), the main cholesterol carrier in blood, is greater than that of ascorbic acid (50). The ferulic acid radical (phenoxy radical) that is formed from its oxidation is very stable and does not initiate an oxidative chain reaction of its own (51), the presence of the methoxy group enhances the resonance stabilization $(23,52)$. In the case of an hydroxyl group instead of the methoxy group (i.e. caffeic acid) the radical-scavenging activity is substantially increased (53).

Beside ferulic acid, wheat grain contains other hydroxycinnamic acids with antioxidant activity: coumaric, sinapic and caffeic acid (54). Among them ferulic acid is the most abundant one. Generally, hydroxycinnamic acids and in particular ferulic acid and dimeric ferulic acid are rather specific phytochemicals of grain. They are not in substantial amounts in fruits and vegetables. This makes whole grain the main contributor to the dietary intake of these antioxidants (43).

Alkylresorcinols are ampiphilic molecules consisting of 2-hydroxyphenol and an alkyl side chain of different length at position 5, the most common are C15:0, C17:0, C19:0, C21:0, C23:0, and C25:0. The alkylresorcinols are mainly located in the bran (Table 1), specifically in the testa (Figure 2) (24). They have little hydrogen donation and peroxyl scavenging activity (55), but they show oxidative prevention of membranes (56). This is due to the lipophilic nature of the alkyl chain in alkylresorcinols, that confers them membrane modulating effects by interactions with phospholipids or proteins in the membranes $(55,57)$. Additionally, alkylresorcinols can prevent in vitro $\mathrm{Fe}^{2+}$-induced oxidation of fatty acids (58) and $\mathrm{Cu}^{+}$-induced oxidation of LDL (59). Alkylresorcinols are phytochemicals rather specific from grain source and they are therefore commonly used as biomarkers of whole-grain consumption.

Vitamin $\mathbf{E}$ is the collective name for a set of eight related compounds or vitamers: $\alpha-, \beta-, \gamma^{-}$, and $\delta$-tocopherols and the corresponding four tocotrienols. Vitamin E is lypophilic and, therefore, primarily found in the germ of the wheat grain. Despite the fact that all the different forms of vitamin $\mathrm{E}$ have similar antioxidant activity (rate constants for hydrogen donation), a-tocopherol is preferentially maintained in plasma. This is due to (i) the specific binding to the atocopherol transfer protein and (ii) the extensive hepatic metabolism of the other 
vitamers (60). The a-tocopherol molecule consists of a chroman head, which is responsible for the antioxidant function, and a phytyl chain that intercalates with the phospholipids of the cell membrane. The free hydroxyl group on the aromatic ring is responsible for the antioxidant properties. The hydrogen from this group is donated to the free radical, resulting in a relatively stable free radical form of vitamin $\mathrm{E}$ (61). In this way, vitamin $\mathrm{E}$ molecules can interrupt free radical chain reactions. Vitamin $\mathrm{E}$ also has protective effects on glutathione-dependent enzymes (62). The function of vitamin $\mathrm{E}$ in the human body has been recently reviewed, the major function appeared to be as radical scavenger protecting the polyunsaturated fatty acids from oxidation, hereby maintaining the integrity of the cell membrane (60).

Lignin biopolymers have heterogeneous structure; they constitute $30 \%$ of plant biomass and belong to the most abundant organic polymers on earth. Lignins are a major component of whole-grain cereals, and may account for 3-7\% of the bran fraction $(15,63)$. Their polyphenolic structure confers them potential antioxidant capacities (64), such as on DNA damage (oxidative lesions) in cells $(65,66)$. Lignins can be metabolized into mammalian lignans (67).

Lignans are dietary phyto-oestrogens that are present in a wide variety of plant foods including whole grain wheat. The group includes secoisolariciresinol, matairesinol, lariciresinol, pinoresinol and syringaresinol. They all have a polyphenolic structure and have antioxidant effects $(15,63,68)$. Lignans and their metabolites, the mammalian lignans enterodiol and enterolactone, have antioxidant activity in different lipid and aqueous in vitro model systems and decrease lipid oxidation (69). An antioxidant mechanism of lignans may be metal chelation (70). Lignans have less marked effects than lignins upon oxidative genetic damage (71).

Methyl donors: Folate, choline and betaine participate in recycling the potentially toxic amino acid homocysteine to methionine and, ultimately, to the methyl donor S-adenosylmethionine (SAM). Their interplay is depicted in Figure 3.

Folates are classified as B-vitamins, namely vitamin $\mathrm{B}_{9}$. They are present in the grain mainly as reduced forms (tetrahydrofolates) rather than as folic acid (pteroylmonoglutamic acid). Tetrahydrofolates have a varying number of glutamyl residues (1-7) and can be methylated or formylated at $\mathrm{N}_{5}$ and $\mathrm{N}_{10}$. Among all these possible structures, 5-methyltetrahydrofolate is biologically the main active form (72) (Figure 3). Some forms of folate have radical scavenging properties in vitro (73) and prevent mitochondrial dysfunction and apoptosis via intracellular superoxide scavenging $\left(\mathrm{O}_{2} \cdot{ }^{--}\right)(74)$. However, the main mechanism of folate in antioxidant protection has been reported to be indirect, by lowering homocysteine $(75,76)$ and 
as electron and hydrogen donor to tetrahydrobiopterin $\left(\mathrm{H}_{4} \mathrm{~B}\right)$, an essential cofactor for the endothelial nitric oxide synthase (eNOS) to form nitric oxide $(75,77)$.

Betaine (trimethylglycine) is present in wheat grain, mainly in bran (1\%) (Table 1), but it can also be formed from oxidation of choline in liver and kidney. The two principal biological functions of betaine are as osmolyte and as methyl donor (78) (Figure 3). Choline is also contained in wheat grain, although in lower amounts than betaine (Table 1). Choline can also be synthesized in the liver (79).

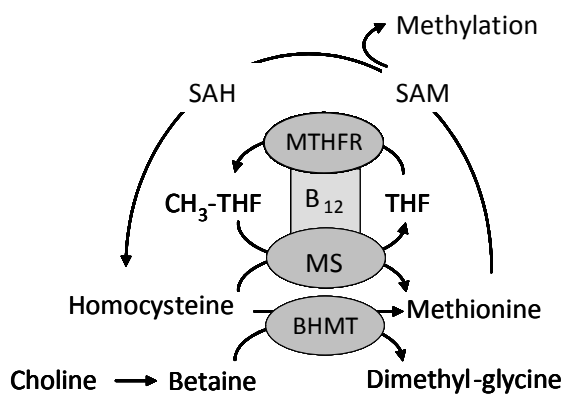

Figure 3: Betaine and transmethylation in the methionine cycle. $\mathrm{B}_{12}$ : vitamin $\mathrm{B}-12$ (cobalamin); BHMT, betaine homocysteine methyltransferase; MS, methionine synthase; MTHFR, methylenetetrahydrofolate reductase; THF, tetrahydrofolate; $\mathrm{CH}_{3}-\mathrm{THF}$, 5methyltetrahydrofolate; SAM: S-adenosylmethionine; SAH: S-adenosylhomocysteine (78).

Wheat grain contains several B-vitamins, mainly riboflavin, niacin and pantothenic acid. They are mainly contained in the bran (Table 1). Cereals and cereal products contribute around $30 \%$ of the daily intake of these vitamins in the $\operatorname{diet}(80)$.

Niacin or pyridine-3-carboxylic acid is also known as vitamin $\mathrm{B}_{3}$ or as nicotinic acid. Niacin is a water soluble vitamin abundant in wheat grain. Besides the dietary source, niacin can be formed from tryptophan in liver. Niacin is present in two natural forms, free (nicotinic acid) and bound (nicotinamide). Nicotinamide is used to form the coenzymes nicotinamide adenine dinucleotide $\left(\mathrm{NAD}^{+}\right)$and nicotinamide adenine dinucleotide phosphate $\left(\mathrm{NADP}^{+}\right) . \mathrm{NAD}^{+}$and $\mathrm{NADP}^{+}$are required by as many as 200 enzymes to donate electrons in redox reactions, as well as for the activity of the enzyme poly(ADP-ribose) polymerase-1, involved in DNA synthesis and repair (81). Niacin is used for the treatment of dyslipidemia and atherosclerosis for years. Recently this vitamin has been reported to increase the redox state (NADPH, GSH) that leads to a decrease in ROS and LDL oxidation 
(82), and at the same time to inhibit redox-sensitive genes in aortic endothelial cells (83).

Pantothenic acid or 3-[(2,4-dihydroxy-3,3-dimethylbutanoyl)amino]propanoic acid is also known as vitamin $B_{5}$. Pantothenic acid is a water soluble vitamin that cannot be synthesized in the human body, but it is widely available in the diet. Whole grain is a good source of this vitamin. Pantothenic acid and its reduced derivative pantothenol are precursors of two important enzyme cofactors: coenzyme A (CoA) and acyl carrier protein (ACP). Both cofactors contain a sulfhydryl group (-SH), which reacts with activated carboxylic acids to form thioesters. Pantothenic acid is not an antioxidant in the sense of radical scavenging, but indirectly its intake is related with an increase in glutathione content $(84,85)$.

Riboflavin or 7,8-dimethyl-10-ribityl-isoalloxazine is also known as vitamin $\mathrm{B}_{2}$. In wheat grain only a small amount of riboflavin is present in the free form, while the most of it is present as flavin adenine dinucleotide (FAD) and a smaller amount as flavin mononucleotide (FMN). Upon digestion, FAD and FMN need to be hydrolyzed to riboflavin in order to be absorbed. FAD and FMN act as intermediate hydrogen acceptors in the mitochondrial electron transport chain and pass on electrons to the cytochrome system in cellular respiration (86). Riboflavin does not have significant inherent antioxidant action. Its powerful antioxidant properties are derived from its role as precursor of FAD and FMN. FAD forms the reactive catalytic centre of glutathione reductase, an enzyme that converts glutathione disulfide (GSSG) into glutathione (GSH) (86).

Glutathione or L-gammaglutamyl-L-cysteinyl-glycine is a tri-peptide of the amino acids cystein, glycine, and glutamic acid. It is produced in liver and other organs and is present in all cells. GSH is found free or bound to proteins in the cell (87). GSH participates directly in the neutralization of free radicals, reactive oxygen compounds. GSH also participates in indirect mechanisms; GSH acts as an electron donor in enzymatic reactions such as GSH-dependent dehydroascorbate reductase to regenerate ascorbate (vitamin C) from its oxidation product, dehydroascorbate $(88,89)$. GSH is also used by glutathione peroxidases and glutathione-Stransferases in the detoxification of peroxides. In both reactions GSH acts as electron donor, which leads to its oxidation to glutathione disulfide (GSSG). As mentioned above, the cellular GSH pool can be regenerated from GSSG via the NADPH-dependent enzyme glutathione reductase. Therefore, GSH is considered an important endogenous antioxidant (90).

Whole grain wheat also contains considerable amounts of iron, magnesium and zinc, as well as lower levels of many trace elements, e.g. selenium and manganese. They are mainly found in the bran, and highly concentrated in the aleurone. The contents vary greatly depending on the location due to the soil characteristics. The 
essential question about the bioavailability of the minerals and trace elements in grain is whether it is depleted through the chelation by phytate. Processing conditions that activate phytases are able to hydrolyze the phytate, such as in the case of fermentation, which has been shown to improve the bioavailability of minerals (91).

Iron $(\mathrm{Fe})$ is the most abundant trace element in the body, and almost all iron is bound to proteins. Free iron concentrations are particularly low for two reasons: $\mathrm{Fe}^{3+}$ is not water soluble, and $\mathrm{Fe}^{2+}$ participates in the generation of free radicals, such as $\cdot \mathrm{OH}$ (Fenton reaction). An increase in free iron concentrations can result from dietary protein deficiency, dietary iron loading, low concentrations of ironbinding proteins, or cell injury. This will result in production of reactive oxygen species, lipid peroxidation, and oxidative stress. Increasing the extracellular concentration of non-heme iron also enhances inducible nitric oxide synthase (iNOS) protein expression and inducible NO synthesis in many cell types, which can further exacerbate oxidative damage via peroxynitrite generation (92).

Manganese $(\mathrm{Mn})$ is essential for many ubiquitous enzymatic reactions such as the manganese superoxide dismutase (Mn-SOD). Consequently a deficiency of this mineral markedly decreases the Mn-SOD activity and results in peroxidative damage and mitochondrial dysfunction (92).

The main function of zinc $(\mathrm{Zn})$ is in a structural role as zinc finger involved in the DNA domains of many proteins, peptides, enzymes, hormones, transcriptional factors and growth factors, including cytokines, relevant to the maintenance of body homeostatic mechanisms. A zinc finger is made up of a short stretch of 28-40 amino acids containing a characteristic $\mathrm{Cys}_{2} \mathrm{His}_{2}$ (cysteine, histidine) motif that are stabilized by one or more zinc ions (93). Zinc also plays a critical role in the structure, function, stabilization and fluidity of biomembranes because of zinc binding to thiol groups (94). The antioxidant action of zinc is as cofactor for the activities of $\mathrm{Cu} / \mathrm{Zn}$-superoxide dismutase (95). On the other hand, Zn itself may be a strong inducer of oxidative stress by promoting mitochondrial and extramitochondrial production of reactive oxygen species (96).

Selenium (Se) is an essential trace mineral that occurs mainly as selenomethionine (Se-Met) in cereal grains. Se-Met can be non-specifically incorporated into proteins as a substitution for methionine. It can also be converted into selenocysteine (Se-Cys) and into inorganic selenium by demethylation. Selenocysteine is an important component of selenoproteins, such as selenoprotein $\mathrm{P}$ (main plasma carrier of Se), iodothyronine deiodinases, thioredoxin reductase and the selenium-dependent glutathione peroxidases. These selenoproteins are all selenium dependent, and generally have selenocysteine at their active sites. In these enzymes selenium functions as a redox centre (97). The best-known example 
of this redox function is the reduction of hydroperoxides by the family of Sedependent glutathione peroxidases (98).

\section{Anti-inflammatory mechanisms}

Inflammation is an adaptive response that is triggered by noxious stimuli, such as infection and tissue injury. In principle inflammation is a physiological defensive response that is beneficial, for example in providing protection against infection, but it can become detrimental if dysregulated. Moreover, inflammation is a feed-forward process that amplifies itself and needs to be controlled.

The innate inflammatory response is triggered by bacterial products and proinflammatory mediators (cytokines, chemokines, vasoactive amines, eicosanoids and products of proteolytic cascades, growth factors, ROS) that interact with membrane receptors such as the CD14 and Toll-like receptors in phagocytic leucocytes (macrophages, monocytes, mast cells, dendritic cells, neutrophils) $(99,100)$.

One of the consequences of this first interaction is the assembly of the multicomponent flavoprotein NADPH oxidase to catalyze large amounts of superoxide:

$$
\mathrm{NADPH}+2 \mathrm{O}_{2} \rightarrow \mathrm{NADP}^{+}+2 \mathrm{O}_{2}^{\cdot-}+\mathrm{H}^{+}
$$

Via superoxide dismutation, hydrogen peroxide is formed:

$$
2 \mathrm{O}_{2} \cdot-+2 \mathrm{H}^{+} \rightarrow \mathrm{H}_{2} \mathrm{O}_{2}+\mathrm{O}_{2}
$$

These reactive species lead to the formation of other reactive oxygen species (ROS). During this process, known as respiratory burst, large amounts of ROS are produced $(100,101)$. Also other toxic metabolites such as reactive nitrogen species, proteinase 3, cathepsin G, and elastase, are released by the cell. Unfortunately, these potent toxic effectors do not discriminate between microbial and host targets, so collateral damage to host tissues is unavoidable (99).

The receptor mediated signaling produced by ROS and other inflammatory mediators activate serine/threonine kinases known as the family mitogen activated protein kinases (MAPKs) (Figure 4). The most documented MAPKs are the extracellular signal-regulated protein kinase (ERK 1/2), c-Jun $\mathrm{N}$-terminal kinase (JNK) and p38 $(99,101)$. ROS have also been reported to activate the ERK pathway without receptor interactions (102). 


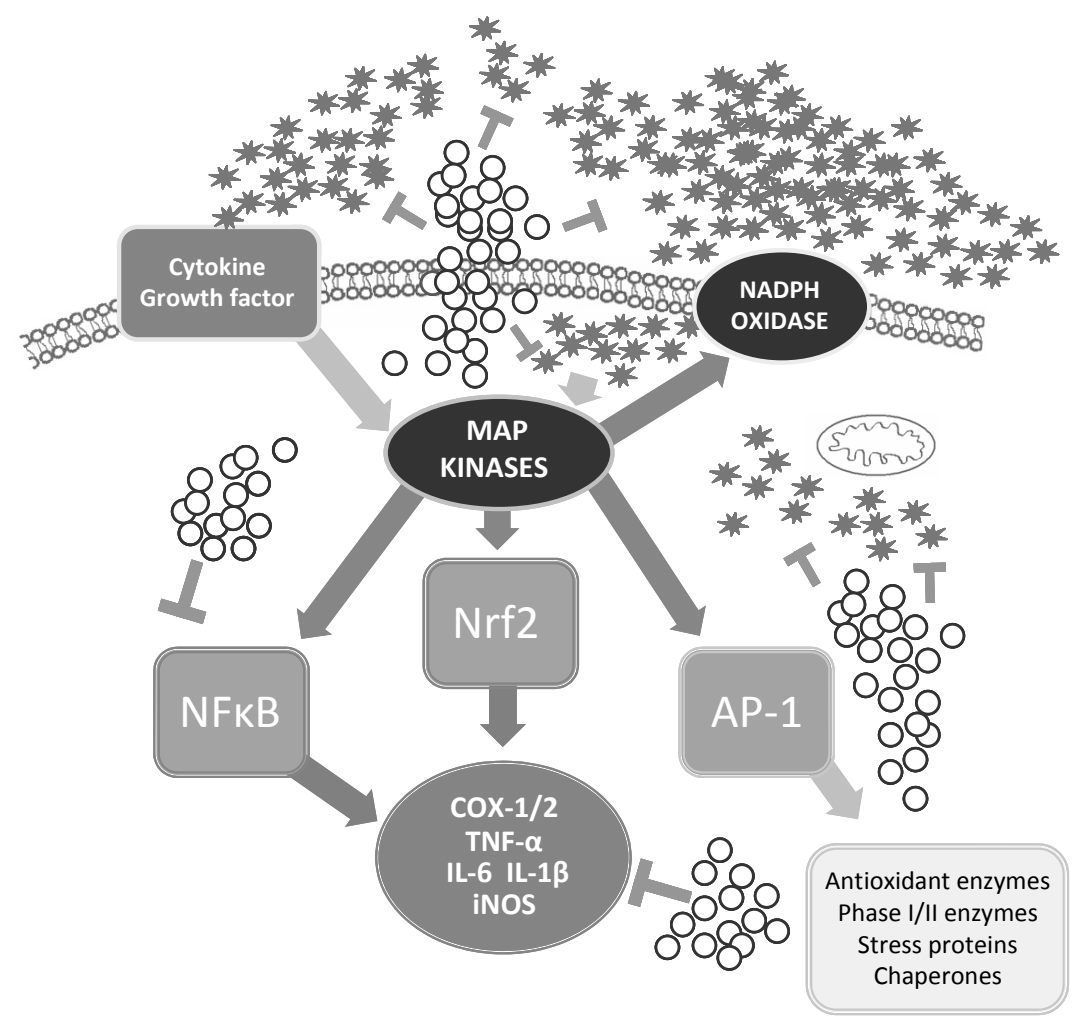

Figure 4. Simplified inflammatory pathways modulated by free radicals: radical oxygen species and others (star symbol), and antioxidants such as dietary phenols (circle symbol).

MAPKs activate transcription factors such as the nuclear factor kappa B (NF$\mathrm{\kappa B})$, the activator protein 1 (AP-1) and the NF-E2-related factor 2 (Nrf-2). Subsequently, the inflammatory response is amplified via upregulation of several pro-inflammatory genes, such as those codifying cytokines (TNF- $\alpha$, IL-1 $\beta$, IL-6) and enzyme systems: phospholipase A2, cyclooxygenase-1/2 (COX), inducible nitric oxide synthase (iNOS). This leads to oxidative damage and feed-forward of the inflammatory response. Alternatively, Nrf-2 activates the antioxidant response element (ARE) containing genes that lead to the expression of antioxidant enzymes, stress proteins and phase II detoxifying enzymes (Figure 4).

The inflammatory modulation of phenols has been proposed to proceed by various mechanisms, including (i) down-regulation of NF-KB or the various enzyme systems involved (including those that generate ROS), (ii) inhibition of the activity of those enzymes, (iii) antioxidant protection of the cell by ROS scavenging or by increasing the cellular antioxidant systems $(103,104)$. Dietary phenols can exert their effects on these pathways separately or sequentially and also the occurrence of crosstalk between these pathways cannot be overlooked. 
Table 2. Anti-inflammatory effects of ferulic acid (FA) in in vitro and in vivo models of inflammation.

\begin{tabular}{|c|c|c|c|c|}
\hline Model of inflammation & $\begin{array}{l}\text { Inflammatory } \\
\text { messengers }\end{array}$ & $\begin{array}{c}\text { OX } \\
\text { enzymes }\end{array}$ & $\begin{array}{c}\text { AOX } \\
\text { enzymes }\end{array}$ & REF \\
\hline LPS-BV2 microglial cells & $\downarrow \downarrow \downarrow \downarrow$ & $\downarrow$ & & $(105)$ \\
\hline Glutamate toxicity in cortical neurons & $\downarrow^{b}$ & & & $(106)$ \\
\hline LPS/ INF- $\nu$ - RAW macrophages & - & - & & $(107)$ \\
\hline$A \beta$ stimulated histocyte from rats & $\downarrow$ & $\downarrow \downarrow^{a}$ & & $(108)$ \\
\hline Human PBMC & $\uparrow$ & & & (109) \\
\hline PHA -splenocytes & $\downarrow$ & & & $(110)$ \\
\hline LPS/ INF- $\nu$-RAW macrophages & - & & & (111) \\
\hline PMA - adenocarcinoma cells (MTLN) & $\downarrow^{\mathrm{b}}$ & & & $(112)$ \\
\hline LPS -RAW macrophages & $\downarrow$ & & & (113) \\
\hline Influenza virus - RAW macrophages & $\downarrow$ & & & $(114)$ \\
\hline Respiratory burst in polymorphonuclear cell & & $\downarrow^{\mathrm{e}}$ & & $(115)$ \\
\hline \multicolumn{5}{|l|}{ In vivo } \\
\hline Model of inflammation & $\begin{array}{c}\text { Inflammatory } \\
\text { messengers }\end{array}$ & $\begin{array}{c}\text { OX } \\
\text { enzymes }\end{array}$ & $\begin{array}{c}\text { AOX } \\
\text { enzymes }\end{array}$ & REF \\
\hline Osteoarthritis in rats & & $\downarrow^{\mathrm{a}}$ & & $(116)$ \\
\hline Aged rats & $\downarrow \downarrow \downarrow^{b} \downarrow^{c}$ & $\downarrow$ & & $(117)$ \\
\hline Acetic acid induced colitis in rats & $\downarrow \downarrow^{b} \downarrow^{c}$ & $\downarrow$ & & $(118)$ \\
\hline Nicotine toxicity in rats & $\downarrow^{b} \downarrow^{c}$ & & & $(119)$ \\
\hline Hemorrhagic shock after reperfusion in rabbits & $\downarrow$ & & $\uparrow$ & $(120)$ \\
\hline$A \beta$ induced toxicity in hippocampus in rats & $\downarrow^{b}$ & & & $(121)$ \\
\hline$A \beta$ induced Alzheimer in rats & $\downarrow \downarrow^{\mathrm{b}}$ & & $\uparrow^{d}$ & $(122)$ \\
\hline$A \beta$ toxicity in hippocampus in rats & $\downarrow$ & & & $(123)$ \\
\hline$A \beta$ toxicity on astrocytes of mice & $\downarrow$ & $\downarrow$ & & (124) \\
\hline
\end{tabular}

Inflammatory messengers: cytokines or prostaglandins, ${ }^{b}$ linked to transcription factors and kinases, ${ }^{\mathrm{c}}$ linked to the enzyme cyclooxygenase (COX).

OX enzymes: nitric oxide synthase (NOS) activity, ${ }^{a}$ measured as NO formation, ${ }^{e}$ measured as ROS formation. AOX enzymes: superoxide dismutase (SOD), ${ }^{d}$ linked to transcription factors of the Nrf-2/ARE pathway.

- No effect observed. 
Table 3. Anti-inflammatory effects of ferulic acid (FA) derivatives in in vitro models of inflammation.

\begin{tabular}{|c|c|c|c|c|c|}
\hline FA derivative & $\begin{array}{c}\text { Model of } \\
\text { inflammation }\end{array}$ & $\begin{array}{c}\text { Inflammatory } \\
\text { messengers }\end{array}$ & $\begin{array}{c}\text { OX } \\
\text { enzymes }\end{array}$ & $\begin{array}{c}\text { AOX } \\
\text { enzymes }\end{array}$ & REF \\
\hline FA dehydromer & PHA -splenocytes & $\downarrow$ & & & (110) \\
\hline $\begin{array}{l}\text { NO-releasing derivative of } \\
\text { FA }\end{array}$ & $\begin{array}{l}\text { Carrageenan - } \\
\text { RAW macrophages }\end{array}$ & $\downarrow \downarrow^{c}$ & & & (125) \\
\hline $\begin{array}{l}\text { NO-releasing derivative of } \\
\text { FA }\end{array}$ & $\begin{array}{l}\text { LPS/ INF- } \gamma \text { - RAW } \\
\text { macrophages }\end{array}$ & $\downarrow^{b}$ & $\downarrow$ & & (107) \\
\hline Phytosteryl ferulate & LPS - macrophages & $\downarrow^{\mathrm{c}}$ & $\downarrow$ & $\uparrow$ & (126) \\
\hline FA ethyl ester & $\begin{array}{l}\text { Hippocampal } \\
\text { cultures }\end{array}$ & & & $\uparrow^{d}$ & (127) \\
\hline 2-methyl-1-butyl ferulic acid & $\begin{array}{l}\text { LPS/ INF- } \gamma \text { - RAW } \\
\text { macrophages }\end{array}$ & $\downarrow^{b} \downarrow^{c}$ & $\downarrow$ & & (111) \\
\hline $\begin{array}{l}\text { Phenethyl FA in extract of } \\
\text { Qianghuo }\end{array}$ & COX assay & $\downarrow^{\mathrm{c}}$ & & & (128) \\
\hline $\begin{array}{l}\text { FA containing ethyl acetate } \\
\text { extract from adlay testa }\end{array}$ & $\begin{array}{l}\text { LPS-RAW } \\
\text { macrophages }\end{array}$ & $\downarrow^{\mathrm{c}}$ & $\downarrow$ & & (129) \\
\hline Colonic metabolites of FA & Colonic HT-29 cells & $\downarrow^{c}$ & & & (130) \\
\hline Colonic metabolites of FA & IL-1 $\beta$ - fibroblasts & $\downarrow$ & & & (131) \\
\hline Colonic metabolites of FA & LPS - PBMC & $\downarrow \downarrow \downarrow$ & & & (132) \\
\hline
\end{tabular}

Inflammatory messengers: cytokines or prostaglandins, ${ }^{b}$ linked to transcription factors and kinases, ${ }^{\mathrm{c}}$ linked to the enzyme cyclooxygenase (COX).

OX enzymes: nitric oxide synthase (NOS) activity, ${ }^{a}$ measured as NO formation, ${ }^{\mathrm{e}}$ measured as ROS formation. AOX enzymes: superoxide dismutase (SOD), ${ }^{d}$ linked to transcription factors of the Nrf-2/ARE pathway.

The most abundant phenolic compound in wheat grain is ferulic acid. Ferulic acid is a secondary plant metabolite formed from shikimic acid. Shikimic acid is transformed to phenylalanine in the so called 'shikimic pathway' and subsequently converted by an ammonia lyase to transcinnamic acid. Hydroxylation at $\mathrm{C} 4$ and methoxylation at C3 result in ferulic acid. Ferulic acid has been used for years in traditional Chinese medicine and is approved by the State Drugs Administration of China as a drug for the treatment of cardiovascular and cerebrovascular diseases (133). A recent review also highlights the possible action of ferulic acid as an hormetic agent interfering in the Nrf-2/ARE pathway (134). 
The anti-inflammatory effects of ferulic acid and ferulic acid derivatives have been investigated in different in vitro and in vivo studies. The main findings of these studies are summarized in Table 2 and Table 3.

The main anti-inflammatory effects of ferulic acid seem on COX regulation and the MAP kinase/NFkB pathway, although recent investigations point ferulic acid as a possible hormetic agent in activating the Nrf-2/ARE pathway and the expression of protective genes.

\section{BIOACTIVITY - BIOAVAILABILITY - BIOACCESSIBILITY}

The concept of bioavailability originates from the pharmacological term referring to the portion of an oral dose that reaches systemic circulation. In nutritional sciences, bioavailability reflects the efficiency with which nutrients are utilized. In reference to food bioactives, bioavailability generally includes: 1) availability for absorption in the gastrointestinal (GI) system also referred to as "bioaccessibilty", 2) absorption through small or large intestinal epithelium, 3) metabolism before, during, or after metabolism by phase I and II enzymes, 4) tissue distribution, and 5) bioactivity $(135,136)$.

First factors involved in the bioavailability of food bioactives are the intake as well as the bioaccessibility from the food. The intake of bioactive molecules depends on their content in the food, which is normally low in plant and animal products. The bioaccesibility from the product is restrained by compound-food matrix interactions. Processing of food has been extensively reported to lower the level of bioactive molecules in foods. On the other hand, processing can increase their availability for intestinal absorption by modifying the food matrix and consequently increasing the bioavailability and ultimate bioactivity. 


\section{AIM AND OUTLINE OF THE THESIS}

The four years of research assembled in this thesis were aimed at investigating the bioactive compounds in whole grain wheat with focus on those with antioxidant and anti-inflammatory effects. This investigation was triggered by the need to elucidate the mechanisms underlying the health effect of whole-grain consumption.

Chapter 1 introduces the relevance of whole grain in global nutrition and health. In addition, the content of several bioactives in wheat grain as well as their antioxidant and anti-inflammatory mechanisms are reviewed with a particular interest in ferulic acid.

In chapter 2, the antioxidant capacity of several fractions of a wheat grain is studied, and the main contributor to the capacity is identified.

In chapter 3, the bioaccessibility of ferulic acid from wheat fractions and breads is investigated with the use of an in vitro system of upper gastrointestinal tract.

In chapter 4, the antioxidant and anti-inflammatory capacity of bioaccessible compounds from the wheat fractions: flour, bran, and aleurone, are assessed with the use of in vitro models.

In chapter 5, the effect of bioprocessing of bran on the bioaccessibility of phenolic compounds was studied in whole-meal breads enriched with bran. Additionally in this chapter, the colonic metabolism of the non bioaccessible phenolics was investigated with an in vitro model of human colon.

In chapter 6, the effect of bioprocessing of bran is further investigated in relation to the fiber metabolism and production of short chain fatty acids.

Following the "from in vitro to in vivo approach", the in vivo study conducted in chapter 7 shows the effect of bioprocessing on the bioavailability of ferulic acid and other phenolic compounds. Furthermore, the postprandial plasma antioxidant capacity and an ex-vivo LPS induced inflammation are also studied.

Finally in chapter 8 the most important findings are discussed and the future perspectives are given. 


\section{REFERENCES}

1. Moore JC. Enhancing the availability of natural antioxidants in wheat-based food ingredients and food products through improved post-harvest treatments and processing conditions Maryland, USA: University of Maryland, College Park; 2007.

2. Slavin J. Whole grains and human health. Nutr Res Rev. 2004;17:99-110.

3. Curtis BC. Wheat in the world. In: Curtis BC, Rajaram S, Macpherson HG, editors. Bread wheat improvement and production. Rome, Italy: Plant production and protection series. FAO 2002. p. 1-19.

4. Peña RJ. Wheat for bread and other foods. . In: Curtis BC, Rajaram S, Macpherson HG, editors. Bread wheat improvement and production. Rome, Italy: Plant production and protection series. FAO 2002.

5. Trowell H. The development of the concept of dietary fiber in human nutrition. Am J Clin Nutr. 1978;31:3S-11.

6. Truswell AS. Cereal grains and coronary heart disease. Eur J Clin Nutr. 2002;56:1-14.

7. Anderson JW, Hanna TJ, Peng X, Kryscio RJ. Whole Grain Foods and Heart Disease Risk. J Am Coll Nutr. 2000;19:291S-9.

8. McKeown NM, Meigs JB, Liu S, Wilson PW, Jacques PF. Whole-grain intake is favorably associated with metabolic risk factors for type 2 diabetes and cardiovascular disease in the Framingham Offspring Study. Am J Clin Nutr. 2002;76:390-8.

9. Sahyoun NR, Jacques PF, Zhang XL, Juan W, McKeown NM. Whole-grain intake is inversely associated with the metabolic syndrome and mortality in older adults. Am J Clin Nutr. 2006;83:124-31.

10. Liu S. Whole-grain foods, dietary fiber, and type 2 diabetes: searching for a kernel of truth Am J Clin Nutr. 2003;77:527-9.

11. Slavin J. Whole grains and human health. Nutr Res Rev. 2004;17:99-110.

12. Anderson JW. Whole grains and coronary heart disease: the whole kernel of truth. Am J Clin Nutr. 2004;80:1459-60.

13. Liu S, Stampfer MJ, Hu FB, Giovannucci E, Rimm E, Manson JE, Hennekens CH, Willett WC. Whole-grain consumption and risk of coronary heart disease: results from the Nurses' Health Study. Am J Clin Nutr. 1999;70:412-9.

14. Jensen MK, Loh-Banerjee P, Franz M, Sampson L, Gronbaek M, Rimm EB. Whole grains, bran, and germ in relation to homocysteine and markers of glycemic control, lipids, and inflammation. Am J Clin Nutr. 2006;83:274-83.

15. Fardet A, Rock E, Remesy E. Is the in vitro antioxidant potential of whole-grain cereals and cereal products well reflected in vivo? J Cereal Sci. 2008;48: 258-76.

16. Fulcher RG, Duke TK. Whole-grain structure and organization: Implications for nutritionists and processors. In: Marquart L, Slavin L, Fulcher R, G., editors. Wholegrain foods in health and disease. St. Paul, Minnesota: American Association of Cereal Chemists; 2002. p. 9-45.

17. Hemery Y, Rouau X, Lullien-Pellerin V, Barron C, Abecassis J. Dry processes to develop wheat fractions and products with enhanced nutritional quality. J Cereal Sci. 2007;46:327-47.

18. Hemery $Y$, Lullien-Pellerin V, Rouau X, Barron C, Abecassis J, Samson M-F, Åman P, von Reding W, Spoerndli C, Barron C. Biochemical markers: efficient tools for the assessment of wheat grain tissue proportions in milling fractions. J Cereal Sci. 2009;49:55-64.

19. Fath A, Bethke PC, Belligni MV, Spiegel YN, Jones RL. Signalling in the cereal aleurone: hormones, reactive oxygen and cell death. New Phytol. 2001;151:99-107. 
20. García-Estepa RM, Guerra-Hernández E, García-Villanova B. Phytic acid content in milled cereal products and breads. Food Res Int. 1999;32:217-21.

21. Adom KK, Sorrells ME, Liu RH. Phytochemical Profiles and Antioxidant Activity of Wheat Varieties. J Agr Food Chem. 2003;51:7825-34.

22. Barron C, Surget A, Rouau X. Relative amounts of tissues in mature wheat (Triticum aestivum L.) grain and their carbohydrate and phenolic acid composition. J Cereal Sci. 2007;45:88-96.

23. Zhao Z, Moghadasian MH. Chemistry, natural sources, dietary intake and pharmacokinetic properties of ferulic acid: A review. Food Chem. 2008;109:691-702.

24. Landberg R, Kamal-Eldin A, Salmenkallio-Marttila M, Rouau X, Åman P. Localization of alkylresorcinols in wheat, rye and barley kernels. J Cereal Sci. 2008;48:401-6.

25. Chen Y, Ross AB, Aman P, Kamal-Eldin A. Alkylresorcinols as Markers of Whole Grain Wheat and Rye in Cereal Products. J Agr Food Chem. 2004;52:8242-6.

26. Cho S, Pratt CJ. Active components in whole grain foods. In: Marquart L, Jacobs DR, McIntosh GH, editors. Whole grain \& Health. Iowa, US: Blackwell Publishing; 2007.

27. Likes R, Madl RL, Zeisel SH, Craig SAS. The betaine and choline content of a whole wheat flour compared to other mill streams. J Cereal Sci. 2007;46:93-5.

28. Zeisel SH, Mar M-H, Howe JC, Holden JM. Concentrations of Choline-Containing Compounds and Betaine in Common Foods. J Nutr. 2003;133:1302-7.

29. Windahl KL, Trenerry VC, Ward CM. The determination of niacin in selected foods by capillary electrophoresis and high performance liquid chromatography: acid extraction. Food Chem. 1999;65:263-70.

30. Ndaw S, Bergaentzlé M, Aoudé-Werner D, Hasselmann C. Enzymatic extraction procedure for the liquid chromatographic determination of niacin in foodstuffs. Food Chem. 2002;78:129-34.

31. Davis KR, Cain RF, Peters LJ, Le Tourneau D, McGinnis J. Evaluation of the Nutrient Composition of Wheat. II. Proximate Analysis, Thiamin, Riboflavin, Niacin, and Pyridoxine. Cereal Chem. 1981;58:116 - 20.

32. Calhoun WK, Hepburn FN, Bradley WB. Distribution of the vitamins of wheat in commercial mill products. Cereal Chem. 1960;37:755-61.

33. Batifoulier F, Verny MA, Chanliaud E, Rémésy C, Demigné C. Variability of B vitamin concentrations in wheat grain, milling fractions and bread products. Eur J Agron. 2006;25:163-9.

34. Patring J, Wandel M, Jägerstad M, Frølich W. Folate content of Norwegian and Swedish flours and bread analysed by use of liquid chromatography-mass spectrometry. J Food Compos Anal. 2009;22:649-56.

35. Sarwin R, Walther C, Laskawy G, Butz B, Grosch W. Determination of free reduced and total glutathione in wheat flours by an isotope dilution assay. Z Lebensm Unters Forsch. 1992;195:27-32.

36. Schofield JD, Chen X. Analysis of free reduced and free oxidised glutathione in wheat flour. J Cereal Sci. 1995;21:127-36.

37. Harman D. Aging: a theory based on free radical and radiation chemistry. J Gerontol. 1956;11:298-300.

38. Halliwell B. How to characterize a biological antioxidant. Free Radical Res. 1990;9: 132.

39. Halliwell B. Free radicals, antioxidants, and human disease: curiosity, cause, or consequence? The Lancet 1994;344:721-4.

40. Bast A, Haenen GR, Doelman CJ. Oxidants and antioxidants: state of the art. Am J Med. 1991;91:2S-13S.

41. Hotamisligil GS. Inflammation and metabolic disorders. Nature. 2006;444:860-7. 
42. Lamb RE, Goldstein BJ. Modulating an oxidative-inflammatory cascade: potential new treatment strategy for improving glucose metabolism, insulin resistance, and vascular function. Int J Clin Pract. 2008;62:1087-95.

43. Liu RH. Whole grain phytochemicals and health. J Cereal Sci. 2007;46:207-19.

44. Graf E. Applications of phytic acid. J Am Oil Chem Soc. 1983;60:1861-7.

45. Muraoka S, Miura T. Inhibition of xanthine oxidase by phytic acid and its antioxidative action. Life Sci. 2004;74:1691-700.

46. Miyamoto S, Kuwata G, Imai M, Nagao A, Terao J. Protective effect of phytic acid hydrolysis products on iron-induced lipid peroxidation of liposomal membranes. Lipids. 2000;35:1411-4.

47. Graf E. Antioxidant potential of ferulic acid. Free Radical Bio Med. 1992;13:435-48.

48. Klepacka J, Fornal L. Ferulic acid and its position among the phenolic compounds of wheat. Crit Rev Food Sci. 2006;46:639-47.

49. Toda S, Kumura M, Ohnishi M. Effects of phenolcarboxylic acids on superoxide anion and lipid peroxidation induced by superoxide anion. Planta Med. 1991; 57:8-10.

50. Castelluccio C, Bolwell GP, Gerrish C, Rice-Evans C. Differential distribution of ferulic acid to the major plasma constituents in relation to its potential as an antioxidant. Biochem J. 1996 316:691-4.

51. Palacios JPC. Poly(ferulic acid) by oxalyl chloride activated polycondensation. New Polym Mater. 1990; 2 167-74.

52. Rietjens SJ, Bast A, de Vente J, Haenen GR. The olive oil antioxidant hydroxytyrosol efficiently protects against the oxidative stress-induced impairment of the NObullet response of isolated rat aorta. Am J Physiol Heart Circ Physiol. 2007;292:H1931-6.

53. Srinivasan M, Sudheer AR, Menon VP. Ferulic Acid: therapeutic potential through its antioxidant property. J Clin Biochem Nutr. 2007;40:92-100.

54. Shahidi F, Chandrasekara A. Hydroxycinnamates and their in vitro and in vivo antioxidant activities. Phytochem Rev. 2009.

55. Kamal-Eldin A, Pouru A, Eliasson C, man P. Alkylresorcinols as antioxidants: hydrogen donation and peroxyl radical-scavenging effects. J Sci Food Agr. 2001;81:3536.

56. Hladyszowski J, Zubik L, Kozubek A. Quantum Mechanical and Experimental Oxidation Studies of Pentadecylresorcinol, Olivetol, Orcinol and Resorcinol. Free Radical Res. 1998;28:359 - 68.

57. Alastair BR, Afaf K-E, Per Å. Dietary Alkylresorcinols: Absorption, Bioactivities, and Possible Use as Biomarkers of Whole-grain Wheat- and Rye-rich Foods. Nutr Rev. 2004;62:81-95.

58. Kozubek A, Tyman JHP. Resorcinolic Lipids, the Natural Non-isoprenoid Phenolic Amphiphiles and Their Biological Activity. Chem Rev. 1998;99:1-26.

59. Parikka K, Rowland IR, Welch RW, Wahala K. In Vitro Antioxidant Activity and Antigenotoxicity of 5-n-Alkylresorcinols. J Agr Food Chem. 2006;54:1646-50.

60. Traber MG, Atkinson J. Vitamin E, antioxidant and nothing more. Free Radical Bio Med. 2007;43:4-15.

61. Sies H, Murphy ME. Role of tocopherols in the protection of biological systems against oxidative damage. J Photoch Photob B. 1991;8:211-.

62. van Haaften RIM, Haenen GRMM, Evelo CTA, Bast A. Effect of Vitamin E on Glutathione-Dependent Enzymes. Drug Metab Rev. 2003;35:215 - 53.

63. Bondia-Pons I, Aura A-M, Vuorela S, Kolehmainen M, Mykkänen H, Poutanen K. Rye phenolics in nutrition and health. J Cereal Sci. 2009;49:323-36. 
64. Dizhbite T, Telysheva G, Jurkjane V, Viesturs U. Characterization of the radical scavenging activity of lignins--natural antioxidants. Bioresource Technol. 2004;95:30917.

65. Lábaj J, Wsólová L, Lazarová M, Košíková B, Slameňová D. Repair of oxidative DNA lesions in blood lymphocytes isolated from Sprague-Dawley rats; the influence of dietary intake of lignin. Neoplasma. 2004;51:451-7.

66. Slamenova D, Kosikova B, Labaj J, Ruzekova L. Oxidative/antioxidative effects of different lignin preparations on DNA in hamster V79 cells. Neoplasma. 2000;47:349-53.

67. Begum AN, Nicolle C, Mila I, Lapierre C, Nagano K, Fukushima K, Heinonen SM, Adlercreutz H, Remesy C, Scalbert A. Dietary lignins are precursors of mammalian lignans in rats. J Nutr. 2004;134:120-7.

68. Niemeyer HB, Metzler M. Differences in the antioxidant activity of plant and mammalian lignans. J Food Eng. 2003;56:255-6.

69. Kitts DD, Yuan YV, Wijewickreme AN, Thompson LU. Antioxidant activity of the flaxseed lignan secoisolariciresinol diglycoside and its mammalian lignan metabolites enterodiol and enterolactone. Mol Cell Biochem. 1999;202:91-100.

70. Morello J-R, Vuorela S, Romero M-P, Motilva M-J, Heinonen M. Antioxidant Activity of Olive Pulp and Olive Oil Phenolic Compounds of the Arbequina Cultivar. J Agr Food Chem. 2005;53:2002-8.

71. Pool-Zobel BL, Adlercreutz H, Glei M, Liegibel UM, Sittlingon J, Rowland I, Wahala K, Rechkemmer G. Isoflavonoids and lignans have different potentials to modulate oxidative genetic damage in human colon cells. Carcinogenesis. 2000;21:1247-52.

72. Verwei M. Bioavailability of folate from fortified milk products. Wageningen, The Netherlands: Wageningen University; 2004.

73. Rezk BM, Haenen GRMM, van der Vijgh WJF, Bast A. Tetrahydrofolate and 5methyltetrahydrofolate are folates with high antioxidant activity. Identification of the antioxidant pharmacophore. FEBS Lett. 2003;555:601-5.

74. Huang RFS, Yaong HC, Chen SC, Lu YF. In vitro folate supplementation alleviates oxidative stress, mitochondria-associated death signalling and apoptosis induced by 7 ketocholesterol. Brit J Nutr. 2004;92:887-94.

75. Hayden M, Tyagi S. Homocysteine and reactive oxygen species in metabolic syndrome, type 2 diabetes mellitus, and atheroscleropathy: The pleiotropic effects of folate supplementation. Nutr J. 2004;3:4.

76. Matté C, Mackedanz V, Stefanello FM, Scherer EBS, Andreazza AC, Zanotto C, Moro AM, Garcia SC, Gonçalves CA, Erdtmann B, Salvador M, Wyse ATS. Chronic hyperhomocysteinemia alters antioxidant defenses and increases DNA damage in brain and blood of rats: Protective effect of folic acid. Neurochem Int. 2009;54:7-13.

77. Das UN. Folic acid says NO to vascular diseases. Nutrition. 2003;19:686-92.

78. Craig SAS. Betaine in human nutrition. Am J Clin Nutr. 2004;80:539-49.

79. Zeisel SH, Blusztajn JK. Choline and Human Nutrition. Ann Rev Nutr. 2003;14:269-96.

80. McKevith B. Nutritional aspects of cereals. Nutr Bull. 2004;29:111-42.

81. Hageman GJ, Stierum RH. Niacin, poly(ADP-ribose) polymerase-1 and genomic stability. Mutat Res-Fund Mol M. 2001;475:45-56.

82. Ganji SH, Qin S, Zhang L, Kamanna VS, Kashyap ML. Niacin inhibits vascular oxidative stress, redox-sensitive genes, and monocyte adhesion to human aortic endothelial cells. Atherosclerosis. 2009;202:68-75.

83. Kamanna V, Ganji S, Kashyap M. Niacin: An old drug rejuvenated. Current Atherosclerosis Reports. 2009;11:45-51.

84. Slyshenkov VS, Dymkowska D, Wojtczak L. Pantothenic acid and pantothenol increase biosynthesis of glutathione by boosting cell energetics. FEBS Letters. 2004;569:169-72. 
85. Slyshenkov VS, Piwocka K, Sikora E, Wojtczak L. Pantothenic acid protects jurkat cells against ultraviolet light-induced apoptosis. Free Radical Biol Med. 2001;30:1303-10.

86. Powers HJ. Riboflavin (vitamin B-2) and health. Am J Clin Nutr. 2003;77:1352-60.

87. Pastore A, Federici G, Bertini E, Piemonte F. Analysis of glutathione: implication in redox and detoxification. Clin Chim Acta. 2003;333:19-39.

88. Maellaro E, Del Bello B, Sugherini L, Santucci A, Comporti M, Casini AF. Purification and characterization of glutathione-dependent dehydroascorbate reductase from rat liver. Biochem J. 1994;301:471-6.

89. Ishikawa T, Casini AF, Nishikimi M. Molecular Cloning and Functional Expression of Rat Liver Glutathione-dependent Dehydroascorbate Reductase. J Biol Chem. 1998;273:28708-12.

90. Masella R, Di Benedetto R, Varì R, Filesi C, Giovannini C. Novel mechanisms of natural antioxidant compounds in biological systems: involvement of glutathione and glutathione-related enzymes. J Nutr Biochem. 2005;16:577-86.

91. Lopez HW, Duclos V, Coudray C, Krespine V, Feillet-Coudray C, Messager A, Demigné C, Rémésy C. Making bread with sourdough improves mineral bioavailability from reconstituted whole wheat flour in rats. Nutrition. 2003;19:524-30.

92. Fang Y-Z, Yang S, Wu G. Free radicals, antioxidants, and nutrition. Nutrition. 2002;18:872-9.

93. Laity JH, Lee BM, Wright PE. Zinc finger proteins: new insights into structural and functional diversity. Curr Opin Struc Biol. 2001;11:39-46.

94. O'Dell BL. Role of Zinc in Plasma Membrane Function. J Nutr. 2000;130:1432S-6.

95. Shaheen AA, Abd El-Fattah AA. Effect of dietary zinc on lipid peroxidation, glutathione, protein thiols levels and superoxide dismutase activity in rat tissues. Int J Biochem Cell B. 1995;27:89-95.

96. Frazzini V, Rockabrand E, Mocchegiani E, Sensi S. Oxidative stress and brain aging: is zinc the link? Biogerontology. 2006;7:307-14.

97. Behne D, Kyriakopoulos A. Mammalian Selenium-Containing Proteins. Ann Rev Nutr. 2001;21:453-73.

98. Brown KM, Arthur JR. Selenium, selenoproteins and human health: a review. Public Health Nutr. 2001;4:593-9.

99. Medzhitov R. Origin and physiological roles of inflammation. Nature. 2008;454:428-35.

100. Robinson J. Phagocytic leukocytes and reactive oxygen species. Histochem Cell Biol. 2009;131:465-9.

101. Gwinn MR, Vallyathan V. Respiratory Burst: Role in Signal Transduction in Alveolar Macrophages. J Toxicol Env Health B. 2006;9:27 - 39.

102. Torres M, Forman HJ. Activation of Several MAP Kinases upon Stimulation of Rat Alveolar Macrophages: Role of the NADPH Oxidase. Arch Biochem Biophys. 1999;366:231-9.

103. Stevenson D, Hurst R. Polyphenolic phytochemicals - just antioxidants or much more? Cell Mol Life Sci. 2007;64:2900-16.

104. Knasmuller S, Nersesyan A, Misik M, Gerner C, Mikulits W, Ehrlich V, Hoelzl C, Szakmary A, Wagner KH. Use of conventional and -omics based methods for health claims of dietary antioxidants: a critical overview. Brit J Nutr. 2008;99 E Suppl 1:ES3-52.

105. Kong PJ, Park JI, Kwon OY, Han YH, Kim SY, Lee SN, Son HJ, Kim SS. Comparison of Inhibitory Potency of Various Antioxidants on the Activation of BV2 Microglial Cell Lines Induced by LPS. Korean J Physiol Pharmacol. 2007;11:9-13.

106. Jin Y, Yan E-Z, Fan Y, Guo X-1, Zhao Y-j, Zong Z-h, Liu Z. Neuroprotection by sodium ferulate against glutamate-induced apoptosis is mediated by ERK and PI3 kinase pathways. Acta Pharmacol Sin. 2007;28:1881-90. 
107. Ronchetti D, Impagnatiello F, Guzzetta M, Gasparini L, Borgatti M, Gambari R, Ongini E. Modulation of iNOS expression by a nitric oxide-releasing derivative of the natural antioxidant ferulic acid in activated RAW 264.7 macrophages. Eur J Pharmacol. 2006;532:162-9.

108. Yao S-Y, Zhang B-Y, Zheng D-Y, Jin Y, Liu Z. Dose-dependent effect of sodium ferulate in inhibiting inflammatory factors activated by beta-amyloid protein Chinese Journal of Clinical Rehabilitation 2005;9 134-6.

109. Chiang L-C, Ng LT, Chiang W, Chang M-Y, Lin C-C. Immunomodulatory Activities of Flavonoids, Monoterpenoids, Triterpenoids, Iridoid Glycosides and Phenolic Compounds of Plantago Species. Planta Med. 2003;69:600-4.

110. Ou L, Kong L-Y, Zhang X-M, Niwa M. Oxidation of Ferulic Acid by Momordica charantia Peroxidase and Related Anti-inflammation Activity Changes. Biol Pharm Bull. 2003;26:1511-6.

111. Murakami A, Nakamura Y, Koshimizu K, Takahashi D, Matsumoto K, Hagihara K, Taniguchi H, Nomura E, Hosoda A, Tsuno T, Maruta Y, Kim HW, Kawabata K, Ohigashi H. FA15, a hydrophobic derivative of ferulic acid, suppresses inflammatory responses and skin tumor promotion: comparison with ferulic acid. Cancer Lett. 2002;180:121-9.

112. Maggi-Capeyron M-F, Ceballos P, Cristol J-P, Delbosc S, Le Doucen C, Pons M, Leger CL, Descomps B. Wine Phenolic Antioxidants Inhibit AP-1 Transcriptional Activity. J Agr Food Chem. 2001;49:5646-52.

113. Sakai S, Ochiai H, Nakajima K, erasawa K. Inhibitory effect of ferulic acid on macrophage inflammatory protein- 2 production in a murine macrophage cell line, RAW264.7 Cytokine. 1997;9:242-8.

114. Hirabayashi T, Ochiai H, Sakai S, Nakajima K, Terasawa K. Inhibitory effect of ferulic acid and isoferulic acid on murine interleukin- 8 production in response to influenza virus infections in vitro and in vivo. Planta Med. 1995;61:221-6. .

115. Meng S, Lu Z-J, Zhang Z-N, Li D-G. Inhibition of respiratory burst of polymorphonuclear cells (PMN) by herbal ingredients. Chin Pharmacol Bull. 1994;10 439-41.

116. Liang S, Jun Q, Liao-Bin C, Bao-Xin L, Magdalou J, Hui W. Effects of Sodium Ferulate on Human Osteoarthritic Chondrocytes and Osteoarthritis in Rats. Clin Exp Pharmacol P. 2009;36:912-8.

117. Jung KJ, Go EK, Kim JY, Yu BP, Chung HY. Suppression of age-related renal changes in NF-[kappa]B and its target gene expression by dietary ferulate. J Nutr Biochem. 2009;20:378-88.

118. Liu S-P, Dong W-G, Luo H-S, Yu B-P, Yu J-P. Protective effects of sodium ferulate on injury in acetic acid-induced rat colitis. World Chin J Digestol. 200412 108-11

119. Sudheer AR, Muthukumaran S, Devipriya N, Devaraj H, Menon VP. Influence of ferulic acid on nicotine-induced lipid peroxidation, DNA damage and inflammation in experimental rats as compared to N-acetylcysteine. Toxicology. 2008;243:317-29.

120. Zou H-D, Wu L-X, Zhou Q-S, Huang H-B, Hou W. Protective effect of ferulic acid on celiac visceral organs of hemorrhagic shock rabbits after reperfusion injury. Chin J Clin Rehab. 2006 10:114-6

121. Jin $Y$, Yan E-Z, Fan Y, Qi Z-M, Bao C-F. Effects of sodium ferulate on A $\beta 25-35$-induced cognitive deficits and expression of IL-1 $\beta$ and p38MAPK in rats. Chin Pharmacol Bull. 2006;22 602-6

122. Jin Y, Fan Y, Yan E-Z, Liu Z, Zong Z-H, Qi Z-M. Effects of sodium ferulate on amyloidbeta-induced MKK3/MKK6-p38 MAPK-Hsp27 signal pathway and apoptosis in rat hippocampus. Acta Pharmacol Sin 2006;27 1309-16. 
123. Yan JJ, Cho JY, Kim HS, Kim KL, Jung JS, Huh SO, Suh HW, Kim YH, Song DK. Protection against beta-amyloid peptide toxicity in vivo with long-term administration of ferulic acid. Br J Pharmacol 2001;133:89-96.

124. Cho J, Kim H, Kim D, Yan J, Suh H, Song D. Inhibitory effects of long-term administration of ferulic acid on astrocyte activation induced by intracerebroventricular injection of beta-amyloid peptide (1-42) in mice. Prog NeuroPsychoph. 2005;29:901-7.

125. Ronchetti D, Borghi V, Gaitan G, Herrero JF, Impagnatiello F. NCX 2057, a novel NOreleasing derivative of ferulic acid, suppresses inflammatory and nociceptive responses in in vitro and in vivo models Brit J Pharmacol. 2009;158 569-79

126. Nagasaka R, Chotimarkorn C, Shafiqul IM, Hori M, Ozaki H, Ushio H. Antiinflammatory effects of hydroxycinnamic acid derivatives. Biochem Bioph Res Co. 2007;358:615-9.

127. Sultana R, Ravagna A, Mohmmad-Abdul H, Calabrese V, Butterfield D. Ferulic acid ethyl ester protects neurons against amyloid beta-peptide(1-42)-induced oxidative stress and neurotoxicity: relationship to antioxidant activity. J Neurochem. 2005;92:74958.

128. Zschocke S, Lehner M, Bauer R. 5-Lipoxygenase and cyclooxygenase inhibitory active constituents from Qianghuo (Notopterygium incisum). Planta Med. 1997;63:203-6.

129. Huang D-W, Kuo Y-H, Lin F-Y, Lin Y-L, Chiang W. Effect of adlay (Coix lachryma-jobi L. var. ma-yuen Stapf) testa and its phenolic components on Cu2+-treated low-density lipoprotein (LDL) oxidation and lipopolysaccharide (LPS)-lnduced inflammation in RAW 264.7 macrophages J Agr Food Chem. 2009;57:2259-66

130. Karlsson PC, Huss U, Jenner A, Halliwell B, Bohlin L, Rafter JJ. Human fecal water inhibits COX-2 in colonic HT-29 cells: Role of phenolic compounds. J Nutr. 2005;135 2343-9.

131. Russell WR, Scobbie L, Chesson A, Richardson AJ, Stewart CS, Duncan SH, Drew JE, Duthie GG. Anti-inflammatory implications of the microbial transformation of dietary phenolic compounds. Nutr Cancer. 2008;60:636-42.

132. Monagas M, Khan N, Andres-Lacueva C, Urpi-Sarda M, Vazquez-Agell M, LamuelaRaventos RM, Estruch R. Dihydroxylated phenolic acids derived from microbial metabolism reduce lipopolysaccharide-stimulated cytokine secretion by human peripheral blood mononuclear cells. Br J Nutr. 2009;102:201-6.

133. Bao-Hua W, Jing-Ping O-Y. Pharmacological Actions of Sodium Ferulate in Cardiovascular System. Cardiovasc Drug Rev. 2005;23:161-72.

134. Barone E, Calabrese V, Mancuso C. Ferulic acid and its therapeutic potential as a hormetin for age-related diseases. Biogerontology. 2008.

135. Kroon PA, Clifford MN, Crozier A, Day AJ, Donovan JL, Manach C, Williamson G. How should we assess the effects of exposure to dietary polyphenols in vitro? Am J Clin Nutr. 2004;80:15-21.

136. Stahl W, van den Berg H, Arthur J, Bast A, Dainty J, Faulks RM, Gartner C, Haenen G, Hollman P, Holst B, Kelly FJ, Polidori MC, Rice-Evans C, Southon S, van Vliet T, VinaRibes J, Williamson G, Astley SB. Bioavailability and metabolism. Mol Aspects Med. 2002;23:39-100. 



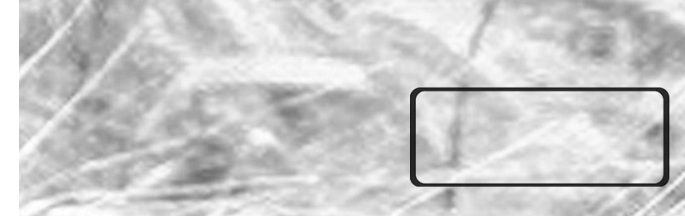




\begin{abstract}
Grain is an important source of phytochemicals which have potent antioxidant capacity. They have been implicated in the beneficial health effect of whole grains in reducing cardiovascular disease and type 2 diabetes. The aim of the present study was to identify the most important antioxidant fractions of wheat grain. It was found that the aleurone content of these fractions was highly correlated with the antioxidant capacity of the fractions $(\mathrm{r}=0.96, p<0.0001)$. Ferulic acid appeared to be the major contributor to the antioxidant capacity in the fractions with higher antioxidant capacity. The contribution of protein, was rather limited. It was concluded that the antioxidant potency of wheat grain fractions is predominantly determined by the aleurone content, which can be attributed to the presence of relatively large amount of phenolic compounds, primarily ferulic acid.
\end{abstract}




\section{INTRODUCTION}

Epidemiological studies strongly suggest that whole grain consumption can reduce the incidence of diet related disorders such as cardiovascular disease, type 2 diabetes and some types of cancers (1-6). Grain is an important source of phytochemicals (7). Some of them have marked antioxidant activity, as is the case of vitamins (vitamin E, tocotrienols), phenolic compounds (phenolic acids, lignans, flavanoids), trace minerals (selenium, manganese), and phytic acid (6-10). The potential health benefit of antioxidants is associated with protection against oxidative stress $(11,12)$. This is defined as an imbalance in the production of reactive molecules, such as oxygen and nitrogen reactive species, with the capacity for the elimination of these molecules, in favor of the former $(13,14)$. An excess of reactive species will lead to oxidative damage and altered intracellular signaling, for instance by triggering the activation of serine/threonine kinase cascades such as c-Jun $\mathrm{N}$-terminal kinase, nuclear factor-kB, and others (15). In this way, oxidative stress can result in chronic inflammation and possible insulin resistance, leading to the aggravation of type 2 diabetes. Reduction of oxidative stress mediated damage may therefore be implicated in the molecular basis of the reported health benefit of grain $(11,12,15)$.

Traditionally, the milling process of grain aimed at the refinement of flour and removal of bran as by-product (16). However, several studies have shown the abundant presence of micro-nutrients and phytochemicals in bran $(7,17,18)$. Current pre-treatments and new debranning processes preceding the milling have been developed in order to obtain innovative wheat fractions. These fractions vary in their composition of micro-nutrients and phytochemicals (19).

The objective of this study was to examine the total antioxidant capacity of different wheat fractions and its distribution within the wheat grain. By identifying the most important fractions, the health benefit associated with whole-grain can be optimized. Several studies have been performed on the antioxidant capacity of cereals and its milling fractions $(17,18,20-22)$. Most have focused on the quantification of different antioxidant compounds; however, their relative contribution to the total antioxidant capacity has not been fully evaluated. We determined the total antioxidant capacity of the several fractions by the Trolox equivalent antioxidant capacity (TEAC) assay (23), which has been designed to quantify the summed activity of all the antioxidants in a sample. Furthermore, the relative contribution of protein and phenolic compounds to the total antioxidant capacity was also studied. 


\section{MATERIALS AND METHODS}

\section{Materials}

Ferulic acid (4-hydroxy-3-methoxycinnamic acid), ABTS (2,2' azino-bis(3ethylbenzthiazoline-6-sulfonic acid)), Bradford reagent, BSA (bovine serum albumin, faction V), gallic acid (97\% purity), Trolox (6-Hydroxy-2,5,7,8tetramethylchroman-2-carboxylic Acid) were provided by Sigma-Aldrich Canada Ltd. (Oakville, ON). ABAP (2,2-azobis(2-aminopropane) hydrochloride) was obtained from Polyscience (Warrington, PA). Amicon Ultra Millipore Spin columns of 30 and $5 \mathrm{kDa}$ molecular weight cut-off (MWCO) were purchased from Vivascience AG (Hannover, Germany). All chemicals used in the study were of analytic grade quality.

\section{Sample preparation}

Wheat samples (Triticum aestivum L.) from the wheat cultivars Tiger and Crousty, were provided by Bühler AG Uzwil, Switzerland. The samples were provided as milled fractions.

Table 1. Description of the different fractions of the wheat cultivars Tiger and Crousty

\begin{tabular}{|c|c|c|c|}
\hline & & Fraction & Description \\
\hline \multirow[t]{2}{*}{ Aleurone fractions } & 1 & Aleurone 2 & $\begin{array}{l}\text { Aleurone fraction high purity. Aleurone content } \\
\text { of } 75-90 \%\end{array}$ \\
\hline & 2 & Aleurone 1 & Aleurone fraction. Aleurone content of $55-70 \%$ \\
\hline \multirow[t]{4}{*}{ Bran fractions } & 3 & Bran after peeling & $\begin{array}{l}\text { Bran fraction of the milling process of peeled } \\
\text { wheat kernels. Aleurone content of } 40-50 \%\end{array}$ \\
\hline & 4 & Bran after pearling & $\begin{array}{l}\text { Bran fraction of the milling process of pearled } \\
\text { wheat kernels. Aleurone content of } 35-40 \%\end{array}$ \\
\hline & 5 & Pearling fraction & $\begin{array}{l}\text { Bran fraction that comes off during the pearling } \\
\text { of peeled wheat kernels. Aleurone content of } \\
30-35 \%\end{array}$ \\
\hline & 6 & Peeling fraction & $\begin{array}{l}\text { Bran fraction which comes off during the peeling } \\
\text { process. Aleurone content of } 24-25 \%\end{array}$ \\
\hline \multirow[t]{4}{*}{ Flour fractions } & 7 & $100 \%$ Flour from peeling & $\begin{array}{l}\text { Flour from the whole kernels after peeling. } \\
\text { Aleurone content of } 7-8 \%\end{array}$ \\
\hline & 8 & $100 \%$ Flour from pearling & $\begin{array}{l}\text { Flour from the whole kernels after peeling and } \\
\text { pearling. Aleurone content of 5-6\% }\end{array}$ \\
\hline & 9 & $76 \%$ Flour from pearling & $\begin{array}{l}\text { White flour from milling of peeled and pearled } \\
\text { kernels. Aleurone content of } 1-2 \%\end{array}$ \\
\hline & 10 & $76 \%$ Flour from peeling & $\begin{array}{l}\text { White flour from milling of peeled kernels. } \\
\text { Aleurone content of } 1-2 \%\end{array}$ \\
\hline
\end{tabular}


Aleurone 1 (fraction 2) is a bran fraction enriched in aleurone cells, obtained by grinding and air-classification. Aleurone 1 is further purified by electrostatic separation to give aleurone 2 (fraction 1). Details about the preparation of the aleurone fractions can be found in the patent application (24).

Bran and flour fractions were obtained by two different debranning processes before milling; peeling and pearling. In the peeling process, bran is removed by friction of the outermost skin of the wheat kernel. This bran fraction is the peeling fraction (fraction 6), that constitutes approximately $4 \%$ of the wheat kernel (25). The peeled wheat kernels are milled to $76 \%$ flour (fraction 10) and bran after peeling (fraction 3). In the pearling process, bran is removed by abrasion from peeled wheat kernels. This bran fraction is the pearling fraction (fraction 5), that constitutes approximately $3 \%$ of the wheat kernel $(26,27)$. The pearled wheat kernels are milled to $76 \%$ flour (fraction 9) and bran after pearling (fraction 4). Peeled and pearled wheat kernels were used to obtain the 100\% flour from peeling (fraction 7) and $100 \%$ flour from pearling (fraction 8) respectively. Figure 1 shows an overview of the tested samples. The description and aleurone content of the different wheat fractions is given in Table 1. The aleurone content was determined as previously described $(28,29)$.

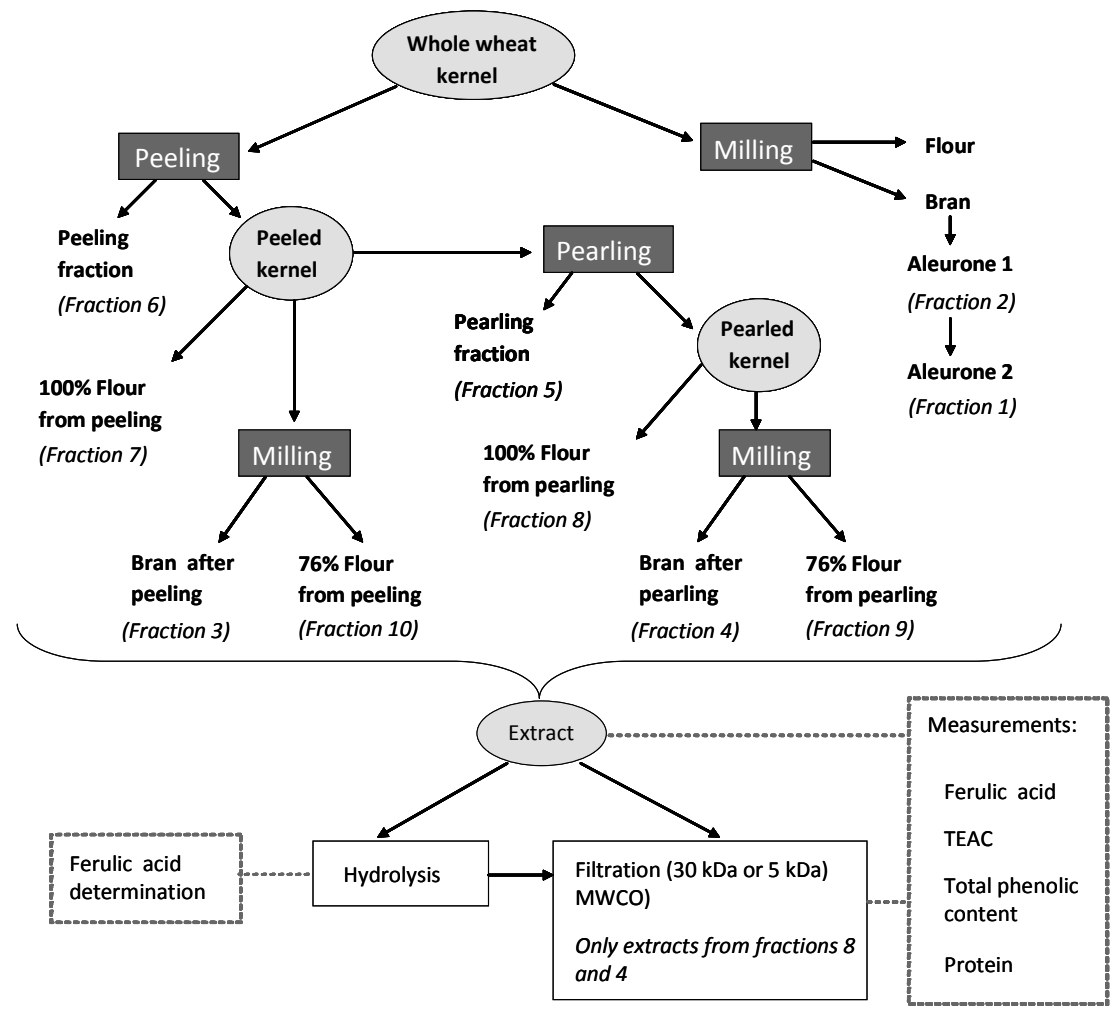

Figure 1. Flow chart of the experimental setup. 


\section{Sample extraction}

The extraction procedure has been described in a comparative study of different extraction methods of free and bound phenolic compounds (30). The selected extraction method showed the highest results in antioxidant capacity. Minor modifications were made in order to optimize the extraction. Briefly, samples were extracted by mixing $0.5 \mathrm{~g}$ of sample with $25 \mathrm{ml}$ diluted hydrochloric acid $(\mathrm{pH}=1)$ for 30 minutes continuously shaking in a water bath at $80^{\circ} \mathrm{C}$. After centrifugation at $3000 \times \mathrm{g}$ for $10 \mathrm{~min}$, the supernatant was removed. The extraction was repeated twice and the supernatants were pooled. This procedure was designed for the determination of total antioxidant capacity in fractions with a wide range of antioxidant capacity.

A part of the extract $(5 \mathrm{ml})$ was mixed with $1 \mathrm{ml} \mathrm{NaOH} 2 \mathrm{M}$ and incubated for 1 hour at room temperature $\left(22 \pm 3{ }^{\circ} \mathrm{C}\right)$ and under a $\mathrm{N}_{2}$ atmosphere. After this alkaline hydrolysis, extracts were acidified to $\mathrm{pH}<2$ using $6 \mathrm{M} \mathrm{HCl}$.

In order to remove protein, extracts and hydrolyzed extracts were filtrated using spin columns of 30 and $5 \mathrm{kDa}$ molecular weight cut-off (MWCO) centrifuged at $3000 \times \mathrm{g}$ for 20 minutes.

Total antioxidant capacity, total phenolic content, total soluble ferulic acid and protein were determined in the various extracts.

\section{Determination of the Trolox equivalent antioxidant capacity (TEAC)}

Total antioxidant capacity was analyzed in the extracts of all the wheat fractions using the TEAC assay described by van den Berg et al (23) with minor modifications. Briefly, ABTS•- radicals were prepared by mixing $2.5 \mathrm{mM}$ ABAP with $20 \mathrm{mM}$ ABTS2- stock solution in phosphate buffered saline (PBS). The solution was heated for 18 minutes at $60{ }^{\circ} \mathrm{C}$ until a maximum absorbance of $0.65 \pm 0.05$ at $734 \mathrm{~nm}$ was reached. A fresh ABTS•- radical solution was prepared each day. Extracts, in a suitable and similar dilution, were added to the ABTS/ABAP solution and the reduction in absorbance was measured after 6 minutes. The TEAC of the extract corresponds to the concentration of a Trolox solution that causes an equal decrease in absorbance at $734 \mathrm{~nm}$. The antioxidant capacity of a sample was expressed as $\mu \mathrm{mol}$ Trolox Equivalent per gram of sample ( $\mu \mathrm{mol} \mathrm{TE} / \mathrm{g})$.

\section{Determination of total phenolic content}

The total phenolic content of the extract was determined using the method described by Singleton et al (31). Briefly, an appropriate dilution of the extract was mixed with Folin-Ciocalteu reagent and the mixture was neutralized with sodium carbonate. The absorbance was measured after 1 hour at $765 \mathrm{~nm}$. Gallic acid was 
used as standard and total phenolic content was expressed as $\mu \mathrm{mol}$ of Gallic Acid Equivalents per gram of sample ( $\mu \mathrm{mol} \mathrm{GAE} / \mathrm{g})$.

\section{Determination of ferulic acid}

Ferulic acid was determined by using HPLC with diode array detection of the UV absorption, based on the method described by Mattila et al (32) with minor modifications. The separation was achieved using a Hypersil BDS 5 C18 column. The solvents consisted of $0.085 \%(\mathrm{w} / \mathrm{v})$ of $\mathrm{H}_{3} \mathrm{PO}_{4}$ in water (solvent $\mathrm{A}$ ) and acetonitrile (solvent $\mathrm{B}$ ). The linear gradient used was: $0 \mathrm{~min} 90 \% \mathrm{~A}, 13 \mathrm{~min} 78 \% \mathrm{~A}$, $14.0 \mathrm{~min} 60 \% \mathrm{~A}, 15 \mathrm{~min} 90 \% \mathrm{~A}$. The flow rate was $1.0 \mathrm{ml} / \mathrm{min}$, volume of injection $10 \mu \mathrm{l}$ and temperature of the column was $30{ }^{\circ} \mathrm{C}$. Detection was performed at 330 $\mathrm{nm}$. Ferulic acid concentrations of the extracts were extrapolated from a pure transferulic acid standard curve.

\section{Protein determination}

Protein was determined in the extracts according to Bradford (33). Absorbance was measured at $595 \mathrm{~nm}$ and related to calibration standards of bovine serum albumin (BSA).

\section{Calculation of the contribution of ferulic acid and protein to the total antioxidant capacity}

Standard solutions containing different concentrations of ferulic acid were added to the ABTS - radical solution (prepared as described above) and the resulting reduction in absorbance was measured at $734 \mathrm{~nm}$ and related to that of Trolox. The TEAC of ferulic acid shows the antioxidant potency of ferulic acid relative to Trolox on a molar basis. Knowing the concentration of ferulic acid of the extract and the TEAC of ferulic acid, the antioxidant capacity due to ferulic acid in the mixture can be calculated by multiplying the concentration of ferulic acid by the TEAC of ferulic acid.

The contribution of protein to the total antioxidant capacity was estimated from the decrease in TEAC after protein removal. Protein was removed by filtration as previously described in the sample extraction.

\section{Statistical Analysis}

Data are reported as mean and relative percentage difference (RPD) of duplicate analyses. Pearson's correlation test was performed using SPSS 14.0 windows software. Statistical significance was declared at $p<0.05$. 


\section{RESULTS AND DISCUSSION}

\section{Total antioxidant capacity}

The total antioxidant capacity, determined by TEAC, was unevenly distributed over the various fractions of wheat grain. Similar fractions from the wheat cultivars Crousty and Tiger showed no substantial differences in antioxidant capacity (Figure 2). The highest TEAC values were found in the aleurone fractions, followed by the bran fractions, the flour fractions had the lowest TEAC values.

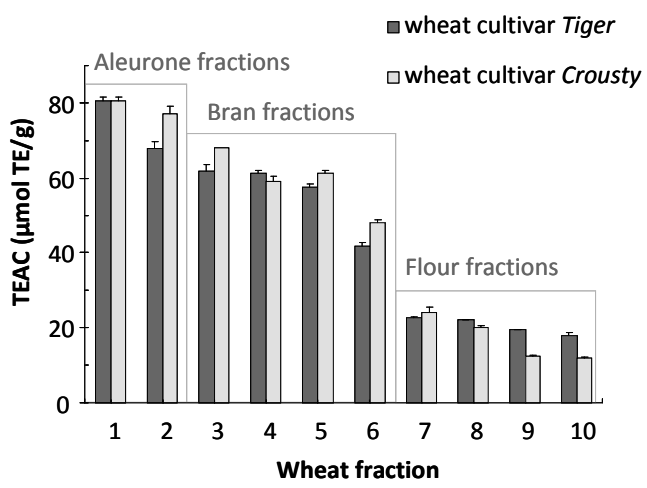

Figure 2. Total antioxidant capacity (TEAC) of different wheat fractions of the wheat cultivars Tiger and Crousty.

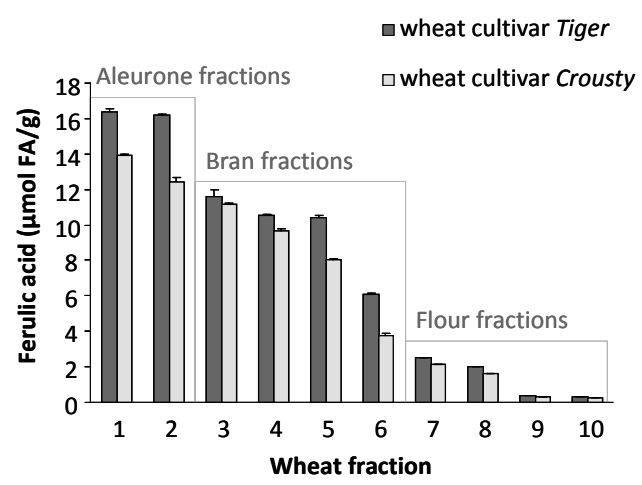

Figure 3. Total soluble ferulic acid content ( $\mu \mathrm{mol} \mathrm{FA/g)}$ of different wheat fractions of the wheat cultivars Tiger and Crousty.

The bran fractions were obtained using different debranning processes before milling, i.e. peeling or pearling. The peeling fraction displayed the lowest antioxidant capacity of the bran fractions (Figure 2). The peeling fraction contains the outermost layers of the bran and less of the aleurone layer than the other bran fractions (Table 1). Thus, within the bran fractions, the antioxidant capacity was in line with the aleurone content of the fraction. In general there was a very strong correlation between the aleurone content (Table 1) and the antioxidant capacity of all fractions $(\mathrm{r}=0.962, p<0.0001)$ (Figure 4).

Aleurone is a monolayer of cubic cells that form the tissue overlaying the endosperm. Because of its high adherence to the pericarp, the aleurone is mainly found in the bran fractions after the milling $(34,35)$. From a nutritional point of view, aleurone is an important source of dietary fiber, minerals, B-vitamins, proteins, phytate and phenolic compounds $(34,36-38)$. In fractions with little or no aleurone content, some antioxidant capacity was also found. This demonstrates the presence of antioxidants in other tissues of the wheat grain. Nevertheless, the 
results indicate that the content of aleurone obtained in the fractionation of grain, is the major determinant of the antioxidant capacity of the fraction.

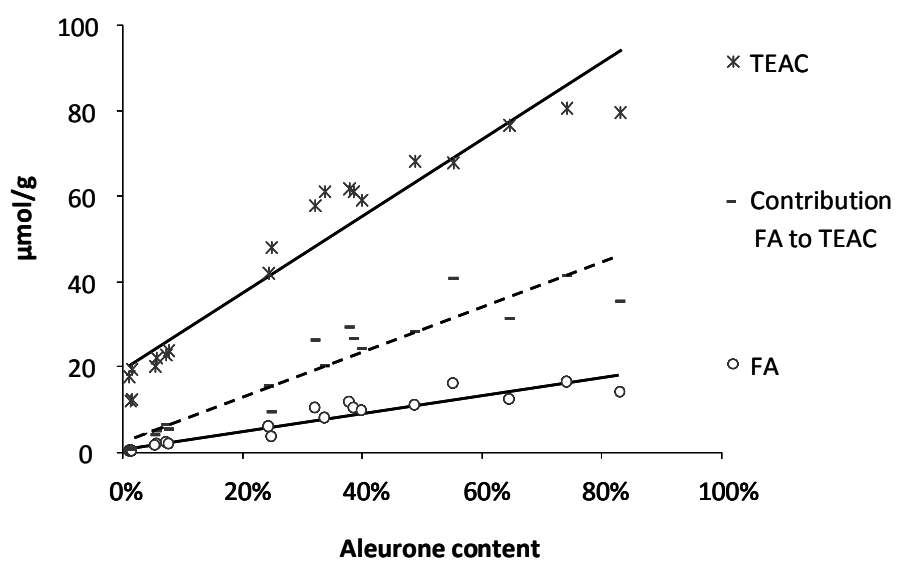

Figure 4. Correlation of the aleurone content in the fraction with the content in total soluble ferulic acid (FA) and the antioxidant capacity (TEAC). The dotted line shows the contribution of ferulic acid to the TEAC of the fraction.

\section{Ferulic acid and contribution to the total antioxidant capacity}

There was a large variation in the ferulic acid content, determined as total soluble ferulic acid, among the various wheat fractions (Figure 3). A strong correlation was found between the antioxidant capacity (TEAC) and ferulic acid ( $\mathrm{r}$ $=0.960, p<0.000001)$. The TEAC of ferulic acid was found to be $2.5 \pm 0.1$. This means that $2.5 \mu \mathrm{mol}$ of Trolox are needed to scavenge the same amount of ABTS •radicals than $1 \mu \mathrm{mol}$ of ferulic acid. In other words, ferulic acid has 2.5 times higher antioxidant capacity than Trolox, of which the TEAC value is 1 . Using the TEAC value of ferulic acid and its concentration, the contribution of ferulic acid to the antioxidant capacity was calculated for each fraction. The results show that contribution of ferulic acid to the antioxidant capacity was larger in the aleurone fractions $(41-60 \%)$ than in the bran fractions $(20-47 \%)$. In the flour fractions, the antioxidant capacity was low and the contribution of ferulic acid to the total antioxidant capacity was limited (4-28\%).

The highest ferulic acid concentrations were found in the extracts of the aleurone fractions and a strong correlation was found between ferulic acid and aleurone content $(r=0.936, p<0.0001)$ (Figure 4). This can be explained by the localization of ferulic acid as a structural component in the cell walls of aleurone cells (39). Among the wide variety of phenolic compounds, ferulic acid is the most abundant in wheat. In wheat grain, ferulic acid is found free or bound by ester and 
ether linkages to complex carbohydrates or proteins (40). Several studies have reported the occurrence of bound ferulic acid in cereals $(7,40)$. This observation was confirmed in the present study. Bound ferulic acid was released after hydrolysis resulting in a large increase in free ferulic acid in the hydrolyzed extracts, e.g. from 0.5 to $11.1 \mu \mathrm{mol} / \mathrm{g}$ (bran fraction 4) and from 0.1 to $1.9 \mu \mathrm{mol} / \mathrm{g}$ (flour fraction 8).

In the hydrolyzed extracts, the antioxidant capacity (TEAC) was also increased. This can be explained by the increase in free ferulic acid and possibly other phenolic compounds that are released from their bound forms by the hydrolysis. Binding of antioxidants has been reported to reduce their antioxidant capacity (4143); esterification and dimerization of ferulic acid affect the antioxidant capacity of the resulting structure (44). Merely from the increase in ferulic acid $(\sim 10 \mu \mathrm{mol}$ ferulic acid/g bran), it was expected an increase in antioxidant capacity of at least $\sim 25 \mu \mathrm{mol} \mathrm{TE} / \mathrm{g}$ bran (i.e. the increase in ferulic acid multiplied by the TEAC value of ferulic acid). However, only an increase of $\sim 10 \mu \mathrm{mol} \mathrm{TE} / \mathrm{g}$ bran was detected (Figure 5A). Release of bound ferulic acid did not result in the expected increase of antioxidant capacity from the rise in free ferulic acid. From these results we can conclude that ferulic acid, still bound to other molecules, has a substantial antioxidant capacity. However, it should be noticed that binding of ferulic acid to other molecules might limit its bioavailability and compromise the systemic health effects (45).

\section{Contribution of other compounds to the antioxidant capacity}

The strong correlation found between the TEAC and protein content of the various fractions $(r=0.687, p<0.001)$ prompted us to investigate other potential contributors than ferulic acid to the antioxidant capacity, such as protein itself and other polyphenols. Two fractions were selected to study these possible contributors; a bran fraction (fraction 4, bran after pearling), with high antioxidant capacity, and a flour fraction (fraction 8, 100\% flour from pearling), with low antioxidant capacity.

In order to study the contribution of protein to the total antioxidant capacity, protein was removed from the extracts by filtration. Filters of two molecular weight cut-offs (MWCO), $30 \mathrm{kDa}$ and $5 \mathrm{kDa}$, were used for the removal of protein. The filter of $5 \mathrm{kDa}$ MWCO was more efficient in removing protein, namely $95 \%$ of the protein was removed, compared to the filter of $30 \mathrm{kDa}$ MWCO that removed 85 $\%$ (Figure 5). Filtration with the lowest MWCO had also a more pronounced effect on the antioxidant capacity and total polyphenols. The antioxidant capacity was decreased by $59 \%$ in the bran extract and by $74 \%$ in the flour extract. Also total polyphenols were reduced by $57 \%$ in the bran extract and by $80 \%$ in the flour extract. This indicates the presence of polyphenols of high molecular weight or a strong interaction of low molecular weight phenolic compounds with protein or 
other large molecules that are removed in the filtration. Cereal cell walls are composed of complex polysaccharides of large molecular weight $(20-300 \mathrm{kDa})$, such as B-glucans and arabinoxylans (39). Some studies have reported about the binding of polyphenols with proteins and cell wall polysaccharides $(46,47)$. This may explain the reduction in phenolic content observed after the filtrations. In the hydrolyzed extracts, the effect of filtration on the antioxidant capacity and total polyphenols was relatively small, probably due to the release of polyphenols from these large molecular weight complexes.
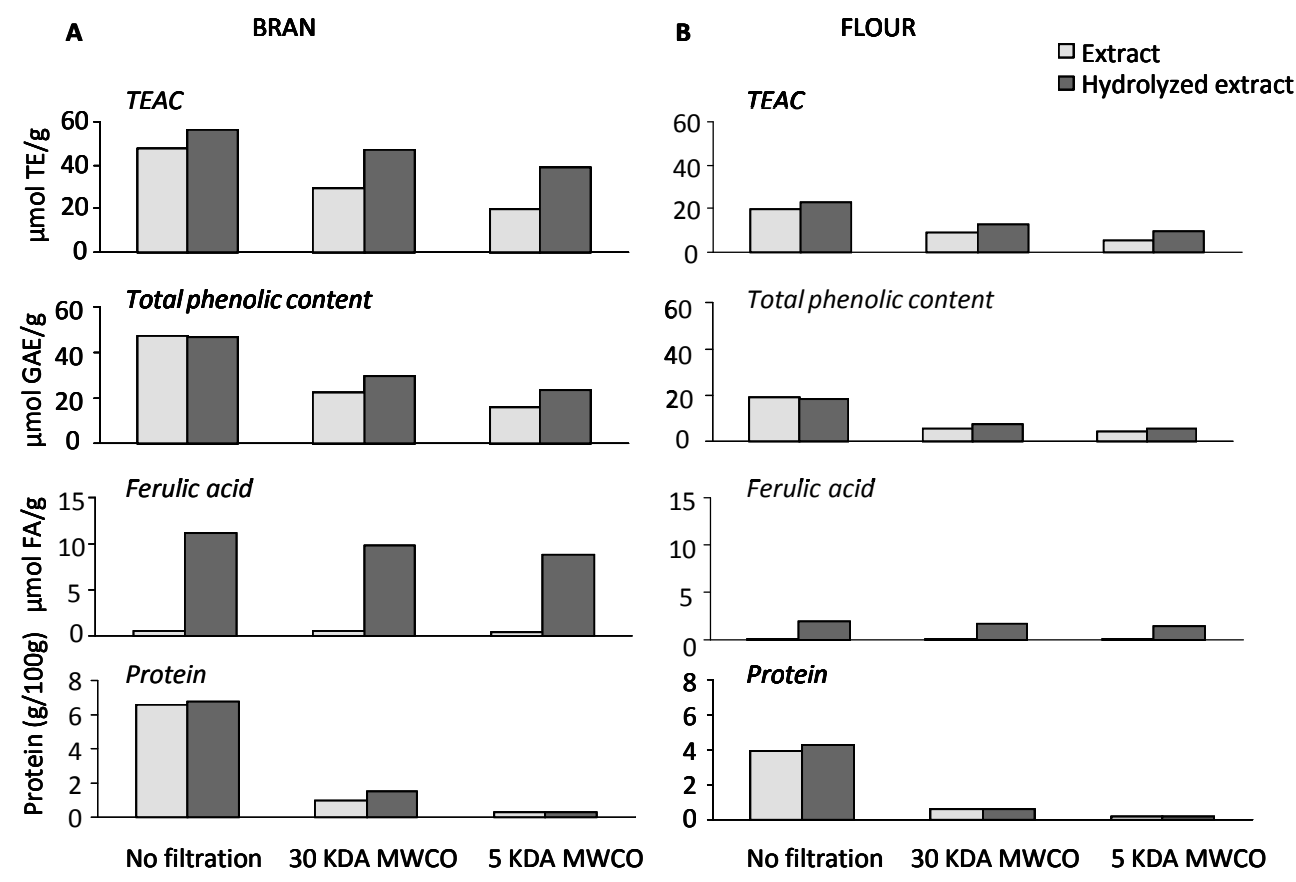

Figure 5. Antioxidant capacity (TEAC) ( $\mu \mathrm{mol} \mathrm{TE} / \mathrm{g}$ ), total phenolic content ( $\mu \mathrm{mol} \mathrm{GAE} / \mathrm{g})$, ferulic acid ( $\mu \mathrm{mol} \mathrm{FA} / \mathrm{g})$ and protein $(\mathrm{g} / 100 \mathrm{~g})$ in extracts and hydrolyzed extracts of the bran fraction 4 (bran after pearling) (A) and the flour fraction 8 (100\% flour from pearling) (B) before and after filtration with 30 or $5 \mathrm{KDa}$ of molecular weight cut-off (MWCO). Results are expressed as mean of duplicate determinations with RPD $<10 \%$.

The concentration of free ferulic acid in the extracts was not strongly affected by filtration (Figure 5). Filtration with 5kDa produced a small decrease in ferulic acid of $0.5 \mu \mathrm{mol} / \mathrm{g}$ flour fraction and $2.4 \mu \mathrm{mol} / \mathrm{g}$ bran fraction. However, due to the high TEAC value of ferulic acid, a loss of $2.4 \mu \mathrm{mol} / \mathrm{g}$ implicates a reduction of the antioxidant capacity of $6 \mu \mathrm{mol} \mathrm{TE} / \mathrm{g}$. In total, the antioxidant capacity decreased by $18 \mu \mathrm{mol} \mathrm{TE} / \mathrm{g}$ in the bran fraction due to filtration, and consequently protein 
removal, of the hydrolyzed extract (Figure 5A). As $6 \mu \mathrm{mol} \mathrm{TE} / \mathrm{g}$ of the $18 \mu \mathrm{mol}$ $\mathrm{TE} / \mathrm{g}$ are due to the loss in ferulic acid, apparently only $12 \mu \mathrm{mol} \mathrm{TE} / \mathrm{g}$ can be attributed to the removal of protein. This represents approximately $20 \%$ of the antioxidant capacity of the not filtrated extract. From these experiments, we can conclude that the contribution of protein to the antioxidant capacity of bran is low, certainly much lower than $20 \%$ since some polyphenols were also removed along with protein. Protein is, therefore, not considered as a major contributor to the antioxidant capacity of the wheat fractions. The correlation found between protein and antioxidant capacity $(\mathrm{r}=0.687, p<0.001)$ is likely to have resulted from the high protein content of aleurone $(34,36,38)$ together with the strong correlation of the aleurone content with the antioxidant capacity of the fraction $(\mathrm{r}=0.962, p<$ $0.0001)$.

The results of the present study show that the wheat fractions with high aleurone content have the highest antioxidant capacity, which can be attributed to the high phenolic content and primarily to ferulic acid. Other factors besides the high antioxidant content of the wheat grain fraction are important to consider in the ultimate health effect, as the effect of processing and bioavailability. The fact that ferulic acid and other phenolics occur in grain mostly bound to indigestible cell wall material may limit their bioavailability $(45,48)$. Nevertheless, it has been recently reported that wheat bran consumption increased total phenols and antioxidant capacity in plasma to a comparable extent to some other phenolic-rich foods (49). Regarding the antioxidant capacity within the wheat kernel, the aleurone is the fraction with the highest potential. Wheat fractions with the highest aleurone content might be used in cereal products to optimize the beneficial health effect associated to whole-grain.

Acknowledgement. We thank INRA for the data of aleurone content of the wheat fractions and Jon Prinz for his support with the use of English. This research was financially supported by the European Commission in the Communities 6th Framework Programme, Project HEALTHGRAIN (FOOD-CT-2005-514008). It reflects the author's views and the Community is not liable for any use that may be made of the information contained in this publication. 


\section{REFERENCES}

1. Anderson JW. Whole grains and coronary heart disease: the whole kernel of truth. Am J Clin Nutr. 2004;80:1459-60.

2. Fulcher R, Rooney Duke T. Whole-Grain Foods in Health and Disease. St Paul MN: Eagan Press; 2002.

3. Jacobs DR, Jr., Marquart L, Slavin J, Kushi LH. Whole-grain intake and cancer: an expanded review and meta-analysis. Nutr Cancer. 1998;30:85-96.

4. McKeown NM, Meigs JB, Liu S, Wilson PW, Jacques PF. Whole-grain intake is favorably associated with metabolic risk factors for type 2 diabetes and cardiovascular disease in the Framingham Offspring Study. Am J Clin Nutr. 2002;76:390-8.

5. Mellen PB, Walsh TF, Herrington DM. Whole grain intake and cardiovascular disease: a meta-analysis. Nutr Metab Cardiovasc Dis. 2008;18:283-90.

6. Slavin JL, Jacobs D, Marquart L, Wiemer K. The role of whole grains in disease prevention. J Am Diet Assoc. 2001;101:780-5.

7. Liu R. Whole grain phytochemicals and health. J Cereal Sci. 2007;46:207-19.

8. Richardson DP. Improving health by exploiting bioactivity of European grains: HEALTHGRAIN. Nutr Bull. 2006;31:145-9.

9. Slavin JL, Jacobs D, Marquart L. Grain processing and nutrition. Crit Rev Biotechnol. 2001;21:49-66.

10. Slavin JL, Martini MC, Jacobs DR, Jr., Marquart L. Plausible mechanisms for the protectiveness of whole grains. Am J Clin Nutr. 1999;70:459S-63S.

11. Halliwell B. Reactive oxygen species in living systems: source, biochemistry, and role in human disease. Am J Med. 1991;91:14S-22S.

12. Willcox JK, Ash SL, Catignani GL. Antioxidants and prevention of chronic disease. Crit Rev Food Sci Nutr. 2004;44:275-95.

13. Bast A, Haenen GR, Doelman CJ. Oxidants and antioxidants: state of the art. Am J Med. 1991;91:2S-13S.

14. Kohen R, Nyska A. Oxidation of biological systems: oxidative stress phenomena, antioxidants, redox reactions, and methods for their quantification. Toxicol Pathol. 2002;30:620-50.

15. Evans JL, Maddux BA, Goldfine ID. The molecular basis for oxidative stress-induced insulin resistance. Antioxid Redox Signal. 2005;7:1040-52.

16. Dexter JE, Wood PJ. Recent applications of debranning of wheat before milling. Trends Food Sci Technol. 1996;7:35-41.

17. Adom KK, Sorrells ME, Liu RH. Phytochemicals and antioxidant activity of milled fractions of different wheat varieties. J Agr Food Chem. 2005;53:2297-306.

18. Martinez-Tome M, Murcia MA, Frega N, Ruggieri S, Jimenez AM, Roses F, Parras P. Evaluation of antioxidant capacity of cereal brans. J Agr Food Chem. 2004;52:4690-9.

19. Hemery Y, Rouau X, Lullien-Pellerin V, Barron C, Abecassis J. Dry processes to develop wheat fractions and products with enhanced nutritional quality. J Cereal Sci. 2007;46:327-47.

20. Gallardo C, Jiménez L, García-Conesa MT. Hydroxycinnamic acid composition and in vitro antioxidant activity of selected grain fractions. Food Chem. 2006;99:455-63.

21. Liyana-Pathirana C, Dexter J, Shahidi F. Antioxidant properties of wheat as affected by pearling. J Agr Food Chem. 2006;54:6177-84.

22. Zielinski H, Kozlowska H. Antioxidant activity and total phenolics in selected cereal grains and their different morphological fractions. J Agr Food Chem. 2000;48:2008-16. 
23. van den Berg R, Haenen GRMM, van den Berg H, Bast A. Applicability of an improved Trolox equivalent antioxidant capacity (TEAC) assay for evaluation of antioxidant capacity measurements of mixtures. Food Chem. 1999;66:511-7.

24. Bohm A, Bogoni C, Behrens R, Otto T, inventors; Method for the extraction of aleurone from bran; patent WO 02/157711 A2. 2002.

25. Eugster W, Gerschwiler O, inventors; Method and installation for cleaning cereal; patent US 2006/0147591 A1. 2006.

26. Wellman $W$, inventor Wheat milling process; patent US 5089 282. 1992.

27. Wellman $\mathrm{W}$, inventor Wheat milling process and milled wheat products; patent US 5 194287.1993.

28. Antoine C, Lullien-Pellerin V, Abecassis J, Rouau X. Effect of wheat bran ball-milling on fragmentation and marker extractability of the aleurone layer. J Cereal Sci. 2004;40:27582.

29. Hemery Y, Lullien-Pellerin V, Rouau X, Barron C, Abecassis J, Samson M-F, Åman P, von Reding W, Spoerndli C, Barron C. Biochemical markers: efficient tools for the assessment of wheat grain tissue proportions in milling fractions. J Cereal Sci. 2009;49:55-64.

30. Bonoli M, Verardo V, Marconi E, Caboni MF. Antioxidant phenols in barley (Hordeum vulgare L.) flour: comparative spectrophotometric study among extraction methods of free and bound phenolic compounds. J Agr Food Chem. 2004;52:5195-200.

31. Singleton VL, Orthofer R, Lamuela-Raventós RM, Lester P. Analysis of total phenols and other oxidation substrates and antioxidants by means of folin-ciocalteu reagent. Methods in Enzymology: Academic Press; 1999. p. 152-78.

32. Mattila P, Hellström J. Phenolic acids in potatoes, vegetables, and some of their products. J Food Compos Anal. 2007;20:152-60.

33. Bradford MM. A rapid and sensitive method for the quantitation of microgram quantities of protein utilizing the principle of protein-dye binding. Anal Biochem. 1976;72:248-54.

34. Derrick JS. The aleurone layer of wheat. III. Isolation and scanning electron microscope examination of the layer and of its component parts. J Sci Food Agr. 1973;24:307-17.

35. Evers AD, Bechtel DB. Microscopic structure of the wheat grain. In: Pomeranz Y, editor. Wheat: Chemistry and Technology. St Paul, MN: AACC; 1988.

36. Amrein TM, Gränicher P, Arrigoni E, Amadò R. In vitro digestibility and colonic fermentability of aleurone isolated from wheat bran. Lebensm-Wiss U-Technol. 2003;36:451-60.

37. Barron C, Surget A, Rouau X. Relative amounts of tissues in mature wheat (Triticum aestivum L.) grain and their carbohydrate and phenolic acid composition. J Cereal Sci. 2007;45:88-96.

38. Rhodes DI, Sadek M, Stone BA. Hydroxycinnamic Acids in Walls of Wheat Aleurone Cells. J Cereal Sci. 2002;36:67-81.

39. Fincher GB, Stone BA. Cell wall and their components in cereal grain technology. In: Pomeranz Y, editor. Advance in Cereal Science and Technology. St Paul, MN: AACC; 1986.

40. Klepacka J, Fornal L. Ferulic acid and its position among the phenolic compounds of wheat. Crit Rev Food Sci Nutr. 2006;46:639-47.

41. Arts MJ, Haenen GR, Voss HP, Bast A. Masking of antioxidant capacity by the interaction of flavonoids with protein. Food Chem Toxicol. 2001;39:787-91.

42. Arts MJ, Haenen GR, Wilms LC, Beetstra SA, Heijnen CG, Voss HP, Bast A. Interactions between flavonoids and proteins: effect on the total antioxidant capacity. J Agr Food Chem. 2002;50:1184-7. 
43. Liyana-Pathirana CM, Shahidi F. Importance of insoluble-bound phenolics to antioxidant properties of wheat. J Agr Food Chem. 2006;54:1256-64.

44. Williamson G, Plumb GW, Garcia-Conesa MT. Glycosylation, esterification and polymerization of flavonoids and hydroxycinnamates: effects on antioxidant properties. Basic Life Sci. 1999;66:483-94.

45. Kern SM, Bennett RN, Mellon FA, Kroon PA, Garcia-Conesa MT. Absorption of hydroxycinnamates in humans after high-bran cereal consumption. J Agr Food Chem. 2003;51:6050-5.

46. Charlton AJ, Baxter NJ, Khan ML, Moir AJ, Haslam E, Davies AP, Williamson MP. Polyphenol/peptide binding and precipitation. J Agr Food Chem. 2002;50:1593-601.

47. Renard CM, Baron A, Guyot S, Drilleau JF. Interactions between apple cell walls and native apple polyphenols: quantification and some consequences. Int J Biol Macromol. 2001;29:115-25.

48. Karakaya S. Bioavailability of phenolic compounds. Crit Rev Food Sci Nutr. 2004;44:453-64.

49. Price RK, Welch RW, Lee-Manion AM, Bradbury I, Strain JJ. Total Phenolics and Antioxidant Potential in Plasma and Urine of Humans After Consumption of Wheat Bran. Cereal Chem. 2008;85:152-7. 



\begin{abstract}
Epidemiological studies have linked whole grain consumption to prevention of several chronic diseases. Whole grain is source of important phytochemicals, such as ferulic acid (FA). FA is the most abundant phenolic and major contributor to the in vitro antioxidant capacity of wheat grain. Several studies have reported highly variable results on FA bioavailability (0.4 to $98 \%)$. The binding of FA to polysaccharides may limit its bioavailability. Therefore, our study aimed at monitoring release features of FA during gastrointestinal (GI) transit. This was termed bioaccessibility. The bioaccessibility of FA was studied from different wheat fractions and breads with the use of a dynamic in vitro system that simulates the upper GI transit and digestion. The results showed low bioaccessibility of FA from the wheat fractions and breads $(<1 \%)$. However, the bioaccessibility was high when free FA was added to flour $(\sim 60 \%)$. The bioaccessibility of FA appeared determined by the percentage of free FA. In wheat grain, most of FA is bound to arabinoxylans and other indigestible polysaccharides restricting its release in small intestine. New processing developments should be considered to increase free FA in the cereal matrix in order to improve its bioavailability and systemic health effect.
\end{abstract}




\section{INTRODUCTION}

Epidemiological studies have linked the consumption of whole-grain products to the prevention of chronic diseases such as type 2 diabetes, cardiovascular disease and some type of cancers (1-6). Although the mechanisms behind this protective effect are still not completely known, antioxidant protection might be implicated (6-8). Grain is an important source of numerous phytochemicals with potential biological activity, such as phenolic compounds (9). In wheat, ferulic acid (FA) is the most abundant phenolic acid, 70-90 \% (10-12). FA is mainly present within the cell walls of the aleurone layer bound to arabinoxylans and other polysaccharides or proteins $(13,14)$. The aleurone is a monolayer of cells overlying the endosperm and highly adhered to the pericarp. Aleurone cells are rich in dietary fiber and several bioactive compounds (15). Furthermore, the aleurone fraction has the highest antioxidant capacity among the wheat fractions, which was attributed to its high content in FA. FA could explain $60 \%$ of the antioxidant capacity of the aleurone fraction (16). Free FA may have a positive effect on inflammation, diabetes, cancer, aging and other disorders, possibly due to its high antioxidant capacity (17-20). In order to further elucidate the potential role of FA on health benefits, data on the bioavailability of FA from its major natural matrix, i.e. cereal products, are needed. The bioavailability of FA has been addressed in several studies quantified as urinary excretion with variable results: from low to high bioavailability (0.4 to $98 \%$ ), in part depending on the food source (21-23). For instance, by consumption of cereal products, particularly bran, FA presented a low bioavailability: $3 \%$ in humans (24), 2.5-5 \% in rat (25) and even lower, $0.4-0.5 \%$, from corn bran in rat (26). The bioavailability of FA was somewhat higher from other food matrices such as tomato, 11-25\% (21) or rye bread, $28 \%$ (27), while from beer, FA was highly bioavailable, 19-98 \% (28).

Many different factors can influence the bioavailability of a compound. The concept of bioavailability incorporates: bioaccessibility, absorption, tissue distribution and bioactivity. The first factor is the bioaccessibility or availability for absorption in the gastrointestinal tract (29).

The aim of the present study was to investigate the bioaccessibility of FA from different cereal food matrices. As the bioaccessibility of FA seems the first limiting step influencing its bioavailability, the results of this investigation may provide relevant information to in vivo data. For this study, we have used the in vitro TNO intestinal model (TIM). TIM is a computer-controlled gastrointestinal model developed to simulate upper gastrointestinal transit, $\mathrm{pH}$, composition and rate of secretions and absorption of digested products (30). This gastrointestinal system is a convenient model to monitor release features of a specific compound from the food matrix during gastrointestinal transit. The different samples used in the study were: (i) unprocessed wheat fractions: aleurone (high in FA), bran (intermediate) 
and flour (low), (ii) processed products: bread enriched with aleurone (high in FA) and control white bread (low in FA) and (iii) FA added as free compound to flour.

\section{EXPERIMENTAL}

\section{Chemicals}

Protease (P-5147), a-amylase (A-6211), pepsin (P-7012), bile (porcine bile extract, P-8631) and trans-ferulic acid were obtained from Sigma-Aldrich (St. Louis, MO, USA). Pancreatic juice from porcine pancreas (Pancreax V powder) was obtained from Paines \& Byrne (Greenford, United Kingdom). Rhizopus lipase (150,000 units/mg F-AP 15) was obtained from Amano Enzyme, Inc. (Nagoya, Japan).

\section{Test samples}

The wheat (Triticum aestivum L.) fractions aleurone, bran and flour were obtained from Bühler A.G. (Uzwil, Switzerland) as milled fractions $(<200 \mu \mathrm{m})$ from the wheat cultivar Tiger, harvested in 2005, Germany. The breads were obtained from the University of Ulster, Ireland. The control white bread was made of white flour and the bread enriched with aleurone was obtained by replacing $50 \%$ of the flour by aleurone fraction. The content of aleurone in the final dough was $22 \%$. All breads were freeze-dried in order to facilitate posterior grinding (Grindomix GM 200, Retsch, Germany) and homogenous sample. Samples were stored at $-20^{\circ} \mathrm{C}$ until use. The content of ferulic acid in all test samples is shown in Table 1.

\section{The dynamic computer-controlled gastrointestinal model (TIM system)}

The gastrointestinal model has been previously described in detail (30). The model comprises four compartments that represent the stomach, duodenum, jejunum and ileum. Secretion of digestive juices and $\mathrm{pH}$ adjustment in each section are simulated according to physiological data. The composition of the different digestive juices used in the model was previously described (31). Each compartment consists of a glass exterior with flexible, inner silicon tubing, connected by peristaltic valves that determine the transport rate of the food between the different compartments. All parameters are computer controlled and a protocol of medium transport time of food was chosen in the study to simulate a semi-solid meal. The half time of stomach emptying was 70 minutes. The jejunal and ileal compartments are connected with a semi-permeable hollow fibre membrane units of cellulose diacetate (DICEA-90 high performance dialysers, 
Baxter SA, US). This dialysis system mimics the absorption of water and digested products, which will be transported from lumen to the dialysate-samples. The dialysate-samples will contain the FA that is bioaccessible from the test sample. Dialysate-samples from the jejunal and ileal compartments were collected at 1 hour intervals for 6 hours. FA already bioaccessible at gastric and duodenal levels will be found in the dialysate-sample from the jejunal compartment. Samples were stored at $-20^{\circ} \mathrm{C}$ until analysis.

The amount of test sample used for the TIM experiment was $23 \mathrm{~g}$ of wheat fraction or $35 \mathrm{~g}$ dry matter (DM) of bread, which corresponds with approximately $52 \mathrm{~g}$ fresh weight. As the TIM model is a 3-4 fold down-scale of the human body, a TIM-intake of $52 \mathrm{~g}$ bread represents a realistic human bread intake. Before the start of the experiment, the test sample was mixed with artificial saliva which consisted of $11.5 \mathrm{mg}$ amylase (9600 units), $30 \mathrm{ml}$ citrate buffer $(\mathrm{pH}=6)$ and $100 \mathrm{ml}$ electrolyte solution. Milli-Q water was added to the mixture up to a final volume of $300 \mathrm{ml}$. This final mixture was termed TIM-intake (Table 1). The TIM-intake was introduced in the gastric compartment representing the stomach and the digestion was started, all TIM experiments were performed in duplicate.

\section{Determination of ferulic acid}

Ferulic acid (FA) content was determined in the test samples and quantified as free and total FA as previously described (32). For the determination of free FA, 50 $\mathrm{mg}$ of wheat fraction or freeze-dried bread were mixed with $2 \mathrm{ml}$ water and $\mathrm{HCl}$ to a final concentration of $0.35 \mathrm{M}(\mathrm{pH}<1.5)$. This mixture was extracted twice using ethylacetate. The extracts were pooled and evaporated to dryness. The dry extract was reconstituted in $0.5 \mathrm{ml} \mathrm{50 \%} \mathrm{methanol/water} \mathrm{and} \mathrm{filtrated} \mathrm{through} 0.2 \mu \mathrm{m}$ before injection.

For the determination of total FA, i.e. free and bound, the extracts were mixed with $2 \mathrm{M} \mathrm{NaOH}$ and incubated for 16 hours, in the absence of light and under $\mathrm{N}_{2}$ atmosphere. The extraction of FA was performed as described above.

FA was quantified in the test samples and dialysate-samples using reversed phase UPLC with Photo-Diode Array (PDA) detector. The detection was at $330 \mathrm{~nm}$. Separation was achieved using an Acquity Shield $\mathrm{RP}_{18} \mathrm{BEH}$ column $(100 \times 2.1 \mathrm{~mm}$ I.D., $1.7 \mu \mathrm{m})$. The eluents consisted of $0.1 \%(\mathrm{v} / \mathrm{v})$ of $\mathrm{H}_{3} \mathrm{PO}_{4}$ in water (A) and in acetonitrile (B). The gradient was: $0-4.45 \mathrm{~min} 10-50 \%$ (B), $4.45-4.86 \mathrm{~min} 50-90 \%$ (B), 4.48-5 $\mathrm{min} 90-10 \%$ (B), 5-6 $\mathrm{min} 10 \%$ (B). Flow rate was $0.5 \mathrm{ml} / \mathrm{min}$, the injection volume was $1 \mu \mathrm{l}$ and column temperature was $30^{\circ} \mathrm{C}$.

Dialysate-samples from the time interval 1-2 hour were also hydrolyzed with 1 $\mathrm{M} \mathrm{NaOH}$ during 1 hour under $\mathrm{N}_{2}$ atmosphere in order to quantify the presence of bioaccessible esterified FA. 


\section{Calculations}

The total bioaccessibility was calculated using the summed amount of FA in the dialysate-samples from jejunum and ileum collected every hour during the 6 hours of digestion. The bioaccessibility is the amount of FA in dialysate relative to the intake of total FA in percentage.

By definition, the half-life of a quantity whose value decreases with time is the interval required for the quantity to decay to half its initial value. Half-life $\left(t_{1 / 2}\right)$ of FA in the intestinal compartments was calculated by the formula: $t_{1 / 2}=\ln (2) / \lambda$. The decay constant $(\lambda)$ was obtained by fitting the quantity of FA in jejunal and ileal dialysate in time by first order kinetics. Data points were taken from the FA maximum until the end of digestion (1-6 h) (Figure 1).

All results are expressed as mean of duplicate determinations. The error given in the figure represents half of the range between duplicates.

\section{RESULTS}

The content in free ferulic acid (FA) of the wheat fractions and breads ranged from 2 to $20 \mu \mathrm{g} / \mathrm{g}$. The content in the total FA was much higher, ranging from 33 to $6780 \mu \mathrm{g} / \mathrm{g}$ (Table 1). The relative amount of free FA compared to total FA was very low in the wheat fractions bran and aleurone $(<1 \%)$ and flour $(\sim 2 \%)$ and also in the products: bread enriched with aleurone $(<1 \%)$ and control white bread $(\sim 7 \%)$. In these samples, most of the FA was bound.

Table 1. Ferulic acid (FA) content and bioaccessibility (\%) in the tested samples. Results are expressed as means of duplicate determinations. The difference between duplicates was less than $10 \%$ of the mean.

\begin{tabular}{|c|c|c|c|c|c|c|c|}
\hline & \multicolumn{3}{|c|}{ FA in sample $(\mu \mathrm{g} / \mathrm{g})$} & \multicolumn{2}{|c|}{ TIM-intake (mg) } & \multirow{2}{*}{$\begin{array}{c}\text { FA in } \\
\text { Dialysate } \\
(\mathrm{mg}) *\end{array}$} & \multirow{2}{*}{$\begin{array}{c}\text { Bioaccessibility } \\
\text { of FA (\%) }\end{array}$} \\
\hline & Free & Total & $\begin{array}{c}\text { Free/Total } \\
(\%)\end{array}$ & Free & Total & & \\
\hline Flour & 2.8 & 177 & 1.6 & 0.063 & 4.02 & ND & ND \\
\hline Bran & 19 & 5670 & 0.34 & 0.43 & 127 & 0.71 & 0.56 \\
\hline Aleurone & 16 & 6780 & 0.24 & 0.37 & 154 & 0.85 & 0.55 \\
\hline $\begin{array}{l}\text { Control } \\
\text { white bread }\end{array}$ & 2.4 & 33.5 & 7.1 & 0.13 & 1.81 & ND & ND \\
\hline $\begin{array}{l}\text { Bread with } \\
\text { aleurone }\end{array}$ & 20 & 2290 & 0.86 & 1.0 & 119 & 0.69 & 0.57 \\
\hline$F A+F l o u r$ & 27000 & 27200 & 99 & 27 & 30.8 & 18 & 59 \\
\hline
\end{tabular}

ND means not detectable or calculable. ${ }^{*}$ Free FA. 
The total bioaccessibility of FA in the unprocessed wheat fractions: aleurone, bran and flour, was low. In aleurone and bran, $\sim 0.5 \%$ and $\sim 0.6 \%$ of the total FA was bioaccessible. The total bioaccessibility of FA in the processed wheat product: bread enriched with aleurone was also low $(\sim 0.6 \%)$. The total bioaccessibility of FA added as free compound to flour was $\sim 60 \%$ (Table 1).

In the unprocessed wheat fractions aleurone and bran, as well as in the processed product bread enriched with aleurone, the relative amount of FA was higher in the dialysate-samples of the jejunal compartment compared to the ileal compartment (Figure 1). Dialysate-samples from the jejunal compartment accounted for $71 \%$ of the total bioaccessible FA of bran and aleurone, in the bread enriched with aleurone it was $77 \%$, and in the case of free FA added to flour, $81 \%$. The maximal amount of bioaccessible FA was found in the dialysate-samples of the time interval 1-2 hour of digestion. At this time interval, $40-45 \%$ of the total bioaccessible FA was found in the dialysate from the digestion of bran, aleurone and bread enriched with aleurone and $53 \%$ in the case of free FA added to flour.

In the dialysate-samples obtained from the digestion of flour and control white bread, the concentration of FA was not detectable (limit of detection was 0.05 $\mu \mathrm{g} / \mathrm{ml})$.

Aleurone

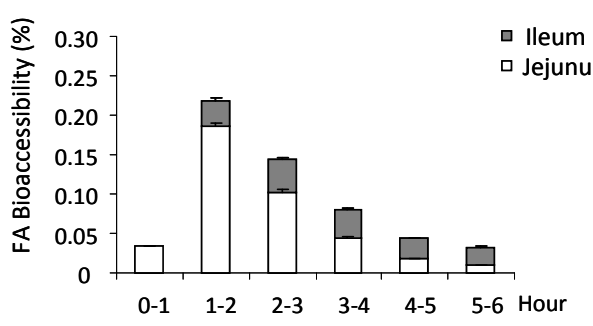

Bran

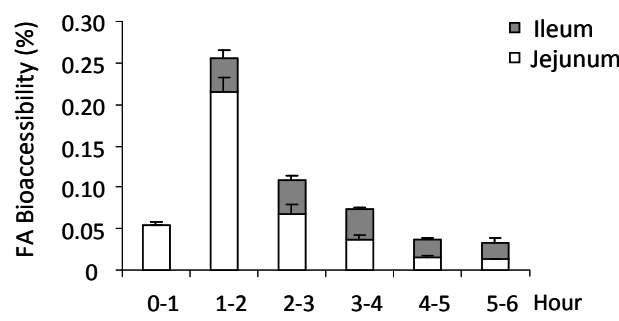

Bread with Aleurone

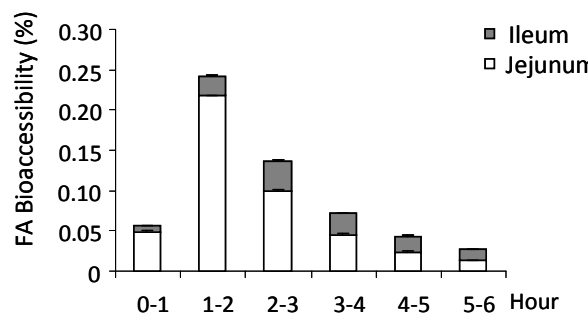

FA + Flour

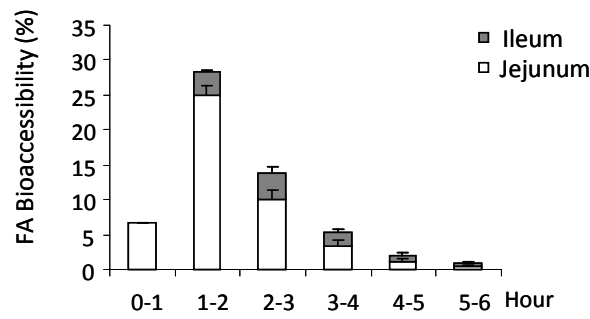

Figure 1. Total bioaccessibility of ferulic acid (FA) during gastrointestinal transit of aleurone, bran, bread enriched with aleurone and FA added to flour in the TIM model. The total bioaccessibility of FA is shown in the dialysate-samples of the jejunal and ileal compartment in 1 hour time intervals and expressed as \% related to the total FA in the TIMintake. The results are means of duplicate experiments. Error bars are the half of the range between duplicates. 
Dialysate-samples of the time interval 1-2 $\mathrm{h}$ were subjected to hydrolysis. Only in the dialysate-sample from the digestion of bread enriched with aleurone, the hydrolysis resulted in an increase in the concentration of FA by a factor of 2 (data not shown).

All tested products, unprocessed fractions or processed breads, have shown a similar profile of the bioaccessibility of ferulic acid, with maxima at the 1-2 $\mathrm{h}$ time interval and low total bioaccessibility. From the maximum until the end of the digestion, the amount of FA taken up in dialysate was fitted in time according to first order kinetics to calculate the half-life of FA in the intestinal compartments. According to this model, the half-life of the bioaccessible FA in the intestinal compartments was 82, 81 and 76 min for aleurone, bran and bread enriched with aleurone respectively. The half-life was $49 \mathrm{~min}$ for free FA added to flour.

\section{DISCUSSION}

Several human and rat studies have shown relatively low urinary excretion of FA after high bran cereal consumption: $3 \%(24), 2.5-5 \%(25)$ and corn bran: 0.4$0.5 \%(26)$. However, high bioavailability of FA ( $50 \%)$ was found when FA was perfused as free pure compound in rat intestine (25). Urinary excretion of FA in humans was also high (19-98\%), as for example from beer, where FA is predominantly present in its free form (28).

The present study shows that the bioaccessibility of FA from unprocessed aleurone, bran and flour was low, which confirms the in vivo low bioavailability from cereal bran consumption (24). The bioavailability of FA seems determined by its release from the food matrix. In bran and aleurone, FA is mainly bound to arabinoxylans and other cell wall polysaccharides that are able to resist digestion in the upper GI tract (33). In bran and aleurone, free FA was less than $1 \%$ of the total amount. Free FA was highly bioaccessible, while only a very small fraction of bound FA was apparently released. The total bioaccessibility remained under $1 \%$ (Table 1).

The same low bioaccessibility was found in the processed breads: control white bread and bread enriched with aleurone. However, a substantial increase in FA, by approximately factor 2, was detected after hydrolysis of the dialysate-sample of bread enriched with aleurone. This indicates the presence of FA esterified to sugar moieties of low molecular weight, lower than the molecular weight cut-off of the dialysis membranes used in the model (5-8 kDa). In small intestinal epithelium some esterase activity has been reported (34). This indicates that FA esters might be hydrolyzed to free FA in vivo. Whether these FA esters will permeate the mucous layer and reach the esterases in the small intestinal mucosa, will depend on their molecular size and structure. Molecules larger than $30 \mathrm{kDa}$ are not expected to diffuse through the mucus, while diffusion of lower molecular weights is size-dependent and influenced by the existence of an electric field (35). Zhao et 
al. (33) showed how differences in the molecular size of FA sugar esters influence the degree of absorption and absorption site of FA within the gut of the rat. When FA was either esterified to just one arabinose or to several arabinoses and xyloses, most of FA (60-70\%) was not absorbed in small intestine, concluding that the major cleavage of FA esters takes place in large intestine (33). This is in accordance with a previous study (36), which reported that the major cleavage of ester bounds in hydroxycinnamates such as FA occurs in colon by bacterial enzymes.

In contrast to the bread enriched with aleurone, hydrolysis did not increase the free FA in the dialysate-samples from the digestion of the unprocessed fractions aleurone and bran. This might be due to structural modifications occurring during the process of bread-making that might release some FA esters, partly by endogenous cell wall-degrading enzymes (37).

Despite the low bioaccessibility of FA from the wheat fractions and breads, free FA added to flour was $60 \%$ bioaccessible, which is in line with the results of intestinal absorption for free FA reported by Adam et al. (25) and averaged urinary excretion of FA from beer (28). In all tested samples the maximum of bioaccessible FA was found during the second hour of digestion (1-2 h). At this time interval, emptying of the stomach compartment of the TIM model is almost completed, and $90 \%$ of the TIM-intake has entered the intestinal compartments. Although all samples shared the same profile of FA bioaccessibility with maxima at the 1-2 hour interval, after the maximum, the half-life of FA uptake in dialysate was affected by the type of sample. In the case of free FA added to flour, the half-life of FA was 50 minutes, while this was almost twice as long $(\sim 80 \mathrm{~min})$ in the case of aleurone, bran or bread enriched with aleurone. Probably, the high fibre content of aleurone and bran (50-60\%) (38) and its complex network slows down the rate of diffusion of free FA from the intestinal compartment to the dialysate.

Absorption of FA in intestine probably occurs by passive diffusion. This is deduced from the uptake of FA that is linear over the concentration and that is not saturable $(25,39)$. However, Konishi and Shimizu (40) and Poquet et al. (39) also reported the possibility of a saturable FA transport via a monocarboxylic acid transporter dependent on $\mathrm{pH}$. Nevertheless, free FA in intestine was extensively absorbed (25), thus absorption itself is probably not the limiting factor for this compound.

The therapeutic potential of free FA has been extensively investigated. Some in vivo studies found elevated levels of detoxifying enzymes, e.g. gluthation Stransferase (GST), in liver and colonic mucosa in rats fed FA at the dose of 100 $\mathrm{mg} / \mathrm{kg}$ of body weight (41). In the same study, FA reduced the incidence and multiplicity of intestinal azoxymethane-induced tumors after 35 weeks of oral administration of $250 \mathrm{mg} \mathrm{FA} \mathrm{kg}^{-1}$ body weight day-1. FA has also shown a dose dependent effect in reducing blood pressure in spontaneously hypertensive rats administered at the concentrations of $1-100 \mathrm{mg} / \mathrm{kg}$ body weight, in which nitric oxide production seems to be involved (17). In vitro, concentration of $10-150 \mu \mathrm{M}$ of FA counteracted nicotine induced lipid peroxidation and glutathione depletion in 
lymphocytes (42) and at concentrations of $250-500 \mu \mathrm{M}$ FA reduced protein and lipid peroxidation induced by reactive oxygen species in neuronal cells and peripheral blood mononuclear cells (17). This extensive evidence of beneficial effects has been however only investigated in vitro and in rodents. The dose used in most of studies is over the estimated human intake and consisting of $100 \%$ free FA. Humans may consume as much as $80-165 \mathrm{mg} \mathrm{FA} /$ meal, which corresponds to approximately $1-2 \mathrm{mg} / \mathrm{kg}$ of body weight (17). In whole grain products, major source of FA in human daily diet, the amount of free FA is limited to $1-4 \%$ and the total content of FA is, thus, slightly bioavailable. Consequently, the maximal concentration of FA in human plasma was $\sim 200 \mathrm{nM}$ after high-bran cereal consumption (24). Nutrigenomic approaches have however illustrated several beneficial effects of phytochemicals on gene regulation despite their low bioavailability (43).

From the findings of our study and review of related literature, we can conclude that the in vitro TNO intestinal model predicts the in vivo bioavailability of FA from structured cereal fractions and breads. It confirms that the limited bioavailability of FA from the cereal matrix is determined by its low bioaccessibility in small intestine and due to the embedment of FA in the indigestible polysaccharides of the cell walls. Processing methods that aim at improving the bioaccessibility of FA from cereal products, may be the most promising approach to expect health benefits at the systemic level.

Acknowledgements: We thank Lesley Hamill and Rob Welch for providing us the breads and Jon Prinz for the revision of the English. This research was financially supported by the European Commission in the Communities 6th Framework Programme, Project HEALTHGRAIN (FOOD-CT-2005-514008). It reflects the author's views and the Community is not liable for any use that may be made of the information contained in this publication. 


\section{REFERENCES}

1. Anderson JW. Whole grains and coronary heart disease: the whole kernel of truth. Am J Clin Nutr. 2004;80:1459-60.

2. Fulcher RG, Duke TK. Whole-grain structure and organization: Implications for nutritionists and processors. In: Marquart L, Slavin L, Fulcher R, G., editors. Wholegrain foods in health and disease. St. Paul, Minnesota: AACC; 2002. p. 9-45.

3. Jacobs DR, Jr., Marquart L, Slavin J, Kushi LH. Whole-grain intake and cancer: an expanded review and meta-analysis. Nutr Cancer. 1998;30:85-96.

4. McKeown NM, Meigs JB, Liu S, Wilson PW, Jacques PF. Whole-grain intake is favorably associated with metabolic risk factors for type 2 diabetes and cardiovascular disease in the Framingham Offspring Study. Am J Clin Nutr. 2002;76:390-8.

5. Mellen PB, Walsh TF, Herrington DM. Whole grain intake and cardiovascular disease: a meta-analysis. Nutr Metab Cardiovasc Dis. 2008;18:283-90.

6. $\quad$ Slavin J. Whole grains and human health. Nutr Res Rev. 2004;17:99-110.

7. Fardet A, Rock E, Remesy E. Is the in vitro antioxidant potential of whole-grain cereals and cereal products well reflected in vivo? J Cereal Sci. 2008;48: 258-76.

8. Willcox JK, Ash SL, Catignani GL. Antioxidants and Prevention of Chronic Disease. Crit Rev Food Sci Nutr. 2004;44:275 - 95.

9. Liu R. Whole grain phytochemicals and health. J Cereal Sci. 2007;46:207-19.

10. Krygier K, Sosulski F, Hogge L. Free, esterified, and insoluble-bound phenolic acids. 1. Extraction and purification procedure. J Agr Food Chem. 1982;30:330-4.

11. Mattila P, Pihlava JM, Hellstrom J. Contents of phenolic acids, alkyl- and alkenylresorcinols, and avenanthramides in commercial grain products. J Agr Food Chem. 2005;53:8290-5.

12. Moore J, Hao Z, Zhou K, Luther M, Costa J, Yu LL. Carotenoid, tocopherol, phenolic acid, and antioxidant properties of Maryland-grown soft wheat. J Agr Food Chem. 2005;53:6649-57.

13. Bunzel M, Ralph J, Marita JM, Hatfield RD, Steinhart H. Diferulates as structural components in soluble and insoluble cereal dietary fibre. J Sci Food Agr. 2001;81:65360.

14. Klepacka J, Fornal L. Ferulic acid and its position among the phenolic compounds of wheat. Crit Rev Food Sci Nutr. 2006;46:639-47.

15. Hemery Y, Rouau X, Lullien-Pellerin V, Barron C, Abecassis J. Dry processes to develop wheat fractions and products with enhanced nutritional quality. J Cereal Sci. 2007;46:327-47.

16. Mateo Anson N, van den Berg R, Havenaar R, Bast A, Haenen GR. Ferulic acid from aleurone determines the antioxidant potency of wheat grain (Triticum aestivum L.). J Agr Food Chem. 2008;56:5589-94.

17. Barone E, Calabrese V, Mancuso C. Ferulic acid and its therapeutic potential as a hormetin for age-related diseases. Biogerontology. 2008.

18. Graf E. Antioxidant potential of ferulic acid. Free Radic Biol Med. 1992;13:435-48.

19. Ou S, Kwok K-C. Ferulic acid: pharmaceutical functions, preparation and applications in foods. J Sci Food Agr. 2004;84:1261-9.

20. Srinivasan M, Sudheer AR, Menon VP. Ferulic Acid: therapeutic potential through its antioxidant property. J Clin Biochem Nutr. 2007;40:92-100.

21. Bourne L, Rice-Evans C. Bioavailability of ferulic acid. Biochem Bioph Res Co. 1998;253:222-7.

22. Karakaya S. Bioavailability of phenolic compounds. Crit Rev Food Sci Nutr. 2004;44:453-64. 
23. Manach C, Williamson G, Morand C, Scalbert A, Remesy C. Bioavailability and bioefficacy of polyphenols in humans. I. Review of 97 bioavailability studies. Am J Clin Nutr. 2005;81:230S-42S.

24. Kern SM, Bennett RN, Mellon FA, Kroon PA, Garcia-Conesa MT. Absorption of hydroxycinnamates in humans after high-bran cereal consumption. J Agr Food Chem. 2003;51:6050-5.

25. Adam A, Crespy V, Levrat-Verny MA, Leenhardt F, Leuillet M, Demigne C, Remesy C. The bioavailability of ferulic acid is governed primarily by the food matrix rather than its metabolism in intestine and liver in rats. J Nutr. 2002;132:1962-8.

26. Zhao Z, Egashira Y, Sanada H. Phenolic antioxidants richly contained in corn bran are slightly bioavailable in rats. J Agr Food Chem. 2005;53:5030-5.

27. Harder $\mathrm{H}$, Tetens I, Let MB, Meyer AS. Rye bran bread intake elevates urinary excretion of ferulic acid in humans, but does not affect the susceptibility of LDL to oxidation ex vivo. Eur J Nutr. 2004;43:230-6.

28. Bourne L, Paganga G, Baxter D, Hughes P, Rice-Evans C. Absorption of ferulic acid from low-alcohol beer. Free Radic Res. 2000;32:273-80.

29. Stahl W, van den Berg H, Arthur J, Bast A, Dainty J, Faulks RM, Gartner C, Haenen G, Hollman P, Holst B, Kelly FJ, Polidori MC, Rice-Evans C, Southon S, van Vliet T, VinaRibes J, Williamson G, Astley SB. Bioavailability and metabolism. Mol Aspects Med. 2002;23:39-100.

30. Minekus M, Marteau P, Havenaar R, Huis In 'T Veld JHJ. A multicompartmental dynamic computer-controlled model simulating the stomach and small intestine. ATLA. 1995;23:197-209.

31. Larsson M, Minekus M, Havenaar R. Estimation of the Bioavailability of Iron and Phosphorus in Cereals using a Dynamic In Vitro Gastrointestinal Model. J Sci Food Agr. 1997;74:99-106.

32. Bartolomé B, Gómez-Cordovés C. Barley spent grain: release of hydroxycinnamic acids (ferulic and $p$-coumaric acids) by commercial enzyme preparations. J Sci Food Agr. 1999;79:435-9.

33. Zhao Z, Egashira Y, Sanada H. Digestion and absorption of ferulic acid sugar esters in rat gastrointestinal tract. J Agr Food Chem. 2003;51:5534-9.

34. Andreasen MF, Kroon PA, Williamson G, Garcia-Conesa MT. Esterase activity able to hydrolyze dietary antioxidant hydroxycinnamates is distributed along the intestine of mammals. J Agr Food Chem. 2001;49:5679-84.

35. Desai MA, Mutlu M, Vadgama P. A study of macromolecular diffusion through native porcine mucus. Experientia. 1992;48:22-6.

36. Kroon PA, Faulds CB, Ryden P, Robertson JA, Williamson G. Release of Covalently Bound Ferulic Acid from Fiber in the Human Colon. J Agr Food Chem. 1997;45:661-7.

37. Boskov H, Hansen HB, Andreasen, Andreasen M, Nielsen, Nielsen M, Larsen, Larsen L, Knudsen B, Meyer, Meyer A, Christensen, Christensen L, Hansen, A H. Changes in dietary fibre, phenolic acids and activity of endogenous enzymes during rye breadmaking. Eur Food Res Technol. 2002;214:33-42.

38. Amrein TM, Gränicher P, Arrigoni E, Amadò R. In vitro digestibility and colonic fermentability of aleurone isolated from wheat bran. Lebensm-Wiss U-Technol. 2003;36:451-60.

39. Poquet L, Clifford MN, Williamson G. Transport and metabolism of ferulic acid through the colonic epithelium. Drug Metab Dispos. 2008;36:190-7.

40. Konishi Y, Shimizu M. Transepithelial transport of ferulic acid by monocarboxylic acid transporter in Caco-2 cell monolayers. Biosci Biotechnol Biochem. 2003;67:856-62. 
41. Kawabata K, Yamamoto T, Hara A, Shimizu M, Yamada Y, Matsunaga K, Tanaka T, Mori H. Modifying effects of ferulic acid on azoxymethane-induced colon carcinogenesis in F344 rats. Cancer Lett. 2000;157:15-21.

42. Sudheer AR, Muthukumaran S, Kalpana C, Srinivasan M, Menon VP. Protective effect of ferulic acid on nicotine-induced DNA damage and cellular changes in cultured rat peripheral blood lymphocytes: a comparison with $\mathrm{N}$-acetylcysteine. Toxicol In Vitro. 2007;21:576-85.

43. Scalbert A, Knasmuller S. Genomic effects of phytochemicals and their implication in the maintenance of health. Br J Nutr. 2008;99 E Suppl 1:ES1-2. 



\begin{abstract}
Whole-grain consumption is associated with several health benefits, in contrast to the consumption of refined grains. This can partly be related to the antioxidant compounds in the outer parts of the grain kernel. The bioaccessibility of these antioxidant compounds from the whole-grain matrix during gastrointestinal digestion is crucial for their absorption and bioavailability. In the current study, the bioaccessible compounds from aleurone, bran and flour were obtained from a dynamic in vitro model of the upper gastrointestinal tract. They were collected at 1 $\mathrm{h}$ time intervals to assess their antioxidant capacity (TEAC assay) and also their anti-inflammatory effect (TNF-a reduction in U937 macrophages stimulated with LPS). The bioaccessible compounds from aleurone had the highest antioxidant capacity and provided a prolonged anti-inflammatory effect, shown by the TNF-a reduction of a relatively late time-interval (3-4 $\mathrm{h}$ after start of digestion). The contribution of ferulic acid to those effects was minor due to its low bioaccessibility. Aleurone seems a promising wheat fraction for cereal products with a healthy added value.
\end{abstract}




\section{INTRODUCTION}

Whole-grain consumption has been associated with a reduced risk for the development of the metabolic syndrome (1-3). The metabolic syndrome increases among others the development of cardiovascular disease and type 2 diabetes. There are some indications that chronic inflammation and oxidative stress may play a central role in the aggravation of these disorders (4-6).

It has been suggested that the outermost component of the grain, i.e. the bran, is the main responsible for the health benefits associated with whole grain (7). Bran contains many bioactive compounds, such as micronutrients (vitamins and minerals), antioxidants (phenolic compounds), and other phytochemicals (phytic acid, sterols). Most of these compounds are particularly concentrated in the aleurone layer, which is a monolayer of cells overlying the endosperm and adhered to the pericarp (8). The aleurone cells play a crucial role in the plant physiology, since the aleurone cells host hormonal signalling processes that are necessary for the seed germination. Some of these processes involve reactive oxygen species, which production in the cell is regulated by antioxidant and oxidant enzymes (9).

Dry fractionation techniques have been developed to obtain fractions of the wheat grain that can be used to produce cereal products of a healthy added value. The different fractions of wheat grain have been characterized for chemical composition in previous studies (10). A high content in biologically active compounds can be used as the first criterion for the selection of a wheat fraction. However, the compound needs to be able to reach its primary site of action in order to be biologically active; in other words, it needs to be bioavailable. The first factor limiting the bioavailability of a compound is the release and solubility of the compound from the food matrix. Only then, it becomes available for intestinal absorption. This concept has been termed as bioaccessibility.

The in vitro model of upper gastrointestinal tract, the TIM system, has been previously used to assess the bioaccessibility of some bioactive compounds in food, such as minerals (11-13), folic acid (14) and ferulic acid (15). Ferulic acid has been identified as the major antioxidant compound in wheat (16) and it has been suggested as marker of antioxidant compounds in wheat grain. The bioavailability of ferulic acid from wheat grain has been determined by its bioaccessibility, which could be well estimated in vitro. The same in vitro model is used in the current study to obtain the bioaccessible compounds from the wheat fractions aleurone, bran, and flour. The aim of the present study was to investigate the antioxidant and anti-inflammatory capacities of the respective bioaccessible compounds in order to identify the most promising wheat fraction for a possible health effect. 


\section{EXPERIMENTAL}

\section{Chemicals}

ABTS (2,2'azino-bis(3-ethylbenzthiazoline)6-sulfonicacid), Lipopolysaccharide (LPS, E. coli 0111:B4), Trolox (6-hydeoxy-2,5,7,8-tetramethylchroman-2-carboxylic acid), protease (P-5147), a-amylase (A-6211), pepsin (P-7012) and bile (porcine bile extract, P-8631) were obtained from Sigma (St. Louis, MO, USA). ABAP (2,2azobis(2-aminopropane) hydrochloride) was obtained from Polyscience (Warrington, PA). Pancreatic juice from porcine pancreas (Pancreax V powder) was obtained from Paines \& Byrne (Greenford, United Kingdom). Rhizopus lipase (150,000 units/mg F-AP 15) was obtained from Amano Enzyme, Inc. (Nagoya, Japan). RPMI-1640 medium, fetal calf serum and L-glutamine were purchased from Life Technologies (Breda, The Netherlands). Phorbol myristate acetate (PMA) was obtained from Omnilabo (Breda, The Netherlands). All chemicals used were of analytical grade quality.

\section{Wheat fractions}

The wheat fractions (Triticum aestivum L.) were obtained from Bühler A.G. (Uzwil, Switzerland) as milled fractions: aleurone 2 (50\% TDF), coarse bran (60\% $\mathrm{TDF})$, and $76 \%$ flour from pearling ( $3 \% \mathrm{TDF})$. The fractions were of the wheat cultivar Tiger, harvested in 2005, Germany. The aleurone fraction (99\% aleurone) was obtained from coarse bran (42\% aleurone) (8) as described in the Bühler A.G. patent applications $(17,18)$. The pure native wheat starch was obtained from AVEBE (Latenstein, The Netherlands) and it was used as blank. The wheat fractions were stored at $-20^{\circ} \mathrm{C}$ until use.

Before the start of each experiment, $23 \mathrm{~g}$ (fresh weight) of aleurone, bran, flour or starch were mixed with artificial saliva, which consisted of $100 \mathrm{ml}$ electrolyte solution, $30 \mathrm{ml}$ citrate buffer $(\mathrm{pH}=6)$ and amylase (9600 units). Milli-Q water was added to the mixture up to a final volume of $300 \mathrm{ml}$. This final mixture was introduced in the gastric compartment of the TIM system as described below and the digestion was started.

\section{The dynamic computer-controlled gastrointestinal model (TIM system)}

The gastrointestinal model has been previously described in detail (19). The model comprises four compartments that represent the stomach, duodenum, jejunum and ileum. The secretion of digestive juices and $\mathrm{pH}$ adjustment in each section are simulated according to physiological data (19). The composition of the different digestive juices used in the model has been previously described (13). Each compartment consists of a glass exterior with flexible, inner silicon tubing, 
connected by peristaltic valves that determine the transport rate of the food through the successive compartments. All parameters are computer-controlled using set-points for a moderate transport time of food to simulate accurately the gastrointestinal conditions of human adults after the intake of a semi-solid meal. The half-time of stomach emptying was 70 minutes. The jejunal and ileal compartments are connected with a semi-permeable hollow fibre membrane units of cellulose diacetate (DICE-90 high performance cellulose diacetate dialysers, Baxter SA, US). These dialysis units mimic the absorption of water and digested compounds of low molecular weight that are in solution, which are referred to as the bioaccessible compounds from the wheat fractions. Dialysate samples from the jejunal and ileal compartments were collected in 1 hour intervals for 6 hours. Dialysate samples were stored at $-20{ }^{\circ} \mathrm{C}$ until analysis. Gastrointestinal in vitro digestions were performed in duplicate.

\section{Antioxidant capacity assay}

The Trolox Equivalent Antioxidant Capacity Assay (TEAC) was used to determine the antioxidant capacity of the wheat fractions and their bioaccessible compounds, obtained from the TIM system. The TEAC assay determines the ability of antioxidants to scavenge ABTS radicals. This was performed as described by van den Berg et al. (20) with some modifications. Briefly, ABTS radicals were produced by incubating a solution of $0.23 \mathrm{mM}$ ABTS and $2.3 \mathrm{mM}$ ABAP in $100 \mathrm{mM}$ sodium phosphate buffer, $\mathrm{pH} 7.4$ at $70{ }^{\circ} \mathrm{C}$ for 10 minutes and cooled down in ice water. The absorption of the solution reached $0.7 \pm 0.02$ at $734 \mathrm{~nm}$. During the experiment, the ABTS - solution was stored in ice. A fresh solution was prepared each day. The bioaccessible compounds in the dialysate collected from TIM were added to the ABTS - solution and the reduction in absorbance was measured after 5 minutes. The TEAC of the bioaccessible compounds corresponds to the concentration of a trolox solution that causes an equal decrease in absorbance at $734 \mathrm{~nm}$. The antioxidant capacity of the bioaccessible compounds from the wheat fractions was expressed in absolute values, $\mu \mathrm{mol}$ Trolox Equivalents (TE), which was calculated by multiplying the concentration of TE by the total volume of dialysate collected from the model in that $1 \mathrm{~h}$ period. The cumulative antioxidant capacity of the bioaccessible compounds was calculated by the successive addition of the antioxidant capacity of each dialysate sample over time. The antioxidant assay was performed in duplicate. Results are expressed as mean and error (half the range between duplicates).

\section{Macrophage activation}

Human monocyte-like histiocytic lymphoma cells U937 obtained from the ATCC (CRL-1593.2, Manassas, VA, USA) were grown in RPMI-1640 medium, supplemented with $10 \%(\mathrm{v} / \mathrm{v})$ fetal calf serum and $2 \mathrm{mM} \mathrm{L}$-glutamine at $37^{\circ} \mathrm{C}, 5 \%$ 
$\mathrm{CO}_{2}$ in a humidified atmosphere (21). U937 monocytic cells were differentiated into macrophages using phorbol myristate acetate (PMA, $10 \mathrm{ng} / \mathrm{ml}$ overnight) as described previously (22). U937 macrophages were cultured at a concentration of 1 $x 10^{6}$ cell/well in 24-well cell culture plates. The PMA-differentiated macrophages were allowed to recover from PMA treatment for $48 \mathrm{~h}$, during which the culture medium was replaced daily. At the third day after PMA treatment, the macrophages were exposed to LPS $(E$. coli, $1 \mu \mathrm{g} / \mathrm{ml})$ for $4 \mathrm{~h}$ in the presence of dialysate containing the bioaccessible compounds or control. The tested dialysate was collected from the jejunal compartment of the TIM system in the time periods: $0-1,1-2,2-3$, and 3-4 h of gastrointestinal digestion of aleurone, bran, flour and starch. The dialysate $(5 \mathrm{ml})$ was lyophilized after collection. Before lyophilization, the $\mathrm{pH}$ of the dialysate $(7.0 \pm 0.1)$ was lowered with $\mathrm{HCl}$ to $\mathrm{pH} 1-2$ for a better stability. The lyophilized samples were reconstituted in sterile water $(0.5 \mathrm{ml})$ and $100 \mu \mathrm{l}$ of the reconstituted sample was added to $900 \mu \mathrm{l}$ of medium containing LPS. As control, $100 \mu \mathrm{l}$ of sterile water $0.1 \mathrm{~N} \mathrm{HCl}$ was used. The final $\mathrm{pH}$ of the medium with the sample or control was $7.0 \pm 0.4$. Cell viability, calculated as described below, was at least $85 \%$, with an average of $92 \pm 4 \%$. The cell experiment was repeated on three independent days.

\section{Immunoassay and enzyme activity measurements}

TNF-a levels were determined in the culture medium by Enzyme-Linked Immunosorbent Assay (ELISA), using a TNF-a ELISA kit (Biosource-Invitrogen, Etten-leur, The Netherlands). The immunoassay was performed according to the instructions of the manufacturer. The results are the mean of three independent experiments and expressed as 100\% related to control. Error is expressed as standard error of the mean (SEM).

The citotoxicity of the tested samples was determined by measuring the enzyme activity of lactate dehydrogenase (LDH). LDH activity was quantitatively determined using the in vitro assay for LDH activity from Roche Diagnostics (Mannheim Germany) with automated chemistry analyzer Hitachi 911 (Roche). The cell toxicity was calculated as \% LDH activity in culture medium related to the sum of LDH activity in lysed cells and medium. Cell viability was calculated by subtraction of the toxicity percentage from $100 \%$.

\section{Statistical analysis}

Mann-Whitney $U$ test was performed to determine significant differences of the mean between the control and the tested wheat fractions. The test was performed with a confidence interval of 95\%, with the SPSS 15.0 for windows software. 


\section{RESULTS}

The wheat fractions of aleurone, bran, flour and native starch (as blank) were digested in a dynamic and multi-compartmental in vitro gastrointestinal model, TIM. The dialysate was collected from the jejunal and ileal compartments in $1 \mathrm{~h}$ intervals for $6 \mathrm{~h}$. The dialysate contains the compounds that are available for intestinal absorption (referred to as the bioaccessible compounds from aleurone, bran and flour), which were investigated on their antioxidant and antiinflammatory capacities with native wheat starch as blank or control.

\section{Antioxidant capacity}

The TEAC values for the wheat fractions were (based on fresh weight): $81 \pm 1$ $\mu \mathrm{mol} \mathrm{TE} / \mathrm{g}$ for aleurone, $62 \pm 2 \mu \mathrm{mol} \mathrm{TE} / \mathrm{g}$ for the bran fraction, and $19 \pm 1 \mu \mathrm{mol}$ $\mathrm{TE} / \mathrm{g}$ for the flour fraction, when the antioxidant capacity was assessed in water extracts from acid hydrolysis (16). Starch did not show ABTS radical scavenging properties and was used as blank to account for the antioxidant capacity derived from the digestive juices used in the TIM system.

During the 6 hours of in vitro digestion, the highest TEAC was observed at the time interval 1-2 $\mathrm{h}$ for aleurone and flour, while bran showed a similarly high activity in the time interval 1-2 $\mathrm{h}$ than in 2-3 h (Figure 1). The bioaccessible compounds from aleurone showed the highest antioxidant capacity in comparison to bran and flour. The total increment in antioxidant capacity after 6 hours of digestion was $640 \mu \mathrm{mol}$ TE for aleurone, $500 \mu \mathrm{mol} \mathrm{TE}$ for bran and $410 \mu \mathrm{mol}$ TE for flour (Figure 2).

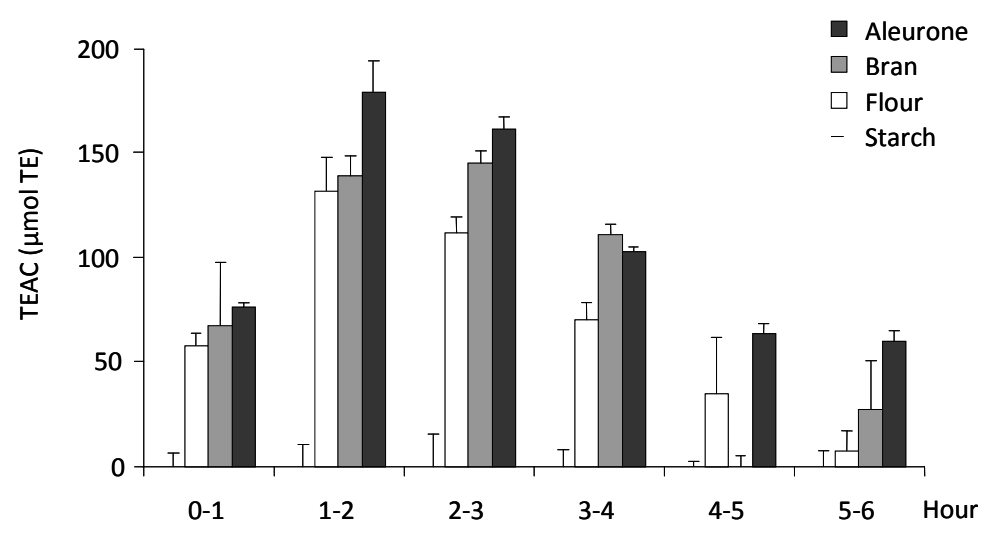

Figure 1. Antioxidant capacity ( $\mu \mathrm{mol} \mathrm{TE}$ ) of the bioaccessible compounds from aleurone, bran and flour, that were collected as dialysate every 1 hour for 6 hours of gastrointestinal digestion in the TIM system. Values are subtracted by starch (blank) and expressed as mean and error (half the range between duplicates). 
The cumulative antioxidant capacity was linearly increased over time during the first three hours (0-3 h time interval). In the next three hours of digestion (3-6 $\mathrm{h}$ time interval), the increment in antioxidant capacity by aleurone was of approximately $120 \mu \mathrm{mol} \mathrm{TE}$, while no further substantial increase was observed for bran and flour (Figure 2).

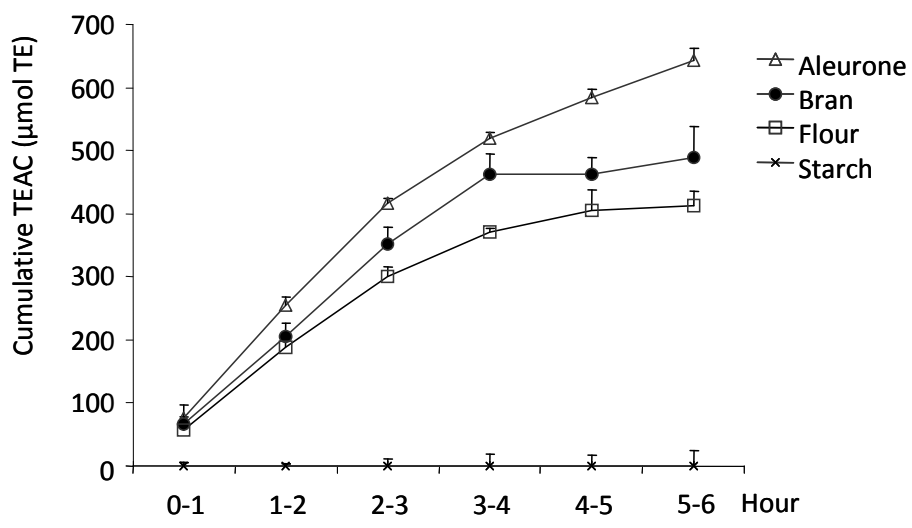

Figure 2. Cumulative antioxidant capacity ( $\mu \mathrm{mol} \mathrm{TE}$ ) of the bioaccessible compounds from aleurone, bran and flour after 6 hours of gastrointestinal digestion in the TIM system. Values are subtracted by starch (blank) and expressed as mean and error (half the range between duplicates)

The contribution of ferulic acid (FA) to the antioxidant capacity was calculated by multiplying of the amount of bioaccessible FA by the TEAC value of ferulic acid, i.e. 2.1 (15). The contribution was: $9.2 \mu \mathrm{mol}$ TE and 7.7 $\mu \mathrm{mol}$ TE for aleurone and bran respectively, and not quantifiable for flour. The contribution of FA to the total antioxidant capacity of the bioaccessible compounds from aleurone and bran represented less than $5 \%$.

\section{Anti-inflammatory capacity}

The anti-inflammatory capacity of the jejunal dialysate, containing the bioaccessible compounds from aleurone, bran, flour and starch, was quantified as the reduction in the LPS-induced production of TNF-a by cultured macrophages. TNF-a production was not affected by the bioaccessible compounds from starch $(p$ $>0.2)$, that was used as control for the secretions in the TIM system, such as gastric and pancreatic juice and bile (Figure 3).

The largest TNF-a reduction was observed for the dialysate collected at the time intervals $1-2 \mathrm{~h}$ and $2-3 \mathrm{~h}$ after the intake of the wheat fractions. The bioaccessible compounds from aleurone, bran and flour dialysed in those time- 
intervals reduced TNF-a production by $67-76 \%$. For the time interval of 3-4 h, only the bioaccessible compounds from aleurone significantly reduced TNF- $\alpha$ production $(p<0.05)$.

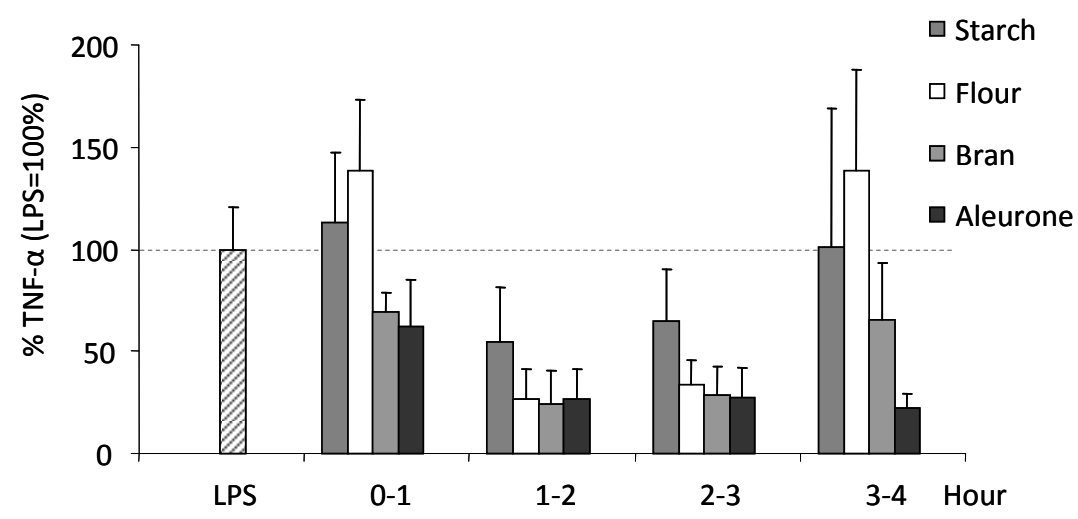

Figure 3. TNF-a production in LPS stimulated U937 macrophages when incubated with the dialysate containing the bioaccessible compounds from aleurone, bran, flour and starch. The dialysate was collected in $1 \mathrm{~h}$ intervals (0-1 h, 1-2 h, 2-3 h and 3-4 h) during gastrointestinal digestion in the TIM system. Results are in percentage related to the control (LPS $=100 \%$ ), values are the mean and SEM of three independent experiments

\section{DISCUSSION}

The aim of the present study was to investigate the antioxidant and antiinflammatory potential of different wheat fractions: aleurone (highest in antioxidant capacity), bran (intermediate), flour (lowest in antioxidant capacity), and starch (as blank or control, with no antioxidant capacity). They were digested during passage through a multi-compartmental in vitro model that simulates the upper gastrointestinal tract. Dialysate was collected from the jejunal and ileal compartments in $1 \mathrm{~h}$ intervals, representing the bioaccessible compounds from the digested wheat fractions, which are available for intestinal absorption.

It was found that the bioaccessible compounds from aleurone had a higher antioxidant capacity than those of bran and flour. The bioaccessible compounds from flour had the lowest antioxidant capacity. This rank-order was similar to that reported in a previous study in which the antioxidant capacity was measured in water extracts from acid hydrolysis of those wheat fractions (16).

Other studies have also shown the higher antioxidant capacity of bran extracts compared to flour extracts (23-26). An in vitro study by Nagah and Seal (27) has reported a higher antioxidant release (expressed as TEAC content) from wholegrain bread in comparison to white bread. In humans, the study by Price et al. (28) has shown that consumption of bran led to a significant postprandial increase in 
plasmatic antioxidant capacity compared to a refined product (white rice). In our study, besides investigating bran and flour, aleurone has been included, since it was the highest in antioxidant capacity (water extract), i.e. $81 \mu \mathrm{mol} \mathrm{TE} / \mathrm{g}$ (fresh weight). This is substantially higher than the calculated average of daily consumed breakfast cereals in US, i.e. $27 \mu \mathrm{mol} \mathrm{TE} / \mathrm{g}$ (fresh weight) (29). Moreover, aleurone led to the highest increase in total antioxidant capacity during in vitro gastrointestinal digestion: $640 \mu \mathrm{mol}$ TE from $23 \mathrm{~g}$ of aleurone (fresh weight). Miller et al. (29) estimated the total daily antioxidant intake to be around $1840 \mu \mathrm{mol} \mathrm{TE}$, from which $26 \%$ was attributed to the consumption of breakfast cereals and the rest to that of fruits and vegetables. From these numbers, it can be deduced that cereals contribute substantially to the daily antioxidant intake and therefore, the use of aleurone in cereal products could increase the daily antioxidant intake, as well as the intestinal uptake.

Bioaccessible compounds from aleurone, bran and flour also exerted antiinflammatory properties, as observed by the reduction in LPS-induced TNF- $\alpha$ production. Neyrinck et al. (30) also reported anti-inflammatory effects of bran on circulating IL-6 in mice. In that study, the higher aleurone content of the bran fraction was not related to a higher anti-inflammatory effect.

In our study, bioaccessible aleurone compounds of a relatively late time-interval (3-4 h after intake) also displayed a significant anti-inflammatory effect, while this was not observed for the bioaccessible fractions of bran and flour. Also with regard to the antioxidant capacity, aleurone showed a higher increment in total antioxidant capacity at late time-intervals (3-6 h after intake) than that of bran and flour. This indicates that aleurone may be the most suitable wheat fraction to provide a continuous release of antioxidant and anti-inflammatory compounds in the gastrointestinal tract.

Ferulic acid (FA) is the most abundant phenolic compound in wheat grain. The content of FA in different wheat fractions has been well correlated with: their scavenging activities against ABTS radical cation $(16,26)$ and superoxide anion (26), their total phenolic content (26), and their aleurone content (16). For this reason, FA has been suggested as a general marker for antioxidant compounds in wheat grain. Besides, FA has been reported to be the major contributor to the antioxidant capacity of aleurone (16). However, the bioaccessibility of FA during gastrointestinal digestion appeared to be less than 1-2\% (15). The results of the present study show again that FA was low among the bioaccessible compounds from aleurone and that the contribution of FA to the total antioxidant capacity was also low, less than $5 \%$. Reducing the particle size of the aleurone fraction, which was $>180 \mu \mathrm{m}$, could influence the bioaccessibility of FA and other antioxidant compounds. Other antioxidant compounds present in bran are: sinapic acid, $\rho$ coumaric acid, vanillic acid, and caffeic acid, syringic acid, and salycilic (31), they might contribute to the antioxidant capacity of the bioaccessible fraction.

Some studies have revised the anti-inflammatory properties of FA (32). For instance, in the study of Sakai et al. (33) FA significantly reduced TNF-a in LPS- 
stimulated murine macrophages at the concentration of $5 \mu \mathrm{M}$. However, the study of Ou et al. (34) did not find a significant TNF- $a$ decrease with FA at concentrations lower than $50 \mu \mathrm{M}$ in spleen cells. Also, in the study of Nagasaka et al. (35) FA did not significantly reduce NF- $\mathrm{kB}$ in LPS-estimulated murine macrophages at the concentration of $1 \mu \mathrm{M}$. The concentration of FA that was calculated to be present in the cell-based assay of our study was maximally $4 \mu \mathrm{M}$. This indicates that FA itself may not be enough to explain the full antioxidant and anti-inflammatory effect of aleurone. The contribution of FA was limited possibly due to its low bioaccessibility. The observed effects may rather be the result of synergism among diverse compounds, that despite being at low concentration still displayed a significant antioxidant and anti-inflammatory effect.

The use of selected wheat fractions for healthy products can enrich their phytochemical potential by increasing their content in bioactive compounds. However, the bioaccessibility of those compounds should be critically considered. From the findings of our study we can conclude that the bioaccessible compounds of aleurone had the highest and most prolonged antioxidant capacity and antiinflammatory effect in comparison to those from bran and flour. This means that aleurone is a promising wheat fraction for the development of cereal products with a healthy added value.

Acknowledgements: This research was financially supported by the European Commission in the Communities 6th Framework Programme, Project HEALTHGRAIN (FOOD-CT-2005514008). It reflects the author's views and the Community is not liable for any use that may be made of the information contained in this publication. 


\section{REFERENCES}

1. Esmaillzadeh A, Azadbakht L. Whole-grain intake, metabolic syndrome, and mortality in older adults. Am J Clin Nutr. 2006;83:1439-40; author reply 41-2.

2. Sahyoun NR, Jacques PF, Zhang XL, Juan W, McKeown NM. Whole-grain intake is inversely associated with the metabolic syndrome and mortality in older adults. Am J Clin Nutr. 2006;83:124-31.

3. Slavin J. Whole grains and human health. Nutr Res Rev. 2004;17:99-110.

4. Forstermann U. Oxidative stress in vascular disease: causes, defense mechanisms and potential therapies. Nat Clin Pract Cardiovasc Med. 2008;5:338-49.

5. Hansel B, Giral P, Nobecourt E, Chantepie S, Bruckert E, Chapman MJ, Kontush A. Metabolic syndrome is associated with elevated oxidative stress and dysfunctional dense high-density lipoprotein particles displaying impaired antioxidative activity. J Clin Endocrinol Metab. 2004;89:4963-71.

6. Van Guilder GP, Hoetzer GL, Greiner JJ, Stauffer BL, Desouza CA. Influence of metabolic syndrome on biomarkers of oxidative stress and inflammation in obese adults. Obesity (Silver Spring). 2006;14:2127-31.

7. Jensen MK, Koh-Banerjee P, Hu FB, Franz M, Sampson L, Gronbaek M, Rimm EB. Intakes of whole grains, bran, and germ and the risk of coronary heart disease in men. Am J Clin Nutr. 2004;80:1492-9.

8. Hemery $Y$, Lullien-Pellerin V, Rouau X, Barron C, Abecassis J, Samson M-F, Åman P, von Reding W, Spoerndli C, Barron C. Biochemical markers: efficient tools for the assessment of wheat grain tissue proportions in milling fractions. . J Cereal Sci. 2009;49:55-64.

9. Fath A, Bethke PC, Belligni MV, Spiegel YN, Jones RL. Signalling in the Cereal Aleurone: Hormones, Reactive Oxygen and Cell Death. New Phytol. 2001;151:99-107.

10. Hemery Y, Rouau X, Lullien-Pellerin V, Barron C, Abecassis J. Dry processes to develop wheat fractions and products with enhanced nutritional quality. J Cereal Sci. 2007;46:327-47.

11. Eklund-Jonsson C, Sandberg A-S, Hulthen L, Larsson-Alminger M. Tempe Fermentation of Whole Grain Barley Increased Human Iron Absorption and In vitro Iron Availability. The open journal nutrition. 2008;2:42-7.

12. Haraldsson A-K, Rimsten L, Alminger M, Andersson R, Åman P, Sandberg A-S. Digestion of barley malt porridges in a gastrointestinal model: Iron dialysability, iron uptake by Caco-2 cells and degradation of [beta]-glucan. J Cereal Sci. 2005;42:243-54.

13. Larsson M, Minekus M, Havenaar R. Estimation of the Bioavailability of Iron and Phosphorus in Cereals using a Dynamic In Vitro Gastrointestinal Model. J Sci Food Agric. 1997;74:99-106.

14. Verwei M, Freidig AP, Havenaar R, Groten JP. Predicted serum folate concentrations based on in vitro studies and kinetic modeling are consistent with measured folate concentrations in humans. J Nutr. 2006;136:3074-8.

15. Mateo Anson N, van den Berg R, Havenaar R, Bast A, Haenen GRMM. Bioavailability of ferulic acid is determined by its bioaccessibility. J Cereal Sci. 2009;49:296-300.

16. Mateo Anson N, van den Berg R, Havenaar R, Bast A, Haenen GR. Ferulic acid from aleurone determines the antioxidant potency of wheat grain (Triticum aestivum L.). J Agr Food Chem. 2008;56:5589-94.

17. Bohm A, Bogoni C, Behrens R, Otto T, inventors; Method for the extraction of aleurone from bran patent WO 02/157711 A2. 2002.

18. Bohm A, Kratzer A, inventors; Method for isolating aleurone particles. US patent 7431228. 2008. 
19. Minekus M, Marteau P, Havenaar R, Huis In 'T Veld JHJ. A multicompartmental dynamic computer-controlled model simulating the stomach and small intestine. ATLA. 1995;23:197-209.

20. van den Berg R, Haenen GRMM, van den Berg H, Bast A. Applicability of an improved Trolox equivalent antioxidant capacity (TEAC) assay for evaluation of antioxidant capacity measurements of mixtures. Food Chem. 1999;66:511-7.

21. Sundstrom C, Nilsson K. Establishment and characterization of a human histiocytic lymphoma cell line (U-937). Int J Cancer. 1976;17:565-77.

22. Verhoeckx KC, Bijlsma S, de Groene EM, Witkamp RF, van der Greef J, Rodenburg RJ. A combination of proteomics, principal component analysis and transcriptomics is a powerful tool for the identification of biomarkers for macrophage maturation in the U937 cell line. Proteomics. 2004;4:1014-28.

23. Adom KK, Sorrells ME, Liu RH. Phytochemicals and antioxidant activity of milled fractions of different wheat varieties. J Agr Food Chem. 2005;53:2297-306.

24. Kim K-H, Tsao R, Yang R, Cui SW. Phenolic acid profiles and antioxidant activities of wheat bran extracts and the effect of hydrolysis conditions. Food Chem. 2006;95:466-73.

25. Liyana-Pathirana C, Dexter J, Shahidi F. Antioxidant properties of wheat as affected by pearling. J Agr Food Chem. 2006;54:6177-84.

26. Zhou K, Laux JJ, Yu L. Comparison of Swiss red wheat grain and fractions for their antioxidant properties. J Agr Food Chem. 2004;52:1118-23.

27. Nagah AM, Seal CJ. In vitro procedure to predict apparent antioxidant release from wholegrain foods measured using three different analytical methods. J Sci Food Agr. 2005;85:1177-85.

28. Price RK, Welch RW, Lee-Manion AM, Bradbury I, Strain JJ. Total Phenolics and Antioxidant Potential in Plasma and Urine of Humans After Consumption of Wheat Bran. Cereal Chem. 2008;85:152-7.

29. Miller HE, Rigelhof F, Marquart L, Prakash A, Kanter M. Antioxidant content of whole grain breakfast cereals, fruits and vegetables. J Am Coll Nutr. 2000;19:312S-9S.

30. Neyrinck AM, De Backer F, Cani PD, Bindels LB, Stroobants A, Portetelle D, Delzenne NM. Immunomodulatory properties of two wheat bran fractions - aleurone-enriched and crude fractions - in obese mice fed a high fat diet. Int Immunopharmacol. 2008;8:1423-32.

31. Verma B, Hucl P, Chibbar RN. Phenolic acid composition and antioxidant capacity of acid and alkali hydrolysed wheat bran fractions. Food Chem. 2009;116:947-54.

32. Ou S, Kwok K-C. Ferulic acid: pharmaceutical functions, preparation and applications in foods. J Sci Food Agr. 2004;84:1261-9.

33. Sakai S, Ochiai H, Nakajima K, Terasawa K. Inhibitory effect of ferulic acid on macrophage inflammatory protein- 2 production in a murine macrophage cell line, RAW264.7. Cytokine. 1997;9:242-8.

34. Ou L, Kong LY, Zhang XM, Niwa M. Oxidation of ferulic acid by Momordica charantia peroxidase and related anti-inflammation activity changes. Biol Pharm Bull. 2003;26:1511-6.

35. Nagasaka R, Chotimarkorn C, Shafiqul IM, Hori M, Ozaki H, Ushio H. Antiinflammatory effects of hydroxycinnamic acid derivatives. Biochem Bioph Res Co. 2007;358:615-9. 




\begin{abstract}
Ferulic acid (FA) is the most abundant phenolic compound in wheat grain, mainly located in the bran. However, its bioaccessibility from the bran matrix is extremely low. Different bioprocessing techniques involving fermentation or enzymatic and fermentation treatments of wheat bran were developed aiming at improving the bioaccessibility of phenolic compounds in bran-containing breads. The bioaccessibility of ferulic acid, $p$-coumaric acid and sinapic acid was assessed with an in vitro model of upper gastrointestinal tract (TIM-1). Colonic metabolism of the phenolic compounds in the non-bioaccessible fraction of the breads was studied with an in vitro model of human colon (TIM-2). The most effective treatment was the combination of enzymes and fermentation that increased the bioaccessibility of FA from $1.1 \%$ to $5.5 \%$. The major colonic metabolites were: $3-(3-$ hydroxyphenyl)propionic acid and 3-phenylpropionic acid. Bran bioprocessing increases the bioaccessibility of phenolic compounds as well as the colonic end metabolite 3-phenylpropionic acid.
\end{abstract}




\section{INTRODUCTION}

Epidemiological studies have linked the consumption of whole grain with reduction of diet-related disorders such as cardiovascular disease, type 2 diabetes and some types of cancer (1). Part of the health effect derived from whole-grain foods could be attributed to the phenolic compounds in the bran. In the plant kingdom, phenolic compounds are essential molecules against oxidative damage, as they have UV-absorption properties and radical scavenging activities. Therefore, the majority of the phenolic compounds are located in the most external tissues of the plant (2). In wheat grain, most of the phenolic compounds are located in the bran, which constitutes the outer-most parts of the grain. Traditionally, the milling of the wheat grain aimed at removing the bran or outer layers of the grain to obtain the refined white flour. Nowadays, it is well known that the outer layers contain phytochemicals with potential bioactivities, suggesting the use of wheat grain as whole instead of refined (3).

One of the most abundant phenolic compounds in wheat grain, especially in wheat bran, is ferulic acid (FA), accounting for $90 \%$ of the total polyphenols in wheat grain (4). In the bran, FA is largely located as a structural component of the cell walls of aleurone and pericarp (3). Most of the FA is covalently bound to complex polysaccharides in the cell walls, mainly arabinoxylans (5). The potential health effect of FA has been partly attributed to its antioxidant properties (6). FA was also identified as the major contributor to the antioxidant capacity of aleurone, which is the fraction of highest antioxidant capacity in wheat grain (7). However, in order to evaluate its biological activity, the bioavailability of this compound should be firstly addressed.

Bioaccessibility, which is defined as the release of the compound from its natural matrix to be available for intestinal absorption, is the first limiting factor to the bioavailability (8). In a previous in vitro study, it was found that the bioaccessibility of FA from aleurone, bran and bread enriched with aleurone was extremely low $(<1 \%)(9)$. Combining these results with in vivo data from other studies, it was concluded that the bioavailability of FA from cereal products was limited by its bioaccessibility. In vivo, some esterase activity has been reported for epithelial cells of small intestine. However, the esterase activity in the luminal contents of large intestine was 10-fold higher than that of extracts from epithelial cells of small intestine (10). Moreover, when FA was administered as feruloyl arabinoxylans purified from bran, the major FA release took place in large intestine, while no significant FA release was detected during passage to ileum (11). Thus, release of FA and possibly other compounds bound to cell wall polysaccharides will mainly occur in the large intestine by bacterial esterases. In the large intestine, the free compounds may exert their activity locally or by bioconversion into colonic metabolites. Metabolism of FA to 3-(3hydroxyphenyl)propionic acid (3OHPPA) has been shown by ruminal microbiota 
(12) and recently by human microbiota (13), but colonic human bioconversion requires further verification.

The development of innovative processing techniques seems a promising approach to improve the bioaccessibility of health promoting compounds in cereal grains. In the current study, bioprocessing strategies to release bound phenolic compounds from wheat bran have been used; such as the use of enzymes targeting specific linkages in wheat bran or the use of fermentation systems as source of these enzymes. Five different wheat breads were prepared: white bread, wholemeal bread, whole-meal bread with native bran, whole-meal bread with fermented bran and whole-meal bread with fermented and enzymatic treated bran. Differences in the bioaccessibility of the major phenolic compounds in the breads were studied with the use of a computer-controlled model of the upper gastrointestinal tract (TIM-1 system). Additionally, the formation of colonic metabolites derived from these phenolic compounds was investigated. This was studied with the use of an in vitro model of large intestine (TIM-2 system), which is inoculated with complex microbiota of human origin in high density.

\section{MATERIAL AND METHODS}

\section{Chemicals}

Standards for the analysis of phenolic acids: sinapic acid was purchased from Fluka (Buchs, Switzerland), p-coumaric and ferulic acids from Extrasynthése (Genay, France). Standards for the analysis of phenolic metabolites: benzoic acid (BA), 3-hydroxybenzoic acid (3OHBA), 3-(4-hydroxyphenyl)propionic acid (4OHPA) and 3-(3,4-dihydroxyphenyl)propionic acid (3,4diOHPA) were products from Aldrich (Steinheim, Germany). 4-Hydroxybenzoic acid (4OHBA), 2-(3hydroxyphenyl)acetic acid (3OHAA) and 2-(3,4-dihydroxyphenyl)acetic acid (3,4diOHAA) were purchased from Sigma (St. Louis, USA), 3-phenylpropionic acid (3PA) and 3,4-dihydroxybenzoic acid (3,4diOHBA) were from Fluka (Buchs, Switzerland) and 3-(3-hydroxyphenyl)propionic acid (3OHPA) was purchased from Alfa Aesar (Karlsruhe, Germany), 2,2,2-Trifluoro-N-methyl-N-trimethylsilylacetamide (MSTFA) from Pierce (Rockford, USA) was used as the silylation reagent. Protease (P-5147), a-amylase (A-6211), pepsin (P-7012) and bile (porcine bile extract, P-8631) were purchased from Sigma (St. Louis, USA). Pancreatic juice from porcine pancreas (Pancreax V powder) was obtained from Paines \& Byrne (Greenford, United Kingdom). Rhizopus lipase (150,000 units/mg F-AP 15) was obtained from Amano Enzyme, Inc. (Nagoya, Japan).

All compounds are named by IUPAC nomenclature or the given abbreviation. All chemicals were of analytical grade. 


\section{Experimental breads}

The wheat flours used for the bread making were: white flour $(76 \%$ flour from peeled wheat grains, variety Tiger, harvest of year 2006) and whole-meal flour (100\% flour made of peeled (3.5\%) wheat grains). The bran fraction used for enrichment was commercial wheat bran from peeled grains. All flour and bran fractions were supplied by Bühler AG (Switzerland).

Five different breads were prepared: white bread (bread 1), whole-meal bread (bread 2), whole-meal bread with native bran (bread 3), whole-meal bread with fermented bran (bread 4) and whole-meal bread with fermented and enzymatic treated bran (bread 5).

The bran fermentation was performed by mixing $22 \%(\mathrm{w} / \mathrm{w})$ bran and $0.27 \%$ $(\mathrm{w} / \mathrm{w})$ Baker's Yeast (Finnish Yeast Ltd) with water. The fermentation mixture was kept at $20^{\circ} \mathrm{C}$ for $20 \mathrm{~h}$. The enzymatic treatment of bran was applied along with the yeast fermentation using an enzyme mixture of: $0.01 \%(w / w)$ Grindamyl A1000 (Danisco), 0.36\% (w/w) Depol 740L (Bioacatalysts) and 0.14\% (w/w) Veron CP (Rohm Gmbh). The enzyme mixture contained a variety of hydrolytic enzymes, mainly xylanase, $\beta$-glucanase, $\alpha$-amylase, cellulase and also ferulic acid esterase (Table 1). The activity profiles of the enzymes were determined using standard assay methods: $\beta$-glucanase as described by Bailey and Linko (14), xylanase as described by Bailey et al. (15), a-amylase using Megazyme Ceralpha method, cellulose as described by IUPAC (16) and ferulic acid esterase by spectrophotometric method (17).

Table 1. Enzymatic activities of the enzyme preparations used for bran bioprocessing.

\begin{tabular}{lccccc} 
Enzyme preparation & $\begin{array}{c}\text { Endoglucanase } \\
\text { (cellulase) }\end{array}$ & Xylanase & $\boldsymbol{\beta}$-Glucanase & $\boldsymbol{\alpha}$-Amylase & $\begin{array}{c}\text { Ferulic acid } \\
\text { esterase }\end{array}$ \\
\hline Veron CP & 91 & 200 & 435 & 1 & 0 \\
\hline Grindamyl A1000 & 0 & 0 & 0 & 12 & 0 \\
\hline${\text { Depol } 740 L^{a}}^{a}$ & 13 & 200 & 100 & ND $^{c}$ & 0.44
\end{tabular}

${ }^{a}$ Enzyme dosages calculated based on the xylanase activity; xylanase dosage per gram bran was 200 nkat.

${ }^{\mathrm{b}}$ Enzyme dosages calculated based on the $\alpha$-amylase activity; $\alpha$-amylase dosage for bran was $0.01 \%(w / w)$, i.e. $12 \mathrm{nkat} / \mathrm{g}$ bran. ${ }^{\mathrm{C}} \mathrm{ND}=$ not determined

For the dough preparation wheat flour, yeast and salt were mixed with water. The proportion of the ingredients in the mixture was: $1 \%$ yeast, $1 \%$ salt, and $98 \%$ white or whole meal flour. For the breads enriched with bran (bread 3, 4 and 5), 16\% of the mixture was bran and $82 \%$ whole meal flour. In the breads with bioprocessed bran (bread 4 and bread 5) also xylanase was used (0.05\%). The use of white flour (76 \% flour) provided a low amount of phenolic acids in the bread (bread 1). In the whole-meal bread (bread 2), the phenolic acid content is derived 
from the use of whole-meal flour (100\% flour) instead (Table 2). In the breads with bran (bread 3, 4 and 5), it has been estimated that approximately half of the total phenolic acid content in the bread can be attributed to the addition of bran.

All doughs were kneaded with spiral kneader (Diosna SP 12 F, Dierks \& Sohne, $\mathrm{GmbH}$, Osnabruck, Germany) for $2 \mathrm{~min}$ at a low speed (100 rpm), followed by 5 min at high speed $(200 \mathrm{rpm})$. After the intermediate proof $\left(45 \mathrm{~min}, 28{ }^{\circ} \mathrm{C}, 70 \%\right.$ relative humidity), the dough was divided into $400 \mathrm{~g}$ pieces, and moulded. The moulded dough pieces were proofed at $37^{\circ} \mathrm{C}$ with $70 \%$ relative humidity for 55 min. The loaves of $400 \mathrm{~g}$ were baked for $10 \mathrm{~min}$ at $220^{\circ} \mathrm{C}$ and $20 \mathrm{~min}$ at $200{ }^{\circ} \mathrm{C}$ (Rack Oven 9000, Sveba Dahlen AB, Sweden). Steam was added for $20 \mathrm{~s}$ during the initial baking phase.

The basic chemical composition of the breads was determined: protein content by Kjeldahl method, total dietary fiber (TDF) by Enzymatic-Gravimetric method (18), fat by Fat in Flour-Mojonnier method (19), arabinoxylans (20) and digestible starch (21). The moisture content of fresh breads was also measured (Table 2).

Table 2. Phenolic acid composition: ferulic acid (FA), $p$-coumaric acid (p-CA) and sinapic acid (SA), and chemical composition of the experimental breads. Results are the mean of triplicate determinations (relative standard deviation $<5 \%$ ).

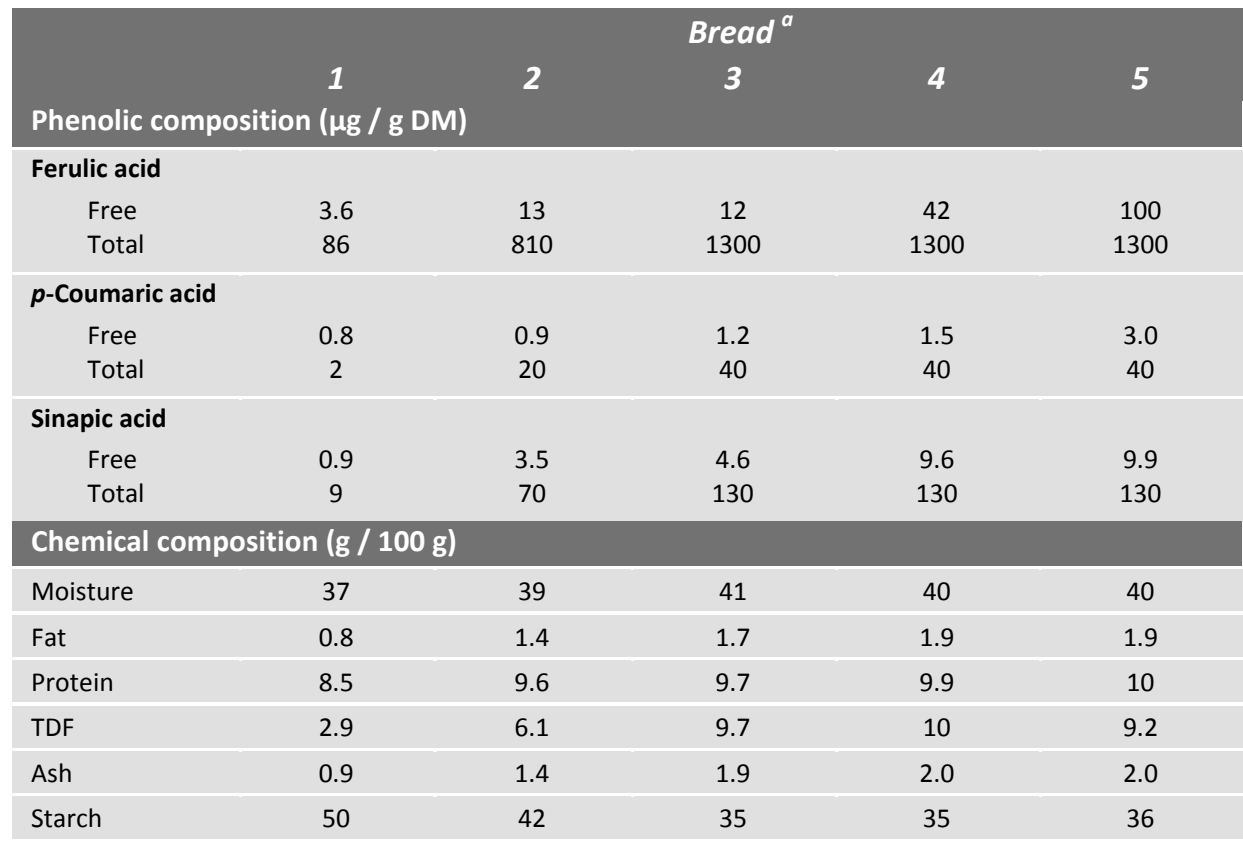

${ }^{a}$ White wheat bread (bread 1), whole-meal wheat bread (bread 2), whole-meal wheat bread with native wheat bran (bread 3), whole-meal wheat bread with fermented wheat bran (bread 4) and whole-meal wheat bread with fermented and enzymatic treated wheat bran (bread 5). 


\section{TIM-1 system}

The gastrointestinal model has been previously described in detail (22). The model comprises four compartments that represent the stomach, duodenum, jejunum and ileum (Figure 1). Secretion of digestive juices and $\mathrm{pH}$ adjustment in each section are simulated according to physiological data (22). The composition of the different digestive juices used in the model was previously described (23). All parameters are computer controlled and a protocol of medium transport time of food was chosen in the study to simulate a semi-solid meal. The half time of stomach emptying was $70 \mathrm{~min}$.
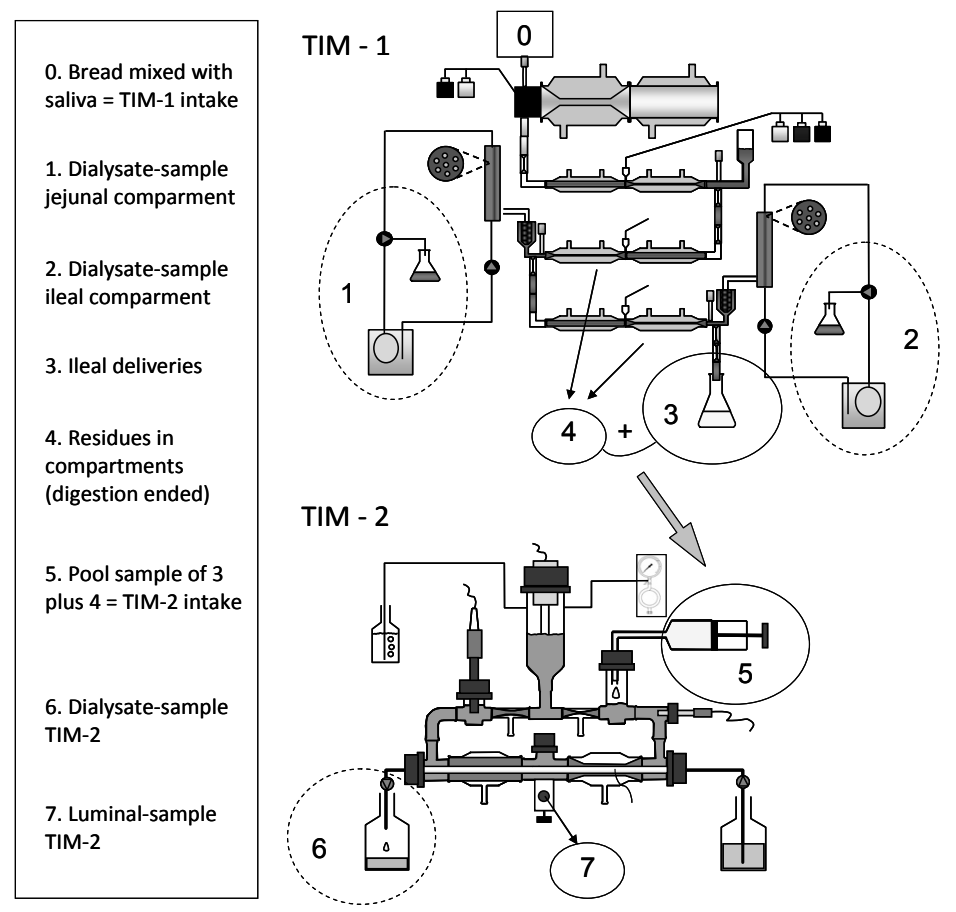

Figure 1. Schematic overview of the experimental setup of the in vitro model of upper gastrointestinal tract (TIM-1) and the in vitro model of human colon (TIM-2).

The jejunal and ileal compartments are connected with a semi-permeable hollow fiber membrane units of cellulose diacetate (DICEA-90 high performance dialysers, Baxter SA, US). This dialysis system removes the water and digested products. For the TIM-1 experiments, $35 \mathrm{~g}$ of freeze-dried bread was mixed with artificial saliva that contained 9600 units amylase, $30 \mathrm{ml}$ citrate buffer $(\mathrm{pH}=6)$ and $100 \mathrm{ml}$ electrolyte solution. Breads were freeze-dried in order to facilitate the posterior grinding. This procedure was chosen in order to obtain a standardized 
homogenous mixture of the bread with the artificial saliva. Milli-Q water was added to the mixture up to a final volume of $300 \mathrm{ml}$. This mixture (TIM-1 intake) was introduced in the gastric compartment representing the stomach and the digestion was started (Figure 1). The digestion took 6 hours, dialysate samples were collected in $2 \mathrm{~h}$ aliquotes, containing the released and dialyzed phenolic acids. This represents the bioaccessible fraction of the bread. The ileum deliveries, ileal material that exits the model over time, were also collected and pooled with the residues in the compartments by the end of the digestion experiment ( 3 and 4 in Figure 1). This represents the non-bioaccesible fraction of the breads in the upper gastrointestinal tract. This pooled sample was freeze-dried and subsequently reconstituted in water to a fixed volume and used as starting material for TIM-2 experiments (TIM-2 intake). All TIM experiments were performed in duplicate.

\section{TIM-2 system}

The colonic fermentation experiments were performed in a dynamic model of human large intestine (TIM-2) explained in detailed by Minekus et al. (24). The model was inoculated with a standardized pool of active microbiota from healthy volunteers (four men and five women; aged 21-35 years). They were non-smokers and had not used antibiotics, prebiotics or laxatives at least 3 months prior to the donation. The model and the preparation of the feacal inoculum were performed under strict anaerobic conditions. After the adaptation of the microorganisms to the standard medium for $16 \mathrm{~h}, 10 \mathrm{ml}$ of this medium was replaced by $10 \mathrm{ml}$ of the TIM-2 intake, mixture of the collected TIM-1 ileal deliveries and residues (Figure 1). During the first 6 hours of colonic fermentation, $50 \mathrm{ml}$ of TIM-2 intake was gradually added at a flow speed of $0.15 \mathrm{ml} / \mathrm{min}$. From 6 to $24 \mathrm{~h}$, the standard medium was gradually added at a flow speed of $0.045 \mathrm{ml} / \mathrm{min}$ as substrate for the microbiota. TIM-2 standardized medium was prepared according to the ileal delivery medium described by Gibson et al. (25) with modifications (g/L): 4.7 arabinogalactan, 4.7 pectin, 4.7 xylan, 4.7 amylopectin, 23.5 casein, 39.2 starch, 23.5 bactopeptone, 17 Tween 80, 0.4 bile (oxoid). After the 24 h experiment, a wash-out period of $20 \mathrm{~h}$ was performed by feeding standard medium before starting the duplicate TIM-2 experiment. Samples were collected from lumen and dialysis fluids as shown in the schematic design.

\section{Determination of phenolic acids in breads and TIM-1 samples}

The content of phenolic acids (ferulic acid, $p$-coumaric acid and sinapic acid) in the breads was determined as free and total phenolic acids as previously described by Bartolomé and Gómez-Cordovés (26). For the determination of the free phenolic acids, $50 \mathrm{mg}$ of freeze-dried bread were first thoroughly mixed with $2 \mathrm{ml}$ water and then the suspension was acidified with $\mathrm{HCl}$ to reach final $\mathrm{HCl}$ concentration of 
$0.35 \mathrm{M}(\mathrm{pH}<1.5)$. This mixture was extracted twice using ethyl acetate $(2 \times 5 \mathrm{ml})$. The extracts were pooled and evaporated to dryness. The residue was dissolved to $0.5 \mathrm{ml}$ of $50 \%$ methanol/water and filtrated through a $0.2 \mu \mathrm{m}$ filter before injection to HPLC. For the determination of total phenolic acids (free and esterified), the samples were hydrolyzed with $2 \mathrm{M} \mathrm{NaOH}$ for $16 \mathrm{~h}$ in absence of light and under $\mathrm{N}_{2}$ atmosphere before the extraction with ethylacetate $(2 \times 5 \mathrm{ml})$. The analytical quantification of the phenolic acids was performed by HPLC and diode array detector as described by Mattila et al. (27).

Table 3. Phenolic acids: total ferulic acid, total sinapic acid and total $p$-coumaric acid calculated in the starting material for the TIM-1 (TIM-1 intake) and TIM-2 (TIM-2 intake) experiments.

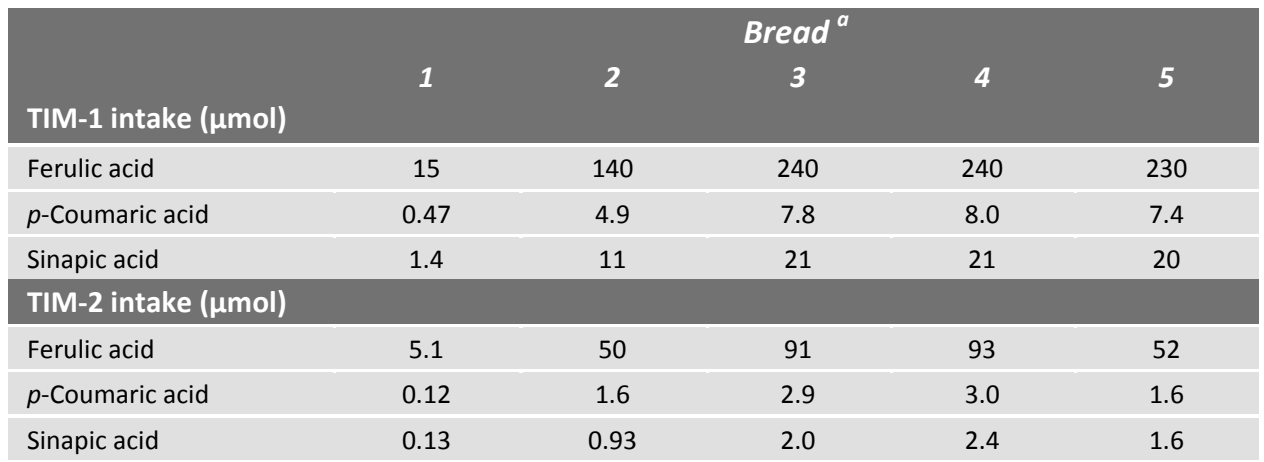

${ }^{a}$ White wheat bread (bread 1), whole-meal wheat bread (bread 2), whole-meal wheat bread with native wheat bran (bread 3), whole-meal wheat bread with fermented wheat bran (bread 4) and whole-meal wheat bread with fermented and enzymatic treated wheat bran (bread 5).

\section{Determination of phenolic metabolites in TIM-2 samples}

In luminal and dialysate samples from TIM-2, besides ferulic acid, $p$-coumaric acid and sinapic acid, the following phenolic metabolites were determined: 3phenylpropionic acid (3PPA), 3-(4-hydroxyphenyl)propionic acid (4OHPPA), 3-(3hydroxyphenyl)propionic acid (3OHPPA), 3-(3,4-dihydroxyphenyl)propionic acid (3,4diOHPPA), 2-(3,4-dihydroxyphenyl)acetic acid (3,4diOHPAA), 2-(3hydroxyphenyl)acetic acid (3OHPAA), benzoic acid (BA), 3-hydroxybenzoic acid (3OHBA), 4-hydroxybenzoic acid (4OHBA) and 3,4-dihydroxybenzoic acid (3,4diOHBA). Luminal and dialysate samples were acidified by addition of $\mathrm{HCl}$ to a final concentration of $0.35 \mathrm{M}(\mathrm{pH}<1.5)$ and the phenolic metabolites were extracted twice using ethylacetate $(2 \times 5 \mathrm{ml})$. Luminal samples were hydrolyzed with $2 \mathrm{M} \mathrm{NaOH}$ during $16 \mathrm{~h}$ as described above to determine the amount of total ferulic acid (free and esterified). Hydrolysis was stopped by addition of $\mathrm{HCl}$, final concentration of $2.8 \mathrm{M}(\mathrm{pH}<1.5)$. The extraction was performed twice with 
ethylacetate $(2 \times 5 \mathrm{ml})$. The extracts were evaporated to dryness under nitrogen, dissolved in $100 \mu \mathrm{l}$ dichloromethane and silylated with $30 \mu \mathrm{l}$ MSTFA (5 min, 50 $\left.{ }^{\circ} \mathrm{C}\right)$. The analytical determination was performed by GC-MS as described by Aura et al. (28).

\section{Calculations}

The bioaccessibility (\%) of ferulic acid, $p$-coumaric acid and sinapic acid were calculated as the sum of the free phenolic acid in the jejunal dialysates and ileal dialysates for the 6 hours of digestion, divided by the total content of phenolic acid (free and esterified) in the bread (TIM-1 intake) times 100.

The phenolic metabolites quantified in the TIM-2 samples are expressed as the sum of the free phenolic metabolite in the dialysate sample and in the luminal sample. They are expressed cumulative over the 24 hours of colonic fermentation.

\section{RESULTS}

The bioprocessing of wheat bran increased the content of free phenolic acids in the bran-containing breads, breads 4 and 5 compared to bread 3, which contained native bran (Table 2). In all breads, ferulic acid (FA) was the most abundant phenolic acid. The total content in FA (free and esterified) was approximately 10fold and 40-fold higher than that of total sinapic acid (SA) and total coumaric acid ( $p$-CA) respectively. Bran fermentation increased the amount of free FA in the bread by approximately 3 -fold. The combination of fermentation and enzymatic treatment of bran increased 8-fold the amount of free FA in the bread, from 12 to $100 \mathrm{\mu g} / \mathrm{g}$ dry matter (DM). These bioprocessing techniques also increased the free form of the other two major phenolic acids in the bread, $p$-CA and SA (Table 2).

To determine the bioaccessibility of the phenolic acids in the breads, each of the five experimental breads were digested in the TIM-1 system that simulates the upper gastrointestinal tract (Figure 1). The dialysate samples that were collected from the model contain the fraction of the compound that is released from the food matrix and consequently available for absorption. The bioaccessible amounts of FA, $p$-CA and SA are shown in Figure 2. Most of the bioaccessible phenolic acid was found in the dialysate-samples from the jejunal compartment and especially in the dialysate sample collected during the first $2 \mathrm{~h}$ interval (Figure 2). FA was the major phenolic acid in the bioaccessible fraction of the breads (Figure 2).

There was a large variation in the bioaccessibility of FA in the different breads (Figure 3). Combination of fermentation and enzymatic treatment increased the bioaccessibility of FA 5 -fold as compared to the bread with native bran, i.e. from $1.1 \%$ in bread 3 to $5.5 \%$ in bread 5 . A strong correlation was found between the bioaccessibility of FA and the percentage of free FA in the bread matrix, except for the white bread which was excluded (Figure 3). 

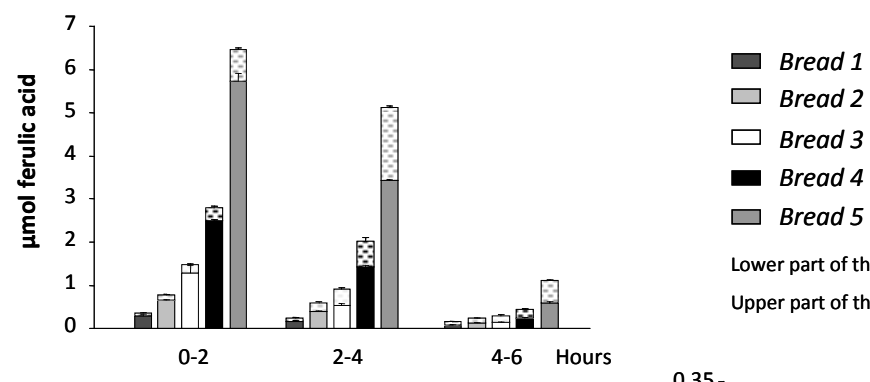

Lower part of the bars represents the jejunal dialysate.

Upper part of the bars represents the ileal dialysate.
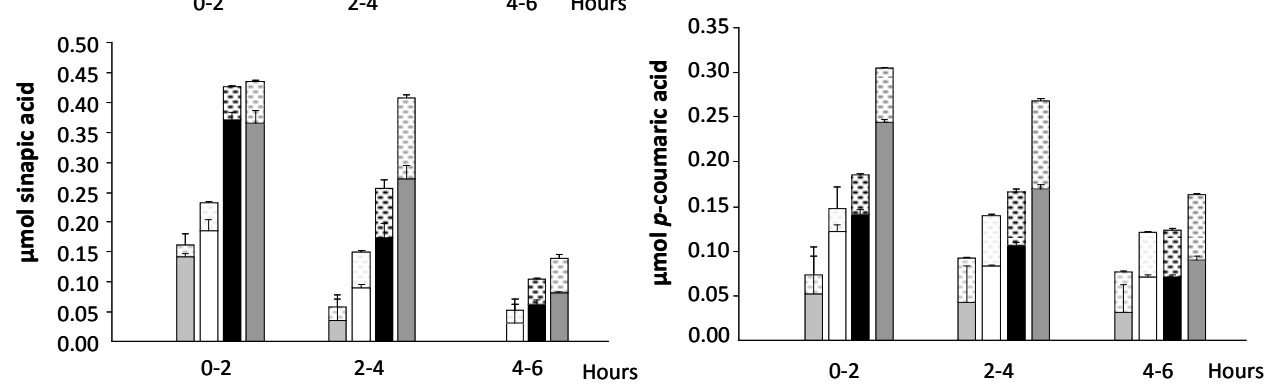

Figure 2. Phenolic acids: ferulic acid, $p$-coumaric acid, and sinapic acid in the bioaccessible fraction (TIM-1 dialysate-samples) of the different breads: white wheat bread (bread 1), whole-meal wheat bread (bread 2), whole-meal wheat bread with native wheat bran (bread 3), whole-meal wheat bread with fermented wheat bran (bread 4) and whole-meal wheat bread with fermented and enzymatic treated wheat bran (bread 5).

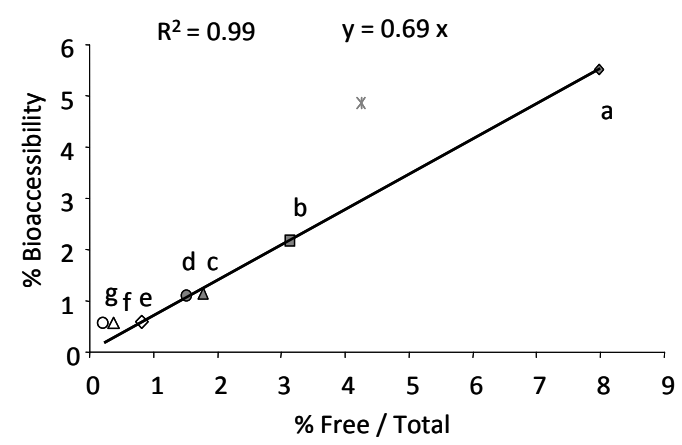

Bioaccessibility (\%)

\begin{tabular}{lll}
\hline $5.5 \%$ & $\diamond$ & 5 (a) \\
$2.2 \%$ & $\square$ & 4 (b) \\
$1.1 \%$ & $\Delta$ & 3 (c) \\
$1.1 \%$ & $\circ$ & 2 (d) \\
$0.57 \%$ & $\diamond$ & Bread with Aleurone (e) \\
$0.56 \%$ & $\Delta$ & Bran (f) \\
$0.55 \%$ & $\circ$ & Aleurone (g) \\
& & \\
$4.9 \%$ & $*$ & White bread
\end{tabular}

e,f and $g$ were taken from a previous study (9).

Figure 3. Correlation between the proportion of free ferulic acid in the breads and the bioaccessibility (\%). White wheat bread (bread 1), whole-meal wheat bread (bread 2), wholemeal wheat bread with native wheat bran (bread 3), whole-meal wheat bread with fermented wheat bran (bread 4) and whole-meal wheat bread with fermented and enzymatic treated wheat bran (bread 5). 
The bioaccessibility of $p$-CA and SA in the breads were also increased by the bioprocessing of bran, although the increase was smaller compared to FA. The bioaccessibility of $p$-CA and SA were increased by around 2-fold by the bioprocessing of bran: $p$-CA bioaccessibility was increased from $5.2 \%$ (bread 3) to 9.9\% (bread 5) and SA bioaccessibility was increased from $2.1 \%$ (bread 3) to $5.0 \%$ (bread 5). Similarly to FA, the increase in bioaccessibility of $p$-CA and SA could be related to the increase in the proportion of free phenolic acid in the bread.

Despite the increase in the bioaccessibility of FA, most of the FA in the breads was recovered in the ileal deliveries and residues in the TIM-1 model (Figure 1) after the digestion was completed. Most of this FA was not free (98-99\%). FA covalently bound to other structures was not bioaccessible from the breads during the simulation of upper-gastrointestinal transit. In order to study the colonic features on the non-bioaccessible fraction of the breads, the ileal deliveries and residues from the TIM-1 system were pooled and used as starting material for the TIM-2 system (TIM-2 intake) as described in the material and methods (Figure 1).

During the first 6 hours, the TIM-2 intake (Table 3) was gradually introduced in the TIM-2 model. This resulted in a gradual increase in the amount of total FA (free and esterified) present in the colonic model during the first 9 hours (Figure $4)$.

From the $9 \mathrm{~h}$ till the end $(24 \mathrm{~h})$, the amount of total FA gradually decreased. In Figure 4, the bars at the $24 \mathrm{~h}$ show the residual amount of total FA (free and esterified) that was not metabolized after the 24 hours of colonic fermentation. Most of this FA was bound, Table 4 shows the amount of FA that was free. The amount of free FA remained low for the entire colonic fermentation, while the total FA decreased, which indicates a rapid metabolism of free FA.

The main phenolic metabolites detected during the TIM-2 experiment were phenylpropionic acid derivatives, namely 3-phenylpropionic acid with different grades of hydroxylation. The metabolites 3-(3-hydroxyphenyl)propionic acid (3OHPPA) and 3-phenylpropionic acid (3PPA) were the highest in amount, while phenylacetic acid and benzoic acid derivatives were in much lower quantities $(<5$ $\mu$ mols) (Table 4). Regarding the time-course formation of the phenylpropionic metabolites: 3,4-dihydroxyphenylpropionic acid (3,4diOHPPA) increased over time until the $9 \mathrm{~h}$, and since then, it decreased (Figure 4), 3hydroxyphenylpropionic acid (3OHPPA) increased longer over time, namely until the $12 \mathrm{~h}$, since then it also decreased (Figure 4). The only metabolite that increased continuously over time for the entire $24 \mathrm{~h}$ experiment was 3-phenylpropionic acid (3PPA) (Figure 4). This time-course of phenolic metabolite formation was similar for all the tested wheat breads. In the breads containing bioprocessed bran, either by fermentation or the combination of enzymatic and fermentation treatment, 3PPA formation was enhanced compared to the bread containing native bran and the other breads. 

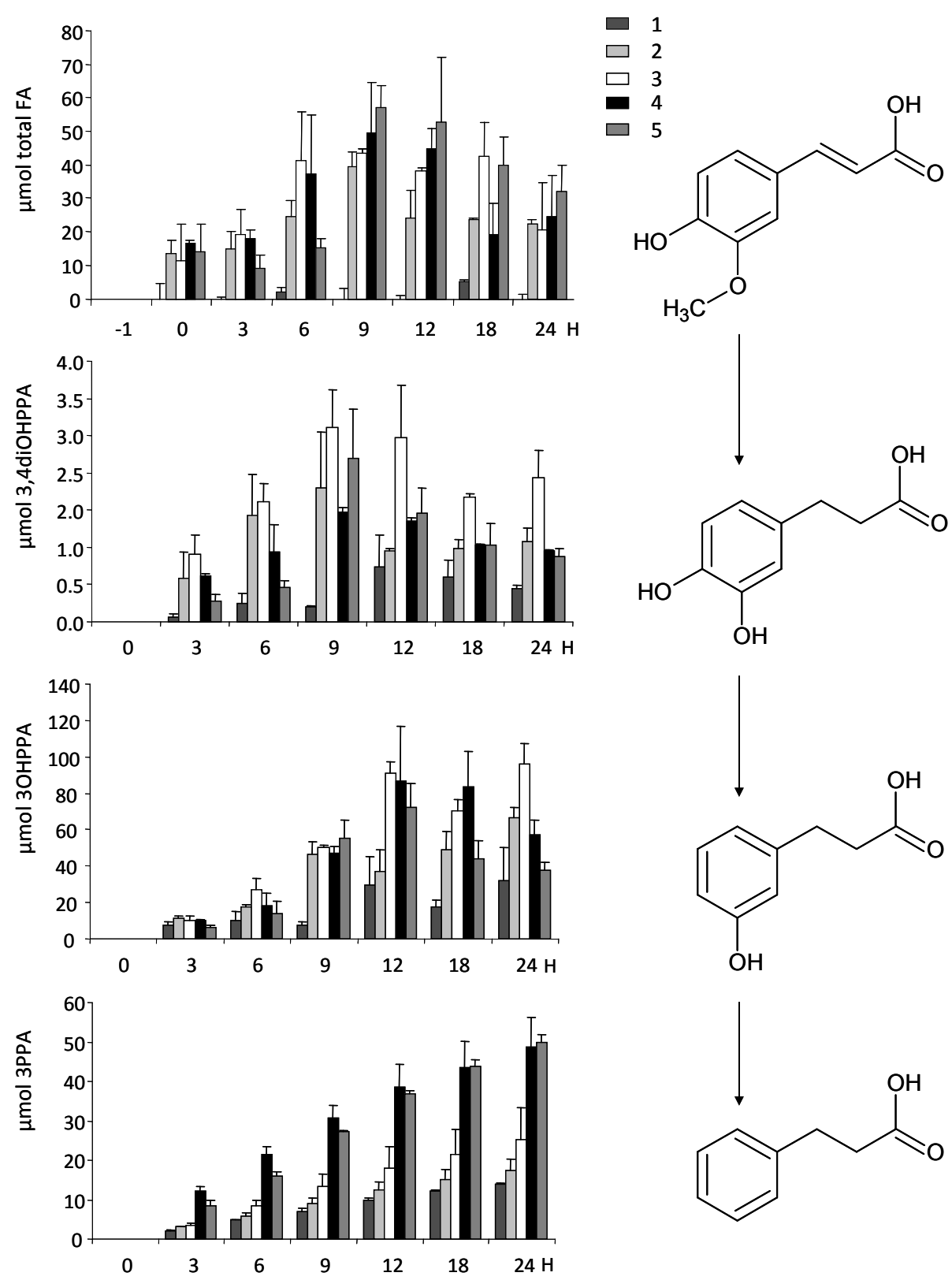

Figure 4. Total ferulic acid (FA) and major identified colonic metabolites: 3,4dihydroxyphenylpropionic acid (3,4diOHPPA), 3-hydroxyphenylpropionic acid (3OHPPA) and 3-phenylpropionic acid (3PPA). The proposed sequence of reactions, based on the results and chemical structures, is also given. White wheat bread (bread 1), whole-meal wheat bread (bread 2), whole-meal wheat bread with native wheat bran (bread 3), wholemeal wheat bread with fermented wheat bran (bread 4) and whole-meal wheat bread with fermented and enzymatic treated wheat bran (bread 5). 
Table 4. Phenolic metabolites determined in samples from the colonic experiment (TIM-2). Results are the cumulative amount in $\mu \mathrm{mol}$ at the end of the experiment (24h), they are expressed as mean \pm half of the range between duplicates.

\begin{tabular}{|lccccc} 
& \multicolumn{5}{c}{ Bread $^{a}$} \\
Cumulative $(\mu \mathrm{mol})$ & $\mathbf{1}$ & $\mathbf{2}$ & $\mathbf{3}$ & 4 & 5 \\
\hline Benzoic acid & $4 \pm 2$ & $2 \pm 0.9$ & $5 \pm 2$ & $3 \pm 0.6$ & $1 \pm 2$ \\
\hline 3OHBA & $0.5 \pm 0.02$ & $0.4 \pm 0.1$ & $0.7 \pm 0.3$ & $0.4 \pm 0.02$ & $0.3 \pm 0.1$ \\
\hline 4OHBA & $0.07 \pm 0.01$ & $0.07 \pm 0.02$ & $0.08 \pm 0.01$ & $0.02 \pm 0.01$ & $0.01 \pm 0.02$ \\
\hline 3,4diOHBA & $0.5 \pm 0.06$ & $0.2 \pm 0.01$ & $0.5 \pm 0.01$ & $0.5 \pm 0.2$ & $0.2 \pm 0.1$ \\
\hline 3OHPAA & $0.1 \pm 0.08$ & $0.1 \pm 0.03$ & $0.1 \pm 0.03$ & $0.4 \pm 0.01$ & $0.2 \pm 0.2$ \\
\hline 3,4diOHPAA & $0.3 \pm 0.09$ & $0.6 \pm 0.08$ & $0.6 \pm 0.03$ & $0.5 \pm 0.05$ & $0.5 \pm 0.1$ \\
\hline 3PPA & $10 \pm 0.07$ & $20 \pm 3$ & $20 \pm 8$ & $50 \pm 7$ & $50 \pm 2$ \\
\hline 3OHPPA & $30 \pm 20$ & $70 \pm 6$ & $100 \pm 10$ & $60 \pm 8$ & $40 \pm 4$ \\
\hline 4OHPPA & $5 \pm 0.2$ & $9 \pm 0.1$ & $8 \pm 0.5$ & $3 \pm 0.3$ & $2 \pm 0.2$ \\
\hline 3,4diOHPPA & $0.4 \pm 0.04$ & $1 \pm 0.2$ & $2 \pm 0.4$ & $0.9 \pm 0.01$ & $0.9 \pm 0.1$ \\
\hline Ferulic acid & $3 \pm 0.6$ & $0.6 \pm 0.7$ & $3 \pm 2$ & $2 \pm 0.7$ & $2 \pm 0.5$ \\
\hline$p$-Coumaric acid & $1 \pm 0.3$ & $0.6 \pm 0.2$ & $1 \pm 0.4$ & $0.6 \pm 0.1$ & $0.9 \pm 0.03$ \\
\hline Sinapic acid & $4 \pm 3$ & $2 \pm 0.5$ & $5 \pm 3$ & $2 \pm 0.2$ & $1 \pm 1$
\end{tabular}

${ }^{a}$ White wheat bread (bread 1), whole-meal wheat bread (bread 2), whole-meal wheat bread with native wheat bran (bread 3), whole-meal wheat bread with fermented wheat bran (bread 4) and whole-meal wheat bread with fermented and enzymatic treated wheat bran (bread 5).

3OHBA: 3-hydroxybenzoic acid. 4OHBA: 4-hydroxybenzoic acid. 3,4diOHBA: 3,4dihydroxybenzoic acid. 3OHPAA: 2-(3-hydroxyphenyl)acetic acid. 3,4diOHPAA: 2-(3,4-dihydroxyphenyl)acetic acid.

3PPA: 3-phenylpropionic acid. 3OHPPA: 3-(3-hydroxyphenyl)propionic acid.

4OHPPA: 3-(4-hydroxyphenyl)propionic acid. 3,4diOHPPA: 3-(3,4-dihydroxyphenyl)propionic acid.

\section{DISCUSSION}

Ferulic acid (FA) is considered the most abundant phenolic compound in wheat grain, however, its bioavailability from the natural cereal matrix is rather low. In a previous study, it was shown that the bioavailability of FA is determined by its low bioaccessibility, which could be assessed in vitro (9). A low bioaccessibility means that most of the FA is not released from the food matrix during gastrointestinal transit and consequently, will not be available for intestinal absorption. The objective of the current study was to investigate whether bioprocessing techniques, such as fermentation and enzymatic treatments could enhance the bioaccessibility of FA from wheat bran. FA, besides being the major phenolic compound in wheat grain, was also found to be the most abundant phenolic compound in the bioaccessible fraction of the wheat breads.

Bioprocessing of wheat bran by fermentation or by the combined action of hydrolytic enzymes and fermentation promoted the release of phenolic acids and increased their free fraction in the wheat breads. Bioprocessing significantly increased the bioaccessibility of the phenolic acids. The most effective bioprocessing technique was the combination of fermentation and enzymatic 
treatment of wheat bran, that increased FA bioaccessibility by 5 -fold compared to native bran.

The enzyme preparations used for the treatment of wheat bran had various cellwall-degrading activities, mainly xylanase, cellulase and $\beta$-glucanase (Table 1). The combined action of these enzymes enables the hydrolysis of different wheat polymers, thus improving the solubility and breaking down of the complex cellwall structures in the bran. One of the enzyme preparations used in our study (Depol 740L) also contained ferulic acid esterase activity (Table 1), which is able to cleave the ester-bound FA of the cell-wall polymers in wheat. It has been reported that ferulic acid esterase can release FA more efficiently in combined action with cell-wall-degrading enzymes, especially with xylanases $(26,29)$. Besides free FA, feruloyl oligosaccharides may have some biological activity (30).

Despite the substantial increase in the bioaccessibility of phenolic compounds achieved by the bioprocessing, the major part of the phenolic acids remained in the non-bioaccessible fraction that will enter the colon. In the colon, fermentation of the cell-wall structures by the action of bacterial enzymes is expected to facilitate the release of phenolic acids that were not accessible in small intestine.

In the colonic model (TIM-2 system) used in our study, total FA (free and esterified) was decreased over the time (9-24 h) (Figure 4), while no substantial increase in free FA was detected (Table 4). Instead, other colonic metabolites were identified, mainly phenylpropionic acids with different grades of hydroxylation, namely 3-(3-hydroxyphenyl)propionic acid (3OHPPA) and 3-phenylpropionic acid (3PPA). This indicates that FA is being rapidly metabolized upon release. Based on the pattern of appearance in time and the structures of these phenolic metabolites, the sequence of reaction has been proposed as indicated in Figure 4. These metabolic reactions involving FA demethylation and dehydroxylation have been also described in other studies $(12,13,31)$. Monohydroxylated phenylpropionic acids have also been identified as colonic metabolites of proanthocyanidins (32), hydroxycinnamates $(33,34)$, flavanones and flavanols $(34)$. Also diferulic acids and other phenolic compounds contained in the breads are likely to be metabolized to phenylpropionic acids. This is the first study that identifies 3OHPPA and 3PPA as the major metabolites of the human colonic metabolism expected after consumption of whole-wheat bread. Hydroxylated phenylacetic acids are mainly colonic metabolites of quercetin and isorhamnetin (31,35), and benzoic acid derivatives have been proposed as result of $\beta$-oxidations of phenylpropionic acids $(31,33)$ or ring-fission of anthocyanins (36). In the present study, 3PPA was identified as the end product of the colonic metabolism of ferulic acid, since this was the only metabolite increasing continuously over time during the entire experiment. The breads with bioprocessed bran led to the highest formation of 3PPA. In the bioprocessed bran, the cell-wall polymers binding the phenolic compounds were already partially degraded by the bran fermentation and enzymatic treatments. Consequently, the colonic enzymes might have displayed a higher activity to the partially hydrolyzed material via an increase in solubility of 
the substrate and the accessibility of the enzymes to the substrate. As a consequence, release and metabolism of phenolic acids in colon was more pronounced.

Future investigations addressing the biological activities of these colonic metabolites are still needed. So far, the recent study of Russell et al. (13) has shown that some of the colonic metabolites derived from FA, like 3,4diOHPPA and 3OHPPA, could reduce prostanoid production in cells, indicating possible antiinflammatory properties.

From the findings in our study we can conclude that: (i) bioprocessing of wheat bran can significantly improve the bioaccessibility of phenolic acids in whole meal breads in intestine and moreover (ii) bioprocessing can also enhance the colonic release and conversion of phenolic acids into their metabolites. Among all the phenolic compounds in the daily diet, phenolic acids have been estimated to be the predominant group, in Finnish adults they were $75 \%$ of the total phenolic intake. The main foods contributing to the intake of phenolic acids were coffee and bread (37). Therefore, increasing the bioaccessibility of phenolic compounds from a daily consumed food such as bread can have an important impact on the uptake of phenolic compounds, their circulating metabolites and possible health benefits.

Acknowledgment: We thank Annika Majanen and Airi Hyrkäs for skillfull technical assistance and Tuulikki Seppänen-Laakso. We also thank Mark Jelier and Annet Maathuis for their technical assistance with the TIM models. The work presented in this paper has been awarded in the 2nd Edition of the Exxentia International Award. This research was financially supported by the European Commission in the Communities 6th Framework Programme, Project HEALTHGRAIN (FOOD-CT-2005-514008). It reflects the author's views and the Community is not liable for any use that may be made of the information contained in this publication. 


\section{REFERENCES}

1. Slavin J. Whole grains and human health. Nutr Res Rev. 2004;17:99-110.

2. Liu L, Gitz I, McClure J. Effects of UV-B on flavonoids, ferulic acid, growth and photosynthesis in barley primary leaves. Physiol Plantarum. 1995;93:725-33.

3. Hemery Y, Rouau X, Lullien-Pellerin V, Barron C, Abecassis J. Dry processes to develop wheat fractions and products with enhanced nutritional quality. J Cereal Sci. 2007;46:327-47.

4. Manach C, Scalbert A, Morand C, Remesy C, Jimenez L. Polyphenols: food sources and bioavailability. Am J Clin Nutr. 2004;79:727-47.

5. Bunzel M, Ralph J, Marita JM, Hatfield RD, Steinhart H. Diferulates as structural components in soluble and insoluble cereal dietary fibre. J Sci Food Agr. 2001;81:65360.

6. Srinivasan M, Sudheer AR, Menon VP. Ferulic Acid: therapeutic potential through its antioxidant property. J Clin Biochem Nutr. 2007;40:92-100.

7. Mateo Anson N, van den Berg R, Havenaar R, Bast A, Haenen GR. Ferulic acid from aleurone determines the antioxidant potency of wheat grain (Triticum aestivum L.). J Agr Food Chem. 2008;56:5589-94.

8. Stahl W, van den Berg H, Arthur J, Bast A, Dainty J, Faulks RM, Gartner C, Haenen G, Hollman P, Holst B, Kelly FJ, Polidori MC, Rice-Evans C, Southon S, van Vliet T, VinaRibes J, Williamson G, Astley SB. Bioavailability and metabolism. Mol Aspects Med. 2002;23:39-100.

9. Mateo Anson N, van den Berg R, Havenaar R, Bast A, Haenen GRMM. Bioavailability of ferulic acid is determined by its bioaccessibility. J Cereal Sci. 2009;49:296-300.

10. Andreasen MF, Kroon PA, Williamson G, Garcia-Conesa MT. Esterase activity able to hydrolyze dietary antioxidant hydroxycinnamates is distributed along the intestine of mammals. J Agr Food Chem. 2001;49:5679-84.

11. Zhao Z, Egashira Y, Sanada H. Digestion and absorption of ferulic acid sugar esters in rat gastrointestinal tract. J Agr Food Chem. 2003;51:5534-9.

12. Chesson A, Provan GJ, Russell WR, Scobbie L, Richardson AJ, Stewart C. Hydroxycinnamic acids in the digestive tract of livestock and humans. J Sci Food Agr. 1999;79:373-8.

13. Russell WR, Scobbie L, Chesson A, Richardson AJ, Stewart CS, Duncan SH, Drew JE, Duthie GG. Anti-inflammatory implications of the microbial transformation of dietary phenolic compounds. Nutr Cancer. 2008;60:636-42.

14. Bailey MJ, Linko M. Production of $\beta$-galactosidase by A. oryzae in submerged bioreactor cultivation. J Biotechnol. 1990;16:57-66.

15. Bailey MJ, Biely P, Poutanen K. Interlaboratory testing of methods for assay of xylanase activity. J Biotechnol. 1992;23:257-70.

16. Measurement of cellulase activities. IUPAC (International Union of Pure and Applied Chemistry) Pure Appl Chem. 1987;59:257-68.

17. Forssell PK, H.; Schols, H. A.; Hinz, S.; Eijsink, V. G. H.; Treimo, J.; Robertson, J. A.; Waldron, K. W.; Faulds, C. B.; Buchert, J. . Hydrolysis of brewer's spent grain by carbohydrate degrading enzymes J Inst Brew 2008;114 306-14.

18. Total dietary fiber. AOAC official methods of analysis. 1990;no. 985.29.

19. Fat in flour. AOAC official methods of analysis. 2000;no. 922.06.

20. Douglas SG. A rapid method for the determination of pentosans in wheat flour. Food Chem. 1981;7:139-45. 
21. McCleary BV, Solah V, Gibson TS. Quantitative Measurement of Total Starch in Cereal Flours and Products. J Cereal Sci. 1994;20:51-8.

22. Minekus M, Marteau P, Havenaar R, Huis In 'T Veld JHJ. A multicompartmental dynamic computer-controlled model simulating the stomach and small intestine. ATLA. 1995;23:197-209.

23. Larsson M, Minekus M, Havenaar R. Estimation of the Bioavailability of Iron and Phosphorus in Cereals using a Dynamic In Vitro Gastrointestinal Model. J Sci Food Agric. 1997;74:99-106.

24. Minekus M, Smeets-Peeters M, Bernalier A, Marol-Bonnin S, Havenaar R, Marteau P, Alric M, Fonty G, Huis in't Veld JHJ. A computer-controlled system to simulate conditions of the large intestine with peristaltic mixing, water absorption and absorption of fermentation products. Appl Microbiol Biot. 1999;53:108-14.

25. Gibson GR, Cummings JH, Macfarlane GT. Use of a three-stage continuous culture system to study the effect of mucin on dissimilatory sulfate reduction and methanogenesis by mixed populations of human gut bacteria. Appl Environ Microbiol. 1988;54:2750-5.

26. Bartolomé B, Gómez-Cordovés C. Barley spent grain: release of hydroxycinnamic acids (ferulic and $p$-coumaric acids) by commercial enzyme preparations. J Sci Food Agr. 1999;79:435-9.

27. Mattila P, Pihlava JM, Hellstrom J. Contents of phenolic acids, alkyl- and alkenylresorcinols, and avenanthramides in commercial grain products. J Agr Food Chem. 2005;53:8290-5.

28. Aura A-M, Mattila I, Seppänen-Laakso T, Miettinen J, Oksman-Caldentey K-M, Oresic M. Microbial metabolism of catechin stereoisomers by human faecal microbiota: Comparison of targeted analysis and a non-targeted metabolomics method. Phytochem Lett. 2008;1:18-22.

29. Vardakou M, Katapodis P, Topakas E, Kekos D, Macris BJ, Christakopoulos P. Synergy between enzymes involved in the degradation of insoluble wheat flour arabinoxylan. Innov Food Sci Emerg Technol. 2004;5:107-12.

30. Glei M, Hofmann T, Kuster K, Hollmann J, Lindhauer MG, Pool-Zobel BL. Both wheat (Triticum aestivum) bran arabinoxylans and gut flora-mediated fermentation products protect human colon cells from genotoxic activities of 4-hydroxynonenal and hydrogen peroxide. J Agr Food Chem. 2006;54:2088-95.

31. Rechner AR, Kuhnle G, Bremner P, Hubbard GP, Moore KP, Rice-Evans CA. The metabolic fate of dietary polyphenols in humans. Free Radical Biol Med. 2002;33:22035.

32. Deprez S, Brezillon C, Rabot S, Philippe C, Mila I, Lapierre C, Scalbert A. Polymeric proanthocyanidins are catabolized by human colonic microflora into low-molecularweight phenolic acids. J Nutr. 2000;130:2733-8.

33. Gonthier MP, Remesy C, Scalbert A, Cheynier V, Souquet JM, Poutanen K, Aura AM. Microbial metabolism of caffeic acid and its esters chlorogenic and caftaric acids by human faecal microbiota in vitro. Biomed Pharmacother. 2006;60:536-40.

34. Rechner AR, Smith MA, Kuhnle G, Gibson GR, Debnam ES, Srai SK, Moore KP, RiceEvans CA. Colonic metabolism of dietary polyphenols: influence of structure on microbial fermentation products. Free Radical Biol Med. 2004;36:212-25.

35. Aura AM, O'Leary KA, Williamson G, Ojala M, Bailey M, Puupponen-Pimia R, Nuutila AM, Oksman-Caldentey KM, Poutanen K. Quercetin derivatives are deconjugated and converted to hydroxyphenylacetic acids but not methylated by human fecal flora in vitro. J Agr Food Chem. 2002;50:1725-30. 
36. Aura AM, Martin-Lopez P, O'Leary KA, Williamson G, Oksman-Caldentey KM, Poutanen K, Santos-Buelga C. In vitro metabolism of anthocyanins by human gut microflora. Eur J Nutr. 2005;44:133-42.

37. Ovaskainen ML, Torronen R, Koponen JM, Sinkko H, Hellstrom J, Reinivuo H, Mattila P. Dietary intake and major food sources of polyphenols in Finnish adults. J Nutr. 2008;138:562-6. 



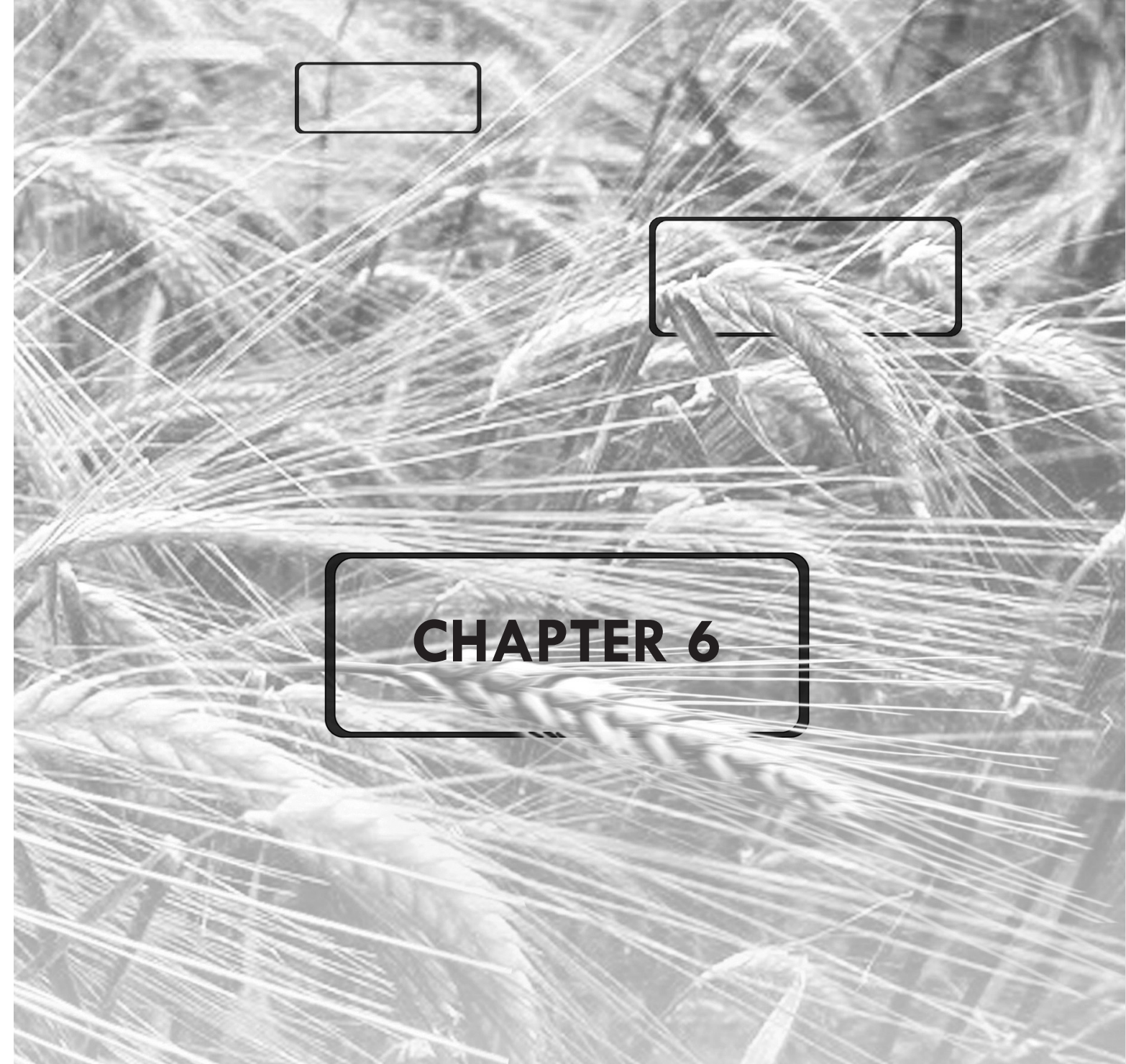

Bioprocessed wheat bran in whole-meal breads increases colonic butyrate production

Nuria Mateo Anson, Robert Havenaar, Koen Venema, Aalt Bast, and Guido R.M.M. Haenen

Food Chemistry, submitted 


\begin{abstract}
The health benefits of whole-grain consumption could be attributed to the inclusion of the bran (outer layers of the grain), which is a good source of dietary fibre. Fibre is fermented in the colon leading to the production of beneficial metabolites such as short-chain fatty acids (SCFA). In the present study, the effect of the addition of wheat bran or bioprocessed wheat bran to whole-meal breads on the formation of SCFA was investigated with an in vitro model of human colon. Butyrate production appeared to be higher in whole-meal breads with bioprocessed bran than in the whole-meal bread with native bran, the whole-meal bread and the white bread. The increase in butyrate seemed in exchange of propionate, while the total SCFA production remained similar. The increase in butyrate was associated with an increase in the solubility of the fibre in bran, as a result of the bioprocessing.
\end{abstract}




\section{INTRODUCTION}

Whole-grain consumption has been associated with a reduced risk for type-2 diabetes (1), cardiovascular disease (2), and some types of cancer: colonic cancer (3, 4), pancreatic cancer (5), and small intestinal cancer (6). The health benefits of whole grains versus refined grains could be attributed to the inclusion of the outer layers of the grain, the bran. It is in the bran, where most of the micronutrients, phytochemicals, and fibre of the grain are located (7).

Fibre intake is reported to decrease intestinal transit time and increase stool bulk, reduce levels of total and/or LDL cholesterol in blood, and reduce concentrations of post-prandial blood glucose and insulin (8). The health benefits of fibre are linked to the formation of metabolic end products by the colon microbiota, such as the short-chain fatty acids (SCFA). SCFA formation is beneficial for the microbiota that colonize the large intestine to obtain energy for maintenance and multiplication, and for the host to maintain $\mathrm{pH}$ and deliver energy to the colonic cells (9). Particularly butyrate is the preferred source of energy for the colonocytes and has been reported to have antiproliferative activities and to modulate gene expression and immunogenicity (10).

The metabolic effects of fibre depend on the physico-chemical properties, the degree of polymerization, the arabinose/xylose ratio, the distribution of side chains, the degree of cross-linking, and the extent of digestion in the small intestine (11). The fibre in wheat bran is mainly composed of the cell wall polysaccharides: arabinoxylan $(\sim 64 \%)$, cellulose $(\sim 29 \%)$, and non cellulosic glucan $(\sim 6 \%)(12)$. The structure of these polysaccharides is cross-linked by small phenolic acids, such as ferulic acid, the most abundant one, and $p$-coumaric acid. A high degree of crosslinking increases the molecular size of the polysaccharide and reduces its solubility (13).

It has been shown that processing can increase the bioavailability of nutrients and other compounds through chemical or enzymatic reactions that hydrolyze or release them from the food matrix $(14,15)$. Similarly, some types of processing may result in structural modifications of the fibre affecting the fermentation properties in the colon. The present study shows the effects of the addition of bran or bioprocessed bran (by fermentation or by enzymatic treatment combined with fermentation) to whole-meal breads on the formation of main metabolic products in an in vitro model of human colon.

\section{MATERIALS AND METHODS}

\section{Chemicals}

Acetic acid, propionic acid, iso-valeric acid, L-lactic acid and D-lactic acid were obtained from Sigma-Aldrich (The Netherlands). Butyric acid, iso-butyric acid, and 
2-ethyl butyric acid were obtained from Fluka AG (Zwiterland). All chemicals were of analytical grade.

\section{Experimental breads}

The wheat flours used for making the test breads were: white wheat flour $(76 \%$ flour from peeled wheat grains, variety Tiger; harvested in 2006) and whole-meal flour ( $100 \%$ flour made from peeled wheat grains, $3.5 \%$ off). The bran fraction used for enrichment of the test breads was commercial wheat bran from peeled grains. All flour and bran fractions were supplied by Bühler AG (Switzerland). Five different breads were tested: white bread (bread 1), whole-meal bread (bread 2), whole-meal bread with native bran (bread 3), whole-meal bread with fermented bran (bread 4), and whole-meal bread with fermented and enzymatic treated bran (bread 5). The elaboration process of the breads has been previously described (14) and their chemical composition is given in Table $\mathbf{1 .}$

Table 1. Chemical composition $(\mathrm{g} / 100 \mathrm{~g})$ of the different breads

\begin{tabular}{|lcccccc|}
\hline \multicolumn{2}{l}{$\begin{array}{c}\text { Chemical composition (g/ } \mathbf{1 0 0 g} \text { ) } \\
\text { Moisture }\end{array}$} & Fat & Protein & TDF & Ash & Starch \\
\hline Bread 1 & 37 & 0.8 & 8.5 & 2.9 & 0.9 & 50 \\
\hline Bread 2 & 39 & 1.4 & 9.6 & 6.1 & 1.4 & 42 \\
\hline Bread 3 & 41 & 1.7 & 9.7 & 9.7 & 1.9 & 35 \\
\hline Bread 4 & 40 & 1.9 & 9.9 & 10 & 2.0 & 35 \\
\hline Bread 5 & 40 & 1.9 & 10 & 9.2 & 2.0 & 36 \\
\hline
\end{tabular}

White bread (bread 1); whole-meal bread (bread 2); whole-meal bread with native bran (bread 3); wholemeal bread with fermented bran (bread 4); whole-meal bread with fermented and enzymatic treated bran (bread 5).

The bran fermentation was performed by mixing $22 \%(\mathrm{w} / \mathrm{w})$ bran and $0.27 \%$ $(\mathrm{w} / \mathrm{w})$ Baker's Yeast (Finnish Yeast, Ltd) with water. The fermentation mixture was kept at $20^{\circ} \mathrm{C}$ for $20 \mathrm{~h}$. The enzymatic treatment of the bran was applied along with the yeast fermentation using an enzyme mixture of: $0.01 \%(w / w)$ Grindamyl A1000 (Danisco), 0.36\% (w/w) Depol 740L (Biocatalysts), and 0.14\% (w/w) Veron $\mathrm{CP}$ (Rohm Gmbh). The enzyme mixture contained a variety of hydrolytic enzymes, mainly consisting of xylanase, $\beta$-glucanase, a-amylase, cellulase, and ferulic acid esterase, which has been previously described in detail (14). 


\section{Determination of pentosans}

The determination of pentosans in the bran was performed in the native bran and after the bioprocessing of the bran by the spectrophotometric method as described by Douglas(16). The coefficient of variation was less than $10 \%$.

\section{TIM-1 system}

The test breads were first digested in vitro in a dynamic model of the upper gastro-intestinal tract (TIM-1 system). This multi-compartmental model has been previously described in detail (17). Secretion of digestive juices, as previously described (18), and $\mathrm{pH}$ adjustment in the stomach and intestinal compartment were simulated according to physiological data. The jejunal and ileal compartments are connected with a semi-permeable hollow fiber cellulose diacetate membrane (DICEA-90 high performance dialysers, Baxter SA, US). This dialysis system removes the water and digested products coming from the digestion of the test bread.

For the TIM-1 experiments, $35 \mathrm{~g}$ of freeze-dried bread was mixed with $100 \mathrm{~g}$ artificial saliva that contained 9600 units of amylase, $30 \mathrm{~g}$ citrate buffer $(\mathrm{pH}=6)$ and $100 \mathrm{~g}$ electrolyte solution. Milli-Q water was added to the mixture up to a final weight of $295 \mathrm{~g}$. This mixture was introduced in the stomach compartment, containing $5 \mathrm{~g}$ of gastric juice at $\mathrm{pH} 1.8$, and the digestion process was immediately started. During 6 hours of digestion, the ileum effluent, i.e. the material that exits the ileum compartment of the model over time, was collected on ice and pooled with the residue in the ileum compartment at the end of the $6 \mathrm{~h}$ period. This pooled material represents the fraction of the bread that was not digested in the upper gastrointestinal tract, which is referred to as the non-digested fraction of the bread. It was freeze-dried and subsequently reconstituted with water to a fixed amount $(210 \mathrm{~g})$ and used as intake material for the following TIM-2 experiments. All TIM-1 experiments were performed in duplicate.

\section{TIM-2 system}

The colonic fermentation was performed in the dynamic model of human colon TIM-2, which has been previously described in detail $(19,20)$. The standardised colonic medium for TIM-2 was prepared according to the ileal delivery medium described by Gibson et al. (21) with modifications, containing (g/L): 4.7 arabinogalactan, 4.7 pectin, 4.7 xylan, 4.7 amylopectin, 23.5 casein, 39.2 starch, 23.5 bactopeptone, 17 Tween 80 , and 0.4 desiccated bile (Oxoid). The compartments of the model were inoculated with metabolic active intestinal microbiota (pooled stools), freshly collected from healthy volunteers (four men and five women, aged 21-35 years). The donors were non-smokers and had not used antibiotics, prebiotics, probiotics or laxatives for at least 3 months prior to the donation. The 
preparation of the feacal inoculum and the inoculation of the TIM-2 system were performed under strict anaerobic conditions. During an adaptation period of $16 \mathrm{~h}$, the microorganisms were fed with the standardised colonic medium, gradually introduced into the colonic compartment $(0.045 \mathrm{ml} / \mathrm{min})$. At the start of the experiment, $10 \mathrm{ml}$ of the content in the colonic compartment was replaced by $10 \mathrm{ml}$ of the TIM-2 intake material (non-digested fraction of the bread collected from TIM-1). The rest of it $(60 \mathrm{ml})$ was gradually added to the colonic compartment $(0.15$ $\mathrm{ml} / \mathrm{min}$ ) for approximately 6 hours to simulate the in vivo passage of the ileum content to the colon via the ileo-caecal valve. After that and until the end of the experiment (period from 6 to $24 \mathrm{~h}$ ), the colonic medium was gradually added $(0.045 \mathrm{ml} / \mathrm{min})$ as substrate for the microbiota. Samples were collected from lumen and dialysate at regular time intervals and immediately frozen in liquid $\mathrm{N}_{2}$ and stored at $-80^{\circ} \mathrm{C}$ for analyses. After the $24 \mathrm{~h}$ experiment, a wash-out period of $20 \mathrm{~h}$ was performed by feeding the colonic medium to the microbiota before starting the next TIM-2 experiment.

\section{Determination of monosaccharides}

The non-digested fraction of the breads (ileal effluent and residue collected from TIM-1) were hydrolysed for $1 \mathrm{~h}$ in $2 \mathrm{M} \mathrm{H}_{2} \mathrm{SO}_{4}$ in a water bath at $100{ }^{\circ} \mathrm{C}$. Glucose, galactose, arabinose, xylose, rhamnose, and fructose were determined with high performance anion exchange chromatography (Dionex Corporation, Sunnyvale, CA) with pulsed amperometric detection (PAD-II, Dionex) as described elsewhere (22). Rhamnose and fructose were below the quantification limit $(<0.2$ $\mu \mathrm{g} / \mathrm{ml})$. Uronic acid was not expected in whole-meal flour (23). The coefficient of variation of the analysis was less than $5 \%$.

\section{Determination of fermentation metabolites}

Acetate, propionate, butyrate, valerate, iso-valerate, and iso-butyrate were analysed in lumen and dialysate samples collected from TIM-2. Samples were centrifuged (12000 rpm for $5 \mathrm{~min}$ ) and $50 \mu \mathrm{l}$ of supernatant was added to $650 \mu \mathrm{l}$ of a mixture of formic acid (20\%), methanol and 2-ethyl butyric acid (internal standard, $2 \mathrm{mg} / \mathrm{ml}$ in methanol) at a ratio of 1:4.5:1. A $0.5 \mu \mathrm{l}$ sample was injected on the GC-column (Stabilwax-DA, length $15 \mathrm{~m}$, ID $0.53 \mathrm{~mm}$, film thickness $0.1 \mu \mathrm{m}$; Resteck, Bad Homburg, Germany) in a Chrompack CP 9001 gas chromatograph using automatic liquid sampler. The column was heated up at $2{ }^{\circ} \mathrm{C} / \mathrm{min}$ from 125 ${ }^{\circ} \mathrm{C}$ to $140{ }^{\circ} \mathrm{C}$ according to the method described by Jouany (24). Peaks were detected with a flame ionisation detector and integrated using MAITRE software (Varian).

L-lactate and D-lactate were determined in the supernatants of lumen and dialysate samples by an enzymatic assay (based on Boehringer, UV-method, Cat. No. 1112821) with a Cobas Mira plus autoanalyser (Roche). Ammonia was also 
quantified in the supernatants of lumen and dialysate samples by enzymatic spectrophotometric determination with the Cobas Mira Plus autoanalyser using $\mathrm{NH}_{4} \mathrm{Cl}$ as standard.

The results were calculated by the sum of total $\mathrm{mmol}$ in lumen and dialysates cumulatively over time. Differences between duplicate experiments were less than $15 \%$ for all breads for the $24 \mathrm{~h}$ period, except for bread 3, which was less than $20 \%$ during the period between $6 \mathrm{~h}$ and $24 \mathrm{~h}$.

\section{RESULTS}

\section{Pentosans and monosaccharides}

Both bioprocessing techniques, fermentation and enzymatic treatment combined with fermentation, increased the content in soluble pentosan of the bran from $0.5 \%$ to $1 \%$ (based on dry bran) in the fermented bran, and to $2 \%$ by fermentation together with enzymatic treatment. The total pentosan content in bran was $16-22 \%$.

After digestion of the test breads in TIM-1, the content in glucose, galactose, arabinose and xylose was quantified in the non-digested fraction. The total monosaccharide content of the non-digested fraction of the breads was: $1.8 \mathrm{~g}, 2.2 \mathrm{~g}$, $2.8 \mathrm{~g}, 2.7 \mathrm{~g}$, and $2.3 \mathrm{~g}$, respectively for the breads 1 to 5 . There were some differences in the monosaccharide composition of the non-digested fraction of the breads: the non-digested fraction of white bread (bread 1) contained $80 \%$ glucose of the total monosaccharides quantified, whereas that of whole-meal bread (bread 2) contained $65 \%$ glucose, and that of the whole-meal breads with added bran (bread 3,4 and 5) contained approximately $60 \%$. In contrast, the non-digested fraction of the whole-meal breads was the highest in relative content of arabinose and xylose $(35-38 \%)$, while the white bread was the lowest $(15 \%)$.

\section{Fermentation metabolites}

The cumulative production of the several fermentation metabolites, after $6 \mathrm{~h}$ and after $24 \mathrm{~h}$ of colonic fermentation, are shown in Table 2. No substantial differences were observed among the breads in the total production of SCFA (Table 3), neither for the first $6 \mathrm{~h}$, nor for the following $18 \mathrm{~h}$ (Table 2). The SCFA production rate during the feeding of the non-digested fraction of the test bread (0$6 \mathrm{~h})$ was $4.0-4.8 \mathrm{mmol} / \mathrm{h}$. This was higher than the production rate during the period from 6 to $24 \mathrm{~h}$ of the experiment, which was $2.7-3.2 \mathrm{mmol} / \mathrm{h}$.

There were no remarkable differences in the acetate production among the breads (Table 2). For propionate, the whole-meal bread with native bran (bread 3) led to the highest propionate formation, $8.2 \mathrm{mmol}(6 \mathrm{~h})$ and $23 \mathrm{mmol}(24 \mathrm{~h})$, while the whole-meal breads with bioprocessed bran (bread 4 and 5) produced lower 
amounts of propionate, 4.7-5.5 mmol $(6 \mathrm{~h})$ and 17-18 $\mathrm{mmol}(24 \mathrm{~h})$. The whole-meal breads with bioprocessed bran, either by fermentation (bread 4) or enzymatic treatment together with fermentation (bread 5), induced the highest butyrate formation, 5.3-5.9 mmol $(6 \mathrm{~h})$ and $13-15 \mathrm{mmol}(24 \mathrm{~h})$. This was especially observed for the first $6 \mathrm{~h}$, the period that corresponded with the administration of the nondigested fraction of the breads in the TIM-2 system and the highest SCFA production rate. In the first three hours of colonic fermentation, the butyrate production was twice as high for the whole-meal breads with treated bran (4.3-4.9 $\mathrm{mmol}$ ) as for the other breads (2.0-2.2 mmol) (Figure 1). Valerate was found in relatively low amounts compared to the other short-chain fatty acids (Table 2).

Table 2 Production of acetate (C2), propionate (C3), butyrate (C4), iso-butyrate (i-C4), valerate (C5), iso-valerate (i-C5), L-lactate (L-la), D-lactate (D-la) and ammonia $\left(\mathrm{NH}_{4}{ }^{+}\right)$in mmol after $6 \mathrm{~h}$ and $24 \mathrm{~h}$ of colonic fermentation in TIM-2. The total production of shortchain fatty acids (total SCFA) is the sum of acetate, propionate, butyrate, and valerate.

\section{Cumulative in $6 \mathrm{~h}$}

\begin{tabular}{|lccccccccccc} 
& C2 & C3 & C4 & i-C4 & C5 & i-C5 & L-La & D-La & NH $_{4}^{+}$ & $\begin{array}{l}\text { Total } \\
\text { SCFA }\end{array}$ \\
\hline Bread 1 & 12 & 7.0 & 3.9 & 0.18 & 0.50 & 0.28 & 0.44 & 0.83 & 7.8 & 24 \\
\hline Bread 2 & 11 & 7.1 & 4.2 & 0.21 & 0.80 & 0.31 & 0.17 & 0.18 & 9.1 & 23 \\
\hline Bread 3 & 12 & 8.2 & 3.8 & 0.22 & 0.96 & 0.35 & 0.48 & 0.29 & 8.5 & 25 \\
\hline Bread 4 & 14 & 5.5 & 5.9 & 0.48 & 1.3 & 0.72 & NA & NA & 14 & 27 \\
\hline Bread 5 & 12 & 4.7 & 5.3 & 0.40 & 1.2 & 0.63 & NA & NA & 12 & 23 \\
\hline
\end{tabular}

Cumulative in $24 \mathrm{~h}$

\begin{tabular}{|lccccccccccc|} 
& C2 & C3 & C4 & i-C4 & C5 & i-C5 & L-La & D-La & NH $_{4}^{+}$ & $\begin{array}{l}\text { Total } \\
\text { SCFA }\end{array}$ \\
\hline Bread 1 & 38 & 13 & 13 & 0.45 & 1.7 & 0.76 & 0.54 & 1.7 & 26 & 65 \\
\hline Bread 2 & 27 & 16 & 13 & 0.55 & 2.4 & 0.92 & 0.19 & 0.04 & 27 & 59 \\
\hline Bread 3 & 35 & 23 & 11 & 0.67 & 2.8 & 1.0 & 0.45 & 0.40 & 29 & 72 \\
\hline Bread 4 & 41 & 17 & 15 & 1.4 & 3.4 & 2.1 & 0.06 & NA & 35 & 76 \\
\hline Bread 5 & 33 & 18 & 13 & 1.2 & 3.7 & 1.7 & NA & NA & 28 & 67 \\
\hline
\end{tabular}

White bread (bread 1); whole-meal bread (bread 2); whole-meal bread with native bran (bread 3); whole-meal bread with fermented bran (bread 4); whole-meal bread with fermented and enzymatic treated bran (bread 5). NA: non applicable (below initial value).

The white bread showed the highest total lactate production, L- and D- form, $1.3 \mathrm{mmol}(6 \mathrm{~h})$ and $2.2 \mathrm{mmol}(24 \mathrm{~h})$. Ammonia and the branched short-chain fatty acids, iso-butyrate and iso-valerate, tended to be higher in the whole-meal breads with bioprocessed bran than in the other breads (Table 2). 


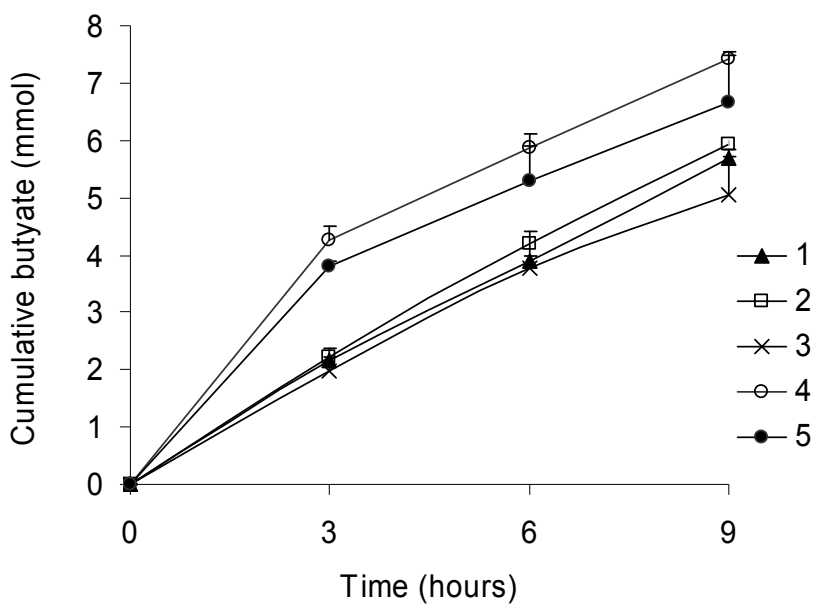

Figure 1. Cumulative production of butyrate (mmol; mean \pm range; $n=2$ ) in the in vitro system simulating the human colon, TIM-2, for the first 9 hours of colonic fermentation of the non-digested fraction of white bread (1), whole-meal bread (2), whole-meal bread with bran (3), whole-meal bread with fermented bran (4), and whole-meal bread with fermented and enzyme treated bran (5).

\section{DISCUSSION}

The current study was aimed at evaluating the effect of adding native wheat bran or bioprocessed wheat bran to whole-meal breads on the production of microbial metabolites in the colon in comparison to whole-meal bread and white bread.

It is generally accepted that a higher intake of fibre leads to a higher production of SCFA, since fibre is quantitatively the main substrate for colonic SCFA formation. However, SCFA concentrations remain remarkably constant in men despite dietary changes, while the excretion of SCFA differs in function of the feacal volume (25). In our experiments, there were no remarkable differences in the total production of SCFA among the different breads. This may be explained by the rather similar amount of total carbohydrate input (1.8-2.8 g). Although the breads were previously digested in a dynamic in vitro model of the stomach and small intestine (TIM-1), some of the carbohydrates appeared to be not completely digested and removed. For white bread, the carbohydrate input from the nondigested fraction, used for the colonic fermentation in TIM-2, was $1.8 \mathrm{~g}$. This represents approximately $6 \%$ of the starch content of the bread. Also in vivo it has been estimated that $5-10 \%$ of the starch from wheat flour escapes the digestion in the upper-gastrointestinal tract and reaches the colon in humans (26). 
Despite the rather similar input of total carbohydrate in TIM-2, the relative proportion of monosaccharides was different among the non-digested fractions of the breads. Particularly, the relative proportion of the pentoses arabinose and xylose was higher in the whole-meal breads with bran. This can be explained by the higher content in arabinoxylans of bran (30\% arabinose and xylose, based on dry weight) compared to the starchy endosperm ( $2 \%$ arabinose and xylose) that is mainly composed of glucose units (60-65\%) (27).

Dietary changes may influence the molar ratio of individual short-chain fatty acid production. The percentage of acetate varied among all breads from 50 to 55\% in the $6 \mathrm{~h}$ of feeding of the non-digested fraction of the breads to the colonic microbiota. Propionate ranged from 22 to $34 \%$ and butyrate from 16 to $25 \%$ (Table $3)$. The overall SCFA ratios found in the present study are within the physiological molar proportion in human colon, i.e. 57:22:21 (28).

Table 3. Relative molar proportion of the production of acetate $(\mathrm{C} 2)$, propionate $(\mathrm{C} 3)$ and butyrate (C4) in relation to their sum $(\mathrm{C} 2+\mathrm{C} 3+\mathrm{C} 4)$ after $6 \mathrm{~h}$ and $24 \mathrm{~h}$ of colonic fermentation in TIM-2.

Ratio C2:C3:C4

\begin{tabular}{|lcc|}
\hline & $6 \mathbf{h}$ & $24 \mathrm{~h}$ \\
\hline Bread 1 & $53: 30: 17$ & $59: 20: 21$ \\
\hline Bread 2 & $50: 32: 19$ & $47: 29: 24$ \\
\hline Bread 3 & $51: 34: 16$ & $51: 33: 16$ \\
\hline Bread 4 & $55: 22: 23$ & $56: 24: 20$ \\
\hline Bread 5 & $54: 22: 25$ & $52: 28: 20$ \\
\hline
\end{tabular}

White bread (bread 1); whole-meal bread (bread 2); whole-meal bread with native bran (bread 3); whole-meal bread with fermented bran (bread 4); whole-meal bread with fermented and enzymatic treated bran (bread 5).

Lactate, valerate, iso-valerate and iso-butyrate were detected in relatively low quantities (Table 2). The white bread (bread 1) led to the highest total lactate production, approximately $1.2 \mathrm{mmol}$ during the $6 \mathrm{~h}$ feeding period. An increase in lactate formation is usually encountered when rapidly fermentable carbohydrates are fed, such as simple sugars (29). This is consistent with the observation that detectable levels of lactate were only found when the main substrate fed to human microbiota was starch and were not detectable in the case of arabinoxylans (30). The iso-butyrate and iso-valerate production in the whole-meal breads with bioprocessed bran were approximately twice as high as those in the other breads during the entire $24 \mathrm{~h}$ fermentation. Iso-butyrate and iso-valerate are branched- 
chain fatty acids formed from proteolytic fermentation, which is considered less desirable than carbohydrate fermentation. Despite the higher production of branched-chain fatty acids in the whole-meal breads with bioprocessed bran, the relative proportion to the total of SCFA was less than $4 \%$, which is within the physiological values found in the proximal and distal colon, $3.4 \%$ and $7.5 \%$ respectively (9). In the present study, ammonia, the main metabolite of proteolytic fermentation, was produced in similar amounts (26-35 mmol in $24 \mathrm{~h}$; Table 2) as those reported for colonic fermentation of different resistant starch preparations using of the same TIM systems (31). In that study (31), it was suggested that the amount of protein present after the in vitro digestion in TIM-1 primarily originated from the digestive juices secreted in the model.

The most interesting finding of the present study is the doubled production of butyrate during the first $6 \mathrm{~h}$ of colonic fermentation in the case of using bioprocessed bran compared to native bran or no bran was added to the wholemeal breads (Figure 1). This increase in butyrate seemed in turn of propionate, while the total SCFA production remained rather similar. An increase in the butyrate production after wheat bran consumption has been shown in piglets (32), in rats (33), and in humans with ulcerative colitis (34). Some studies have attributed the increment in butyrate to the fermentation of arabinoxylan $(35,36)$. In our study, the butyrate formation was most likely the result of the higher solubility of the arabinoxylan and presumably other polysaccharides, as a consequence of the bioprocessing of the bran. This is supported by the increase in soluble pentosan observed after the fermentation and enzymatic treatment of the bran. The fermentation and enzymatic treatment of the bran probably increased the fibre fermentability by the partial degradation of complex carbohydrates into smaller molecules of higher solubility.

From the findings of the present study we can conclude that besides the amount and composition of the total dietary fibre, the structure of the fibre is an important determinant for the formation of beneficial colonic metabolites. Processing techniques that influence the structural arrangements of fibre in wheat bran and their consequent colonic metabolism are potential tools to optimise the health potential of whole-grain products, a natural source of fibre in the human daily diet.

Acknowledgements: The authors thank Emilia Selinheimo, Anna-Marja Aura, and their colleagues at VTT, Finland, for providing the test breads. We also thank the technical assistance of Mark Jelier and Annet Maathuis with the TIM models. This research was financially supported by the European Commission in the Communities 6th Framework Programme, Project HEALTHGRAIN (FOOD-CT-2005-514008). It reflects the author's views and the Community is not liable for any use that may be made of the information contained in this publication. 


\section{REFERENCES}

1. de Munter JS, Hu FB, Spiegelman D, Franz M, van Dam RM. Whole grain, bran, and germ intake and risk of type 2 diabetes: a prospective cohort study and systematic review. PLoS Med. 2007;4:e261.

2. Jensen MK, Koh-Banerjee P, Hu FB, Franz M, Sampson L, Gronbaek M, Rimm EB. Intakes of whole grains, bran, and germ and the risk of coronary heart disease in men. Am J Clin Nutr. 2004;80:1492-9.

3. Larsson SC, Giovannucci E, Bergkvist L, Wolk A. Whole grain consumption and risk of colorectal cancer: a population-based cohort of 60,000 women. Br J Cancer. 2005;92:1803-7.

4. Schatzkin A, Mouw T, Park Y, Subar AF, Kipnis V, Hollenbeck A, Leitzmann MF, Thompson FE. Dietary fiber and whole-grain consumption in relation to colorectal cancer in the NIH-AARP Diet and Health Study. Am J Clin Nutr. 2007;85:1353-60.

5. Chan JM, Wang F, Holly EA. Whole grains and risk of pancreatic cancer in a large population-based case-control study in the San Francisco Bay Area, California. Am J Epidemiol. 2007;166:1174-85.

6. Schatzkin A, Park Y, Leitzmann MF, Hollenbeck AR, Cross AJ. Prospective study of dietary fiber, whole grain foods, and small intestinal cancer. Gastroenterology. 2008;135:1163-7.

7. Hemery Y, Rouau X, Lullien-Pellerin V, Barron C, Abecassis J. Dry processes to develop wheat fractions and products with enhanced nutritional quality. J Cereal Sci. 2007;46:327-47.

8. Anderson JW, Baird P, Davis RH, Jr., Ferreri S, Knudtson M, Koraym A, Waters V, Williams CL. Health benefits of dietary fiber. Nutr Rev. 2009;67:188-205.

9. Macfarlane GT, Gibson GR, Beatty E, Cummings JH. Estimation of short-chain fatty acid production from protein by human intestinal bacteria based on branched-chain fatty acid measurements. FEMS Microbiology Ecology. 1992;10:81-8.

10. Hamer HM, Jonkers D, Venema K, Vanhoutvin S, Troost FJ, Brummer RJ. Review article: the role of butyrate on colonic function. Aliment Pharmacol Ther. 2008;27:10419.

11. Napolitano A, Costabile A, Martin-Pelaez S, Vitaglione P, Klinder A, Gibson GR, Fogliano V. Potential prebiotic activity of oligosaccharides obtained by enzymatic conversion of durum wheat insoluble dietary fibre into soluble dietary fibre. Nutr Metab Cardiovasc Dis. 2009;19:283-90.

12. Fincher GB, Stone BA. Cell wall and their components in cereal grain technology. In: Pomeranz Y, editor. Advance in Cereal Science and Technology. St Paul, MN: AACC; 1986.

13. Izydorczyk MS, Biliaderis CG. Effect of molecular size on physical properties of wheat arabinoxylan. Journal of Agricultural and Food Chemistry. 1992;40:561-8.

14. Anson NM, Selinheimo E, Havenaar R, Aura AM, Mattila I, Lehtinen P, Bast A, Poutanen K, Haenen GR. Bioprocessing of wheat bran improves in vitro bioaccessibility and colonic metabolism of phenolic compounds. J Agr Food Chem. 2009;57:6148-55.

15. Watzke HJ. Impact of processing on bioavailability examples of minerals in foods. Trends Food Sci Technol. 1998;9:320-7.

16. Douglas SG. A rapid method for the determination of pentosans in wheat flour. Food Chem. 1981;7:139-45. 
17. Minekus M, Marteau P, Havenaar R, Huis In 'T Veld JHJ. A multicompartmental dynamic computer-controlled model simulating the stomach and small intestine. ATLA. 1995;23:197-209.

18. Larsson M, Minekus M, Havenaar R. Estimation of the Bioavailability of Iron and Phosphorus in Cereals using a Dynamic In Vitro Gastrointestinal Model. J Sci Food Agric. 1997;74:99-106.

19. Minekus M, Smeets-Peeters M, Bernalier A, Marol-Bonnin S, Havenaar R, Marteau P, Alric M, Fonty G, Huis in't Veld JHJ. A computer-controlled system to simulate conditions of the large intestine with peristaltic mixing, water absorption and absorption of fermentation products. Appl Microbiol Biot. 1999;53:108-14.

20. Venema K, Van Nuenen M, Smeets-Peters M, Minekus M, Havenaar R. TNO's in-vitro large intestinal model: an excellent screening tool for functional food and pharmaceutical research. Nutrition. 2000;24:558-64.

21. Gibson GR, Cummings JH, Macfarlane GT. Use of a three-stage continuous culture system to study the effect of mucin on dissimilatory sulfate reduction and methanogenesis by mixed populations of human gut bacteria. Appl Environ Microbiol. 1988;54:2750-5.

22. Samuelsen AB, Cohen EH, Paulsen BS, Brull LP, Thomas-Oates JE. Structural studies of a heteroxylan from Plantago major L. seeds by partial hydrolysis, HPAEC-PAD, methylation and GC-MS, ESMS and ESMS/MS. Carbohydr Res. 1999;315:312-8.

23. Nandini CD, Salimath PV. Carbohydrate composition of wheat, wheat bran, sorghum and bajra with good chapati/roti (Indian flat bread) making quality. Food Chem. 2001;73:197-203.

24. Jouany JP. Volatile fatty acids and alcohols determination in digestive contents, silage juice, bacterial culture and anaerobic fermenter contents. Sciences des Aliments. 1982;2:131-44.

25. Mortensen PB, Nordgaard I. The production of short-chain fatty acids in the human colon. In: Cherbut C, Barry JL, Lairon D, Durand M, editors. Dietary Fiber: mechanism of action in human physiology and metabolism. Paris: John Libbey Eurotext; 1995.

26. Strocchi A, Levitt MD. Measurement of starch absorption in humans. Can J Physiol Pharmacol. 1991;69:108-10.

27. Barron C, Surget A, Rouau X. Relative amounts of tissues in mature wheat (Triticum aestivum L.) grain and their carbohydrate and phenolic acid composition. J Cereal Sci. 2007;45:88-96.

28. Cummings JH, Pomare EW, Branch WJ, Naylor CP, Macfarlane GT. Short chain fatty acids in human large intestine, portal, hepatic and venous blood. Gut. 1987;28:1221-7.

29. Macfarlane GT, Gibson GR. Carbohydrate fermentation, energy transduction and gas metabolism in the human large intestine. Ecology and physiology of gastrointestinal microbiology. New York: Chapman and Hall; 1997. p. 269-318.

30. Hopkins MJ, Englyst HN, Macfarlane S, Furrie E, Macfarlane GT, McBain AJ. Degradation of cross-linked and non-cross-linked arabinoxylans by the intestinal microbiota in children. Appl Environ Microbiol. 2003;69:6354-60.

31. Fassler C, Arrigoni E, Venema K, Brouns F, Amado R. In vitro fermentability of differently digested resistant starch preparations. Mol Nutr Food Res. 2006;50:1220-8.

32. Molist F, de Segura AG, Gasa J, Hermes RG, Manzanilla EG, Anguita M, Pérez JF. Effects of the insoluble and soluble dietary fibre on the physicochemical properties of digesta and the microbial activity in early weaned piglets. Animal Feed Science and Technology. 2009;149:346-53. 
33. Zoran DL, Turner ND, Taddeo SS, Chapkin RS, Lupton JR. Wheat bran diet reduces tumor incidence in a rat model of colon cancer independent of effects on distal luminal butyrate concentrations. J Nutr. 1997;127:2217-25.

34. Hallert C, Bjorck I, Nyman M, Pousette A, Granno C, Svensson H. Increasing fecal butyrate in ulcerative colitis patients by diet: controlled pilot study. Inflamm Bowel Dis. 2003;9:116-21.

35. Hughes SA, Shewry PR, Li L, Gibson GR, Sanz ML, Rastall RA. In vitro fermentation by human fecal microflora of wheat arabinoxylans. J Agr Food Chem. 2007;55:4589-95.

36. Salvador V, Cherbut C, Barry JL, Bertrand D, Bonnet C, Delort-Laval J. Sugar composition of dietary fibre and short-chain fatty acid production during in vitro fermentation by human bacteria. Br J Nutr. 1993;70:189-97. 



\begin{abstract}
Whole-grain consumption has been linked to a lower risk of metabolic syndrome, which is normally associated with a low-grade chronic inflammation. The benefits of whole grain are in part related to the inclusion of the bran, outerlayers rich in phenolic content and fiber. However, the phenols are poorly bioaccessible from the cereal matrix. The aim of the present study is to investigate the effect of bioprocessing of bran in whole-meal bread on the bioavailability of phenolic compounds, the postprandial plasma antioxidant capacity and the antiinflammatory properties. After consumption of a low phenolic diet for 3 days and overnight fasting, 8 healthy males consumed $300 \mathrm{~g}$ of whole-meal bread containing native bran (control) or bioprocessed bran in a cross-over study. Urine and blood samples were collected during $24 \mathrm{~h}$. Phenolic compounds were quantified by GCxGC-TOF/MS. Plasma antioxidant capacity was measured by TEAC. Cytokines were measured in blood after ex vivo LPS-stimulation. The bioavailability of ferulic acid, vanillic acid, sinapic acid and 3,4-dimethoxybenzoic acid was increased 2 to 3-fold by consumption of the bioprocessed bread compared to control. Phenylpropionic acid and 3-hydroxyphenylpropionic acid were the main colonic metabolites of the non-absorbed phenols. The effect on the total plasma antioxidant capacity was minor. The ratio of pro- and anti-inflammatory cytokines was significantly decreased in LPS-stimulated blood after the consumption of the bioprocessed bread. In conclusion, processing can remarkably increase the bioavailability of phenolic compounds and their consequent circulating concentrations, which should be considered in order to optimize whole-grain products.
\end{abstract}




\section{INTRODUCTION}

High whole-grain consumption has been inversely associated with the risk for developing some diet-related disorders such as type 2 diabetes, cardiovascular events and obesity, these disorders are commonly referred to as the metabolic syndrome (1).

Hyperglycemic and pro-oxidative conditions observed in those metabolic disorders may promote the excessive production of reactive oxygen species and advanced glycation end products leading to tissue damage and malfunction, the main endogenous inducers of inflammation (2). Inflammation that is initially meant as a physiological reaction to restore homeostasis can derive in a pathological process when the trigger persists. Proposed pathological consequences are the shift in the homeostatic set points leading to a low-grade chronic inflammatory status $(2,3)$. The main mediators of the inflammatory process are the cytokines, which act in local and intercellular communications required in the integrated immune response. Numerous cytokines have been identified, but it is the "balance" between pro-inflammatory (e.g. IL-1 $\beta$, TNF- $\alpha$, IL6 , IL-2, IL-8, INF- $\gamma$ ) and anti-inflammatory cytokines (IL-10, IL-4, TGF- $\beta$ ) what is thought to be determinant in the outcome of disease (4).

Whole-grain foods tend to have low glycaemic index (GI) values, resulting in lower postprandial glucose responses and insulin demand in comparison to refined cereal products. Whereas the low GI of whole grain is a generally recognized health benefit, the role of phytochemicals present in whole grain is still under debate (1). Several of these compounds have been reported to exert antioxidant and anti-inflammatory effects, such as some reviewed phenolic acids (5-8).

Among the phenolic compounds found in wheat grain, ferulic acid is the most abundant one and is strongly correlated with the antioxidant capacity of different wheat fractions (9). Therefore, it was proposed as a marker of antioxidants in wheat grain. The outer-most part of the grain, the bran, is high in ferulic acid content, however its bioaccessibility or intestinal release from the grain matrix is very low. The low bioaccessibility is explained by the structural position of most of the ferulic acid, that is covalently bound to the indigestible polysaccharides of the cell walls (10). Innovative processing techniques have been developed to increase the bioaccessibility of phenolic compounds from wheat bran (11).

In the present study, the effect of bioprocessing of bran in whole-meal bread is investigated on the bioavailability of phenolic compounds, plasma antioxidant capacity and anti-inflammatory potential. 


\section{MATERIAL AND METHODS}

\section{Subjects}

Eight healthy male subjects were recruited for the study. The eight men enrolled were of median age 28 years old (21-55) with a BMI between 20 and 30, no smokers nor users of any medication participated in the study. C-reactive protein was $<15 \mathrm{mg} / \mathrm{L}$ indicating no infections in the volunteers (12). Blood donation three months before the start of the study, consumption of three or more glasses of alcohol per day, vegetarian lifestyles or allergies to food components were exclusion criteria in the recruitment. The volunteers were informed of the purposes and risks of the study, and written informed consent was obtained. The study was approved by the Medical Ethical Commission of the Maastricht Academic Hospital and Maastricht University (reference MEC 08-3-079).

\section{Bread supplementation}

For the study, the two types of bread were prepared and analyzed on macronutrient content as described previously (11). Briefly, both the control bread and the bioprocessed bread consisted of whole-meal wheat flour with added wheat bran (9\%). The ingredients were supplied by Bühler AG (Switzerland). The control bread contained native bran. In the bioprocessed bread, the bran was bioprocessed by yeast fermentation (Baker's Yeast, Finnish Yeast Ltd.) combined with enzyme treatment (cell-wall degrading enzymes: mainly xylanase, cellulose, $\beta$-glucanase and feruloyl-esterase) for $20 \mathrm{~h}$ at $20{ }^{\circ} \mathrm{C}$. The phenolic composition (Table 1) was determined by HPLC and diode array as described elsewhere (11).

Table 1. Phenolic composition of the $300 \mathrm{~g}$ bread serving consumed by the participants in the study.

\begin{tabular}{|lcccc|}
\hline In 300 g bread & \multicolumn{2}{c}{ Control bread } & \multicolumn{2}{c|}{ Bioprocessed bread } \\
Phenolic acid $(\mathbf{m g})$ & Total & Free & Total & Free \\
\hline Ferulic acid & 229 & 6.5 & 222 & 28 \\
\hline Sinapic acid & 17 & 0.89 & 17 & 2.6 \\
\hline$p$-Coumaric acid & 5.4 & 0.25 & 4.4 & 0.35 \\
\hline Vanillic acid & 4.9 & 1.6 & 5.3 & 2.3 \\
\hline
\end{tabular}




\section{Study design}

The study design was blind and cross-over, with randomization of the subjects in the two periods and treatments. Between the two periods there was a wash-out period of at least one week. The volunteers were asked to avoid the consumption of phenol-rich foods for three days before the intervention day. Whole-grain cereal products, fruit and fruit-containing products, vegetables, nuts and seeds, chocolate, wine, tea and coffee were excluded from the diet. The volunteers received a standardized low-phenolic meal consisting of wheat noodles the evening prior to the intervention day. After overnight fasting, the subjects solely consumed $300 \mathrm{~g}$ of bread in the morning. During the intervention day $(24 \mathrm{~h})$, only drinking water was permitted besides the evening meal, which was again the standardized low-phenolic noodles. Urine was collected during the 24 hours after ingestion of the bread as a $0-24 \mathrm{~h}$ sample. Urinary collectors of $2 \mathrm{~L}$ capacity containing $1 \mathrm{~g}$ sodium ascorbate were provided for the $0-12 \mathrm{~h}$ period and for the $12-24 \mathrm{~h}$ period. The urine was pooled and aliquots were stored at $-80{ }^{\circ} \mathrm{C}$ until analysis.

Blood was drawn at different time points in NH sodium heparin tubes. Directly after the first blood sample (baseline), $300 \mathrm{~g}$ of bread was consumed (8:30-9:00 a.m.). After the consumption of the bread was completed, blood was taken at 15 min, $30 \mathrm{~min}, 45 \mathrm{~min}, 1 \mathrm{~h}, 1 \mathrm{~h} 15 \mathrm{~min}, 1 \mathrm{~h} 30 \mathrm{~min}, 2 \mathrm{~h}, 3 \mathrm{~h}, 4 \mathrm{~h}, 5 \mathrm{~h}, 6 \mathrm{~h}, 9 \mathrm{~h}, 12 \mathrm{~h}$ and $24 \mathrm{~h}$.

\section{Determination of phenolic acids}

\section{Urine sample preparation}

A urine sample of $500 \mu \mathrm{l}$ was mixed with $30 \mu \mathrm{l}$ of $500 \mathrm{ppm}$ heptadecanoic acid as internal standard and $1500 \mu \mathrm{l}$ of hydrolysis solution containing $\beta$-glucuronidase $(>3000 \mathrm{U})$ and sulfatase (> $100 \mathrm{U})$ from Helix pomatia (Sigma-Aldrich, Germany) in $0.15 \mathrm{M}$ acetate buffer $\mathrm{pH}=4.1$. The solution was incubated for $16 \mathrm{~h}$ at $37^{\circ} \mathrm{C}$. After incubation the solution was extracted with a conditioned Oasis HLP cartridge. The samples were eluted with $1 \mathrm{ml}$ methanol. A $400 \mu \mathrm{l}$ aliquot of the methanol fraction was evaporated under nitrogen and derivatized with $25 \mu \mathrm{l}$ of MOX $\left(45^{\circ} \mathrm{C}, 1 \mathrm{~h}\right)$ and $25 \mu \mathrm{l}$ of MSTFA $\left(45^{\circ} \mathrm{C}, 1 \mathrm{~h}\right)$.

\section{Plasma sample preparation}

Plasma samples were obtained by centrifugation of blood at $1000 \mathrm{~g}$ for $5 \mathrm{~min}$ at $4{ }^{\circ} \mathrm{C}$. A sample of $500 \mu \mathrm{l}$ of plasma was mixed with $15 \mu \mathrm{l}$ of $125 \mathrm{ppm}$ 2-coumaric acid as internal standard. This mixture was extracted twice with $1 \mathrm{ml}$ methanol. The methanol phase was evaporated under nitrogen. Subsequently, 500 $\mu 1$ water and $1500 \mu \mathrm{l}$ hydrolysis solution (mentioned above) were added to the dry extract. 
After $16 \mathrm{~h}$ incubation at $37^{\circ} \mathrm{C}$, the mixture was acidified with $\mathrm{HCl}$ to $\mathrm{pH}<2$ and extracted twice with ethylacetate. The ethylacetate phase was evaporated and derivatized with $25 \mu \mathrm{l}$ of $\operatorname{MOX}\left(45^{\circ} \mathrm{C}, 1 \mathrm{~h}\right)$ and $25 \mu \mathrm{l}$ of MSTFA $\left(45^{\circ} \mathrm{C}, 1 \mathrm{~h}\right)$.

The identification and quantification of phenolic acids was performed in urine and plasma by two-dimensional gas chromatography coupled to a time-of-flight mass spectrometer as described previously (13). Regarding the pharmacokinetic analysis, the integral approximation of the trapezoidal method was used to calculate the area under the curve $\left(\mathrm{AUC}_{0-\mathrm{t}}\right)$ of the compound in plasma from its concentration over time (0-24 h).

\section{Determination of antioxidant capacity in plasma}

Plasma was deproteinated with the addition of $10 \%$ trichloroacetic acid to the plasma in 1:1 ratio. Trolox equivalent total antioxidant capacity (TEAC) was determined in the deproteinated plasma as previously described (14). The concentration of uric acid was determined by HPLC and UV detector (15).

\section{Ex vivo induced inflammatory response}

Blood drawn before the bread ingestion and after $1 \mathrm{~h} 15 \mathrm{~min}, 6 \mathrm{~h}$ and $12 \mathrm{~h}$, was added to RPMI-1640 medium in 1:4 ratio. LPS (from Escherichia coli) was added in a final concentration of $1 \mathrm{ng} / \mathrm{ml}$ and samples were incubated in triplicate for $24 \mathrm{~h}$ at $37^{\circ} \mathrm{C}$ and $5 \% \mathrm{CO}_{2}$ in a humidified atmosphere. After incubation, the supernatants obtained by centrifugation $\left(1000 \mathrm{~g}\right.$ for $5 \mathrm{~min}$ at $4{ }^{\circ} \mathrm{C}$ ) were stored at $-80{ }^{\circ} \mathrm{C}$ until analysis. For the cytokine analysis (IL-10, IL-6, TNF- $\alpha$, IL-1 $\beta$, INF- $\gamma$ and IL-8) human cytokine kits from Millipore BV (Amsterdam, The Netherlands) were used following the instructions of the manufacturer and Luminex XMAP Technology. IL-8 was above the highest limit of quantification (> $20000 \mathrm{pg} / \mathrm{ml})$. For each subject, the cytokine expression (average of triplicate determination) was related to that in the LPS-stimulated blood that was obtained before the bread ingestion $\left(t_{0}\right)$. The pro-inflammatory cytokines were related to the anti-inflammatory cytokine IL10.

\section{Statistical analysis}

The non parametric Wilcoxon's rank-sum test was used to assess possible carryover effects as proposed by Koch (16). No carry-over effects were found $\left(W_{\mathrm{s}}=10, z\right.$ $=-1.04, p=0.39$ ). The non parametric test for related samples, i.e. the Wilcoxon signed-rank test, was used to assess the significant differences between the bioprocessed bread and the control bread for the variables measured in the present study. The values express the 1-tailed exact significance, unless otherwise stated. Results are shown as the median, and the variation of the data is given as the 
interquartile range (difference between the $25^{\text {th }}$ and $75^{\text {th }}$ quartile). Spearman's rho was selected to assess the significance of correlation and correlation coefficient $\left(\mathrm{r}_{\mathrm{s}}\right)$ between variables. SPSS 17.0 software for windows was used for the statistical analysis.

\section{RESULTS}

\section{Pharmacokinetics}

The following phenolic compounds were detected in blood plasma: ferulic acid, vanillic acid, 3-hydroxyphenylpropionic acid, phenylpropionic acid, 3,4dihydroxybenzoic acid, 3,4-dimethoxybenzoic acid, 3-hydroxybenzoic acid, 4hydroxybenzoic acid, benzoic acid, hippuric acid and 3,4-dihydroxytoluene.

The relative bioavailability, i.e. area under the curve $\left(\mathrm{AUC}_{0-\mathrm{t}}\right)$ of the compound from the bioprocessed bread related to the $\mathrm{AUC}_{0-\mathrm{t}}$ of the compound from the control bread, was significantly increased for ferulic acid (2.7-fold), vanillic acid (1.8-fold) and 3,4-dimethoxybenzoic acid (1.8-fold) (Table 2). The highest increase was in the ferulic acid concentrations (Figure 1).

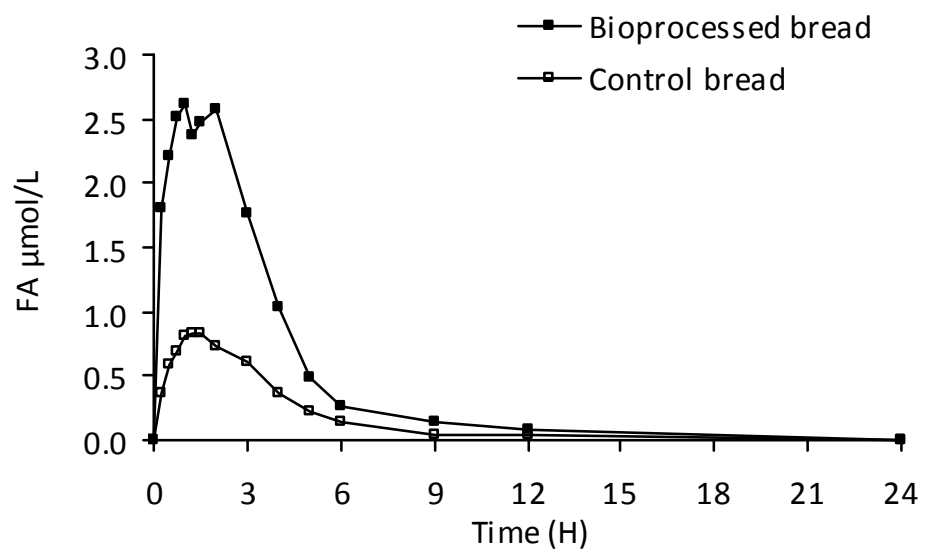

Figure 1. Plasma concentration (median $\mathrm{N}=8$ ) over time of ferulic acid (FA) after ingestion of control bread or bioprocessed bread. Baseline values are substracted.

The $C_{\max }$ of ferulic acid, vanillic acid and 3,4-dimethoxybenozic acid were significantly higher after the ingestion of bioprocessed bread than after the ingestion of control bread. There were no significant differences in the $t_{\max }$ of these compounds between the breads (Table 2). 
Table 2. Pharmacokinetics of the main phenolic acids identified in plasma after ingestion of control bread or bioprocessed bread. Data $(\mathrm{N}=8)$ is expressed as medians and interquartile ranges (IQR).

\begin{tabular}{|c|c|c|}
\hline & Control & Bioprocessed \\
\hline \multicolumn{3}{|l|}{ Ferulic acid } \\
\hline$A \cup C_{0-t}\left(\mu \mathrm{mol}{ }^{*} \mathrm{~min} / \mathrm{L}\right)$ & $242(107)$ & $643(228)^{\mathrm{a}}$ \\
\hline$C_{\max }(\mu \mathrm{mol} / \mathrm{L})$ & $0.88(0.15)$ & $2.7(0.63)^{\mathrm{a}}$ \\
\hline$t_{\max }(\min )$ & $90(38)$ & $105(56)$ \\
\hline \multicolumn{3}{|l|}{ Vanillic acid } \\
\hline$A \cup C_{0-t}\left(\mu \mathrm{mol}{ }^{*} \mathrm{~min} / \mathrm{L}\right)$ & $39(18)$ & $70(35)^{\mathrm{a}}$ \\
\hline$C_{\max }(\mu \mathrm{mol} / L)$ & $0.10(0.00)$ & $0.25(0.18)^{\mathrm{a}}$ \\
\hline $\mathrm{t}_{\max }(\min )$ & $105(45)$ & $120(41)$ \\
\hline \multicolumn{3}{|c|}{ Dimethoxybenzoic acid } \\
\hline$A \cup C_{0-t}\left(\mu \mathrm{mol} *^{*} \mathrm{~min} / \mathrm{L}\right)$ & $5.4(5.3)$ & $9.9(5.9)^{\mathrm{a}}$ \\
\hline$C_{\max }(\mu \mathrm{mol} / \mathrm{L})$ & $0.014(0.00)$ & $0.026(0.02)^{\mathrm{a}}$ \\
\hline$t_{\max }(\min )$ & $150(90)$ & $120(30)$ \\
\hline
\end{tabular}

Plasma concentrations of 3-hydroxyphenylpropionic acid (3-OHPP) and phenylpropionic acid (PP) rose from baseline values at later than $6 \mathrm{~h}$ after ingestion (Figure 2). $C_{\max }$ and $t_{\max }$ could not be accurately determined due to the relatively late increase in plasma concentration and lack of data during night time when blood was not collected. The increase from baseline at $12 \mathrm{~h}$ after ingestion of bioprocessed bread or control bread were compared. The differences observed between the breads for 3-OHPP and PP formation were not significant $(p=0.297$, 2-tailed).

High baseline values were found for hippuric acid $(2.8 \mu \mathrm{mol} / \mathrm{L}$, range 0.29-5.9 $\mu \mathrm{mol} / \mathrm{L})$ and benzoic acid $(1.5 \mu \mathrm{mol} / \mathrm{L}$, range $0.59-2.6 \mu \mathrm{mol} / \mathrm{L})$ and irregular concentration-time profile. Also irregular profiles were observed in the plasma appearance of 3-hydroxybenzoic acid, 4-hydroxybenzoic acid, 3,4dihydroxybenzoic acid and 3,4-dihydroxytoluene (data not shown). 

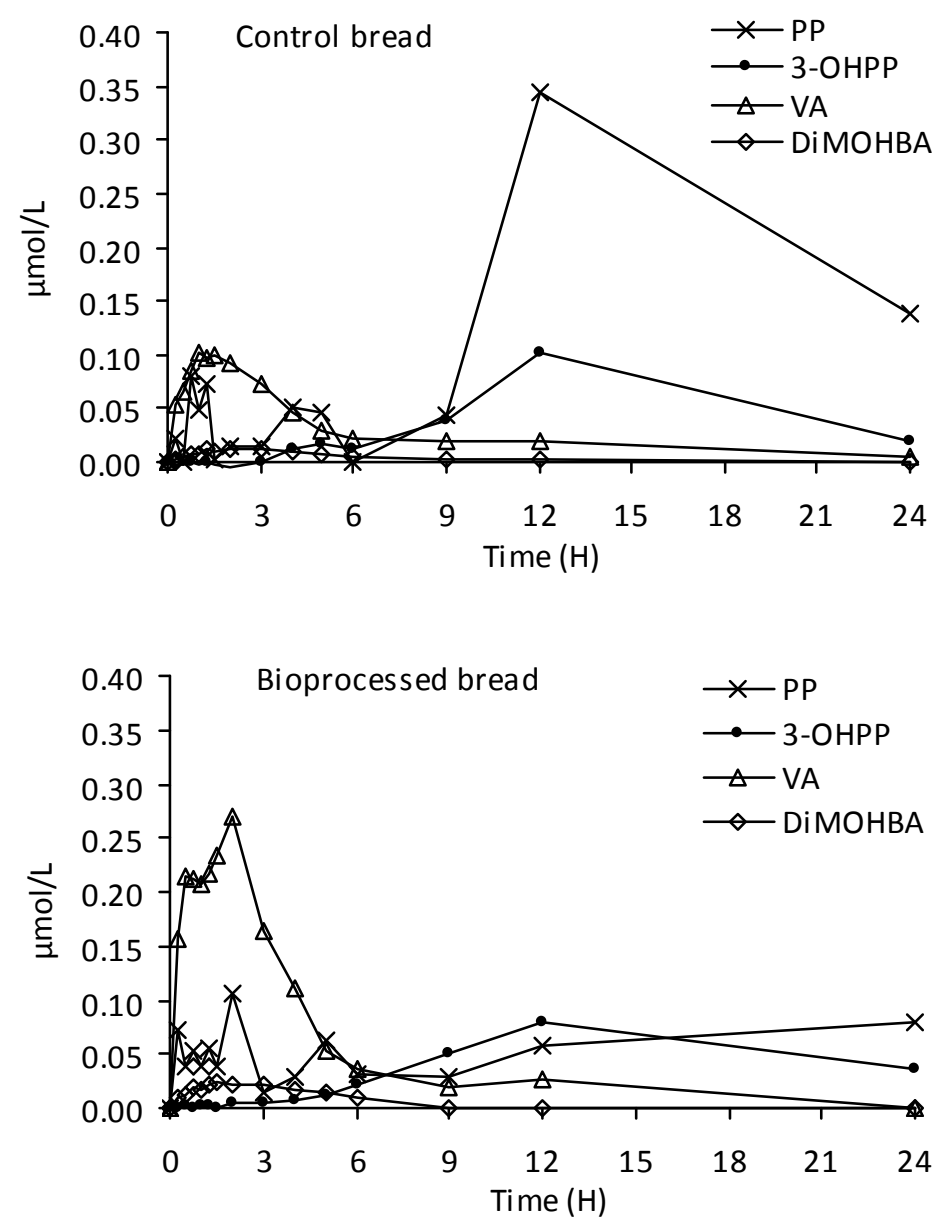

Figure 2. Concentration (median $\mathrm{N}=8$ ) over time of other phenolic acids detected in plasma: vanillic acid (VA), 3,4-dimethoxybenzoic acid (DiMOHBA), 3hydroxyphenylpropionic acid (3-OHPP) and phenylpropionic acid (PP), after ingestion of control bread or bioprocessed bread. Baseline values are substracted.

\section{Excretion of phenolic compounds}

Among the compounds identified in urine, hippuric acid was present in the highest amount. No significant difference was found between the two breads in the amount of hippuric acid excreted in urine. The second highest phenolic compound found in urine was ferulic acid. Ingestion of bioprocessed bread compared to control bread significantly increased the amount of ferulic acid (2.2 fold), sinapic acid (2.4 fold), vanillic acid (1.6 fold) and dimethoxybenzoic acid (1.9 fold) excreted in urine $(p<0.05)$. The amount in urine of some other compounds was significantly 
decreased: 3-coumaric acid (1.4 fold), 4-coumaric acid (1.3 fold), 4hydroxyphenylpropionic acid (2 fold) and 4-hydroxybenzoic acid (1.7 fold) ( $p<$ 0.05 , 2-tailed). The excretion of the rest of compounds was not significantly different between the two breads (Table 3).

Table 3. Urinary excretion in $24 \mathrm{~h}$ of all identified compounds after ingestion of control bread or bioprocessed bread. Values are the medians and interquartile ranges (IQR) of 8 volunteers.

\begin{tabular}{|lcc|}
\hline Urinary excretion in $\mathbf{2 4} \mathbf{h}(\boldsymbol{\mu m o l})$ & Control bread & Bioprocessed bread \\
\hline 3,4-Dihydroxybenzoic acid & $3.9(0.90)$ & $3.3(0.63)$ \\
\hline 3,4-Dihydroxyphenylacetic acid & $8.1(4.7)$ & $6.9(3.5)$ \\
\hline 3,4-Dihydroxyphenylpropionic acid & $1.9(1.1)$ & $2.4(4.8)$ \\
\hline 3,4-Dihydroxytoluene & $6.2(8.4)$ & $6.0(7.9)$ \\
\hline 3,4-Dimethoxybenzoic acid & $1.1(0.85)$ & $2.1(1.9)^{\uparrow}$ \\
\hline 3-Coumaric acid & $1.5(2.5)$ & $1.1(0.65)^{\downarrow}$ \\
\hline 3-Hydroxybenzoic acid & $9.7(5.6)$ & $9.5(6.4)$ \\
\hline 3-Hydroxyphenylacetic acid & $20(14)$ & $14(9.6)$ \\
\hline 3-Hydroxyphenylpropionic acid & $6.1(4.1)$ & $5.6(3.5)$ \\
\hline Phenylpropionic acid & $0.90(1.2)$ & $0.5(0.70)$ \\
\hline 4-Coumaric acid & $0.70(0.40)$ & $0.55(0.30)^{\downarrow}$ \\
\hline 4-Hydroxybenzoic acid & $1.6(3.2)$ & $0.95(0.48)^{\downarrow}$ \\
\hline 4-Hydroxyphenylpropionic acid & $0.60(0.53)$ & $0.30(0.30)^{\downarrow}$ \\
\hline Benzoic acid & $15(9.3)$ & $9.3(7.5)$ \\
\hline Ferulic acid & $51(9.7)$ & $110(46)^{\uparrow}$ \\
\hline Gallic acid & $0.20(0.08)$ & $0.20(0.10)$ \\
\hline Hippuric acid & $1550(1510)$ & $1100(833)$ \\
\hline Vanillic acid & $30(7.8)$ & $49(34)^{\uparrow}$ \\
\hline Sinapic acid & $5.1(3.7)$ & $12(3.2)^{\uparrow}$ \\
\hline
\end{tabular}

${ }^{\uparrow}$ Compound significantly higher excreted after consumption of bioprocessed bread than control bread $(p<0.05)$.

$\downarrow$ Compound significantly lower excreted after consumption of bioprocessed bread than control bread $(p<0.05$, 2-tailed).

Related to the intake (Table 1), 10\% of the ferulic acid content of the bioprocessed bread was excreted in $24 \mathrm{~h}$, while this was only $4 \%$ in the case of the control bread. The amount of sinapic acid in $24-h$ urine was $15 \%$ and $7 \%$ of the intake in the bioprocessed bread and control bread respectively. For $p$-coumaric 
acid, this was $2 \%$ of the intake for both the bioprocessed and the control bread. The amount of vanillic acid excreted in 24 -h urine was $160 \%$ and $104 \%$ of the intake in the bioprocessed bread and the control bread respectively.

\section{Plasma total antioxidant capacity}

The relationship between plasma concentrations of ferulic acid and total antioxidant capacity was determined with all the data. No correlation was found between them $\left(r_{s}=0.07, p=0.128\right)$. There was a correlation between the difference from baseline in plasma ferulic acid and the difference from baseline in antioxidant capacity $\left(\mathrm{r}_{\mathrm{s}}=0.25, p<0.01\right)$. Also, differences from baseline in plasma antioxidant capacity significantly correlated with differences from baseline in uric acid $\left(\mathrm{r}_{\mathrm{s}}=\right.$ $0.47, p<0.01)$.

\section{Anti-inflammatory effects}

Blood drawn from the volunteer was subjected to a LPS-challenge to simulate an inflammatory response. Expression of INF- $\gamma$ by LPS-stimulation was very low (107 pg/ml, range 7.7-665 pg/ml) compared to the other cytokines; IL-6 (11300 $\mathrm{pg} / \mathrm{ml}$, range 634-23400 pg/ml), IL-1 3 (1610 pg/ml, range 394-6950 pg/ml), IL-10 ( $1230 \mathrm{pg} / \mathrm{ml}$, range $303-3120 \mathrm{pg} / \mathrm{ml})$ and TNF- $\alpha(1170 \mathrm{pg} / \mathrm{ml}$, range 324-3260 $\mathrm{pg} / \mathrm{ml}$ ). The ratios between pro- and anti-inflammatory cytokines in each subject's LPS-stimulated blood were compared between the two breads. In blood taken at 1 h $15 \mathrm{~min}$, the ratios IL-6/IL-10 and IL-1 $\beta /$ IL-10 were significantly lower by ingestion of the bioprocessed bread than the control bread (Figure 3). The ratio TNF-a/IL-10 was not statistically different between the two breads $(p>0.05)$. In blood taken at $6 \mathrm{~h}$ and $12 \mathrm{~h}$ no statistical differences were found between the two breads (data not shown).

\section{DISCUSSION}

The aim of this study, in which bioprocessing was applied to bran in wholemeal bread, was first, to study the increase in the bioavailability of phenolic compounds from the whole-grain bread matrix, and second, to investigate its effect on the total antioxidant capacity in plasma and on inflammation.

The relative bioavailability of ferulic acid, vanillic acid, sinapic acid and 3,4dimethoxybenzoic acid were increased by bioprocessing of the bran in whole-meal bread compared to the control bread, which was also whole-meal with the same content in bran but native. The highest increase was in the ferulic acid concentration (Figure 1), with an approximate increase of 3-fold in the $\mathrm{AUC}_{0-\mathrm{t}}$ and $\mathrm{C}_{\max }$ over the control bread. Ingestion of the control bread resulted in a maximal plasma concentration of ferulic acid of $0.88 \mu \mathrm{mol} / \mathrm{L}$ (i.e. $175 \mathrm{ng} / \mathrm{ml}$ ) (Table 2) 
which is consistent with the concentrations reported after the consumption of a high-bran breakfast cereal (150-210 ng/ml), which had a comparable ferulic acid content (250 mg) (17).
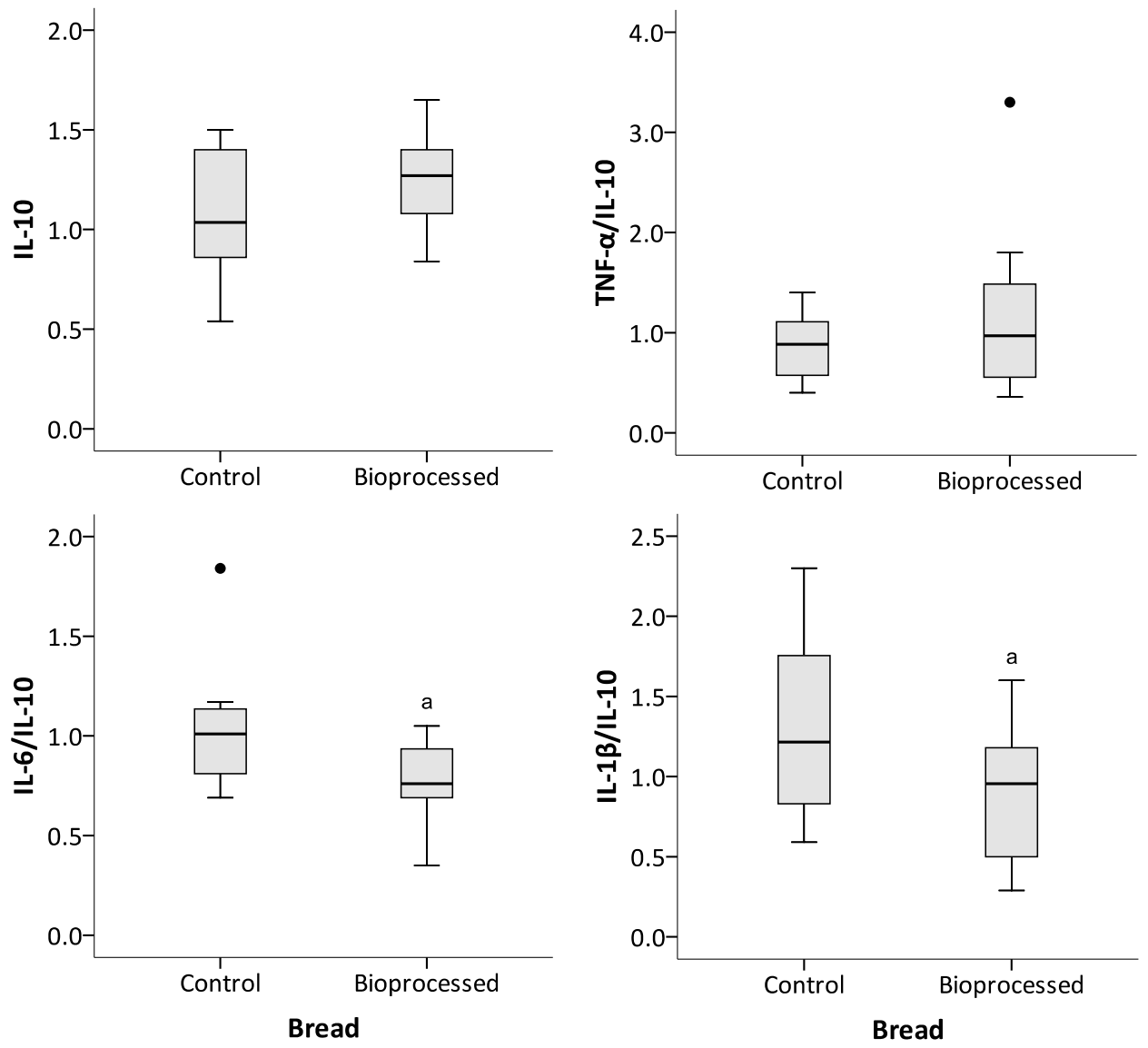

Figure 3. Cytokine production in LPS-stimulated blood, drawn at $1 \mathrm{~h} 15 \mathrm{~min}$ after ingestion of control bread or bioprocessed bread. Values are related to the values of each individual's LPS stimulated blood drawn before the ingestion of bread $\left(t_{0}\right)$. The box plot represents the median $(\mathrm{N}=8)$ and the interquartile range, the outer ends indicate the minimum and maximum values. Possible outlier. aSignificant differences between control bread and bioprocessed bread were found for IL-6/IL-10 ( $p=0.027)$ and IL-1 $\beta /$ IL-10 $(p=0.012)$.

In previous studies with an in vitro gastrointestinal model, the bioaccessibility of ferulic acid from different breads and fractions of the wheat grain was strongly correlated with the percentage of free ferulic acid in the food matrix. It was estimated that $70 \%$ of the free ferulic acid in the food matrix was bioaccessible, i.e. available for intestinal absorption $(10,11)$. This was also observed after beer 
consumption (18). In the present study, after the ingestion of the bioprocessed bread, approximately $70 \%$ of the free ferulic acid ingested was excreted in urine in $24 \mathrm{~h}$. In the case of the control bread, the urinary excretion of ferulic acid $(51 \mu \mathrm{mol})$ was higher than the amount of free ferulic acid ingested $(6.5 \mathrm{mg}$, i.e. $33 \mu \mathrm{mol})$. This indicates some release of bound ferulic acid, probably ferulic acid bound to easily digestible carbohydrates or proteins. Nevertheless, the fraction of ferulic acid released is estimated to account for only $1.5 \%$ of the total ferulic acid ingested.

The $C_{\max }$ of vanillic acid and 3,4-dimethoxybenzoic acid were 10-fold and 100fold lower than that of ferulic acid respectively (Figure 2). Vanillic acid and 3,4dimethoxybenzoic acid may be to some extent metabolites of ferulic acid from $\beta$ oxidation and methylation reactions. This is supported by their structure resemblance (Figure 4 ) and by the results in Table 3 that show an excretion of vanillic acid ( $30 \mu \mathrm{mol}$ and $49 \mu \mathrm{mol}$ ) superior than its intake (approximately $5 \mathrm{mg}$, i.e. $30 \mu \mathrm{mol})$ (Table 1).

The $t_{\max }$ of ferulic acid (90-105 min) after the ingestion of bread was within the range of 1-3 $\mathrm{h}$ reported after consumption of a high-bran breakfast cereal (17). In contrast to a previous study in which ferulic acid was increased in plasma after $1 \mathrm{~h}$ and $8 \mathrm{~h}$ of artichoke consumption (19), no biphasic profile in the plasma appearance of ferulic acid was found in the present study or after high-bran breakfast cereal consumption (17). The short $t_{\max }$ indicates that the absorption of ferulic acid mainly takes place in small intestine, despite the large proportion of ferulic acid that reaches colon bound to fiber (90\%). Instead of a second phase in the absorption of ferulic acid from the colonic release, other compounds were detected to increase in plasma at late time points after ingestion $(6-24 \mathrm{~h})$. This suggests a rapid and extensive colonic metabolism of ferulic acid upon release, which has been reported in a previous in vitro study (11).

The metabolites that increased after $6 \mathrm{~h}$ posterior to the bread ingestion were 3hydroxyphenylpropionic acid and phenylpropionic acid. The time course of their plasma appearance and chemical structure (Figure 4) indicate their colonic origin as reductive metabolites of ferulic acid as previously proposed in vitro $(11,20,21)$. The formation of these colonic metabolites, particularly phenylpropionic acid, seemed higher in the control bread than in the bioprocessed bread based on the amount recovered in $24 \mathrm{~h}$ urine (Table 3) and the plasma concentration at $12 \mathrm{~h}$ (Figure 2), although significant differences in both parameters were not found. Less intestinal uptake of ferulic acid from the bread may have increased the input of this compound in colon for metabolism into phenylpropionic acids. However, statistical differences in colonic metabolites were difficult to establish due to the limited number of late time-concentration points (no blood collection overnight), which also precluded the pharmacokinetic analysis of these compounds $\left(\mathrm{AUC}_{0-\mathrm{t}}\right.$, $\mathrm{C}_{\text {max }}, \mathrm{t}_{\max }$ ). 


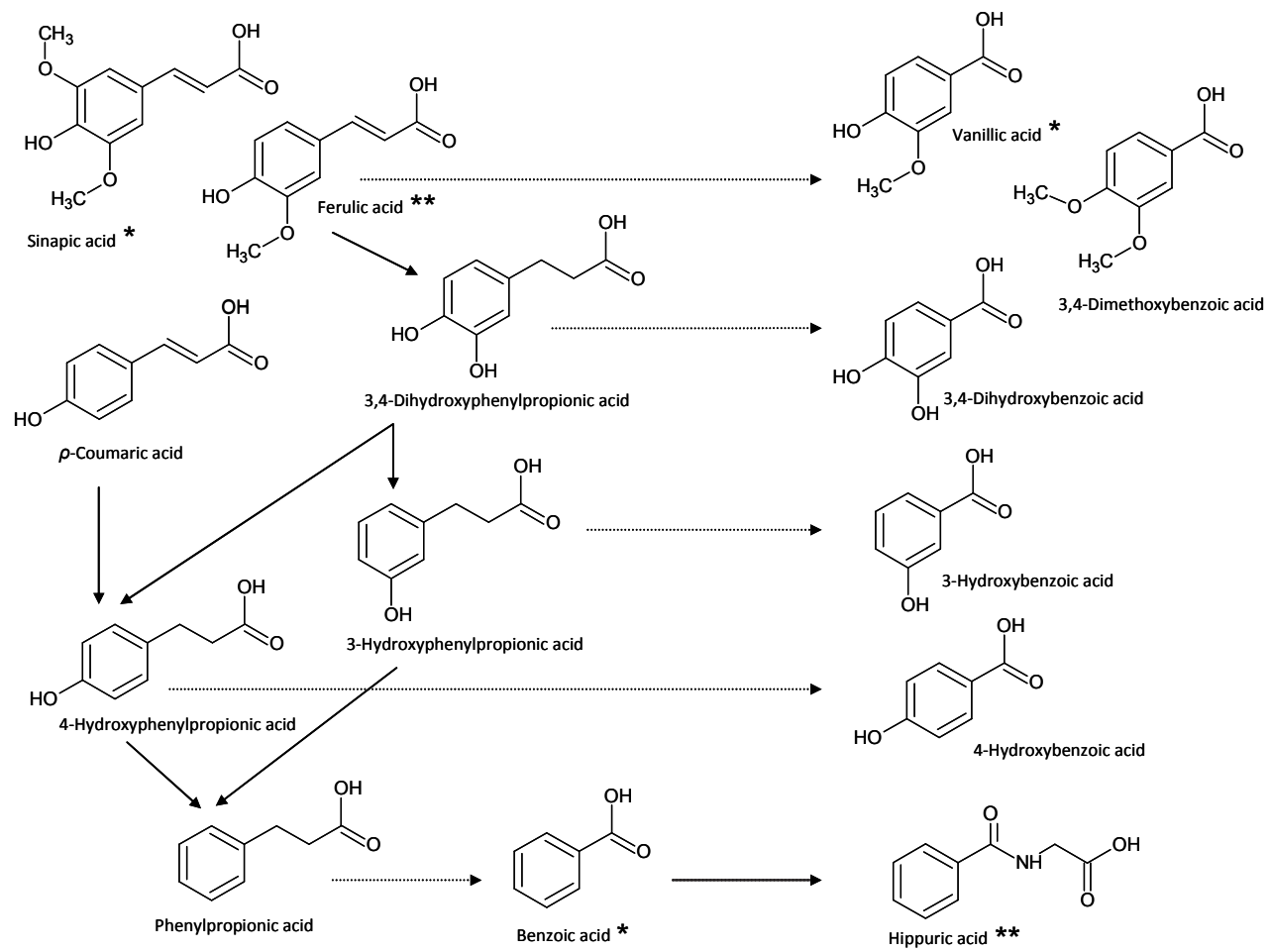

Figure 4. Metabolic scheme of the compounds identified in urine. Dotted lines are $\beta$ oxidations by either hepatocytes or enterocytes. *Amount recovered in urine $(>10 \mu \mathrm{mol})$ ** $(>100 \mu \mathrm{mol})$.

Phenylpropionic acid is one of the $\omega$-phenyl fatty acids used in the classical study by Knoop that led him to propose the mechanism of $\beta$-oxidation for the degradation of fatty acids. Knoop observed that dogs that had been fed phenylpropionic acid excreted hippuric acid in their urine, the glycine conjugate of benzoic acid (19). This indicates that ferulic acid via colonic transformation to phenylpropionic acid could be further converted to benzoic acid by $\beta$-oxidation.

Hippuric acid is formed by the phase II glycine conjugation of benzoic acid in liver (20). Both hippuric acid and benzoic acid were found in high concentrations in plasma. They were also high at baseline and a clear increase above baseline following ingestion of the breads was not observed. Sodium benzoate is widely used as preservative in many foods and beverages in relatively high amounts (maximal allowance of $0.1 \%$ ). Therefore it is difficult to exclude this compound from the diet, which could explain the high baseline values. Furthermore, benzoic acid can also be formed from many aromatic compounds including phenylalanine 
and phenyltyrosine from dietary protein as well as endogenous formation (21). Altogether this indicates that benzoic acid and hippuric acid are not specific of ferulic acid metabolism, although to some extent they can originate from ferulic acid through phenylpropionic acid formation (Figure 4).

\section{Antioxidant effects}

The increase in plasma levels of principally ferulic acid, but also other antioxidant phenolics, could be related to changes in plasma antioxidant capacity. However, the correlation coefficient was lower than that of an endogenous antioxidant, such as uric acid, which is formed from the metabolism of purines and was found in high concentrations in plasma $(200-480 \mu \mathrm{mol} / \mathrm{L})$. This indicates that there is a contribution of ferulic acid to the total antioxidant capacity in plasma, but limited. The variation in plasma ferulic acid can explain approximately $6 \%\left(\mathrm{r}_{\mathrm{s}}{ }^{2}=\right.$ $0.25 \times 0.25)$ of the variation in plasma antioxidant capacity. Therefore, the increment in the bioavailability of ferulic acid had a mild effect on the total antioxidant capacity in plasma, in the sense of total radical scavenging capacity with the present experimental settings. In this respect, the low specificity of the antioxidant capacity assessment should be noted. This rather unspecific method was chosen to account for the general activity of all the diverse compounds from the bread. Other studies using more specific approaches have reported the antioxidant action of ferulic acid on preventing lipid peroxidation (MDA), NO formation (iNOS) and others $(8,22,23)$.

\section{Anti-inflammatory effects}

The bioprocessing of bran added to whole-meal bread was associated to possible anti-inflammatory effects in regard to the decrease in the pro-/antiinflammatory cytokine ratios of IL-6/IL-10 and IL-1 $\beta /$ IL-10 in an ex vivo LPS induced inflammatory response. The non-significant effect on the TNF-a/IL-10 ratio could be due to the long duration of the incubation period $(24 \mathrm{~h})$, suboptimal for this cytokine. TNF- $\alpha$ production peak occurs at 4-6 $\mathrm{h}$ in LPS-stimulated human whole blood (24). The anti-inflammatory effect of the bioprocessed bread compared to the control bread was significant in the cultured blood that was collected at $1 \mathrm{~h} 15 \mathrm{~min}$ after the bread ingestion, which is near the $t_{\max }$ of ferulic acid (1 h $30 \mathrm{~min})$. In blood of later collection times $(6 \mathrm{~h}$ and $12 \mathrm{~h}$ ), no significant difference in the cytokine production was observed between the two breads. Some colonic metabolites of ferulic acid exert anti-inflammatory effects in vitro, such as 3,4-dihydroxyphenylpropionic acid (25), 3-hydroxyphenylpropionic acid, and phenylpropionic acid to a lesser extent (26). In vivo concentrations of these metabolites (Figure 2) are lower than some of those used in vitro and subjected to a large inter-individual variation, probably the result of differences in microbial populations and intestinal transit times. 
Some studies have reported effects of phenolic compounds on Th1 and Th2 cytokine production in whole blood cultures. Our experimental setup using LPS as stimulus primarily reflects the study of monocytic cytokine production. This is also confirmed by the low expression of INF- $\gamma$ in our results, which is typically a Th1 cytokine (7). LPS mainly reacts with the Toll Like Receptor 4 (TLR-4) by binding to CD14 (Cluster of differentiation) mainly expressed in monocytes (27). This results in the activation of IKB kinases (IKK) and the consequent phosphorylation of the inhibitor $\kappa \mathrm{B}$ proteins (ІкB). Degradation of ІкB allows its dissociation from the necrosis factor $\mathrm{KB}(\mathrm{NFKB}), \mathrm{NFKB}$ is then able to translocate to the nucleus and induce the expression of several genes involved in the cytokine production. Although the exact mechanism of action of phenols within this scenario is not elucidated, they are suggested to act in regulating the activation of IKK by redox regulation in the cell or to act in a later stage by interfering in the NFKB binding to DNA.

Besides the effect on cytokine modulation, phenolic compounds derived from cereal fractions have been reported to improve several cellular functions (chemotaxis, lymphoproliferation, microbicidal activity) and the redox state of leucocytes (28).

It can be concluded that an optimized processing has a significant effect on the uptake of bioactive compounds from whole-grain foods. To our knowledge, this is the first study that shows the appearance in plasma of colonic metabolites from the non-absorbed phenolic compounds from whole-grain consumption in humans. Although the anti-inflammatory mechanism of phenols is not fully elucidated, the present study shows that bioprocessing of whole-meal bread besides increasing the bioavailability of phenols, also had modulatory effects on the cytokine production in an ex vivo induced inflammation. Further research is encouraged to optimize a staple food, such as bread, to prevent diet-related disorders, such as those involving chronic inflammation.

Acknowledgements. We thank the technical and intellectual support of Airi Hyrkäs, MarieJosé Drittij, Lisette Bok and Wouter Vaes. This research was financially supported by the European Commission in the Communities 6th Framework Programme, Project HEALTHGRAIN (FOOD-CT-2005-514008). It reflects the author's views and the Community is not liable for any use that may be made of the information contained in this publication 


\section{REFERENCES}

1. McKevith B. Nutritional aspects of cereals. Nutrition Bulletin. 2004;29:111-42.

2. Medzhitov R. Origin and physiological roles of inflammation. Nature. 2008;454:428-35.

3. Hotamisligil GS. Inflammation and metabolic disorders. Nature. 2006;444:860-7.

4. Santangelo C, Vari R, Scazzocchio B, Di Benedetto R, Filesi C, Masella R. Polyphenols, intracellular signalling and inflammation. Ann Ist Super Sanita. 2007;43:394-405.

5. Barone E, Calabrese V, Mancuso C. Ferulic acid and its therapeutic potential as a hormetin for age-related diseases. Biogerontology. 2008.

6. Fardet A, Rock E, Remesy E. Is the in vitro antioxidant potential of whole-grain cereals and cereal products well reflected in vivo? J Cereal Sci. 2008;48: 258-76.

7. Neyestani TR. Polyphenols and Immunity. Wild-Type Food in Health Promotion and Disease Prevention. F. de Meester RRW, editor. Totowa, NJ: Humana Press Inc.; 2008.

8. Shahidi F, Chandrasekara A. Hydroxycinnamates and their in vitro and in vivo antioxidant activities. Phytochem Rev. 2009;DOI 10.1007/s11101-009-9142-8.

9. Mateo Anson N, van den Berg R, Havenaar R, Bast A, Haenen GR. Ferulic acid from aleurone determines the antioxidant potency of wheat grain (Triticum aestivum L.). J Agric Food Chem. 2008;56:5589-94.

10. Mateo Anson N, van den Berg R, Havenaar R, Bast A, Haenen GRMM. Bioavailability of ferulic acid is determined by its bioaccessibility. J Cereal Sci. 2009;49:296-300.

11. Anson NM, Selinheimo E, Havenaar R, Aura AM, Mattila I, Lehtinen P, Bast A, Poutanen K, Haenen GR. Bioprocessing of wheat bran improves in vitro bioaccessibility and colonic metabolism of phenolic compounds. J Agric Food Chem. 2009;57:6148-55.

12. Clyne B, Olshaker JS. The C-reactive protein. J Emerg Med. 1999;17:1019-25.

13. Aura A-M, Mattila I, Seppänen-Laakso T, Miettinen J, Oksman-Caldentey K-M, Oresic M. Microbial metabolism of catechin stereoisomers by human faecal microbiota: Comparison of targeted analysis and a non-targeted metabolomics method. Phytochem Lett. 2008;1:18-22.

14. Fischer MA, Gransier TJ, Beckers LM, Bekers O, Bast A, Haenen GRMM. Determination of the antioxidant capacity in blood. Clin Chem Lab Med. 2005;43:73540.

15. Rietjens SJ, Bast A, Haenen GR. New insights into controversies on the antioxidant potential of the olive oil antioxidant hydroxytyrosol. J Agric Food Chem. 2007;55:760914.

16. Koch GG. The use of non-parametric methods in the statistical analysis of the twoperiod change-over design. Biometrics. 1972;28:577-84.

17. Kern SM, Bennett RN, Mellon FA, Kroon PA, Garcia-Conesa M-T. Absorption of Hydroxycinnamates in Humans after High-Bran Cereal Consumption. J Agric Food Chem. 2003;51:6050-5.

18. Bourne L, Paganga G, Baxter D, Hughes P, Rice-Evans C. Absorption of ferulic acid from low-alcohol beer. Free Radic Res. 2000;32:273-80.

19. Mao L-F, Chu C, Schulz H. Hepatic .beta.-oxidation of 3-phenylpropionic acid and the stereospecific dehydration of (R)- and (S)-3-hydroxy-3-phenylpropionyl-CoA by different enoyl-CoA hydratases. Biochemistry-US. 2002;33:3320-6.

20. Temellini A, Mogavero S, Giulianotti PC, Pietrabissa A, Mosca F, Pacifici GM. Conjugation of benzoic acid with glycine in human liver and kidney: a study on the interindividual variability. Xenobiotica: The fate and safety evaluation of foreign compounds in biological systems. 1993;23:1427 - 33. 
21. Grumer HD. Formation of Hippuric Acid from Phenylalanine labelled with Carbon-14 in Phenylketonuric Subjects. Nature. 1961;189:63-4.

22. Bao-Hua W, Jing-Ping O-Y. Pharmacological Actions of Sodium Ferulate in Cardiovascular System. Cardiovasc Drug Rev. 2005;23:161-72.

23. Srinivasan M, Sudheer AR, Menon VP. Ferulic Acid: therapeutic potential through its antioxidant property. J Clin Biochem Nutr. 2007;40:92-100.

24. DeForge LE, Remick DG. Kinetics of TNF, IL-6, and IL-8 gene expression in LPSstimulated human whole blood. Biochem Bioph Res Co. 1991;174:18-24.

25. Monagas M, Khan N, Andres-Lacueva C, Urpi-Sarda M, Vazquez-Agell M, LamuelaRaventos RM, Estruch R. Dihydroxylated phenolic acids derived from microbial metabolism reduce lipopolysaccharide-stimulated cytokine secretion by human peripheral blood mononuclear cells. Br J Nutr. 2009;102:201-6.

26. Russell WR, Scobbie L, Chesson A, Richardson AJ, Stewart CS, Duncan SH, Drew JE, Duthie GG. Anti-inflammatory implications of the microbial transformation of dietary phenolic compounds. Nutr Cancer. 2008;60:636-42.

27. Dobrovolskaia MA, Vogel SN. Toll receptors, CD14, and macrophage activation and deactivation by LPS. Microbes Infect. 2002;4:903-14.

28. Alvarez P, Alvarado C, Mathieu F, Jimenez L, De la Fuente M. Diet supplementation for 5 weeks with polyphenol-rich cereals improves several functions and the redox state of mouse leucocytes. Eur J Nutr. 2006;45:428-38. 


\section{WHOLE GRAIN AGAINST METABOLIC DISORDERS}

\section{Data supporting the concept}

In the last 20 years numerous epidemiological and clinical studies have presented strong evidence that consumption of whole-grain foods significantly reduces the risk for numerous chronic diet-related conditions, such as the metabolic syndrome.

The metabolic syndrome has a prevalence in the US of $25 \%(7-44 \%)$ and increasing in Europe (7-36\%). The prevalence increases with the age to approximately $40 \%$ in people over 60 years old $(1,2)$.

The metabolic syndrome is a combination of medical disorders that occur together and promote the development of cardiovascular disease (relative risk of 1.6) and diabetes (relative risk of 3) $(3,4)$. Specific definitions were proposed by several organizations, still there is no consensus. The most common factors used in the definitions are an impaired insulin sensitivity and abdominal obesity. This is associated with high blood pressure, high plasma concentration of triglycerides, and chronic inflammatory status (5). Table 1 shows the criteria of the World Health Organization (WHO) for the diagnosis of the metabolic syndrome (6).

Table 1. WHO clinical criteria for the metabolic syndrome.

\section{Insuline resistance}

Type 2 diabetes, impaired glucose tolerance or impaired fasting glucose

\begin{tabular}{|c|c|c|}
\hline & Male & Female \\
\hline Blood pressure & $\begin{array}{l}\geq 140 \text { (systolic) or } \\
90 \text { (diastolic) } \mathrm{mmHg}\end{array}$ & $\begin{array}{c}\geq 140 \text { (systolic) or } \\
90 \text { (diastolic) } \mathrm{mmHg}\end{array}$ \\
\hline Plasma triglycerides & $\geq 1.7 \mathrm{mmol} / \mathrm{L}$ & $\geq 1.7 \mathrm{mmol} / \mathrm{L}$ \\
\hline HDL cholesterol & $\begin{array}{c}<35 \mathrm{mg} / \mathrm{dL} \\
(<0.9 \mathrm{mmol} / \mathrm{L})\end{array}$ & $\begin{array}{c}<39 \mathrm{mg} / \mathrm{dL} \\
(<1.0 \mathrm{mmol} / \mathrm{L})\end{array}$ \\
\hline $\mathrm{BMI}$ & $>30 \mathrm{~kg} / \mathrm{m}^{2}$ & $>30 \mathrm{~kg} / \mathrm{m}^{2}$ \\
\hline Waist : hip ratio & $>0.9$ & $>0.85$ \\
\hline $\begin{array}{l}\text { Albumin (urine) } \\
\text { Albumin : creatinine ratio }\end{array}$ & $\begin{aligned} \text { rate } & \geq 20 \mu \mathrm{g} / \mathrm{min} \\
& \geq 30 \mathrm{mg} / \mathrm{g}\end{aligned}$ & $\begin{aligned} \text { rate } & \geq 20 \mu \mathrm{g} / \mathrm{min} \\
& \geq 30 \mathrm{mg} / \mathrm{g}\end{aligned}$ \\
\hline
\end{tabular}


Hyperglycemic and pro-oxidative conditions observed in the metabolic syndrome may promote the excess of reactive oxygen species and advanced glycation end products. This may lead to tissue damage and malfunction, the main endogenous inducers of inflammation. Anti-inflammatory markers are not currently used as clinical markers for diagnosis of metabolic syndrome, although some studies are based on the commonly assessed CRP and IL-6 $(7,8)$. Rather than a clinical marker, inflammation is the result of a complex pathogenic mechanism involved in the metabolic syndrome. The complexity of inflammation has to do with its dual nature as physiological reaction of protection to restore homeostasis and its pathological counterpart. The persistence of the inflammatory trigger (e.g. tissue malfunction) may lead to the pathological consequences of a shift in the homeostatic set points, which in turn leads to a low grade chronic inflammatory status (9).

Initially it was believed that the content in fiber was the determinant for the whole-grain health effect, since the outermost layers of the grain are rich in fiber. This belief was based on the fiber hypothesis that arose in the seventies from observational studies in African populations that consumed whole-plant foods high in fiber and were free of Western pathologies (10).

More recent investigations point out that the health benefit of whole grain cannot be merely attributed to the fiber content (11-13). Thus it may be that the "co-passengers" of the fiber, the phytochemicals covalently bound to the cell walls, play a main role in the health promoting effects of whole grain. Numerous phytochemicals are found in wheat grain. Many of them accumulate in the outermost tissues, i.e. the bran, and have antioxidant properties (Chapter 1). A large group of these phytochemicals are the phenolic compounds.

\section{Hypothesis on the molecular mechanisms}

Phenolic compounds are considered as secondary metabolites in the plant physiology. However, to view secondary products in plants merely as waste materials does not coincide with our knowledge of the biochemical specificity of secondary metabolism, the strict regulation of its expression at the genetic level and the precise temporal and spatial regulation of secondary metabolic pathways (14). Ernst Stahl was the first to remark that secondary metabolites, rather than being metabolic by-products, have a role in the plant's interaction with its environment and with other organisms to provide a defense against infection, predation and environmental stress (15). From an evolutionary perspective, this defense has been proposed as an alternative to cope with the static nature of the plants.

Thus, the synthesis of phenolic compounds is stress-induced in the plant as a defensive mechanism. At the same time, they seem to up-regulate pathways that provide stress resistance to animals and humans (Figure 1). This stress resistance 
may be beneficial, such as in the prevention of disease. This phenomena has been called xenohormesis (16). Xeno in Greek means stranger and hormesis is a well defined term used to describe the toxicological action of compounds characterized by a J-shaped or inverted $U$ shaped dose-response. In this toxicological phenomenon, the exposure to a low dose of a toxic agent results in a favorable biological response, the opposite response than to large doses. Already about hundred years ago, it was stated in the Arndt-Schulz Law that all poisons are stimulatory in low doses, i.e. doses below which any toxic effects are probable (17).

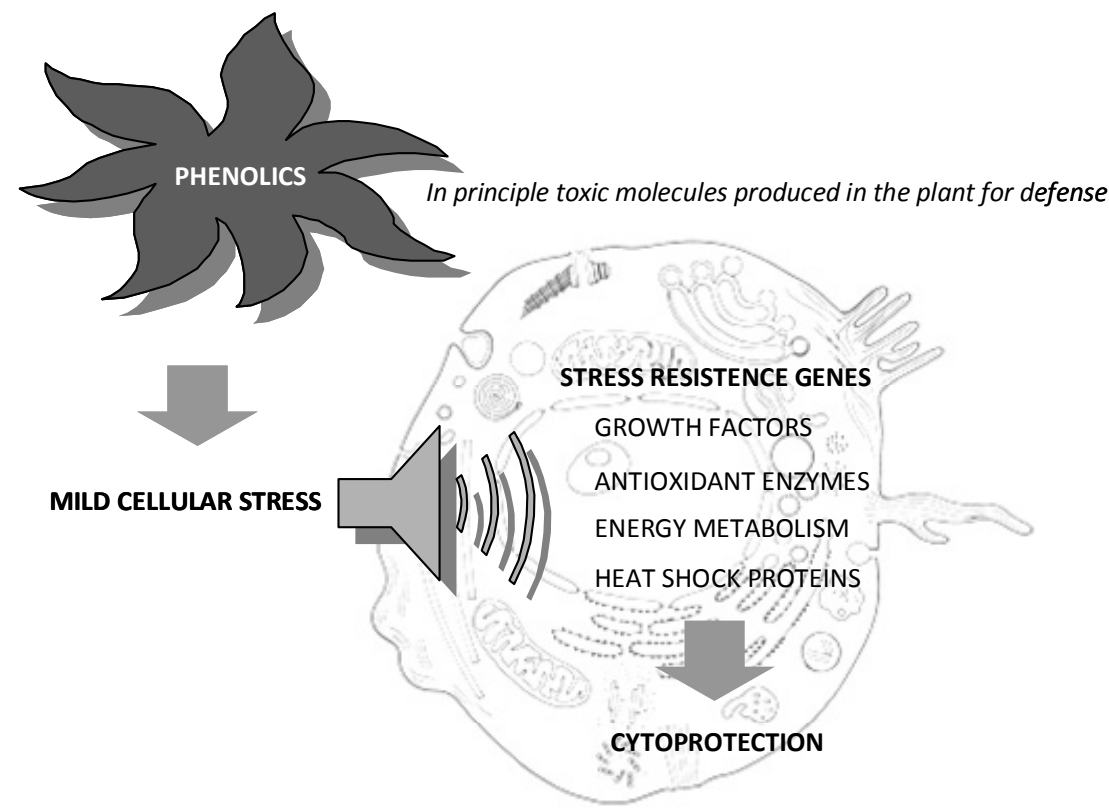

Figure 1. Mechanism of hormesis: plant phenolics exert an stimulatory response of protection in the cell by amplifying the expression of stress resistance genes (18).

An example of this is the low molecular weight phenolic salicylic acid that confers disease resistance to the plant. This molecule, whose synthetic derivative is aspirin, derives from the building block cinnamate (19). Cinnamate is also the metabolic intermediate in the synthesis of the hydroxycinnamates: ferulic acid, sinapic acid, $p$-coumaric acid, and caffeic acid. In plants, these compounds mainly form conjugates with other phenolic compounds, sugars, amines or acid compounds, and are mostly exported to the external tissues and covalently bound into the cell walls. 


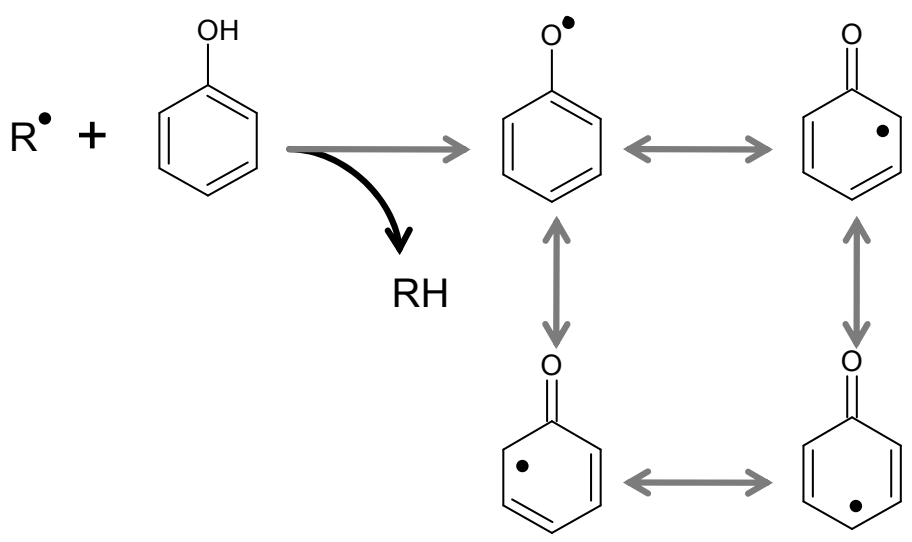

Figure 2: General mechanism of a radical $(\mathrm{R} \bullet)$ scavenging by a phenol. The unlocalized electron $(\bullet)$ of the radical is donated to the phenol. The electron is then stabilized in the different resonance structures of the benzene ring.

The protective activity of phenolic compounds may be the result of various distinct mechanisms that at the same time may be inter-related and synergic. The best known mechanism is free radical scavenging (Figure 2) and the consequent modification of redox regulated signaling pathways.

Phenolic compounds through antioxidant mechanisms can alleviate or prevent oxidative stress and chronic inflammatory status.

\section{Selection of a marker compound for bioactivity in wheat grain (chapter 2)}

Ten different fractions of the wheat grain were obtained by debranning with two different methods (pearling and peeling) preceding the milling. The outermost layers of the wheat grain, i.e. the bran layers, showed the highest antioxidant capacity in comparison to the flour fractions containing mainly the endosperm of the grain. It was observed that the fractions containing more aleurone cells were the highest in antioxidants, namely the aleurone fraction, purified from bran and containing about $95-99 \%$ aleurone cells. The antioxidant capacity of the fraction was strongly correlated with the ferulic acid content. Ferulic acid is the most abundant phenolic compound in wheat grain and the highest content was found in the aleurone fraction. Ferulic acid could explain $60 \%$ of the antioxidant capacity of aleurone.

Ferulic acid is the main contributor to the antioxidant capacity of the wheat fractions and it was therefore selected as a marker of bioactivity. 


\section{BIOAVAILABILITY}

The definition of bioavailability differs among the areas of research.

Typically in pharmacology, bioavailability implies the extent which a drug becomes available in the general circulation. After oral administration, a drug has to overcome a number of hurdles before reaching its sites of action (20).

A drug must: (i) be liberated from its pharmaceutical form (often a tablet), (ii) be dissolved in the gastrointestinal fluid, (iii) escape metabolism by the intestinal flora, (iv) be absorbed through the intestinal wall by passive and/or active (via transporters) permeation, (v) escape metabolism in the gut wall, (vi) escape excretion in the intestine lumen by efflux transporters, (vii) escape metabolism in the blood while being transported to the liver via the portal vein, (viii) escape metabolism in the liver before reaching the general circulation from which it will be cleared, distributed in tissues, excreted, and metabolized.

Taking this definition strictly, the bioavailability of phenolic compounds from most dietary sources is negligible (21). The thorniest issue in the definition of bioavailability is in the question: bioavailabilitity at the site of action? In this case the bioavailability of some phenolic compounds may be very different.

In food science, the concept of bioavailability reflects the efficiency with which food compounds are utilized in the body. In this case, biological activity is an important factor and it leaves open the contribution of the metabolites.

Leaving aside the debate on the definition, the first step in the bioavailability of a food compound is the bioaccessibility from the food source. Bioaccessibility refers to the release of the compound from the food matrix to become available for absorption in the gastrointestinal tract (22).

The bioaccessibility is the first burden in the biological activity of a compound.

\section{Bioaccessibility (chapter 3)}

The bioaccessibility of ferulic acid was studied with the use of an in vitro model of gastrointestinal tract, the multi-compartmental and dynamic TNO intestinal model (TIM). Wheat fractions varying in ferulic acid content (aleurone > bran > flour) and breads: white bread (white flour) and aleurone bread (1:1 white flour : aleurone) were investigated. The bioaccessibility of ferulic acid from wheat fractions and bread products was low $<1 \%$ whereas free ferulic acid added to flour was $60-70 \%$ bioaccessible. The maximal concentration of ferulic acid in the dialysate was reached after 1-2 hours of digestion. Low molecular weight ferulic acid esters were also found in the dialysate, which accounted for approximately another $1 \%$. These esters may be hydrolyzed in vivo by intestinal esterases. Some studies have proposed possible intestinal absorption of small esters of ferulic acid and diferulic acids. Some feruloyl-oligosaccharides have been suggested to have 
some bioactivity too. Nevertheless, most of the ferulic acid was not bioaccessible, and still bound to the cereal matrix will approach the colon.

The low bioaccessibility of ferulic acid from wheat grain can be explained by the covalent binding of most ferulic acid to arabinoxylans and other cell wall polysaccharides that are able to resist digestion in the upper gastrointestinal tract.

The low bioavailability of ferulic acid reported after cereal consumption in humans can be explained by the limited bioaccessibility of ferulic acid from the cereal matrix during gastrointestinal transit.

The bioavailability of ferulic acid is determined by its bioaccessibility which is predominately limited to the free form of the compound in the food matrix.

\section{Antioxidant and anti-inflammatory capacity of bioaccessible compounds (chapter 4)}

The bioaccessibility of antioxidant compounds from the whole-grain matrix is crucial for their absorption and bioavailability. The TIM system has been proved to be a reliable tool to evaluate the bioaccessible compounds from the wheat fractions: flour, bran and aleurone. At 1 hour intervals, the dialysate containing the bioaccessible compounds was collected from the system. The bioaccessible compounds from the wheat fractions exerted antioxidant activity in radical scavenging (TEAC) and anti-inflammatory effects in LPS stimulated U937 macrophages. The bioaccessible compounds from aleurone displayed the highest antioxidant capacity (maximum at 1-2 $\mathrm{h}$ after digestion) and the largest TNF- $\mathrm{\alpha}$ reduction $(67-76 \%)$. The results in the antioxidant capacity were rather modest compared to the large differences in the antioxidant capacity between the wheat fractions. This could be explained by the low bioaccessibility of ferulic acid, and subsequent low concentration of ferulic acid in the dialysate (maximally $4 \mu \mathrm{M}$ ). Although ferulic acid was identified as the main contributor to the antioxidant capacity of the wheat fractions, among the bioaccessible compounds ferulic acid had a limited contribution $(<5 \%)$. The observed antioxidant and anti-inflammatory effects are not merely caused by ferulic acid, but most likely by the synergic action of compounds that despite their individually low concentrations, on the whole exert a significant effect.

By increasing the intestinal release of ferulic acid and other contributing compounds from the cereal matrix, the antioxidant and anti-inflammatory properties of whole grain might be improved. 


\section{Effect of processing on the bioaccessibility (chapter 5)}

Conventional processing conditions such as the grinding during the milling (particle size reduction), and the yeast fermentation during baking can produce modifications in the food matrix that may influence the bioaccessibility of phenolic compounds. Baking had however no effect on the bioaccessibility of ferulic acid from the breads, which was as low as from the unprocessed wheat fractions.

The bioaccessibility of ferulic acid was found to be strongly correlated with the percentage of free ferulic acid in the wheat fraction or bread product. Based on the slope obtained by the linear fit (0.7), the bioaccessibility could be predicted to be $70 \%$ of the free ferulic acid. It should be noted that free ferulic acid does not allude to the strict concept of "free" per se. It makes reference to the ferulic acid that can be extracted chemically without performing hydrolysis. Both the "free" ferulic acid and bound ferulic acid are contained in the food matrix and need to be released to become bioaccessible. The difference is that the bound ferulic acid is attached by covalent binding to complex polysaccharides in the cell wall, while the free ferulic acid may be in solution in cytosol or interacting with components in the cell by non covalent bindings.

The next logical step was to investigate processing techniques targeting the release of bound phenolic compounds from wheat bran such as the use of enzymes targeting specific linkages in the polysaccharides or the use of fermentation systems as source of these enzymes. This type of processing was designated bioprocessing since it needs of the activity of a microorganism in contrast to the physico-chemical processing of baking or grinding.

The enzyme preparations used for the treatment of wheat bran had various cellwall degrading activities, mainly xylanase, cellulose and $\beta$-glucanase. The combined action of these enzymes enables the hydrolysis of different wheat polymers thus improving the solubility and breaking down of the complex cellwall structures in the bran.

Bioprocessing substantially increased the bioaccessibility of phenolic acids in whole-meal breads with bran. The term whole meal refers to the use of $100 \%$ flour made of peeled wheat grains (3.5\% off) for the bread making. The most effective bioprocessing technique was the combination of fermentation with enzymatic treatment of wheat bran, which increased the bioaccessibility of ferulic acid by 5fold compared to native bran, from $1 \%$ to $5 \%$, and other phenolic compounds such as $p$-coumaric acid and sinapic acid were also increased. Still most of the ferulic acid $(95 \%)$ and other phenolics are not bioaccessible and will reach the colon.

Bioprocessing remarkably increased the bioaccessibility of ferulic acid but still most of it is directed to colon where its metabolic fate is unknown. 


\section{COLONIC METABOLISM}

\section{Colonic metabolism of non bioaccessible phenolic compounds (chapter 5)}

Microbial metabolism deserves special attention because many of the diverse polyphenols are broken down into common simpler phenolic compounds. Some of these microbial metabolites could have unique biological effects.

The colonic metabolism of non bioaccessible compounds was studied in vitro with the TNO model of human colon (TIM-2), which was inoculated with complex microbiota of human origin in high density. The non bioaccessible fraction of the digested breads in TIM-1 was used for the TIM-2 experiments.

The amount of total ferulic acid (free and esterified) decreased over the time (24 h) while no substantial increase in free ferulic acid was detected. Instead, some colonic metabolites were identified, mainly phenylpropionic acids with different grades of hydroxylation. In particular 3-hydroxypheylpropionic acid and phenylpropionic acid were produced in the highest amounts.

Based on the pattern of appearance in time and the chemical structure, it is postulated that ferulic acid by reductive reactions and demethylation by bacterial enzymes can result in 3,4-dihydroxyphenylpropionic acid, which by further reductions results in 3-hydroxyphenylpropionic acid and ultimately phenylpropionic acid. Phenylpropionic acid was proposed as the final metabolic product because its production continuously increased over time.

In vivo, the intestinal transit time is largely dependent of the diet and the individual physiology. Nevertheless, $24 \mathrm{~h}$ of experiment were considered to be representative of a normal transit time in colon, after which is followed by another $10 \mathrm{~h}$ for the outwards transit through rectum (23).

In addition to the effect of bioprocessing on the bioaccessibility, also the colonic metabolism of the non bioaccessible phenolic compounds was affected.

The production of phenylpropionic acid was enhanced by the bioprocessing of wheat bran. The colonic enzymes might have displayed higher activity to the partially hydrolyzed bran material (cell-wall polymers binding the phenolics) via an increase in the solubility of the substrate and the accessibility of the enzymes to the substrate.

The compounds 3-hydroxyphenylpropionic acid and phenylpropionic acid were identified as the main colonic metabolites from the non bioaccessible ferulic acid. 


\section{Colonic metabolism of non digestible components: the fiber (chapter 6)}

It has been shown that processing can increase the bioaccessibility of phytochemical compounds through chemical or enzymatic reactions that release them from the food matrix. Similarly, processing may result in structural modifications of the fiber affecting the fermentation properties in the colon.

The effect of bioprocessing on the fiber of wheat bran and the main colonic metabolites, short chain fatty acids, were investigated in the TIM-2 system, as model of human colon.

The production of butyrate, probably the most health promoting colonic metabolite, was approximately double in the whole-meal breads with bioprocessed bran than the whole-meal bread with native bran, the whole-meal bread and the white bread. This effect was only observed in the first 6 hours of colonic experiment, time period in which the bread (firstly digested in TIM-1) was administered. In this period, the fermentability rates of the breads were also the highest. The increase in butyrate was accompanied by a decrease in propionate; while the total production of SCFA remained rather similar among the breads.

Some studies have attributed the increment in butyrate to the fermentation of arabinoxylan $(24,25)$. In our study, the butyrate formation was most likely the result of the higher solubility of the arabinoxylan and presumably other polysaccharides, as a consequence of the bioprocessing of the bran. This is supported by the increase in soluble pentosan observed after the fermentation and enzymatic treatment of the bran. The fermentation and enzymatic treatment of the bran probably increased the fiber fermentability by the partial degradation of complex carbohydrates into smaller molecules of higher solubility.

Bioprocessing of wheat bran enhanced the production of colonic butyrate as consequence of the partial degradation of the fiber and the increase in solubility.

\section{HUMAN STUDY (chapter 7)}

For the ultimate study on the bioavailability of ferulic acid and related compounds, the "from in vitro to in vivo approach" was followed. Based on the in vitro results on the bioaccessibility of phenolic acids, the most efficient bioprocessing technique was selected. This consisted of the combination of yeast fermentation with enzymatic treatment of the wheat bran. The treated bran was added to whole-meal flour to make the bioprocessed bread, whereas the control bread was made of native bran added to whole-meal flour. The total content in phenolic compounds and macronutrient composition was similar for both breads.

The aim of the study was firstly to increase the bioavailability of phenolic compounds from the whole-grain food matrix and secondly to assess the possible 
health effect of this increase on the total plasma antioxidant capacity and inflammatory mediators to ex vivo LPS-challenge in cultured blood.

For this purpose eight healthy male volunteers were enrolled in a cross-over designed study. This design was the most convenient for a short term study like the present one, the characteristics of the paired design makes possible that the same subject acts as a control to compare after the treatment. After a 3-day low phenolic diet, $300 \mathrm{~g}$ of bread were consumed as a single intake and blood and urine was collected in the following 24 hours.

The relative bioavailability, i.e. area under the curve (AUC) of the compound from the bioprocessed bread related to the AUC of the compound from the control bread, was significantly increased for ferulic acid (2.7-fold), vanillic acid (1.8-fold) and 3,4-dimethoxybenzoic acid (1.8-fold). Also the urinary excretion was increased. The maximal increase was in the ferulic acid AUC and $\mathrm{C}_{\max }$. The amount of ferulic acid excreted in urine was also increased. Related to the intake, $10 \%$ of the total content was recovered in urine after consumption of bioprocessed bread compared to the $4 \%$ recovered after consumption of the control bread.

The metabolites increased after 6 hours posterior to bread ingestion were 3hydroxyphenylpropionic acid and phenylpropionic acid. The time course of their plasmatic appearance and structural similarities indicate their colonic origin as previously proposed in vitro. However, the limited number of time-concentration points (no blood collection overnight) did not make possible the pharmacokinetic analysis of AUC, $C_{\max }$ and $t_{\max }$ for these compounds.

Benzoic acid and hippuric acid, although to some extent they can originate from $\beta$-oxidation of phenylpropionic acid to benzoic acid and further glycineconjugation to form hippuric acid in liver, are not specific of ferulic acid metabolism. They can be formed from many other aromatic compounds, such as phenylalanine and phenyltyrosine from dietary protein as well as endogenous formation.

The contribution of ferulic acid to the total antioxidant capacity in plasma was very limited $(6 \%)$, less than that of the endogenous antioxidant uric acid $(22 \%)$. This explains the mild effect on the postprandial antioxidant capacity despite the increment in the bioavailability of ferulic acid.

The anti-inflammatory effect (decrease in IL-6/IL-10 and IL-1 $\beta /$ IL-10) of the bioprocessed bread compared to the control bread was only significant in the cultured blood that was collected at $1 \mathrm{~h} 15 \mathrm{~min}$ after the bread ingestion, which is near the $t_{\max }$ of ferulic acid (1h $\left.30 \mathrm{~min}\right)$.

Bioprocessing can remarkably increase the bioavailability of phenolic compounds and their consequent circulating concentrations. This seems a promising strategy to optimize the healthy value of whole-grain foods. 


\section{SAFETY ASPECTS}

The safety of ferulic acid has been investigated by administration of sodium ferulate (SF), which dissociates at physiological $\mathrm{pH}$. The acute oral $\mathrm{LD}_{50}$ of SF in mice is $3.2 \mathrm{~g} / \mathrm{kg}$ body weight (26). In a subchronic toxicity study in rats, $0.6 \mathrm{~g}$ of SF per $\mathrm{kg}$ per day for 3 months by intragastric administration did not produced hematological changes or pathophysiological changes in the main organs (27). In humans, intravenous doses of 200-300 mg SF per day (approx. 3-4 mg/ kg body weight) for two weeks have been used in patients with angina pectoris and acute myocardial infarction, the major clinical manifestations of coronary heart disease. In rare instances SF caused headache, nausea, abdominal discomfort or skin rash. These adverse reactions disappeared rapidly after discontinuation of the therapy (27).

The daily intake of ferulic acid in humans has been estimated to reach 150-250 $\mathrm{mg} /$ day through the consumption of cereals, coffee, juices, vegetables and fruits. In an average adult, this means an intake of 2-4 $\mathrm{mg}$ of ferulic acid per $\mathrm{kg}$ of body weight. Taking into account that around $90 \%$ of the dietary ferulic acid appear to be not bioaccessible for intestinal absorption, the amount of ferulic acid that is actually bioavailable is approximately 10,000-fold below the acute toxic dose and 2,000 times lower than the non-observed-adverse-effects level (NOAEL) given above.

Optimizing the processing of cereal products to increase the bioavailability of ferulic acid is safe. 


\section{REFERENCES}

1. Ford ES, Giles WH, Dietz WH. Prevalence of the Metabolic Syndrome Among US Adults: Findings From the Third National Health and Nutrition Examination Survey. JAMA. 2002;287:356-9.

2. Tonkin A. The metabolic syndrome - a growing problem. Eur Heart J Suppl. 2004;6:A37-42.

3. Meigs JB, Wilson PWF, Fox CS, Vasan RS, Nathan DM, Sullivan LM, D'Agostino RB. Body Mass Index, Metabolic Syndrome, and Risk of Type 2 Diabetes or Cardiovascular Disease. J Clin Endocrinol Metab. 2006;91:2906-12.

4. Wilson PWF, Meigs JB. Risk of type 2 diabetes mellitus and coronary heart disease: a pivotal role for metabolic factors. European Heart Journal Supplements. 2008;10 B11B5.

5. Grundy SM, Brewer HB, Jr., Cleeman JI, Smith SC, Jr., Lenfant C, for the Conference P. Definition of Metabolic Syndrome: Report of the National Heart, Lung, and Blood Institute/American Heart Association Conference on Scientific Issues Related to Definition. Circulation. 2004;109:433-8.

6. Alberti KGMM, Zimmet PZ, Consultation WHO. Definition, diagnosis and classification of diabetes mellitus and its complications. Part 1: diagnosis and classification of diabetes mellitus. Provisional report of a WHO Consultation. Diabetic Medicine. 1998;15:539-53.

7. Ridker PM, Buring JE, Cook NR, Rifai N. C-Reactive Protein, the Metabolic Syndrome, and Risk of Incident Cardiovascular Events: An 8-Year Follow-Up of 14719 Initially Healthy American Women. Circulation. 2003;107:391-7.

8. Spranger J, Kroke A, Möhlig M, Hoffmann K, Bergmann MM, Ristow M, Boeing H, Pfeiffer AFH. Inflammatory Cytokines and the Risk to Develop Type 2 Diabetes. Diabetes. 2003;52:812-7.

9. Medzhitov R. Origin and physiological roles of inflammation. Nature. 2008;454:428-35.

10. Trowell $\mathrm{H}$. The development of the concept of dietary fiber in human nutrition. Am J Clin Nutr. 1978;31:3S-11.

11. Anderson JW. Whole grains and coronary heart disease: the whole kernel of truth. American Journal of Clinical Nutrition. 2004;80:1459-60.

12. Liu S. Whole-grain foods, dietary fiber, and type 2 diabetes: searching for a kernel of truth Am J Clin Nutr. 2003;77:527-9.

13. Truswell AS. Cereal grains and coronary heart disease. Eur J Clin Nutr. 2002;56:1-14.

14. Rhodes MJC. Physiological roles for secondary metabolites in plants: some progress, many outstanding problems. Plant Mol Biol. 1994;24:1-20.

15. Stahl E. Pflanzen und Schnecken, Biologische Studie tiber die Schutzmittel der Pflanzen gegen Schneckenfrass. Jenaische Z Naturwiss 1988;22:657-84

16. Howitz KT, Sinclair DA. Xenohormesis: sensing the chemical cues of other species. Cell. 2008;133:387-91.

17. Lindsay DG. Nutrition, hormetic stress and health. Nutr Res Rev. 2005;18:249-58.

18. Mattson MP. Hormesis Defined. Ageing Res Rev 2008;7:1-7.

19. Maffei M. Dietary supplements of plant origin. A nutrition and health approach. London: Taylor \& Francis; 2003.

20. van de Waterbeemd H, Testa B. Drug Bioavailability: Estimation of Solubility, Permeability, Absorption and Bioavailability. WILEY-VCH Verlag GmbH \& Co. KGaA, Weinheim; 2009. 
21. Manach C, Williamson G, Morand C, Scalbert A, Remesy C. Bioavailability and bioefficacy of polyphenols in humans. I. Review of 97 bioavailability studies. Am J Clin Nutr. 2005;81:230S-42S.

22. Stahl W, van den Berg H, Arthur J, Bast A, Dainty J, Faulks RM, Gartner C, Haenen G, Hollman P, Holst B, Kelly FJ, Polidori MC, Rice-Evans C, Southon S, van Vliet T, VinaRibes J, Williamson G, Astley SB. Bioavailability and metabolism. Mol Aspects Med. 2002;23:39-100.

23. Arhan P, Devroede G, Jehannin B, Lanza M, Faverdin C, Dornic C, Persoz B, Tétreault L, Perey B, Pellerin D. Segmental colonic transit time. Dis Colon Rectum. 1981;24:625-9.

24. Hughes SA, Shewry PR, Li L, Gibson GR, Sanz ML, Rastall RA. In Vitro Fermentation by Human Fecal Microflora of Wheat Arabinoxylans. J Agr Food Chem. 2007;55:458995.

25. Salvador Vr, Cherbut C, Barry J-L, Bertrand D, Bonnet C, Delort-Laval J. Sugar composition of dietary fibre and short-chain fatty acid production during in vitro fermentation by human bacteria. Brit J Nutr. 1993;70:189-97.

26. Tada Y, Tayama K, Aoki N. Acute Oral Toxicity of Ferulic Acid, Natural Food Additive, in Rats. . Annual Report of Tokyo Metropolitan Research Laboratory of Public Health 1999;50.

27. Bao-Hua W, Jing-Ping O-Y. Pharmacological Actions of Sodium Ferulate in Cardiovascular System. Cardiovas Drug Rev. 2005;23:161-72. 


\section{PERSPECTIVES}

Progress is being made in understanding the role of bioactive compounds in reducing the risk of chronic diseases, and in unraveling the mechanism of these effects. Consequently, a diet rich in food sources of these bioactive compounds is generally recommended. However, once the main food bioactives have been identified, their efficacy needs to be evaluated. In order to evaluate their efficacy, the bioavailability, pharmacokinetic behavior, dose-dependency, safety and molecular mechanism of action should be established.

Most of these points have been addressed in the present thesis. The investigations described in it highlight ferulic acid as an important bioactive compound in whole grain. The main findings were: (i) that the bioavailability of the main phenolic acids could be double or triple by an adequate processing of the bran, the fraction of the grain containing most of these bioactives, and secondly, (ii) that by increasing their bioavailability, the anti-inflammatory properties of wholemeal bread could be enhanced.

Some further research is needed to increase our knowledge in the following aspects:

\section{Biological activity of the colonic metabolites}

The main colonic metabolites of the phenolic compounds in whole-meal bread have been identified in this thesis. Considering the low bioavailability of polyphenols from most food sources, much of their described in vivo health benefits may actually involve their colonic metabolism into other compounds. Still the actual biological activity of these colonic metabolites is unknown as well as their mechanisms of action.

\section{Long term benefit}

By increasing the bioavailability of ferulic acid and other phenolics, the antiinflammatory effect of whole-meal bread can be enhanced. This was achieved by an optimized processing technique. The health benefit of long term consumption of such an optimized whole-meal product should also be investigated within the regular diet, in which other sources of phenolics such as fruit and vegetables are not restricted.

\section{Optimal bioavailability}

The low bioavailability of phenolic acids from whole grain could be increased by an optimized processing, which makes possible the development of wholegrain products of added value. However, the optimal bioavailability of these compounds is still to be found. For this purpose, dose-dependency relationships 
should be established between the uptake of bioactive compounds and the health effect, such as reducing inflammation.

The above research is necessary in transforming cereal foods into efficient functional foods to manage disease prevention. Functional food is a concept that originated from the terms nutrition and pharmaceutical, and that refers to food or food substances that provide health or disease prevention beyond the basic nutritive value. Functional food development is the most recent trend in the evolution of food, nutrition, and health. This field emerged from the growing knowledge that the diet influences the health, quality of life, and chronic diseases of aging. This evolved a "self-care" movement with an increasing awareness of the individual consumer in proactively managing health and wellness through a wellbalanced diet.

In principle, this is feasible in countries with economic wellness. In Third World countries, the nutritional priority is to solve hunger by the supply of a sufficient caloric intake with little regard of the source. This has lead to the growing and widespread problem of "hidden hunger", as reported by the WHO. The term of "hidden hunger" does not refer to the obvious hunger of not having enough to eat, but to a more insidious type caused by eating food that is cheap and filling but deficient in essential vitamins, micronutrients and phytochemicals.

Process-improved food with a high bioavailability of bioactives, such as bioprocessed whole-grain bread, can provide a high supply of these compounds for those suffering of deficiencies. Future research in this line will be conducted, in which cooperation among multidisciplinary academic research groups, the industry, and government regulatory agencies is necessary to ensure success. 


\section{SUMMARY}

The research presented in this $\mathrm{PhD}$ thesis has been conducted within the HealthGrain project, which is financed by the European Commission. In this project, the main European bread grain varieties have been extensively investigated in response to the findings of epidemiological studies that link wholegrain consumption to a lower risk for cardiovascular disease, type 2 diabetes and the metabolic syndrome. In an integrated and multidisciplinary approach, the process-induced changes and human metabolism of bioactive compounds in whole grain have been investigated. The aim was to reveal the physiological mechanisms underlying their health benefit in order to possibly optimize it. Bioactive components found in wheat grain are: vitamins (vitamin E, folate and other B vitamins), minerals (iron, magnesium, selenium), phytochemicals (lignans, sterols, alkylresorcinols, phenolic acids) and indigestible carbohydrates (fibre). The focus of this thesis has been on those bioactive compounds in whole grain wheat that contribute to the antioxidant and anti-inflammatory properties.

The main findings can be summarized according to five research goals met in this thesis:

Identification of the healthy fractions of a wheat grain. Different fractions of the wheat grain were determined for antioxidant and anti-inflammatory effects in vitro. The outer-most fractions of the grain, the bran and within this one the aleurone layer, exerted the largest and most prolonged effects. Paradoxically, these fractions are usually discarded in the milling to obtain the refined flour, while they are mostly incorporated in the whole-meal flour, the basis of the "whole grain" concept in cereal products.

Identification of the main bioactive compounds. Ferulic acid appeared to be responsible for the most of the antioxidant capacity. This phenolic compound is the most abundant antioxidant in wheat grain and, therefore, it was chosen as a marker for antioxidants in wheat grain.

Bioavailability studies. The gastrointestinal release of bioactive compounds from cereal fractions and products was assessed in vitro. The release of a compound from the food matrix to become available for absorption is defined by the term of "bioaccessibility". The poor bioaccessibility of ferulic acid from the cereal matrix limits the bioavailability of this compound after whole-grain consumption, and this is likely applicable to other bioactive compounds as well.

Effect of processing on the bioaccessibility. The effect of several processing techniques of bran was investigated on the bioaccessibility of phenolic compounds. Furthermore, the colonic metabolism of the non bioaccessible phenolics was 
investigated. Bioprocessing of bran, consisting of yeast fermentation combined with enzymatic treatment, could increase the bioaccessibility of ferulic acid 5-fold from whole-meal wheat bread. The colonic metabolism of the non bioaccessible ferulic acid into other compounds (mainly 3-hydroxyphenylpropionic acid and phenylpropionic acid) was also boosted by the bioprocessing. The bioprocessing also affected the colonic fermentation of fibre, which resulted in an increased production of butyrate.

Health benefit. An in vivo intervention with healthy subjects was conducted to confirm the effects of bioprocessing of whole-meal bread on the bioavailability of phenolic compounds. Additionally, the postprandial antioxidant and antiinflammatory effects of bioprocessed whole-meal bread were investigated. Bioprocessing increased the bioavailability of ferulic acid among other phenolics by 3-fold from the whole-meal bread. The effect on the total antioxidant capacity in plasma was negligible. Before and after the bread consumption, blood was drawn from the volunteers, and subsequently an inflammatory response was induced $e x$ vivo. The anti-inflammatory effect of consuming bioprocessed bread versus control bread was assessed by the decrease in the ratio of pro-inflammatory and antiinflammatory cytokines. Bioprocessing enhanced the anti-inflammatory effect of whole-meal bread. This finding highlights processing as a useful tool to optimize the benefits of whole-grain consumption.

It is widely known that consuming whole-grain products brings health benefits. This is associated with its rich content in bioactive compounds, such as ferulic acid, which are mostly found in the outer-layers of the wheat grain, normally discarded in the milling to obtain the refined flour. Not only the intake of bioactives plays a role in the health benefit, also their actual uptake from whole-grain products should not be overlooked. Processing can have a favorable impact on their bioavailability and subsequent biological activity, in that way the health benefit of whole-grain products can be optimized. 


\section{RESUMEN}

Las investigaciones recogidas en esta tesis doctoral han sido desarrolladas dentro del proyecto HealthGrain, financiado por la Comisión Europea. En dicho proyecto, las principales variedades europeas de cereal de panadería han sido extensivamente investigadas en respuesta a los hallazgos de estudios epidemiológicos que asocian el consumo de productos de cereal integral con un menor riesgo de padecer enfermedades cardiovasculares, diabetes tipo 2 y síndrome metabólico. Siguiendo una estrategia de integración multidisciplinar, los cambios inducidos por el procesado y el metabolismo de los compuestos bioactivos en el cereal han sido investigados. El objetivo de estas investigaciones ha sido el de revelar los mecanismos fisiológicos que explican dicho efecto saludable para así poder optimizarlo. El grano de trigo contiene numerosos compuestos bioactivos: vitaminas (vitamina $\mathrm{E}$, folatos y otras vitaminas del grupo B), minerales (hierro, magnesio, selenio) y phytoquímicos (lignanos, alquilresorcinoles, ácidos fenólicos) y carbohidrato indigestible (fibra). Esta tesis se concentra en los compuestos bioactivos del grano de trigo integral que le confieren propiedades antioxidantes y anti-inflamatorias.

Los hallazgos de mayor importancia se han resumido atendiendo a los principales objetivos de las investigaciones englobadas en esta tesis:

Identificación de las fracción saludable del grano de trigo. La capacidad antioxidante y anti-inflamatoria de diferentes fracciones del grano de trigo se determinó con modelos in vitro. Los mayores y más prolongados efectos antioxidante y anti-inflamatorio fueron obtenidos con las capas más superficiales del grano de trigo, el salvado y dentro de éste la aleurona. Paradójicamente, estas fractiones del cereal se suelen descartar durante la molienda para obtener harina refinada, mientras que suelen ser incorporados en la harina integral, la base del producto cereal integral.

Identificación de los principales compuestos bioactivos. El ácido ferúlico resultó ser el responsable de la mayor parte de la capacidad antioxidante. Este compuesto fenólico es el antioxidante más abundante en el grano de trigo y por ello fue seleccionado como marcador de los antioxidantes en trigo.

Estudios de biodisponibilidad. La liberación gastrointestinal de los compuestos bioactivos de las fracciones del trigo y del producto cereal fue determinada in vitro. La liberación de un compuesto de la matriz alimenticia para hacer posible su absorción, se define con el término de "bioaccesibilidad". La escasa bioaccesibilidad del ácido ferúlico de la matriz cereal limita la biodisponibilidad de este compuesto al ingerir productos integrales, y esto sea posiblemente aplicable a otros compuestos bioactivos del cereal. 
El efecto del procesamiento alimentario sobre la bioaccesibilidad. Varias técnicas de procesado del salvado de trigo fueron investigadas en cuanto a sus efectos sobre la bioaccesibilidad de compuestos fenólicos. El bioprocesado del salvado, que consiste en la fermentación alcohólica a base de levadura y la aplicación de tecnología enzimática, logró aumentar por cinco la bioaccessibilidad del ácido ferúlico en pan integral. Además, la metabolización colónica del ácido ferúlico a otros compuestos (principalmente ácido 3-hidroxifenil propiónico y ácido fenil propiónico) fue favorecida por el bioprocesado. El bioprocesado también afectó a la fermentación colónica de la fibra, que resultó en una incrementada producción de butirato.

Beneficio para la salud. Una intervención in vivo en sujetos sanos fue llevada a cabo con el fin de confirmar los efectos del bioprocesado aplicado a pan integral sobre la biodisponibilidad de compuestos fenólicos. Adicionalmente, los efectos antioxidante y anti-inflamatorio tras el consumo del pan integral fueron investigados. El bioprocesado triplicó la biodisponibilidad de ácido ferúlico entre otros fenoles del pan integral. No se detectó efecto alguno del bioprocesado sobre la capacidad antioxidante en plasma. Antes y después de la ingesta del pan integral, se extrajo sangre de los voluntarios, en la que posteriormente se indujo una respuesta inflamatoria ex vivo. El efecto anti-inflamatorio de la ingesta de pan integral bioprocesado frente al pan integral control fue determinado por una disminución en la relación entre citocinas pro-inflamatorias y anti-inflamatorias. El bioprocesado aumentó el efecto anti-inflamatorio del pan integral. Este descubrimiento resalta el uso del procesado alimentario como herramienta útil para optimizar los beneficios asociados al consumo de productos integrales.

Es generalmente reconocido que el consumo de productos integrales conlleva beneficios para la salud. Esto se ha asociado a su rico contenido en compuestos bioactivos, como el ácido ferúlico, que se encuentran principalmente en las capas más superficiales del grano de trigo, que son normalmente descartadas en la molienda para obtener la harina refinada. No solamente la ingesta de estos compuestos bioactivos es importante para el beneficio de la salud, también su biodisponibilidad no debería ser subestimada. El procesado alimentario puede tener un impacto favorable en su biodisponibilidad y consecuente actividad biológica, con lo que el efecto saludable del producto de cereal integral puede ser optimizado. 


\section{SAMENVATTING}

Het promotieonderzoek beschreven in dit proefschrift is uitgevoerd binnen het HealthGrain project van de Europese Unie. Binnen dit project wordt onderzoek gedaan naar het gezondheidsbevorderend effect van granen die gebruikt worden voor brood. Uit epidemiologisch onderzoek is naar voren gekomen dat de consumptie van volkorenbrood een gunstig effect heeft op het optreden van harten vaatziekten en op de complicaties van diabetes. Met een multidisciplinaire benadering wordt het effect van het productieproces en van het metabolisme in de mens op de biologisch actieve stoffen in brood bestudeerd. Het doel is om de fysiologische mechanismen die ten grondslag liggen aan de gezondheidsbevorderende werking te ontrafelen en het gezondheidseffect te optimaliseren. De bioactive verbindingen in tarwekorrels zijn vitaminen (zoals folaat en vitamine E), phytochemicaliën (lignanen, sterolen, alkylresorcinolen, fenol zuren) en onverteerbare koolhydraten zoals vezel.

Het promotieonderzoek heeft zich toegespitst op de bioactive verbindingen in tarwekorrels die verantwoordelijk zijn bij de antioxidant en ontstekingsremmende werking. De belangrijkste bevindingen, gerangschikt naar de vijf onderzoekdoelstellingen van het onderzoek zijn:

Identificatie van de gezondheidsbevorderende fracties van de tarwekorrels.

Van verschillende fracties van de graankorrel werden in vitro de antioxidant en ontstekingsremmende activiteit bepaald. De fracties die afkomstig zijn van de buitenkant van de korrel (de zemelen en het aleuron) bleken de hoogste activiteit te bezitten. Deze fracties worden bij de productie van geraffineerde bloem veelal weggegooid. Dit in tegenstelling tot de productie van volkorenmeel, de grondstof voor de tarweproducten van het "volkoren" concept.

Identificatie van de belangrijkste bioactive verbindingen. Ferulazuur bleek grotendeels verantwoordelijk te zijn voor de antioxidantcapaciteit van tarwe. Het is de meest voorkomende antioxidant in de tarwekorrel. Mede daarom is deze fenolische verbinding gekozen als marker voor antioxidanten in de tarwekorrel.

Studie naar de biologische beschikbaarheid. Het vrijkomen van bioactive verbindingen uit de graanfracties en producten in het maagdarmkanaal werd in een in vitro model bepaald. Gevonden werd dat de biologische beschikbaarheid van ferulazuur en waarschijnlijk andere bioactive verbindingen wordt gelimiteerd door het vrijkomen uit de voedselmatrix, een proces aangeduid met de term "bioaccessibility".

Effect van de voorbewerking op de "bioaccessibility". Het effect van bewerking (fermentatie en enzym behandeling) van de zemelenfractie van 
volkorenbrood op het vrijkomen van bioactive verbindingen in de darm en op het metabolisme in het colon werd onderzocht. Het bleek dat de toegepaste behandeling de bioaccessibility van ferulazuur met een factor 5 vergrootte. Daarnaast nam hierdoor ook het metabolisme van fenolen in het colon toe. Bovendien werd de fermentatie van vezel in het colon verbeterd, hetgeen resulteerde in een verhoogde butyraatproductie.

Gezondheidswinst. Een pilot interventiestudie in gezonde proefpersonen werd uitgevoerd naar het effect van de bewerkingsprocedure op de biologische beschikbaarheid van fenol verbindingen. Ook de antioxidant en ontstekingremmende activiteit werd bepaald. Het bleek dat door voorbewerking de biologische beschikbaarheid van onder meer ferulazuur uit volkorenbrood verdrievoudigde. De bewerkingsprocedure had geen meetbaar effect op de postprandiale antioxidantcapaciteit van plasma van de gezonde proefpersonen. In het bloed werd na een ex vivo stimulatie de ontstekingsreactie gemeten door de ratio van pro- en anti-inflammatoire cytokines te bepalen. De bewerking van de volkorenproducten bleek hierop een gunstig effect te hebben. Deze resultaten wijzen erop dat bewerkingstechnieken de gezondheidswinst van volkorenproducten zou kunnen vergroten.

Het is algemeen bekend dat het eten van volkerenproducten bevorderlijk is voor de gezondheid. Dit wordt in verband gebracht met het hoge gehalte aan bioactive verbindingen die voornamelijk in de buitenste laag van de graankorrel zitten, een laag die gewoonlijk weggegooid wordt bij het malen. Naast de hoeveelheid geconsumeerd, speelt ook de uiteindelijke opname van biologische verbindingen uit volkerenproducten mee. Voorbewerking kan een gunstig effect hebben op de opname en de daaropvolgende biologische activiteit. Hierdoor neemt de behaalde gezondheidswinst van volkerenproducten toe. 


\section{PUBLICATIONS}

Ferulic acid from aleurone determines the antioxidant potency of wheat grain (Triticum aestivum L.).

Authors: Nuria Mateo Anson, Robin van den Berg, Rob Havenaar, Aalt Bast, Guido R M M Haenen.

Source: Journal of Agricultural and Food Chemistry. 2008. Vol. 56, pp. 5589-5594.

Bioavailability of ferulic acid is determined by its bioaccessibility.

Authors: Nuria Mateo Anson, Robin van den Berg, Rob Havenaar, Aalt Bast, Guido R M M Haenen.

Source: Journal of Cereal Science. 2009. Vol. 49. pp. 296-300.

Antioxidant and anti-inflammatory capacity of bioaccessible compounds from wheat fractions after gastrointestinal digestion.

Authors: Nuria Mateo Anson, Robert Havenaar, Aalt Bast, Guido R M M Haenen.

Source: Journal of Cereal Science. 2010. Vol. 51, pp. 110-114.

Bioprocessing of wheat bran improves in vitro bioaccessibility and colonic metabolism of phenolic compounds.

Authors: Nuria Mateo Anson, Emilia Selinheimo, Rob Havenaar, Anna-Marja Aura, Ismo Mattila, Pekka Lehtinen, Aalt Bast, Kaisa Poutanen, Guido R M M Haenen.

Source: Journal of Agricultural and Food Chemistry. 2009. Vol. 57, pp. 6148-6155.

Bioprocessed wheat bran in whole-meal breads increases colonic butyrate production.

Authors: Nuria Mateo Anson, Wouter Vaes, Robert Havenaar, Koen Venema, Aalt Bast, Guido R M M Haenen.

Source: Food Chemistry, submitted.

Effect of bioprocessing of wheat bran in whole-meal breads on the bioavailability of phenolic compounds and postprandial antioxidant and anti-inflammatory potential.

Authors: Nuria Mateo Anson, Robin van den Berg, Emilia Selinheimo, Anna-Marja Aura, Ismo Mattila, Robert Havenaar, Wouter Vaes, Pekka Lehtinen, Kaisa Poutanen, Aalt Bast, Guido R. M. M. Haenen.

Source: This thesis, in preparation 
Dry-fractionation of wheat bran increases the bioaccessibility of phenolic acids in breads made from processed bran fractions.

Authors: Youna M. Hemery, Nuria Mateo Anson, Rob Havenaar, Guido H.M.M. Haenen, Martijn W.J. Noort and Xavier Rouau.

Source: Food Research International, submitted.

Effet des procédés de fractionnement sur la composition et quelques propriétés nutritionnelles des produits céréaliers.

Authors: Rouau, X., Mateo Anson, N., Barron, C., Chaurand, M., Lullien-Pellerin, V., Mabille, F., Samson, M.F., Abecassis, J., Hemery, Y.

Source: Cahiers de Nutrition et de Diététique, in press.

\section{PROCEEDINGS}

Low bioaccessibility of ferulic acid in wheat grain.

Authors: Nuria Mateo Anson, Robin van den Berg, Rob Havenaar, Aalt Bast, Guido R M M Haenen.

Source: Polyphenols Communications 2008.

Antioxidant and anti-inflammatory potency of different wheat varieties and fractions.

Authors: Nuria Mateo Anson, Robin van den Berg, Rob Havenaar, Aalt Bast, Guido R M M Haenen.

Source: Proceedings of the Nutrition Society. 2008. 67:E56

Fermentation-induced changes on the structural and nutritional properties of bran. Authors: Kati Katina, Arja Laitila, Pekka Lehtinen, Nuria Mateo Anson, Rob Havenaar, Kaisa Poutanen.

Source: Cereal Foods World. 2009. Vol. 54, OS21

\section{POSTERS}

Antioxidant potency of different wheat varieties and fractions.

Authors: Nuria Mateo Anson, Robin van den Berg, Rob Havenaar, Aalt Bast, Guido R M M Haenen.

Conference: 10th European Nutrition Conference FENS 10-13 July 2007, Paris, France. 
Antioxidant and anti-inflammatory potency of different wheat varieties and fractions.

Authors: Nuria Mateo Anson, Robin van den Berg, Rob Havenaar, Aalt Bast, Guido R M M Haenen.

Conference: 1st International Immunonutrition Workshop, 3-5 October 2007, Valencia, Spain.

Low bioaccessibility of ferulic acid in wheat grain.

Authors: Nuria Mateo Anson, Robin van den Berg, Rob Havenaar, Aalt Bast, Guido R M M Haenen.

Conference: 24th International Conference on Polyphenols, 8-11 July 2008, Salamanca, Spain.

\section{PRESENTATIONS}

HealthGrain. In: VLAG PhD week. 30 October - 2 November 2006, Emelo, Netherlands.

HealthGrain. In: Socrates intensive programme "Food and Health", 18 February -3 March 2007, Cluj Napoca, Romania.

Antioxidant and anti-inflammatory capacity of wheat fractions. In: Joint annual EU-meeting, 6-8 June 2007, Budapest, Hungary.

Product characteristics, release features and bioaccessibility of components associated with the "whole grain concept". In: Joint EU-project meeting, 15-17 January 2008, Cork, Ireland

Bioactive compounds in wheat grain. In: "Health benefits of whole grain components and products - new insights and support of claims" General Assembly EU-meeting, 6th IP Workshop, 11-13 June 2008, Madrid, Spain.

Different processing of whole-grain breads influences colonic butyrate production. In: "Grains as a source of dietary fiber for human wellness" symposium at AACC International annual meeting, 21-24 September 2008, Honolulu, Hawaii.

Product characteristics, release features and bioaccessibility of components associated with the "whole grain concept". In: Joint EU-project meeting, 14-15 January 2009, Warsaw, Poland. 
The nutritional impact of bioactive compounds in wheat grain. In: CSM IP meeting, 2nd April 2009, Bingen am Rhein, Germany.

The role of bio-available and non-available ferulic acid. In: "What could make cereal foods healthy? Bioavailability and physiological impact of nutrients and non-nutrients. General Assembly EU-meeting, 8th IP Workshop and NIN, 10-11 June 2009, La Grande Motte, France.

Anti-inflammatory effect of breads in relation to the bioavailability of phenolic compounds. In: The 3rd International Immunonutrition Workshop, 21-24 October 2009, Girona, Spain.

Bioavailability studies of phenolic compounds in wheat grain "from in vitro to in vivo approach". In: Joint EU-project meeting, 15-17 January 2010, Saariselkä, Finland. 


\section{Curriculum vitae}

Nuria Mateo Ansón was born on the $9^{\text {th }}$ June 1982, in Zaragoza, Spain. In 2000, she concluded her Secondary Education in the IES Goya with magna cum laude. From 2000 to 2005, she studied in the Faculty of Veterinary of Zaragoza obtaining the degree of MSc in Veterinary Sciences specialized in Food Science, Public Health and Food Technology. In 2005, she collaborated in a developing project about dairy products in collaboration with the Technological University Equinoccial in Ecuador. Later that year, she received the Leonardo da Vinci grant within the mobility programme for training and education of the European Commission. Through this programme, she conducted an internship at TNO Quality of Life in Zeist, The Netherlands. From 2006 to 2010, she has been working in her doctoral thesis at the Department of Pharmacology and Toxicology of Maastricht University and at the Department of Analytical Research of TNO Zeist. Her PhD project was part of the HealthGrain project, funded by the Sixth Framework Programme of the European Commission. During that time, she also obtained the Pedagogical Aptitude Certificate of the Institute of Educational Sciences of Zaragoza. Among other courses, she was trained in the Problem Based Learning system of the Maastricht University. Her international interest brought her to participate in the EU-Socrates Intensive Programme "Food and Health" in Romania and in several working collaborations with HealthGrain partners in Finland (VTT) and France (INRA). In 2008, she received the AACC International Nutrition Division Travel Award for her oral presentation at the AACC annual meeting in Honolulu, USA. In 2009, she received the Exxentia International Award for young researchers in the area of medicinal plants and nutritional plant species. Recently, she has been awarded with the Kootstra Fellowship for talented future Postdoctoral researchers at the Faculty of Medicine, Health and Life Sciences of the Maastricht University. 


\section{ACKNOWLEDGEMENTS}

\section{Starting in a chronological order....}

\section{ZARAGOZA}

\section{MADRID}

\section{AZUARA}

\section{ZARAGOZA}

Primeramente he de agradecer a mis padres y abuelos. Gracias porvuestro cariño y apoyo. También por haberme motivado en la formación académica, especialmente en el aprendizaje de idiomas, que aunque no siempre me gustaban, si que despertaron en mi un cierto interés por viajar.

Edu, me alegro de tener un hermano siempre tan interesado en la ciencia y de extraordinaría capacidad mental, siempre pensamos que tu serías el científico. Elena, gracias por el efecto tan positivo que ejerces en él día a día. Por supuesto, gracias a los dos por vuestra hospitalidad en Madrid, aunque a veces la nevera estuviera casi vacía.

Azuarinas! Sari, Esther e isabel, qué bonitos recuerdos de nuestra infancia en el pueblo! Gracias también por las visitas y cartas!

Goyescas! Ana, Bea B, Bea P, Letí, Mamen, Cecí... Los tantos cumpleanos celebrados en vuestra compañía, nuestras primeras salidas nocturnas, primeros viajes (Berlin, cambrils)... inolvidables! Gracias! Y que buenas vuestras visitas a Holanda: ceci yJavi, y tambien Ana, Leti y Nieves, batisteis el record de número de ciudades en 4 dias y conmigo a veces de copiloto, increíble! Gracias por las fotos tan artisticas del album interminable! :)

ZARAGOZA CUENCA SANTANDER HUESCA BARCELONA

Veterinarios! Píli, Carlitos, Muni, Diego, Ainhoa, Bertis, Martis, Clari, Martita, Celia, Teresa, Alberto M, Alberto E yjuan, "biólogo inculado", gracias por las innumerables fiestas (patrones, paso de Ecuador, fin de carrera), cenas, trabajos compartidos (explotaciones en infecciosas, el trabajo de carne), apuntes prestados, partidos de vóley, acampadas (Pirineo Sur, Ayerbe...), viajes (santander con tecno, Barcelona Alimentaria, fin de estudios en Túnez...), e infinitos momentos memorables.

GUADALAJARA

\section{VALENCIA}

Marta L, compañera nocturna en el estudio, agradezco tu compañia en tantas noches y en la peculiar variante de estudiar en las terrazas!

Marta M gracias por tus visitas tan energéticas (utrecht, Maastricht) y los viajes juntas (Colonia, Estambul), siempre Llenos de la intensidad que tanto te caracteriza!

Rafa, que siempre te alegras por mi, gracias! tambien por tus varias visitas y cartas postales! 


\section{End of university and....to The Netherlands!}

\section{ZEIST}

From my first day at TNO I need to thank jaap jan for helping me with my fiscal legality in the Netherlands. To Jan I want to thank his never ending hope in me learning de nederlandse uitdrukkingen, altijd moeilijk, maar wel lachen! ook de rest van mijn collega's in het vitamin lab en de analytical research afdeling wil ik bedanken: Irma "master in foliumzuur bepaling", Ajan en Arjan "masters in chromatographie", Angelique "master in cellkweken en ELISAS", Ria "master in Spaans", Lars "master in janpanse kunst en moral support". De geweldige mensen van monsterbeheer (Corie, Marja, Raymond) will ik nog bedanken.

To Wouter vaes I am thankful for welcoming me at TNO Zeist for my Leonardo da Vinci internship and to Robin for proposing me a PhD project. Thank you both for all the related scientific discussions and supervising.

Uit de groep van de TIM modellen moet ik aan sanne, Mark, Hans, Susann, Mans, Annet (SCFA bepaling), Koen (Lactaat en ammonia bepalingen) bedanken. En bovenop moet aan Rob Havenaar veel bedanken voor de onderzoek mogelikheiden en samen reisen naar Healtharain meetings (Milaan, cork, Lapland) en congresen (FENS, Paris), sneewmobil ríjden is echt niet mijn ding!

Nog aan TNO, moet ik aan de gezelligheid denken van mijn lunch groepje (Joost, sonna, Barbara) die word groter met new nice arrivals (Jeffrey, Willem, Leti, Liesbeth, sam, Carlton, Imo, Jasja).

\section{En na het werk.....}

\section{UTRECHT}

Ik wil mijn eerste huisgenoten in Nederland (utrecht) bedanken, de "in you tube" beken de trots op Raadwijk (Wouter, Fanny, Robert en de 3 Mariekes). Ze lieten me zien hoe het is om in een typisch nederlands studentenhuis te wonen, met een "suïcidale" trap en een nooit vríje maar altijd stinkende WC! Toen dacht ik dat Marieke de populairste naam in Nederland was! Leuke feesten bij Diergeneeskunde Marieke!

BUDAPEST

Eszti, one of my first friends in the cold low lands. 1 miss your contagious positivism. Sad you had to return to Budapest, but there we met again once, and twice, and here again, and again soon! :)

TEXEL

Ines, it was fun having you around, both at TNO and after work: Tivoli, Texel, really fun.

clau and Andy, my Dutch learning companions, glad to have met you at our very first adventure in Dutch learning. 
Groningers! Pjotr (het bleek dat je misschien toch wel uit Groningen komt!), Marleen (nog niet uit Groningen), Nynke, Martijn, Tom, bedankt voor alle leuke reizen (ski-vakanties, Lapland), festivals (Lowlands, Pinkpop), saunas, stappen, Koninginnedagen, etentjes, etc.

\section{UTRECHT}

Maria, te convertiste en mi risoterapia durante tu estancia en la TNO, una imagen mental me queda: carcajadas de altos decibelios al lado de la máquina del café y extrañas miradas de incomprensión alrededor. Y por supuesto Ainhoa y Rocio, también contribuisteís a muchas risotadas, incluyendo las del conocido caso Bokito (aún queda pendiente un posible negocio de camisetas), de aquel fin de semana intenso en Maastricht $y$ de alguna que otra noche loca en wageningen.

Irene y Angeles, del club "española holandés", tantas risas, manualidades, Brillantes, lentejas compartidas....Gracias!

Ana, compañera de birras y conciertos, que intensa tu visita a Maastricht! Gracias también por tu hospitalidad en los Madriles.

And then 1 discovered.... 1 was no longer the only Mediterranean foreigner at TNO! Maria Stolaki it was nice meeting you and sharing our need for warm lunches thanks to the little microwave illegally placed in my room! :)

Susann, ich möchte mich bei dir bedanken. Das erste was bei mir im Kopf kommt, ist das ich bei dir schlafen konnte um mein TIM Experiment erfolgreich zu machen.

MONTPELLIER

Youna, I enjoyed so much of your company during the so many Healtharain meetings, the greatest social PhD fellow! I am proud of your research stay at TNO and thankful for the co-publishing. It was fun learning from you, besides research skills, some other skills, like making of trinkets necklaces and brooches.

\section{En dan naar Maastricht verhuisen....}

MAASTRICHT
From Maastricht university, I will firstly thank quido Haenen and Aalt Bast, the best supervisors ever, thank you for showing me how much fun research can be!. You have this extraordinary positivism, and approach in motivating people 1 won't forget. And neither the philosophical discussions! Collega's van de afdeling Farmacologie en Toxicologie (Marie-José, Roger, Erik, Jiska, Bart, Pieter) bedankt voor jullie hulp, vooral met de in vivo studie, ook dank aan Mark en steven. Erik $R$. dankjewel voor jou help met alle mijn vragen over InDesign! Students; quy, nice work with the ESR, you did a good job, also with writing, thank you! Doreen, it was fun with you in our office. 
MAASTRICHT

MILAN

FARO

TILBURG

Esther (cocktails mate! Bedaank veur dien hölp met arrangeere!), Raffaele (il mio "odioato" vicino!), Rita (La capoeirista acrobatica!), Ruben (with the best suicidal humor!), Mirjam (dance companion), and Erile (the greatest office mate), you full fill my social live in Maastricht after work. Moving and living here would have been much harder without you to hang around.

De mensen van Schepen de Wicstraat: Tim, Lauren, Mitch, Larissa, Mayckel, RoelgTim, Loreen, Ralph, bedankt voor jullie gezelligheid, de lol en de feestjes, soms voelde ik me de oma van het huis, maar wel welkom tussen jullie! Limburgers zíjn toch leuk!

HELSINKI From my research stay at VTT, I really want to thank Annuka, Emilia, ismo and Airi (thanks for the cloudberries too). It was a great and efficient collaboration.

REYKJAVIK

Travelling companions to Nordic countries, Alejandro (mi compañero "hispanohablante"), Mo, imke, thanks for the great moments: escape from evil sheep, cleaning the dishes in public toilets (forbidden? Why the police?), playing Mcciver with the shuffler of the car, the visit to that museum...

\section{Now breaking the chronological order, since such as an important opening deserves such a closing...}

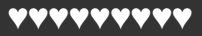

Bob en Moni, bedankt voor de hele grote steun die ik van jullie gekregen heb. Ik ben blij dat ik zulke leuke schoonouders heb.

And like the dessert, the best is for the last: ingo, thank you for your never ending support, especially in the very bad moments....tsja, it is not easy to live in the country of the countless rules and depressing winters! Above all, thanks for your patience and flexibility in this $200 \mathrm{~km}$ LAT relationship. 


\section{ACKNOWLEDGEMENTS}

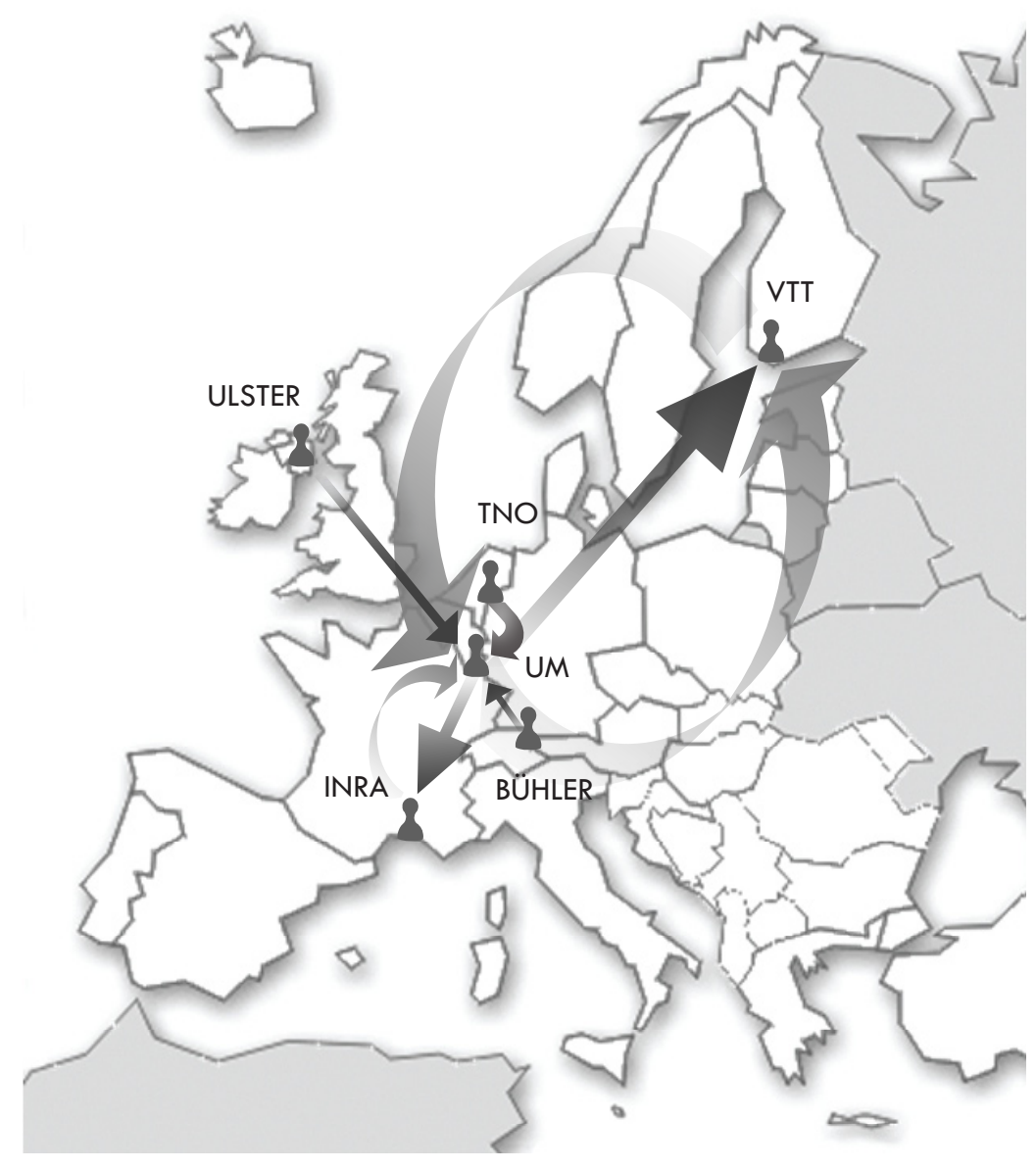

Thank you all HealthGrain partners that contributed to the research in this thesis. 

